Orientador: Prof. Dr. Evoneo Berti Filho Co-orientador: Prof. Dr. Joachim Adis

Tese apresentada à Escola Superior de Agricultura "Luiz de Queiroz", da Universidade de São Paulo, para obtenção do título de Doutor em Ciências. Área de Concentração: Entomologia.

$\begin{array}{llllllllll}P & I & R & A & C & I & C & A & B & A\end{array}$

Estado de São Paulo - Brasil Janeiro - 1995 
CÁTALOGACAO MA FUELICACAO

DIVISAO DE GIHLJOTECA E DOCUMENTAGFO - CAMPUS "LUIZ DE DULEROZ"/USF

Herais. Juse Hellingoten de

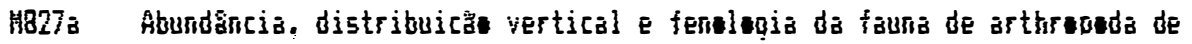

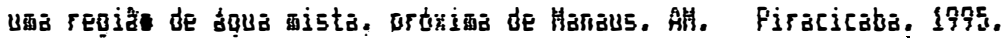

2260. jlus.

TESE - ESALB

Giblieorafía.

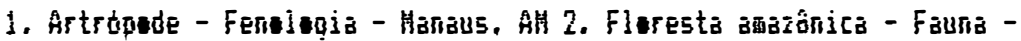

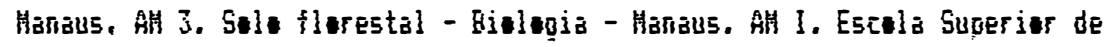
Aarricultura Luiz de Bueirez, Firacicaba 


\section{ABUNDÂNCIA, DISTRIBUIÇÃO VERTICAL E FENOLOGIA DA FAUNA DE ARTHROPODA DE UMA REGIÃO DE ÁGUA MISTA, PRÓXIMA DE MANAUS, AM}

JOSÉ WELLINGTON DE MORAIS

Aprovada em: 03.03.1995

Comissão julgadora:

Prof. Dr. Joachim U. ADIS

Prof. Dr. Sinval SILVEIRA NETO

MPI / Plön/Alemanha

Prof. Dr. José Djair VENDRAMIM ESALQ/USP

Prof. Dr. Sérgio A. VANIN

ESALQ/USP

Prof. Dr. Gilberto RIGHI

$\mathrm{USP} / \mathrm{SP}$

$\mathrm{USP} / \mathrm{SP}$

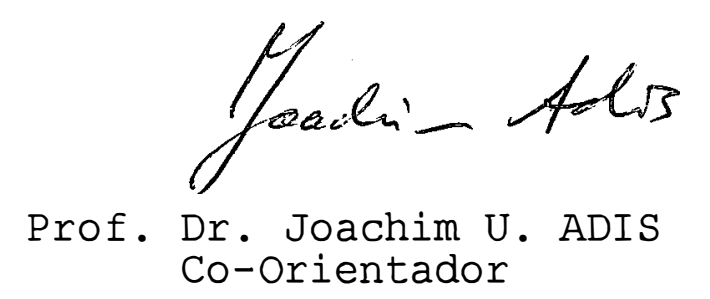


In memorian de

Luiz Augusto Santiago e

Maria Pereira Santiago,

meus avós

Aos meus pais, Ferreira e Olindina, pela obstinação em prol da minha educação, 


\section{AGRADECIMENTOS}

Ao Prof. Dr. Evoneo BERTI FILHO (Orientador), pela orientação, discussões, análises dos resultados, sugestões, críticas e incentivo.

Ao Prof. Dr. Joachim ADIS (Co-orientador), pela orientação constante durante toda a minha formação profissional, apoio, estímulo, amizade e suporte concedido para realização deste trabalho.

Ao Dr. Wolfgang J. JUNK, pelo apoio financeiro e oportunidade para realização deste trabalho no Instituto Max-Planck, Plön, Alemanha, conveniado no projeto Ecologia de áreas alagáveis: várzea e igapó, entre o Instituto Nacional de Pesquisas da Amazônia (Manaus, AM/Brasil) e o Instituto Max-Planck (Plön/Alemanha).

Ao Instituto Nacional de Pesquisas da Amazônia (Manaus,AM/Brasil), Instituto Max-Planck de Limnologia (Plön/Alemanha), na pessoa de seus diretores e ao centro de Pesquisas de produtos Florestais /CPPF, pela oportunidade de realizar este trabalho.

Ao Deutscher Akademischer Austauschdienst/DAAD, pela concessão da bolsa de estudos e especialmente a Sra. Helga WAKRE, por toda a atenção e dedicação dispensada durante o período de trabalho.

Aos professores do Departamento de Entomologia da ESALQ/USP, pelos valiosos ensinamentos e consideração. 
Ao Prof. Dr. V. MAFNERT, Genebra (Suíça), pela identificação de Pseudoscorpiones.

Ao Dr. U. SCHELLER, Järpås (Suécia), pela identificação de Symphyla.

Ao Dr. S.I. Golovatch, Moscou (Rússia), pela identificação de Diplopoda.

Ao Dr. H. STURM, Hildesheim (Alemanha), pela identificação de Meinertellidae (Archaeognatha).

Ao amigo Jörg BOHLEN, pela ajuda inicial nos programas de computação e a suelly Nunes MENDONÇA pela valiosa ajuda na fase final do trabalho.

A Ivanira MORAIS, minha irmã, pela ajuda, leitura do texto e apoio constante.

À família ADIS: Dr. Joachim, Irmgard e Bethania, e aos amigos Volker JÄGER e Karin ECKERT, por todo o carinho, atenção, paciência, amizade e a valiosa ajuda durante toda a minha estadia na Alemanha.

Aos amigos do Instituto Max-Planck, especialmente Norbert DOCKAL, Susanne HAMANN, Brigitte ALBRECHT, Elsbeth HAMMERICH e Thomas PAPENFUB, pela amizade e atenção.

As amigas Sonia Shigueyo KOMATSU, Terezinha A. GIUSTOLIN e Silvia M. GOMES, pela amizade, apoio e incentivo durante o período final. 
Às bibliotecárias da ESALQ, pela revisão das referências bibliográficas e à bibliotecária do Instituto Max-Planck, Brigitte LECHNER, pelo eficiente auxilio diante das minhas solicitações.

A Ana MERCK, pela ajuda, incentivo e apoio durante a fase de redação e ao Paulo BOTrosso, Maristela AMORIM e Elizabeth Franklin, pela leitura do texto e amizade.

Aos colegas do curso de Pós-Graduação em Entomologia, pelo companheirismo e amizade e a todos que direta ou indiretamente contribuíram para a realização deste trabalho. 


\section{SUMÁRIO}

LISTA DE FIGURAS $\ldots \ldots \ldots \ldots \ldots \ldots \ldots \ldots \ldots \ldots \ldots \ldots \ldots \ldots \ldots$

LISTA DE TABELAS $\ldots \ldots \ldots \ldots \ldots \ldots \ldots \ldots \ldots \ldots \ldots \ldots \ldots \ldots \ldots \ldots$

RESUMO $\quad \ldots \ldots \ldots \ldots \ldots \ldots \ldots \ldots \ldots \ldots \ldots \ldots \ldots \ldots \ldots \ldots \ldots \ldots \ldots \ldots$

SUMMARY $\ldots \ldots \ldots \ldots \ldots \ldots \ldots \ldots \ldots \ldots \ldots \ldots \ldots \ldots \ldots \ldots \ldots \ldots \ldots$

1. INTRODUÇÃo $\ldots \ldots \ldots \ldots \ldots \ldots \ldots \ldots \ldots \ldots \ldots \ldots \ldots \ldots$

2. REVISÃo dE Literatura ................. 3

2.1. Estratégias de sobrevivência a inundação utilizadas pelos artrópodos em florestas inundáveis da Amazônia Central .......... 3

2.1.1. Animais terrícolas ............. 4

2.1.1.1. Animais terrícolas migrantes 4

2.1.1.2. Animais terrícolas não migrantes ............... 5

2.1.2. Animais arborícolas ........... 6

2.1.2.1. Animais arborícolas migran-

2.1.2.2. Animais $\begin{aligned} & \text { tes } \\ & \text { migrantes } \ldots \ldots \ldots \ldots \ldots \ldots \ldots \ldots \ldots \ldots \ldots\end{aligned}$

2.2. Aspectos gerais sobre a migração em áreas inundáveis ..................... 7

2.3. Abundância e distribuição vertical de artrópodos do solo ...................... 11

2.4. Outros estudos desenvolvidos com artrópodos 14

2.5. Ação da fauna de solo na decomposição do

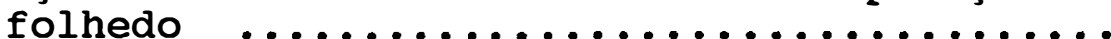

2.6. Pulso de inundação e categorias de vegetação em áreas inundáveis .................. 18

3. MATERIAL E MÉTODOS ..................... 21

3.1. Características gerais da região

3.1.1. Localização da área ............. 21

3.1.2. Solo ....................... 21

3.1.3. Vegetação ................... 22 
3.1.4. Dados climatológicos da área ....... 24

3.2. Metodologia .................... 27

3.2.1. Método de Kempson.............. 27

3.2.2. Fotoeclectores ............... 31

3.2 .2 .1 . Fotoeclector de solo ...... 32

3.2 .2 .2 . Fotoeclector de árvore .... 33

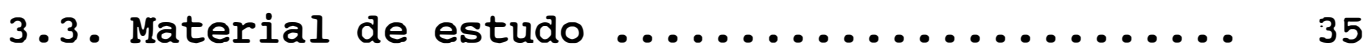

3.4. Termos ecológicos traduzidos ........... 36

3.4.1. Abundância de emergência ou densidade de emergência (Schlüpfabundanz ou

Schlüpfdichte) $\ldots \ldots \ldots \ldots \ldots \ldots \ldots . \ldots . \ldots$

3.4.2. Densidade de atividade

(Aktivitätsdichte) ............ 37

3.4.3. Freqüência de ocorrência (Häufgkeit). 37

3.4.4. Aparecimento (Apparenz) ......... 37

4. RESULTADOS

4.1. PSEUDOSCORPIONES ................ 38

4.1.1. Captura no solo com o método de

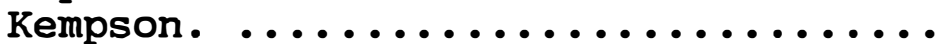

4.1.2. Captura no folhedo com fotoeclectores

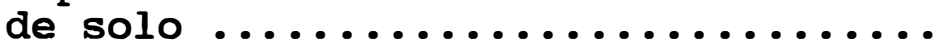

4.1.3. Captura nos troncos com fotoeclectores de árvore $B E \uparrow$ e $B E \downarrow . \ldots \ldots \ldots \ldots$.... 41

4.2. CHILOPODA. ..................... 49

4.2.1. Geophilomorpha ............. 49

4.2.1.1. Captura no solo com o método de Kempson...............

4.2.1.2. Captura no folhedo com fotoeclectores de solo .........

4.2.1.3. Captura nos troncos com fotoeclectores de árvore BE $\uparrow$ e $B E \downarrow$.

4.3 . DIPLOPODA $\ldots \ldots \ldots \ldots \ldots \ldots \ldots \ldots \ldots \ldots \ldots \ldots \ldots \ldots$

4.3.1. Captura no solo com o método de Kempson......................

4.3.2. Captura no folhedo com fotoeclectores de solo....................... 56

4.3.3. Captura nos troncos com fotoeclectores de árvore $\mathrm{BE} \uparrow$ e $\mathrm{BE} \downarrow \ldots . \ldots \ldots \ldots \ldots$ 
4.4. SYMPHYLA $\ldots \ldots \ldots \ldots \ldots \ldots \ldots \ldots \ldots \ldots \ldots$

4.4.1. Captura no solo com o método de Kempson ......................

4.4.2. Captura no folhedo com fotoeclecto-

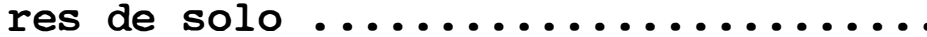

4.4.3. Captura nos troncos com fotoeclectores de árvore $B E \uparrow$ e $B E \downarrow$.......... 69

4.5. ARCHAEOGNATHA (MICROCORYPHIA) $\ldots \ldots \ldots \ldots \ldots . \ldots 78$

4.5.1. Captura no folhedo com fotoeclectores de solo .......................

4.5.2. Captura nos troncos com fotoeclectores de árvore BE $\uparrow$ e $B E \downarrow$.......... 79

4.6. COLEOPTERA ...................... 83

4.6.1. Captura no solo com o método de

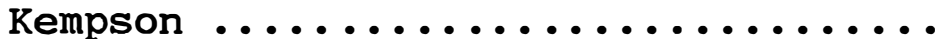

4.6.2. Captura no folhedo com fotoeclectores de solo ....................

4.6.3. Captura nos troncos com fotoeclectores de árvore $B E \uparrow$ e $B E \downarrow \ldots \ldots \ldots \ldots \ldots .86$

4.7. RESULTADO GERAL A NIVEL DE GRANDES GRUPOS CAPTURADOS NO SOLO, NO FOLHEDO E NOS TRONCOS

4.7.1. Captura no solo com o método de Kempson.......................

4.7.2. Captura no folhedo com fotoeclectores de solo .......................

4.7.3. Captura nos troncos com fotoeclectores de árvore $B E \uparrow$ e $B E \downarrow . . \ldots \ldots \ldots \ldots$.

5. DISCUSSÃO

5.1. PSEUDOSCORPIONES.................

5.1.1. Tyrannochthonius amazonicus Mahnert,

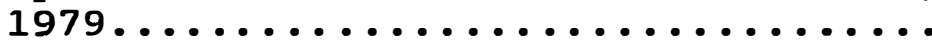

5.1.2. Pseudochthonius homodentatus

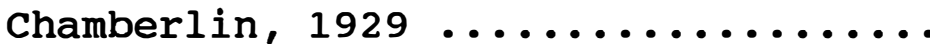

5.1.3. Pachyolpium irmgardae Mahnert, 1979..

5.1.4. Geogarypus amazonicus Mahnert, 1979..

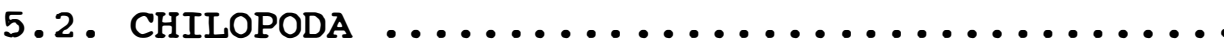

5.2.1. Geophilomorpha .............. 118 
5.3. DIPLOPODA .......................... 120

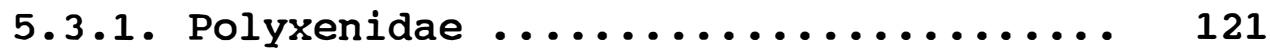

5.3.2. Fuhrmannodesmidae ............. 122

5.3.2.1. Moojenodesmus wellingtoni

n.sp. Golovatch, 1994 e

Moojenodesmus pumilus

Schubart, 1943. ..........

5.3.2.2. Fuhrmannodesmus rhinocerus

n.sp. Golovatch, 1994......

5.3.3. Pyrgodesmidae..................

5.3.3.1. Muyudesmus obliteratus

Kraus, $1960 \ldots \ldots \ldots \ldots \ldots \ldots . \ldots 125$

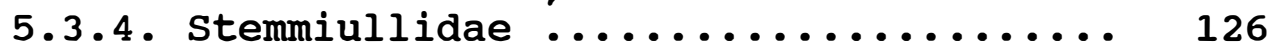

5.4. SYMPHYLA $\ldots \ldots \ldots \ldots \ldots \ldots \ldots \ldots \ldots \ldots \ldots \ldots$

5.4.1. Ribautiella amazonica Scheller, 1984. 127

5.4.2. Symphylella adisi Scheller, $1992 \ldots . .2128$

5.4.3. Hanseniella arborea Scheller, 1979... 129

5.5. ARCHAEOGNATHA (MICROCORYPHIA)........... 131

5.5.1. Neomachilellus scandens Wygodzinsk,

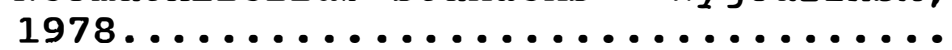

5.5.2. Meinertellus adisi sturm, $1983 \ldots \ldots .133$

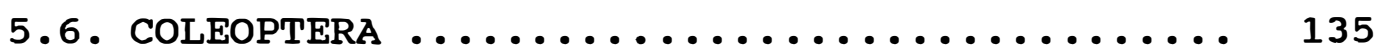

5.6.1. Abundância e distribuição vertical de coleópteros no solo...............

5.6.2. Densidade de atividade de coleópteros no folhedo......................

5.6.3. Densidade de atividade e migração vertical de coleópteros nos troncos..

5.6.4. Densidade de atividade e fenologia das famílias de coleópteros classificadas em níveis tróficos...........

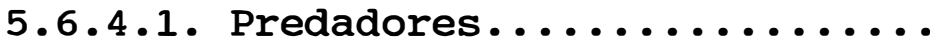

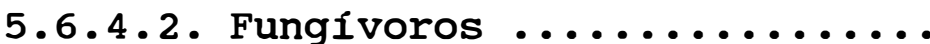

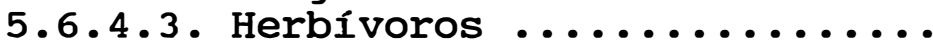

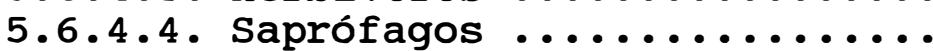
5.6.5. Relação entre os fatores abióticos e a densidade populacional de Coleoptera.................... 148

5.7. DISCUSSÃO GERAL DOS GRUPOS DE ARTHROPODA CAPTURADOS NO SOLO, NO FOLHEDO, E NOS TRONCOS. 
5.8. COMPARAÇÃO ENTRE A FAUNA DA FLORESTA INUNDADA POR ÁGUA MISTA E A FAUNA DAS FLORESTAS DE VÁRZEA E IGAPÓ........................ 164

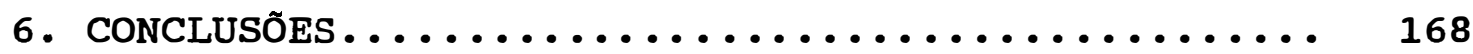

REFERENCIAS BIBLIOGRÁFICAS................ 171

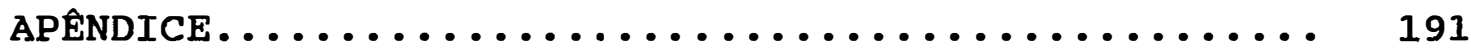


LISTA DE FIGURAS

Figura

Página

1 Localização da área de estudo (LJ = Lago Janauari)....................

2 Esquema do aparelho de extração da fauna de solo tipo Kempsom/Mc-Fadyen (KEMPSON,

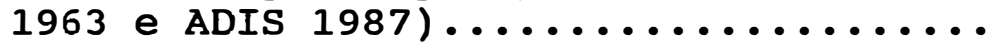

3 Esquema do fotoeclector de solo com armadilha de fosso (FUNKE, 1971).......

4 Esquema do fotoeclector de árvore para cima (FUNKE, 1971).................

5 Captura mensal de Tyrannochthonius amazonicus Mahnert, 1979 (Chthoniidae, Pseudoscorpiones), nos diferentes tipos de armadilhas, na floresta inundada por água mista, no período de julho/1987 a junho/1988. $\mathrm{K}=$ método de Kempson, $\mathrm{E}=$ fotoeclector de solo, $\mathrm{BE} \uparrow=$ fotoeclector de árvore direcionado para cima, $\mathrm{BE} \downarrow=$ fotoeclector de árvore direcionado para

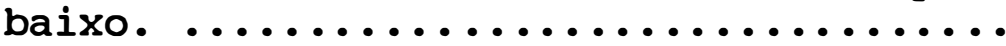

6 Abundância vertical de Tyrannochthonius amazonicus Mahnert, 1978 (Chthoniidae, Pseudoscorpiones), nas diferentes camadas do solo, na floresta inundada por água mista, no período de agosto/1987 a maio/1988. Captura com 0 método de Kempson. ....................

7 Captura mensal no solo dos estágios de desenvolvimento de Tyrannochthonius amazonicus Mahnert, 1979 (Chthoniidae, Pseudoscorpiones), na floresta inundada por água mista, no período de agosto/ 1987 a maio/1988. Coleta com o método de Kempson. ..................... 
8 Captura mensal no folhedo dos estágios de desenvolvimento de Tyrannochthonius amazonicus Mahnert, 1979 (Chtoniidae, Pseudoscorpiones), na floresta inundada por água mista, no período de agosto/ 1987 a maio/1988. Coleta com fotoeclectores de solo................

9 Captura mensal de Pseudochthonius homodentatus Chamberlin, 1929 (Chthoniidae, Pseudoscorpiones), nos diferentes tipos de armadilhas, na floresta inundada por água mista, no período de julho/1987 a junho/1988. $\mathrm{K}=$ método de Kempson, $E$ = fotoeclectores de solo, $\mathrm{BE} \uparrow$ = fotoeclector de árvore direcionado para cima, $B E \downarrow$ = fotoeclector de árvore direcionado para baixo. .............

10 Captura mensal no folhedo dos estágios de desenvolvimento de Pseudochthonius homodentatus Chamberlin, 1929 (Chthoniidae, Pseudoscorpiones), na floresta inundada por água mista, no período de agosto/1987 a maio/1988. Coleta com fotoeclectores de solo.......

11 Captura mensal dos estágios de desenvolvimento de Pseudochthonius homodentatus Chamberlin, 1929 (Chthoniidae, Pseudoscorpiones), na floresta inundada por água mista, no período de julho/1987 a junho/1988. $\quad A=$ Coleta com fotoeclector de árvore direcionado para cima $(\mathrm{BE} \uparrow) . \quad \mathrm{B}=$ Coleta com fotoeclector de árvore direcionado para baixo (BE $\downarrow)$. ...

12 Captura mensal dos estágios de desenvolvimento de Tyrannochthonius amazonicus Mahnert, 1979 (Chthoniidae, Pseudoscorpiones), na floresta inundada por água mista, no período de julho/1987 a junho/1988. $A=$ Coleta com fotoeclector de árvore para cima ( $\mathrm{BE} \uparrow)$. $\mathrm{B}=$ coleta com fotoeclector de árvore para baixo $(\mathrm{BE} \downarrow) \ldots \ldots \ldots \ldots \ldots \ldots \ldots \ldots . . \ldots$ 
13 Distribuição de Geophilomorpha (Chilopoda) nas diferentes camadas do solo, na floresta inundada por água mista, no periodo de agosto/1987 a maio/ 1988. Captura com o método de Kempson...

14 Captura mensal no solo dos estágios de desenvolvimento de Geophilomorpha (Chilopoda), na floresta inundada por água mista, no período de agosto/1987 a maio/1988. Coleta com o método de Kempson......................

15 Captura mensal no solo dos estágios de desenvolvimento de Pectiniunguis ascendens Pereira, Minelli \& Barberi, 1993 (Geophilomorpha, Chilopoda), na floresta inundada por água mista, no período de agosto/1987 a maio/1988. Coleta com o método de Kempson.........

16 Captura mensal e distribuição vertical nas diferentes camadas do solo de Polyxenidae (Polyxenida, Diplopoda), na floresta inundada por água mista, no periodo de julho/1987 a junho/1988. $A=$ Captura com $O$ método de Kempson (K), fotoeclectores de solo (E), fotoeclector de árvore direcionado para cima (BE $\uparrow$ ) e fotoeclector de árvore direcionado para baixo $(\mathrm{BE} \downarrow) . \quad$ B $=$ Distribuição vertical no solo.......................

17 Captura mensal de Fuhrmannodesmidae (Polyxenida, Diplopoda), nos diferentes tipos de armadilhas, na floresta inundada por água mista, no periodo de julho/ 1987 a junho/1988. $\mathrm{K}=$ método de Kempson; $\mathrm{E}=$ fotoeclectores de solo; $\mathrm{BE} \uparrow=$ fotoeclector de árvore direcionado para cima; $B E \downarrow$ = fotoeclector de árvore direcionado para baixo..............

18 Distribuição vertical de Moojenodesmus wellintoni n.sp. Golovatch, 1994 e Moojenodesmus pumilus Schubart, 1943 (Fuhrmannodesmidade, Diplopoda), nas diferentes camadas do solo, na floresta inundada por água mista, no periodo de agosto/1987 a maio/1988. Captura com o método de Kempson................. 
19 Captura mensal de imaturos e adultos de Moojenodesmus wellingtoni n.sp. Golovatch, 1994 e Moojenodesmus pumilus Schubart, 1943 (Fuhrmannodesmidae, Diplopoda), na floresta inundada por água mista, no período de agosto/1987 a maio/1988. Coleta com o método de Kempson......................

20 Distribuição vertical dos estágios de desenvolvimento de Moojenodesmus wellingtoni n.sp. Golovatch, 1994 e Moojenodesmus pumilus Schubart, 1943 (Fuhrmannodesmidae, Diplopoda), na floresta inundada por água mista, no período de agosto/1987 a maio/1988. Captura com o método de Kempson........

21 Captura mensal das famílias mais abundantes de Diplopoda, no folhedo, na floresta inundada por água mista, no período de agosto/1987 a maio/1988. Coleta com fotoeclectores de solo.......

22 Abundância dos estágios de desenvolvimento no folhedo de Moojenodesmus wellingtoni n.sp Golovatch, 1994 e Moojenodesmus pumilus Schubart, 1943 (Fuhrmannodesmidae, Diplopoda), na floresta inundada por água mista, no período de agosto/1987 a maio/1988. Captura com fotoeclectores de solo......

23 Captura mensal das principais famílias de Diplopoda, no tronco, na floresta inundada por água mista, no período de julho/1987 a junho/1988. Coleta com fotoeclector de árvore direcionado para cima $\mathrm{BE} \uparrow \ldots \ldots \ldots \ldots \ldots \ldots \ldots \ldots . \ldots . \ldots$

24 Captura mensal de imaturos e adultos de Moojenodesmus pumilus Schubart, 1943 (Fuhrmannodesmidae, Diplopoda), no tronco, na floresta inundada por água mista, no período de julho/1987 a junho/ 1988. Coleta com fotoeclector de árvore direcionado para cima $(B E \uparrow)$. $\mathbf{A}=$ Captura mensal de imaturos e adultos. $B=$ Freqüência de ocorrência dos estágios de desenvolvimento................. 
25 Captura mensal dos estágios de desenvolvimento de Muyudesmus obliteratus Kraus, 1960 (Pyrgodesmidae, Diplopoda), nos troncos, na floresta inundada por água mista, no período de julho/1987 a junho/ 1988. Coleta com fotoeclectores de árvores BE $\uparrow$ e $B E \downarrow$. A = Captura mensal . $\mathrm{B}=$ Freqüência de ocorrência dos estágios de desenvolvimento.............

26 Captura mensal das principais famílias de Diplopoda, no tronco, na floresta inundada por água mista, no período de Julho/1987 a junho/1988. Captura com fotoeclector de árvore direcionado para baixo $(\mathrm{BE} \downarrow) \ldots \ldots \ldots \ldots \ldots \ldots \ldots \ldots \ldots$

27 Captura mensal dos estágios de desenvolvimento de Fuhrmannodesmus rhinocerus n.sp.Golovatch, 1994 (Fuhrmannodesmidae, Diplopoda), no tronco, na floresta inundada por água mista, no período de julho/1987 a junho/1988. Captura com fotoeclector direcionado para baixo $(B E \downarrow) \cdot A=$ Captura mensal. $\mathbf{B}=$ Freqüência de ocorrência dos estágios de desenvolvimento.......................

28 Abundância vertical e estágios de desenvolvimento de Ribautiella amazonica Scheller, $1984 \quad$ (Scolopendrellidae, Symphyla), no solo, da floresta inundada por água mista, no período de agosto/ 1987 a maio/1988. Captura com o método de Kempson. $\mathbf{A}=$ Abundância vertical $\cdot \mathbf{B}=$ Abundância por estágios de desenvolvimento........................

29 Captura mensal dos estágios de desenvolvimento e distribuição vertical de Ribautiella amazonica Scheller, 1984 (Scolopendrellidae, Symphyla), no solo, na floresta inundada por água mista, no período de agosto/1987 a maio/1988. Coleta com o método de Kempson. $\mathbf{A}=$ Abundância mensal por estágios de desenvolvimento. $\mathbf{B}=$ Abundância vertical..... 
30 Abundância vertical e estágios de desenvolvimento de symphylella adisi Scheller, $1989 \quad$ (Scolopendrellidae, Symphyla), no solo, da floresta inundada por água mista, no periodo de agosto/ 1987 a maio/1988. Coleta com o método de Kempson. $\mathbf{A}=$ Abundância vertical. $\mathbf{B}=$ Abundância por estágios de desenvolvimento........................

31 Captura mensal dos estágios de desenvolvimento e distribuição vertical de Symphylella adisi Scheller, 1989 (Scolopendrellidae, Symphyla), no solo, na floresta inundada por água mista, no periodo de agosto/1987 a maio/1988. Coleta com 0 método de Kempson. $\mathbf{A}=$ Abundância mensal por estágios de desenvolvimento. $\mathbf{B}=$ Abundância vertical.....

32 Abundância vertical e estágios de desenvolvimento de Hanseniella arborea Scheller, 1979 (Scutigerellidae, Symphyla), no solo, da floresta inundada por água mista, no período de agosto/ 1987 a maio/1988. Coleta com o método de Kempson. $\mathbf{A}=$ Abundância vertical. $\mathbf{B}=$ Abundância por estágios de desenvolvimento........................

33 Captura mensal dos estágios de desenvolvimento e distribuição vertical de Hanseniella arborea Scheller, 1979 (Scutigerellidae, Symphyla), no solo, da floresta inundada por água mista, no periodo de agosto/1987 a maio/1988. Coleta com o método de Kempson. $\mathbf{A}=$ Abundância mensal por estágios de desenvolvimento. $\mathbf{B}=$ Abundância vertical.....

34 Captura mensal dos estágios de desenvolvimento de Neomachilellus scandens Wygodzinsky, 1978 (Meinertellidae, Archaeognatha), no folhedo, da floresta inundada por água mista, no periodo de setembro/1987 a março/1988. Coleta com fotoeclectores de solo. $\quad \mathbf{A}=$ Freqüência de ocorrência dos estágios de desenvolvimento. Dados de medições do comprimento da cabeça e datas de captura. $\quad \mathbf{B}=$ Captura mensal.................. 
35 Captura mensal dos estágios de desenvolvimento de Meinertellus adisi Wigodzinsky, 1978 (Meinertellidae, Archaeognatha), no folhedo, da floresta inundada por água mista, no período de agosto/1987 a maio/1988. Coleta com fotoeclectores de solo. A = Freqüência de ocorrência dos estágios de desenvolvimento. Dados de medições do comprimento da cabeça e datas de captura. $\mathbf{B}=$ Captura mensal..................

36 Captura mensal dos estágios de desenvolvimento de Meinertellus adisi Wygodzinsky, 1978 (Meinertellidae, Archaeognatha), em fotoeclector direcionado para cima ( $B E \uparrow)$, na floresta inundada por água mista, no período de julho/1987 a junho/1988. A = Freqüência de ocorrência dos estágios de desenvolvimento. Dados de medições do comprimento da cabeça e datas de coleta. B $=$ Captura mensal ................

37 Abundância vertical de Coleoptera adultos (familias) e captura mensal de adultos e larvas, no solo, na floresta inundada por água mista, no período de agosto/1987 a maio/1988. Coleta com o método de Kempson. $\mathbf{A}=$ Abundância vertical. $\mathbf{B}=$ Captura mensal de adultos e larvas........................

38 Abundância vertical de larvas de Coleoptera, no solo, na floresta inundada por água mista, no período de agosto/ 1987 a maio/1988. Captura com o método de Kempson.......................

39 Captura mensal de Staphylinidae (Coleoptera), nos diferentes tipos de armadilhas, na floresta inundada por água mista, no período de julho/1987 a junho/1988. $\mathrm{K}=$ método de Kempson; $\mathrm{E}=$ fotoeclectores de solo; $\mathrm{BE} \uparrow=$ fotoeclector de árvore direcionado para cima. $B E \downarrow=$ fotoeclector de árvore direcionado para baixo.............. 
40 Captura mensal de Carabidae e Pselaphidae (Coleoptera), nos diferentes tipos de armadilhas, na floresta inundada por água mista, no período de julho/1987 a junho/1988. $\mathrm{K}=$ método de Kempson; $\mathrm{E}=$ fotoeclectores de solo; $\mathrm{BE} \uparrow=$ fotoeclector de árvore para cima; $\mathrm{BE} \downarrow$ = fotoeclector de árvore direcionado para baixo. $\mathbf{A}=$ Carabidae. $\mathbf{B}=$ Pselaphidae...................

41 Captura mensal de Chrysomelidae e Scolytidae (Coleoptera), nos diferentes tipos de armadilhas, na floresta inundada por água mista, no período de julho/ 1987 a junho/1988. $\mathrm{K}=$ método de Kempson; $\mathrm{E}=$ fotoeclectores de solo; $\mathrm{BE} \uparrow$ = fotoeclector de árvore direcionado para cima; $\mathrm{BE} \downarrow$ = fotoeclector de árvore direcionado para baixo. $\mathbf{A}=$ Chrysomelidae. $\mathbf{B}=$ Scolytidae..........

42 Captura mensal de Curculionidae e Ptiliidae (Coleoptera), nos diferentes tipos de armadilhas, na floresta inundada por água mista, no período de julho/ 1987 a junho/1988. $\mathrm{K}=$ método de Kempson; $\mathrm{E}=$ fotoeclectores de solo; $\mathrm{BE} \uparrow=$ fotoeclector de árvore direcionado para cima; $\mathrm{BE} \downarrow=$ fotoeclector de árvore direcionado para baixo. $\mathbf{A}=$ Curculionidae. $\mathbf{B}=$ Ptiliidae..........

43 Captura mensal de Scydmaenidae (Coleoptera), nos diferentes tipos de armadilhas, na floresta inundada por água mista, no período de julho/1987 a junho/1988. $K=$ método de Kempson; $E=$ fotoeclectores de solo; $\mathrm{BE} \uparrow=$ fotoeclector de árvore direcionado para cima; $\mathrm{BE} \downarrow=$ fotoeclector de árvore direcionado para baixo.............

44 Abundância dos grupos de Arthropoda, capturados em maíor número, no solo, da floresta inundada por água mista, no período de agosto/1987 a maio/1988. Coleta com o método de Kempson......... 
45 Abundância vertical dos grupos de Arthropoda, nas diferentes camadas do solo, na floresta inundada por água mista, no período de agosto/1987 a maio/ 1988. Coleta com o método de Kempson.... 
LISTA DE TABELAS

Tabela

Página

1 Captura de Coleoptera (famílias) de 0 a $14 \mathrm{~cm}$ de profundidade no solo, por estações sazonais e classificação em níveis tróficos, no período de agosto/ 1987 a maio/1988, na floresta inundada por água mista (número total de captura, abundância (indivíduos $/ \mathrm{m}^{2}$ ), percentagem $(\%)$, média e desvio padrão(S)). Est.1 = estação menos chuvosa. Est. 2 = estação

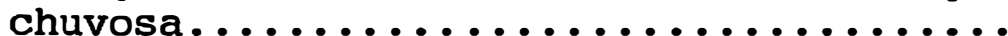

2 Captura de Coleoptera (famílias), no folhedo, por estações sazonais e classificação em níveis tróficos, no período de agosto/1987 a maio/1988, na floresta inundada por água mista (número total de captura, abundância (indivíduos $/ \mathrm{m}^{2}$ ), percentagem $(\%)$, média e desvio padrão (S)). Est.1 = estação menos chuvosa. Est.2 = estação chuvosa.............

3 Captura de Coleoptera (famílias) em fotoeclector direcionado para cima (BE $\uparrow$ ) por estações sazonais e classificação em níveis tróficos, no período de julho/ 1987 a junho/1988, na floresta inundada do Lago Janauari (número total de captura, percentagem $(\%)$, média e desvio padrão $(S))$. Est. $1=$ estação menos chuvosa. Est. 2 = estação chuvosa......

4 Captura de Coleoptera (famílias) em fotoeclector direcionado para baixo (BE $\downarrow$ ) por estações sazonais e classificação em níveis tróficos, no período de julho/1987 a junho/1988, na floresta inundada do Lago Janauari (número total de captura, percentagem $(\%)$, média e desvio padrão (S)). Est. 1 = estação menos chuvosa. Est. 2 = estação chuvosa.. 


\section{ABUNDÂNCIA, DISTRIBUIÇÃO VERTICAL E FENOLOGIA DA FAUNA DE ARTHROPODA DE UMA REGIÃO DE ÁGUA MISTA, PROXIMA DE MANAUS, AM}

Autor:

Orientador:

Co-orientador:
JOSÉ WELLINGTON DE MORAIS

Prof. Dr. EVONEO BERTI FILHO

Prof. Dr. JOACHIM ADIS

RESUMO

Estudou-se a fauna de Arthropoda, do solo, do folhedo e dos troncos, da floresta inundada na região de água mista do Lago Janauari, cerca de $10 \mathrm{Km}$ próximo de Manaus/AM. Para extração dos artrópodos do solo, utilizou-se o método do Kempson. A captura dos artrópodos no folhedo e nos troncos foi feita através de fotoeclectores de solo e fotoeclectores de árvores, respectivamente. Os animais coletados foram identificados por ordens, famílias e alguns grupos a nível de espécies. Do total de 111.921 Arthropoda coletados, $14,5 \%$ (16.189 indivíduos) foram extraídos do solo, 63,7\% (71.270 indivíduos) foram obtidos do folhedo, e $21,8 \%$ (24.462 indivíduos) nos troncos, sendo que, destes últimos, $15,9 \%$ ( 17.906 indivíduos) foram capturados em armadilhas direcionadas para cima e 5,9 $\%$ (6.556 indivíduos) em armadilhas direcionadas para baixo. Determinou-se a abundância e a distribuição vertical dos artrópodos nas diferentes camadas do solo, assim como, sua migração para as árvores, ocasionada pela inundação anual de 5 a 7 meses. Para os artrópodos terrícolas, foram determinadas as estratégias de sobrevivência à inundação em espécies de Pseudoscorpiones, Chilopoda, Diplopoda Symphyla e Archaeognatha. A atividade, abundância e a distribuição vertical dos animais foi influenciada pelas estações anuais, 
pelos fatores abióticos locais e pelo pulso de inundação. Foram feitas observações sobre a fenologia de algumas espécies, e foram estudadas a sua abundância, densidade de atividade e freqüência de ocorrência. Foram feitas comparações entre a fauna de Arthropoda estudada na floresta inundada por água mista, (Lago Janauari), com a fauna, já conhecida, de uma floresta inundada por água preta (igapó) e uma floresta inundada por água branca (várzea). 


\section{ABUNDANCE, VERTICAL DISTRIBUTION AND PHENOLOGY OF \\ THE ARTHROPOD FAUNA FROM THE MIXEDWATER REGION NEAR \\ MANAUS, AM}

$\begin{array}{ll}\text { Author: } & \text { José Wellington DE MORAIS } \\ \text { Adviser: } & \text { Prof. Dr. Evoneo BERTI FILHO } \\ \text { Co-Adviser: } & \text { Prof. Dr. Joachim ADIS }\end{array}$

SUMMARY

The arthropod fauna from the soil, from the litter and from tree trunks was studied in an inundation forest in the mixedwater region at Lake Janauari near Manaus. For extraction of arthropods from the soil the Kempson method was used. Capture of arthropods in the litter and on tree trunks was done by means of ground and arboreal photoeclectors, respectively. Animals caught were classified to orders, to families and some groups to species. Of the total of 111,921 arthropods captured, $14,5 \%(16,189$ specimens) were extracted from the soil, $63,7 \%(71,270$ specimens ) were obtained from the litter and $21,8 \%(24,462$ specimens) from tree trunks. Of the latter, $15,9 \%(17,906$ specimens $)$ were caught in traps positioned upwards and 5,9 $\%(6,556$ animals) positioned downwards. Abundance and vertical distribution of artrhopods for the different soil layers was determined as well as their migration to tree trunk, caused by the annual inundation of 5-7 month duration. In terricolous arthropods, the survival strategies to inundation were determined for species of Pseudoscorpiones, Chilopoda, Diplopoda, Symphyla and Archaeognatha. Animal activity, abundance and their vertical distribution was influenced by annual seasons, by local abiotic factors and by the flood pulse. The phenology of some species, their emergence, activity-density and commoness were studied. The arthropod fauna from the 
mixedwater inundation forest (Lake Janauari) was compared with the already known arthropod fauna from a blackwater inundation forest (igapó) and from two whitewater inundation forests (várzea). 


\section{INTRODUÇÃo}

As florestas da Amazônia Central são divididas em florestas de terra firme e florestas inundáveis (BRAGA, 1979). Florestas de terra firme são aquelas que não são atingidas pela inundação periódica, ocasionada pelo aumento no nível da água dos rios, enquanto que, as florestas inundáveis estão sujeitas a uma inundação anual por um período de 5 a 6 meses (SIOLI, 1956; IRMLER, 1977 e PRANCE, 1979, 1980). A fauna de invertebrados que habitam as áreas alagáveis, por ocasião da inundação, migram, dentro do possível, para florestas de terra firme adjacentes, ou permanecem na área, onde morrem ou sobrevivem, utilizando estratégias de sobrevivência à inundação. A fauna de artrópodos das áreas inundáveis por água preta e água branca já foram estudadas por ADIS (1984, 1992a, 1992b) e IRMLER (1981), sendo que, sobre a fauna de floresta inundada por água mista pouco se conhece até o momento. Portanto, esta pesquisa teve como objetivo estudar a fenologia, a dominância, a abundância, e a densidade de atividade da fauna de Arthropoda numa floresta periodicamente inundável por água mista, e identificar as espécies existentes na área; verificar a abundância e distribuição vertical da fauna de Arthropoda de solo numa camada de $14 \mathrm{~cm}$ de profundidade; determinar as estratégias de sobrevivência à inundação dos artrópodos na área experimental; verificar a influência dos fatores abióticos na abundância e na fenologia dos artrópodos ao longo do ano e comparar a fauna de artrópodos da floresta inundada por água mista com a fauna já conhecida da floresta inundada por água preta, e da floresta inundada por água branca, como também em florestas não inundáveis de terra 
firme (floresta primária e secundária). O material para este estudo foi coletado por ADIS, MORAIS e colaboradores. Outras coletas, por exemplo, em armadilhas de solo e na copa das árvores não foram avaliadas neste estudo. 
2 REVISÃO DE LITERATURA

2.1 Estratégias de sobrevivência à inundação utilizadas pelos artrópodos em florestas inundáveis da Amazônia Central

Estratégias de sobrevivência são adaptações de organismos às condições externas desfavoráveis, que aumentam sua capacidade de sobrevivência (TISCHLER, 1984)

Estas estratégias, segundo ADIS (1982b, 1985, 1992b) são utilizadas pelos animais que habitam as áreas alagáveis. Algumas semanas antes da inundação podem ser observadas migrações horizontal e vertical para a região de troncos e copas, de numerosos grupos de artrópodos, particularmente aqueles não voadores. Entretanto, muitos deles morrem durante a inundação ou tornam-se presas de artrópodos predadores, particularmente de Formicidae (ADIS, 1981,1984 ).

A fauna de coleópteros de áreas inundáveis da Amazônia na região da Ilha do Curari, do Rio Tarumã Mirim e do Lago Janauari foi estudada por IRMLER, (1979). O autor dividiu as famílias em grupos de acordo com o tipo de colonização: 1) - Coleópteros que alternam seu habitat árvore - solo - árvore. 2) - Habitantes de solo que migram segundo o nível da água. 3) - Habitantes do solo que sobrevivem durante a inundação na fase de ovo. 4) - Habitantes de árvores que raramente alcançam o solo. 5) - Coleópteros sem preferência por árvore ou solo. 6) - Habitantes do solo que imigram durante a fase emersa, porque sua população foi totalmente destruída pela inundação anterior. Posteriormente, IRMLER (1981) classificou as estratégias de sobrevivência a inundação em três tipos: 1) - Animais que apresentam uma alta taxa de reprodução e um período de desenvolvimento curto. 2) 
- Animais que apresentam adaptações as flutuações do nível da água. 3) - Animais que apresentam vida tanto terrestre quanto aquática.

Mais tarde, esta classificação foi ampliada e aperfeiçoada por ADIS (1992b) que dividiu a fauna de invertebrados terrestres em animais terrícolas e animais arborícolas. Ambos os grupos incluem os animais migrantes e não migrantes. Os animais não migrantes completam o seu ciclo de vida em apenas um habitat, seja no chão ou nas árvores. Entretanto, há movimento de pequena escala dentro do habitat e ocorrências temporárias. Os animais migrantes se reproduzem primariamente em apenas um dos habitats, mas seu ciclo de vida inclui estágios que mudam de habitat.

\subsubsection{Animais terrícolas}

São habitantes da camada orgânica e da parte superior da camada inorgânica do solo e podem ser migrantes e não migrantes.

\subsubsection{Animais terrícolas migrantes}

Segundo ADIS (1992a, 1992b), existem três modos distintos de ação que representam a reação dos animais do solo à inundação sazonal: a) migração horizontal: é efetuada por animais que se movem para áreas mais altas à frente da linha d’água, que avança durante os períodos de subida do nível dos rios. Após o recuo das águas estes animais retornam para o lugar de origem (Oligochaeta: Glossoscolecidae, Tairona tipema (ADIS \& RIGHI, 1989) e Coleoptera: Staphylinidae, Lathrobium sp. (IRMLER, 1979)) . b) migração vertical: é efetuada pelos animais que se movem temporariamente para os troncos das árvores, podendo passar 
o período de inundação no próprio tronco ou nas copas. Este tipo de migração pode ser realizada por todos ou somente um dos estágios ativos da espécie, que realiza a migração antes da inundação (estágio migrante). A principal reprodução ocorre no chão da floresta durante o período não submerso. 0 ciclo de reprodução e a duração do estágio de vida são sincronizados com a flutuação periódica do nível de água (ecofator primário). Por exemplo, oligochaeta: Andiorrhinus venezuelanus tarumanis, Glossoscolecidae (ADIS \& RIGHI, 1989). Entretanto, a maioria dos artrópodos reage a ecofatores secundários, sendo que, eles estão correlacionados com o início da estação chuvosa, 3 a 4 meses antes da inundação. Por exemplo, Pseudoscorpiones: Tyrannochithonius amazonicus, Tyranochthonius migrans, Chthoniidae (ADIS \& MAHNERT, 1985); Opiliones: Eucynortula lata (Cosmetidae) e stygnidius inflatus (Gonyleptidae) (FRIEBE \& ADIS, 1983)). c) Vôo: Alguns animais, quando possível, realizam vôos temporários para florestas de terra firme vizinhas e retornam ao lugar de origem no final da inundação. Normalmente o vôo ocorre algumas semanas antes da inundação e após o início da estação chuvosa. A reprodução principal se efetua no chão da floresta durante a fase emersa. A duração do estágio de desenvolvimento terrestre e a velocidade do ciclo reprodutivo são sincronizados com a flutuação periódica do nível da água (Carabidae, Polyderis nympha (ADIS et alii, 1986)).

\subsubsection{Animais terrícolas não migrantes}

São considerados animais terrícolas não migrantes, aqueles que apresentam um dos estágios, que permanece submerso no solo inundado, durante cinco a seis meses por ano. Em algumas espécies este estágio permanece 
ativo, em outras, ele permanece em fase de dormência durante todo este período, da seguinte forma: a) Dormência sob a água: é representada por animais que não abandonam seu habitat e passam o período de inundação em dormência sobre ou dentro do solo da floresta inundável, nos seguintes tipos de abrigos: 1) - disponiveis em abrigos naturais (Symphyla: Ribautiella amazonica, ADIS \& ARNETT, (1987)); 2) - em abrigos construídos, por exemplo casulos (Japygidae, Diplura, ADIS et alii (1989)); 3) - constroem uma proteção de cera (Pseudococcidae, Homoptera, ADIS \& MESSNER (1991)); 4) depositam os ovos no solo, onde permanecem durante todo o período inundado e eclodem no final da inundação (Eremobelba foliata, Acari, BECK (1972) e Neomachilellus scandens, Meinertellidae, ADIS \& STURM (1987a)) b) Ativos sob a água: são aqueles animais que permanecem ativos no solo da floresta inundada, ou na região dos troncos que permanecem sob a água (Diplopoda, Pyrgodesmidae, Gonographis adisi, ADIS (1986); MESSNER \& ADIS (1988)) •

\subsubsection{Animais arborícolas}

São aqueles que habitam a região dos troncos e as copas das árvores e também podem ser migrantes e não migrantes.

\subsubsection{Animais arborícolas migrantes}

São os animais que vivem principalmente nos troncos, ou na copa das árvores, onde realizam sua reprodução principal. Todos, ou somente alguns dos estágios do ciclo de vida fazem parte da migração descendente e ascendente nos troncos. (Pseudoscorpiones: Brasilatemnus browni (Miratemnidae) e Pachyolpium irmgardae (Olpiidae), ADIS \& 
MAHNERT (1985); ADIS et alii (1988)).

\subsubsection{Animais arborícolas não migrantes}

Compreendem os animais que vivem e se reproduzem exclusivamente nos troncos e nas copas das árvores onde efetuam somente movimentos de pequena escala. Eles podem ser encontrados temporariamente no chão da floresta durante um curto período de tempo. (Archaeognatha: Meinertellidae, Meinertellus adisi e Neomachilellus adisi, ADIS \& STURM $(1987 a))$.

2.2 Aspectos gerais sobre a migração em áreas inundáveis.

No que diz respeito aos estudos desenvolvidos sobre os diversos grupos de invertebrados em áreas alagáveis da Amazônia, a reação de oligochaeta à inundação foi estudado por ADIS \& BOGEN (1982). Os autores verificaram que, durante a subida da água, os Glossoscolecidae migram na direção da terra firme, acompanhando a margem da água numa distância de $16 \mathrm{~m}$ até $26 \mathrm{~m}$. Durante a descida do nível da água, eles retornam para o igapó, seguindo a margem da água numa distância de 5m a 10m. Posteriormente, ADIS \& RIGHI (1989), em estudo sobre a estratégia de sobrevivência de Tairoma tipema (Glossoscolecidae), observaram que, pouco antes da inundação, ocorreu migração horizontal em massa de imaturos para áreas mais elevadas de terra firme (vale do Rio Negro). Migração vertical em massa foi relatada para Andiorrhinus venezuelanus tarumanis (Glossoscolecidae), numa floresta de inundação, perto do vale do Rio Solimões. Os animais mudam do solo, saturado por água, para a área do tronco e da copa, pouco antes da inundação anual. A secreção de muco facilita 
as ascenções noturnas pelos troncos, dos indivíduos com até $19 \mathrm{~cm}$ de comprimento. Os autores afirmaram que outras estratégias de sobrevivência à inundação podem ser utilizadas pelos oligochaeta tais como: sobrevivência no solo da floresta inundada; uso de respiração anaeróbica via ácido láctico ou resistência dos ovos à inundação, conforme já relatado para insetos por BECK $(1969,1972)$, ADIS \& STURM (1987b), MESSNER \& ADIS (1988), MESSNER et alii (1992), ADIS \& MESSNER (1991).

ADIS et alii (1993) verificaram que alguns estágios migratórios imaturos de cutervodesmus adisi (Fuhrmannodesmidae), em áreas inundáveis por água preta, migram para as regiões dos troncos e copas, durante o período inundado e retornam ao solo após a inundação, onde se reproduzem. ADIS (1986) verificou que estágios imaturos e subadultos de Gonographis adisi (Pyrgodesmidae, Diplopoda) sobrevivem todo o período inundado ( 5 a 6 meses) sob cascas submersas nos troncos, em floresta inundada por água preta. Posteriormente, MESSNER \& ADIS (1988) verificaram, nesta mesma espécie, a presença de uma estrutura cuticular (plastrão), que permite a respiração durante o período submerso.

Coleoptera é um dos grupos mais abundantes nas florestas da Amazônia e, dentre eles, Carabidae foi a família com a qual maiores estudos sobre estratégia de sobrevivência à inundação foi realizada. Assim, ADIS (1982a) observou que, quando próximos a áreas não inundáveis, os carabídeos podem escapar da enchente, caminhando ou voando para estes locais. Eles também podem permanecer em fase de estivação sob cascas de árvores; como exemplo, Pachyteles sp. tem sido coletada em estivação sob cascas de Aldinia latifolia. Evidências de estivação, independente da flutuação do nível da água, também têm sido observadas, por exemplo, em Diplopoda 
(Epinannolenidae, Stemmiulidae) e parecem ser reguladas pelos fatores abióticos, especialmente pelas mudanças microclimáticas entre a estação chuvosa e a estação menos chuvosa.

Estudos desenvolvidos por PAARMANN et alii (1982), com Carabidae (Cicindelinae) da Amazônia Central, indicaram que Pentacomia egregia apresenta um desenvolvimento univoltino, como adaptação às variações no nível de água. Durante a fase de submersão, os adultos apresentam uma fase de dormência gonodal e vivem nos troncos e copas. Algumas semanas antes do final da fase de submersão, os machos atingem sua maturidade e copulam com as fêmeas que ainda se encontram sexualmente imaturas. No final da fase de emersão, as fêmeas completam a maturidade gonadal. Observações feitas por ADIS et alii (1986), com Polyderis nympha, indicam que durante a inundação os adultos voam para áreas adjacentes, onde atingem a maturidade sexual e retornam para recolonizar o solo da floresta após a inundação.

ADIS et alii (1990) observaram uma dormência gonodal em Scarites spp.(Scaritini, Carabidae, Coleoptera), como um tipo de reação de adaptação à inundação anual e, ADIS (1982a) dividiu os carabídeos de áreas alagáveis em três grupos, baseado no tipo de colonização: a) - habitantes de florestas inundáveis. b) - habitantes tanto de florestas inundáveis, como da margem, incluindo solo e região inferior do tronco. c) - habitantes somente da região da margem.

Com relação às estratégias de sobrevivência à inundação utilizadas pelos Meinertellidae (Archaeognatha), ADIS \& STURM (1987a) estudaram o ciclo de vida, a ecologia e adaptações em florestas inundáveis de Neomachilellus scandens, N. amazonicus e Meinertellus adisi. A inundação é considerada como o fator principal responsável por um desenvolvimento sazonal. Morfologicamente, as espécies das 
diferentes regiões são iguais, entretanto, estudos de eletroforese realizados por WOLF \& ADIS (1992), entre as populações de áreas de terra firme e áreas alagáveis ( $N$. scandens), mostraram uma diferença nas características genéticas das populações das duas regiões.

o ciclo de vida, adaptações e a resistência dos ovos de Neomachilellus scandens (Meinertellidae, Archaeognatha) à inundação, foram estudados por ADIS \& STURM (1987b), em florestas inundáveis da Amazônia Central. Estudos posteriores, realizados por STURM \& ADIS (1984), sobre o desenvolvimento de Meinertellidae, revelaram as primeiras observações sobre o comportamento de acasalamento e transferência de esperma de $N$. scandens.

Com relação aos Pseudoscorpiones da Amazônia MAHNERT \& ADIS (1985) e ADIS \& MAHNERT (1990a) relacionaram a occorrência das espécies, caracterizando os tipos de florestas, habitats e área de amostragem para cada espécie. A mudança no habitat de 20 espécies de Pseudoscorpiones da Amazônia, em resposta à inundação, foi estudada por ADIS \& MAHNERT (1985). Os autores discutiram sobre as adaptações no ciclo de vida e a migração para os troncos e copas em áreas inundáveis. Os dados são baseados na captura com fotoeclectores de árvores, fotoeclectores de solo, extração do solo com o método de Kempson, pulverização das copas e coleta em epifitas. Posteriormente, ADIS et alii (1988) estudaram as adaptações de Pseudoscorpiones de floresta primária de terra firme, para florestas inundáveis. Eles constataram uma reprodução univoltina como adaptação a florestas inundáveis em relação à reprodução polivoltina que ocorre em florestas de terra firme.

No que concerne aos Symphyla, ADIS \& SCHELLER (1984) desenvolveram estudos sobre a ecologia e a biologia de Hanseniella arborea (Scutigerellidae) e verificaram que $H$. 
arborea é a primeira espécie migrante encontrada nesta ordem. o estudo foi desenvolvido em floresta inundada por água preta na Amazônia.

\section{Posteriormente, SCHELLER \& ADIS (1984)}

descreveram e estudaram a ecologia e biologia de Ribautiella amazonica Scheller, 1984 (Scolopendrellidae), em floresta inundada por água preta na Amazônia. o trabalho registrou, pela primeira vez, a ocorrência deste gênero nas Américas. A permanência no solo como estratégia de sobrevivência à inundação desta espécie, juntamente com Chilopoda (Lamyctes sp.), foi relatada por ADIS (1992b).

No que diz respeito aos Diplura, apenas as adaptações de Japygidae, em áreas alagáveis, foi estudada por ADIS et alii (1989). Os autores relataram a descoberta da construção de um casulo de seda que possibilita a sobrevivência a inundação no solo da floresta.

Isoptera de áreas alagáveis constroem seus ninhos em regiões do tronco e copa, que não são atingidas pela inundação e, segundo MARTIUS (1992), armazenam a alimentação a ser consumida durante o período de enchente. Os ninhos vazios de cupins servem de abrigo para outros artrópodos durante a inundação (MARTIUS, 1994b).

\subsection{Abundância e distribuição vertical de artrópodos do solo}

No que concerne à distribuição vertical da fauna no solo, PETERSEN \& LUXTON (1982) afirmaram que a maioria da fauna se concentra na camada superior de 0 a $10 \mathrm{~cm}$ de solo. A afirmação foi baseada na distribuição vertical de Collembola em diferentes tipos de ecossistemas. No exemplo mencionado com floresta tropical (Costa do Marfim, África), a maior densidade populacional ocorreu também na camada mais 
superficial do solo (de 0 a $10 \mathrm{~cm}$ de profundidade). Os autores afirmaram que, a variabilidade entre as amostras pode não ser somente devido a mudanças no tamanho da população causada pela mortalidade e natalidade, mas pode também ser causada por migrações horizontais ou verticais ao longo do ano. A dominância de alguns grupos, em determinados habitats, indica uma tolerância relativamente maior a fatores ambientais adversos destes grupos, quando comparados aos outros, ou certamente devido a um maior potencial reprodutivo. Diferenças na mobilidade entre as espécies e diferentes padrões de biologia também influenciam.

Em estudos desenvolvidos sobre a abundância e distribuição vertical da fauna da Amazônia, ADIS (1988) afirmou que, em média, 30.000 artrópodos $/ \mathrm{m}^{2}$ vivem na camada de 0 a $3,5 \mathrm{~cm}$ de profundidade em floresta primária de terra firme (Reserva Ducke). Aproximadamente $70 \%$ da fauna encontrada foram ácaros (50\%) e colêmbolos (25\%). Dos $25 \%$ restantes, Formicidae, Isoptera e Pseudoscorpiones foram particularmente numerosos. Aproximadamente $70 \%$ de toda fauna foi capturada na camada de 0 a $3,5 \mathrm{~cm}$ do solo e $30 \%$ foi extraída na camada de 3,5 a $7 \mathrm{~cm}$ de profundidade com o método do Kempson (MORAIS, 1985; ADIS \& SCHUBART, 1984; ADIS, 1987). Em floresta secundária de terra firme (Tarumã Mirim e no campus do INPA) foi capturada uma média de 70.000 artrópodos $/ \mathrm{m}^{2}$, valor aproximadamente duas vezes maior que em floresta primária (ADIS at alii 1987a, 1987b; RODRIGUES, 1986). Na camada superior do solo (de 0 a $3,5 \mathrm{~cm}$ de profundidade) os ácaros representaram mais de $20 \%$ do total capturado (método de Kempson) (ADIS, 1988). Isoptera, Formicidae, Pseudoscorpiones e Protura, foram os grupos mais abundantes no solo. Aproximadamente 61 a $64 \%$ da fauna vivem nos primeiros $3,5 \mathrm{~cm}$ de profundidade, 20 a $21 \%$ entre $3,5 \mathrm{a}$ $7 \mathrm{~cm}, 10$ a $12 \%$ entre 7 a $10,5 \mathrm{~cm}$ e 5 a $8 \%$ entre 10,5 a 14 
Cm de profundidade no solo (ADIS et alii 1987a, 1987b; ADIS, 1988 ) .

Maiores detalhes sobre a abundância e distribuição vertical dos artrópodos de solo, em outros tipos de florestas da Amazônia foram apresentados por: MORAIS (1985) e NEW et alii (1991), em floresta primária de terra firme; RODRIGUES (1986) e ADIS et alii (1987a, 1987b), em floresta secundária de terra firme e ADIS et alii (1989a, b), em floresta de Campinarana ( = Caatinga arbórea).

ADIS \& MAHNERT (1990b) estudaram a abundância e distribuição vertical de Pseudoscorpiones no solo, numa profundidade de $14 \mathrm{~cm}$, em floresta secundária da Amazônia Central. Os autores fizeram uma comparação entre a estação chuvosa e a estação menos chuvosa, e correlacionaram a abundância e a distribuição vertical no solo com os fatores abióticos da área. Em estudos posteriores, ADIS \& MAHNERT (1993) compararam a abundância e a distribuição vertical de Pseudoscorpiones no solo, em dois diferentes tipos de floresta primária, durante a estação chuvosa e a estação menos chuvosa, na Amazônia. Os autores concluíram qua não houve migração vertical, nas duas estações, como acontece em outros lugares da região Neotropical, em resposta aos fatores ambientais.

HARADA \& BANDEIRA (1994) estudaram a estratificação e a densidade de invertebrados em solo arenoso em floresta e plantios arbóreos, na Amazônia. Os autores afirmaram que $45 \%$ de toda fauna ocorreu na faixa de 0 a $5 \mathrm{~cm}$ de profundidade do solo. Houve diminuição na densidade de todos os grupos (exceto Isoptera) até a profundidade de $20 \mathrm{~cm}$, com subsequente aumento até $30 \mathrm{~cm}$ de profundidade, causado principalmente pela presença de Isoptera. 
Trabalhos desenvolvidos por MERINO \& SERAFINO (1978) e SERAFINO \& MERINO (1978), com populações de artrópodos em três diferentes tipos de solo cultivados da Costa Rica (plantação de café, mandioca e milho), demonstraram que há um decréscimo gradual na densidade dos artrópodos com a profundidade do solo. Entretanto, alguns grupos podem ser mais abundantes nas camadas inferiores do solo, dependendo do tipo de plantação. PRICE \& BENHAM (1977) também afirmaram que a densidade populacional dos artrópodos diminui, com a profundidade do solo, e que alguns grupos são mais abundantes nas camadas mais profundas do solo.

GILL (1969), estudando a abundância de microartrópodos do solo (em Michigan, EUA), verificaram que os fatores físicos do ambiente, tais como umidade do solo, temperatura do solo e a presença de folhedo, foram de maior importância na determinação da distribuição vertical e da abundância dos microartrópodos do solo.

GUPTA \& MUKHARJI (1976) investigaram a composição qualitativa dos artrópodos nas diferentes camadas de solos cultivados e não cultivados (em Varanasi, na Índia) e sua distribuição sazonal.

\subsection{Outros estudos desenvolvidos com artrópodos}

Segundo GRIMM et alii (1974), para realizar levantamento da fauna de Arthropoda terrestre em ecossistemas florestais, é necessário o uso simultâneo de vários métodos de coleta, por exemplo, fotoeclector de solo (FUNKE, 1971), armadilha de solo (ADIS, 1974) e fotoeclector de árvore (FUNKE, 1971). ADIS (1977) afirmou que a combinação dos diferentes tipos de armadilhas permite considerações sobre o inventário de espécies, a dominância, a fenologia e a abundância de artrópodos terrestres. 
ADIS \& RIBEIRO (1989) estudaram o impacto do desmatamento, sobre a fauna de invertebrados do solo de uma floresta inundável na Amazônia Central, comparando uma floresta de várzea com uma área de plantação de milho e mandioca. Foram obtidos cerca de 42.300 invertebrados por $\mathrm{m}^{2}$ de solo, extraído de 0 a $7 \mathrm{~cm}$ de profundidade, na floresta de várzea e, 13.550 na área de plantação de milho.

ERWIN (1983) estudou a fauna de insetos da copa em florestas inundáveis e em florestas de terra firme da Amazônia e verificou que, dentre os coleópteros, Curculionidae e Chrysomelidae foram mais abundantes. Em todas as áreas e em todas as amostras as formigas foram mais dominantes em número de indivíduos e biomassa.

FRIEBE (1984), estudando a fauna de coleópteros de floresta inundada por água preta e floresta inundada por água branca, verificou que a colonização durante o período de emersão foi mais densa no igapó e a proporção de saprófagos foi maior, enquanto que, na várzea, os predadores foram dominantes.

Trabalhos desenvolvidos por MARTIUS (1994a, 1994c), sobre a diversidade e ecologia de térmitas da Amazônia Central, indicaram que, aproximadamente 15 espécies foram registradas, em floresta inundada por água branca e que metade das espécies presentes pertencem à subfamília Nasutitermitinae.

HÖFER (1990) desenvolveu estudos em floresta inundada por água preta (igapó), com a fauna de aranhas. Aproximadamente 22.000 indivíduos foram identificados e os dados ecológicos foram avaliados. Algumas novas espécies foram encontradas e descritas por PLATNICK \& HÖFER (1990), BRESCOVIT \& HÖFER (1994a, 1994b), HÖFER et alii (1994).

ERWIN \& SCOTT (1980) estudaram a fauna de coleópteros, na copa das árvores, na Zona do canal do Panamá, 
comparando a ocorrência das famílias de acordo com os níveis tróficos e com as estações do ano.

CEPEDA-PIZARRO (1992), no Chile, estudaram o

efeito das estações anuais, a qualidade do substrato, a qualidade do folhedo $e$ as condições de solo sobre os microartrópodos edáficos.

LEVINGS \& WINDSOR (1985) estudaram a fauna de artrópodos de uma floresta tropical no Panamá e verificaram que os grupos de artrópodos mostraram diferentes padrões de abundância sazonal. As variações sazonais dos artrópodos também foi observada por WOLDA \& WRIGHT (1992) no Panamá. Estes autores testaram o efeito da irrigação, durante a estação seca, na abundância dos insetos por um período de 3 anos.

Trabalhos desenvolvidos por BELFIELD (1956) sobre a distribuição da fauna de solo, na África, indicaram que o aumento na densidade populacional dos artrópodos está diretamente relacionada com a umidade do solo.

Estudos desenvolvidos por STRÜVE-KUSENBERG (1981), sobre a sucessão e a estrutura trófica da fauna de solo em três diferentes áreas da Alemanha (Göttingen), mostraram que a abundância dos grupos variou entre as áreas de estudo.

AL-ASSIUTY et alii (1993), em estudos desenvolvidos com fauna de solo, verificaram a influência do tipo de vegetação sobre a abundância e a composição das espécies em diferentes localidades do Egito. Os experimentos foram desenvolvidos em plantações de banana e laranja. 0 efeito da estrutura do solo sobre a fauna de artrópodos, no sul do Egito foi estudado por MIKHAIL (1993).

SGARDELIS \& MARGARIS (1993), na Grécia, realizaram estudo sobre o efeito do fogo na população de microartrópodos do solo. Na Amazônia, OLIVEIRA \& FRANKLIN 
(1993) estudaram o efeito do fogo sobre a mesofauna do solo, numa área cuja cobertura vegetal foi derrubada e queimada para plantação de pastagem. Os resultados mostraram que a densidade populacional da fauna foi drasticamente afetada pelo fogo.

SCHELLER (1992) descreveu duas novas espécies de Symphyla na Amazônia (Symphylella adisi e scolopendrellopsis tropicus) e registrou, pela primeira vez, a ocorrência de Hanseniella orientalis na América do Sul. o autor apresentou uma chave de identificação para os gêneros Neotropicais.

NEW et alii (1991) realizaram estudos sobre a fenologia, a abundância e a distribuição de Psocoptera em floresta primária e secundária de terra firme na Amazônia, e BAZ (1991), trabalhando com o mesmo grupo, na Espanha, estudou a distribuição, no folhedo, de diferentes localidades. SEASTEDT (1984) afirmou que eles são importantes na decomposição da matéria orgânica.

\subsection{Ação da fauna de solo na decomposição do folhedo}

PETERSEN \& LUXTON (1982) fizeram uma análise comparativa da fauna de solo e sua função nos processos de decomposição e afirmaram que a decomposição da matéria orgânica tem sido considerada como uma interação sinérgica entre a fauna de invertebrados e a microflora, seguindo a um periodo inicial de desgaste, quando alguns nutrientes solúveis e polifenóis são eliminados.

JANBU et alii (1988) afirmaram que a decomposição do folhedo é fundamentalmente obra dos microorganismos. Contudo, segundo KURCHEVA (1967), a fauna de solo contribui na destruição de 7 a $23 \%$ dos resíduos vegetais que caem no solo. Sua intervenção é direta pela ação 
mecânica e bioquímica e/ou indireta favorecendo a ação dos microorganismos. Entretanto, HEATH et alii (1966) afirmaram que a presença da fauna acelera apenas a decomposição dos tecidos mais duros. De certo modo, os invertebrados no solo são capazes de modificar os processos de decomposição agilizando, assim, a microflora que os coloniza. HANLON \& ANDERSON (1979) mostraram que a atividade da fauna de solo favorece o desenvolvimento de bactérias, em detrimento aos fungos. Além disso, EDWARDS (1974) afirmou que a fauna de solo é responsável pela quebra inicial do folhedo. Em regiões tropicais, os principais artrópodos envolvidos na quebra do folhedo são os Isoptera, enquanto que, em áreas temperadas, são Diplopoda e larvas de Diptera.

Trabalhos desenvolvidos por MARTIUS (1989), sobre o papel dos cupins xilófagos no processo de decomposição de madeira, na várzea, indicaram que mais da metade da madeira morta, encontrada no chão, se apresentou roída pelos cupins, indicando, deste modo, que a fragmentação pelos térmitas deve ser um fator importante na decomposição. STORK \& EGGLETON (1992) discutiram a importância dos invertebrados, como determinantes e indicadores da qualidade do solo, sua relação com os habitats e as funções dos principais grupos de invertebrados do solo.

\subsection{Pulso de inundação e categorias de vegetação em áreas inundáveis}

O degelo dos Andes e os períodos diferentes de chuva, nas áreas de captação dos rios da Amazônia, provocam enchentes anuais. Conseqüentemente, na Amazônia Central, isto causa uma subida do nível das águas de aproximadamente 10m, em relação ao nível do Rio Negro e Rio Solimões, inundando extensas áreas, conhecidas como áreas alagáveis (IRMLER, 
1977). Estas áreas alagáveis representam aproximadamente $2 \%$ da região amazônica brasileira (ADIS, 1984).

IRION \& ADIS (1979) demonstraram que as primeiras florestas de inundação já existiam há mais de 1 milhão de anos, nas adjacências das margens do Rio Negro, conseqüentemente também na confluência dos rios Tarumã-Mirim e Rio Negro. Estas regiões tem estado, desde então, expostas a flutuações anuais do nível da água do Rio Negro. Estas áreas denominadas ATTZ (Aquatic Terrestrial Transition Zone, JUNK et alii, 1989), são zonas de transição terrestreaquática, com características ambientais aquáticas e/ou terrestres, uma vez que esses ambientes se alternam com 0 pulso de inundação do rio. O pulso de inundação, segundo JUNK et alii (1989), é definido pelo número de inundações, sua altitude e duração no ciclo anual. Os períodos de inundação conduziram à adaptação de plantas e animais, inclusive dos artrópodos terrestres.

JUNK (1989) desenvolveu estudos, sobre tolerância à inundação e a distribuição da vegetação em áreas alagáveis (florestas de várzea e igapó) e verificou que a composição florística destas áreas corresponde com o período de inundação e varia de acordo com o nível de elevação do terreno. 0 autor determinou três diferentes níveis, sendo que no nível mais baixo encontra-se a comunidade de arbustos que permanecem submersos durante o período da inundação. A relação e composição da vegetação no nível médio e no nível mais alto também foram descritas.

PRANCE (1979, 1980) classificou as principais categorias de vegetação inundável na região amazônica, introduzindo os termos "igapó sazonal". e "várzea sazonal"; entretanto, a classificação mais simples e utilizada pela maioria dos liminologistas é aquela proposta por sIoLI (1951), que utiliza o termo "várzea" para as áreas inundáveis 
por água branca (Rio Solimões) e igapó para as áreas inundáveis por água preta (Rio Negro). Esta mesma terminologia foi utilizada por IRMLER (1977). A classificação de SIOLI (1951) é baseada no tipo de água que define água branca: de cor café com leite devido a grande quantidade de material inorgânico em suspensão, $\mathrm{pH}$ em torno de 7 e altos valores de condutividade; água preta: apresenta coloração marrom-escura, rica em compostos húmicos dissolvidos, $\mathrm{pH}$ em torno de 4 e baixa condutividade e água clara: de coloração verde, transparente e límpida, pobre em sólidos minerais em suspensão, e apresentando valores intermediários de condutividade e pH. A pronunciada diferença físico-química dos vários tipos de águas reflete na flora e fauna aquáticas (KLINGE et alii, 1987). A origem destes diferentes tipos de água está ligada às peculiaridades ambientais da região e características geológicas. A mistura entre a água preta e a água branca constitui o que se conhece na região como água mista: com transparência intermediária à água preta e à água branca; o pH, apesar do efeito acidificante da água preta, flutua no intervalo de variação do $\mathrm{pH}$ da água branca e temperatura intermediária as águas geradoras. Maiores detalhes sobre os aspectos físicos e químicos da água mista são encontrados no trabalho de LOPES (1992) desenvolvido numa área conhecida regionalmente como "encontro das águas". 
3 MATERIAL E MÉTODOS

3.1 Características gerais da região

3.1.1 Localização da área

A área experimental localiza-se numa faixa de terra entre o Rio Negro e o Rio Solimões, distante aproximadamente $10 \mathrm{Km}$ de Manaus $\left(03^{\circ} 20^{\prime} \mathrm{S}-60^{\circ} 17^{\prime} \mathrm{W}\right)$, e durante o período da inundação sofre influência do Rio Solimões na enchente e do Rio Negro na vazante (Figura 1). Não existe conexão direta da área experimental com áreas de terra firme não inundáveis (ADIS \& RIGHI, 1989).

A duração do período de estudo foi de julho/1987 a junho/1988, sendo que durante esta época o periodo não inundado foi mais longo do que o normal e se estendeu aproximadamente dez meses da seguinte forma:

Período de estudo: de julho/1987 a junho/1988.

Período não inundado: de agosto/1987 a maio/1988.

Período inundado: de julho/1987 e a partir de junho/1988.

Período chuvoso: de dezembro/1987 a maio/1988.

Período menos chuvoso: de julho/1987 a novembro/1987 e junho/1988

3.1.2 Solo

Segundo IRMLER (1975), o solo da área experimental consiste de argila, predominantemente montmorilonita, e representa depósitos aluviais do Rio Solimões. Apresenta uma fina camada de folhedo com aproximadamente $3,5 \mathrm{~cm}$ de profundidade, que durante o período 
menos chuvoso, próximo do início da inundação, atinge em média 5,4 t/ha de peso seco. Predominam sedimentos de argila de $2 \mu \mathrm{m}$ de diâmetro. Maiores detalhes sobre a descrição da área em estudo são apresentados nos trabalhos de IRMLER (1975) e ERWIN (1983).

A análise granulométrica do solo e a determinação do percentual das partículas de argila e silte na área experimental foi feita por IRION \& $\mathrm{ADIS}^{2}$ estes dados foram utilizadas para os cálculos das correlações com a distribuição vertical dos artrópodos no solo (Apêndice 2).

\subsubsection{Vegetação}

Não existe um estudo completo da vegetação na área experimental. AMARAL \& ADIS $^{2}$ realizaram um levantamento das plantas, numa área de $1 / 2$ hectare na região, e constataram a presença de 201 indivíduos, distribuídos em 31 famílias, 59 gêneros, e 63 espécies, indicando um grau de heterogeneidade bastante alto.

A vegetação é basicamente floresta densa de várzea com pequenas clareiras provocadas pela morte natural das árvores e sem interferência do homem. As espécies mais abundantes (em ordem decrescente) são: Pterocarpus amazonum (mutiti),

${ }^{1}$ IRION, G. \& ADIS, J. (Instituto Senckenberg, wilhelmshaven, Alemanha e Instituto Max-Planck de Limnologia, Plön, Alemanha). Comunicação pessoal, 1994.

2AMARAL, I.L. \& ADIS, J. (Instituto Nacional de Pesquisas da Amazônia, Manaus/Brasil e Instituto Max-Planck de Limnologia, Plön/Alemanha). Levantamento de $1 / 2$ hectare do lago Janauari no estado do Amazonas. (Em elaboração). 
seguido por uma Sapotaceae ainda não identificada, Calophyllum brasiliensis (jacareúba), Pseudolmedia laevis e Hura creptans (assacu). As plantas dominantes existentes no sub-bosque são principalmente, uma palmeira conhecida regionalmente como "marajá" (Bactris sp.) e uma graminea, não identificada, conhecida como "taboquinha".

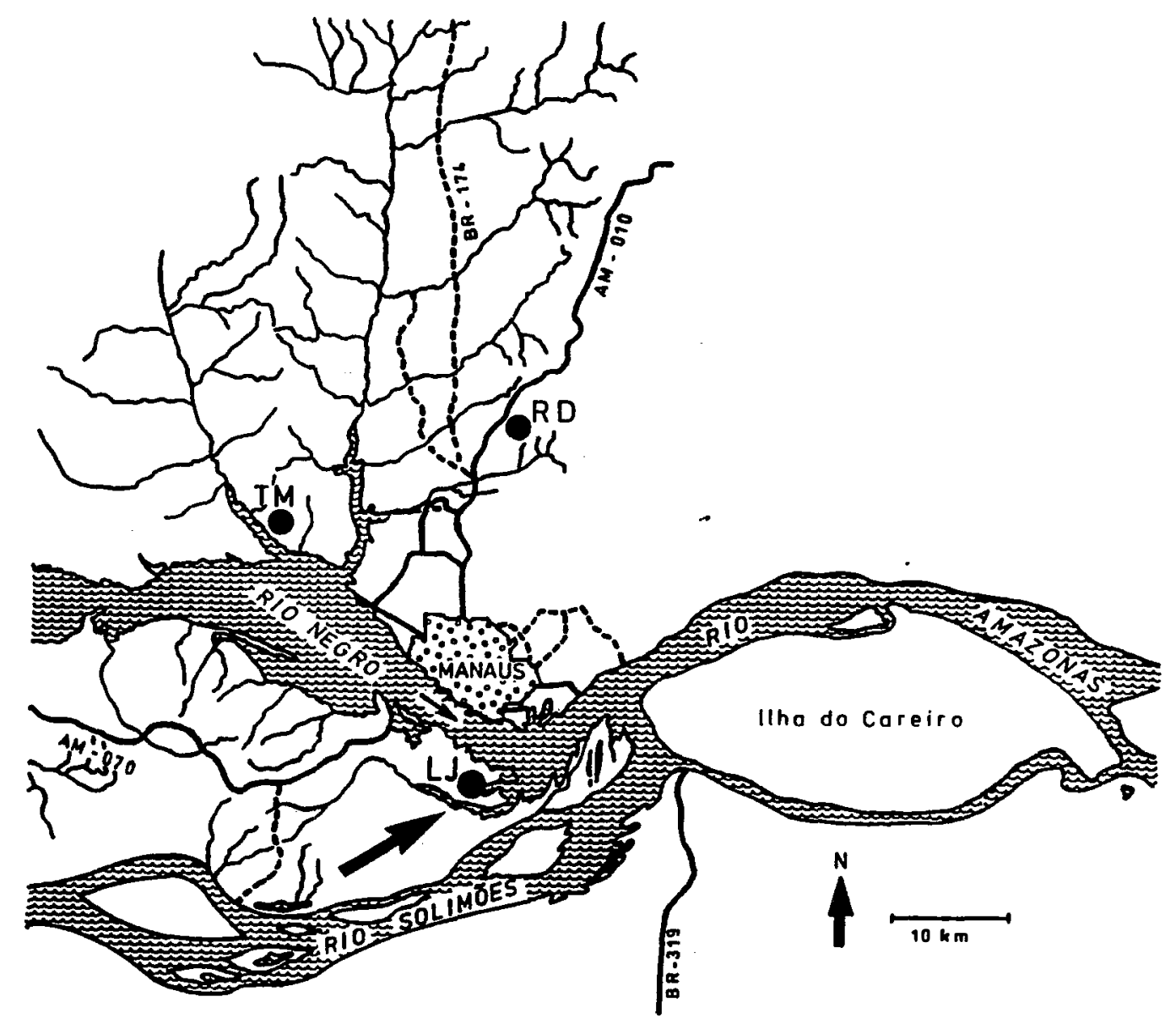

Figura 01 - Localização da área de estudo (LJ = Lago Janauari ) . 
Além das plantas acima mencionadas, as seguintes espécies foram identificadas por IRMLER (1975): Quiinia rhytidopus, Cassia leiandra, Piranhea trifoliata, Vitex cymosa, Inga sp., Pseudoxandra polyphleba, Paullinia sp. , Ceiba pentandra, olmediophaena maxima, Hevea spruceana, Buchenavia grandis e Aspidosperma excelsum.

\subsubsection{Dados climatológicos da área}

Durante o período de coleta foram instalados equipamentos na área experimental para registro dos dados climatológicos locais: precipitação pluviométrica, temperatura e umidade relativa do ar, temperatura, umidade e $\mathrm{pH}$ do solo.

A temperatura e a umidade relativa do ar foram medidas com um termohigrógrafo tipo Thies através de registros contínuos e avaliados, diariamente, a cada 6 horas (6:00, 12:00, 18:00 e 24:00 horas).

A temperatura, a umidade e o $\mathrm{pH}$ do solo foram determinados mensalmente no dia da coleta do solo nas 4 camadas em estudo $(0-14 \mathrm{~cm})$. Foram feitas 3 medições em cada camada de $3,5 \mathrm{~cm}$ de espessura e retirado um valor médio para todos os parâmetros.

Para determinação da temperatura do solo, usou-se um termômetro elétrico, tipo Thermophil-ultrakust. Devido a problemas no aparelho de medição não foram obtidos dados nos meses de janeiro e fevereiro/1988. Portanto, para efeito nos cálculos de correlações usou-se a média obtida dos meses anterior e posterior (dezembro/1987 e março/1988).

Para determinação da umidade, foram coletadas amostras de solo através de um cilindro de metal com altura de $27 \mathrm{~cm}$ e diâmetro de $5 \mathrm{~cm}$.

No laboratório, a umidade foi determinada pela 
diferença entre o peso úmido $(\mathrm{Pu})$ e o peso seco (Ps), em estufa a $110^{\circ} \mathrm{C}$, através da seguinte fórmula:

$$
\%=\frac{P u-P s}{P s} \times 100
$$

A determinação do $\mathrm{pH}$ do solo foi feita com as mesmas amostras utilizadas para a determinação da umidade do solo. Após secagem em laboratório, as amostras foram diluídas em água destilada num becker de $250 \mathrm{ml}$ e o pH medido após um período de 2 horas com um pH-metro (WTW pH DIGI 88).

Os dados de precipitação pluviométrica foram obtidos através de registros contínuos com um aparelho tipo Hellmann. Paralelamente, coletou-se a água da chuva através de uma garrafa com funil, e estes dados de precipitação foram avaliados a cada duas semanas. A partir de 16 de maio, a água foi coletada em cima de um flutuante localizado próximo da área de coleta, pois a área já estava totalmente inundada. A finalidade da coleta da água da chuva com a garrafa foi de usar os dados de precipitação em substituição aos dados obtidos pelo aparelho, no caso de eventuais falhas. Portanto, devido a problemas no funcionamento do aparelho foram utilizados os dados de precipitação coletados através da garrafa durante os períodos de: julho/1987; de 1 12/agosto/1987; de 1 - 13/janeiro/1988; de 13 29/fevereiro/1988 e de 1 - 29/abril/1988. Também não foram obtidos dados de precipitação pluviométrica no período de 29/abril a 16 de maio/1988. Todos os dados referentes aos fatores abióticos da área foram registrados (Apêndices 1 e 2).

RIBEIRO \& ADIS (1984), em estudos desenvolvidos sobre a variação anual da precipitação na região amazônica, confirmaram a existência de uma época seca 
( = menos chuvosa) de junho a novembro e uma época chuvosa de dezembro a maio. Os dados foram baseados na precipitação registrada durante o período de 1910 a 1979 em Manaus. Assim, a época menos chuvosa (de junho a novembro) foi caracterizada com uma precipitação média de 550,8 mm e a época chuvosa (de dezembro a maio) com uma precipitação média de 1.553,8 mm. A precipitação anual somou $2.105 \mathrm{~mm}$, com aproximadamente $75 \%$ de precipitação registrada durante a época de chuva. A precipitação anual foi menor nas regiões inundadas e os padrões de intensidade, frequência e hora de chuva variaram de acordo com o local. Os meses de maior precipitação são, geralmente, de janeiro a abril e os meses de menor precipitação são, geralmente, de julho a setembro.

Na área experimental a precipitação pluviométrica variou de $81,5 \mathrm{~mm}$ a $291,3 \mathrm{~mm}$, sendo que, durante a estação menos chuvosa, foi registrado um total de $\approx 814 \mathrm{~mm}$ (de julho a novembro/1987 e junho/1988) e, durante a estação chuvosa foi registrado um total de $\approx 1.200 \mathrm{~mm}$ (de dezembro/1987 a maio 1988) (Apêndice 1). A temperatura do ar variou de $21,5^{\circ} \mathrm{C}$ a $29,8^{\circ} \mathrm{C}$ (Apêndice 1 ). A umidade relativa do ar variou de $73,0 \%$ a $100 \%$ (Apêndice 1 ). A umidade do solo variou nas diferentes. camadas: de $10,8 \%$ a $23,3 \%$, na camada de 0 a $3,5 \mathrm{~cm}$ de profundidade; de $14,6 \%$ a $24,2 \%$, na camada de 3,5 a $7 \mathrm{~cm}$; de $15,7 \%$ a $23,9 \%$, na camada de 7 a $10,5 \mathrm{~cm}$ e de $17,0 \%$ a $24,0 \%$, na camada de 10,5 a $14 \mathrm{~cm}$ (Apêndice 2). A variação da temperatura no solo foi: de 24,7 ${ }^{\circ} \mathrm{C}$ a $27,0^{\circ} \mathrm{C}$, na camada de 0 a $3,5 \mathrm{~cm}$; de $25,2^{\circ} \mathrm{C}$ a $26,6^{\circ} \mathrm{C}$, na camada de 3,5 a $7 \mathrm{~cm}$; de $25,5^{\circ} \mathrm{C}$ a $26,4^{\circ} \mathrm{C}$, na camada de 7 a $10,5 \mathrm{~cm}$ e de $25,5^{\circ} \mathrm{C}$ a $26,4^{\circ} \mathrm{C}$, na camada de 10,5 a $14 \mathrm{~cm}$. 0 $\mathrm{pH}$ variou de 4,1 a 5,5, na camada de 0 a $7 \mathrm{~cm}$; de 4,1 a 5,0, na camada de 7 a $10,5 \mathrm{~cm}$ e de 4,1 a 4,9, na camada de 10,5 a $14 \mathrm{~cm}$ de profundidade (Apêndice 2). A variação no teor de argila e silte, nas diferentes camadas do solo, foram 
registrados (Apêndice 2 ).

\subsection{Metodologia}

Os artrópodos foram monitorados no solo (método do Kempson) e na superfície (fotoeclectores de solo) durante o período não inundado, bem como na parte inferior dos troncos (fotoeclectores de árvores) durante os períodos não inundado e inundado.

\subsubsection{Método de Kempson}

Foram coletadas, mensalmente, 6 amostras de solo durante o período de agosto/1987 a maio/1988. Para coleta das amostras, utilizou-se o seguinte material: um cilindro de metal com aproximadamente $30 \mathrm{~cm}$ de altura e $21 \mathrm{~cm}$ de diâmetro com alças e abertura lateral; um cepo de madeira com aproximadamente $40 \times 20 \times 10 \mathrm{~cm}$ e marreta de madeira revestida por uma camada de borracha. Para extração do solo - cilindro foi colocado em posição vertical, num ponto previamente marcado. Em seguida, o cepo de madeira foi colocado sobre o cilindro, o qual foi introduzido no solo através de marretadas sucessivas.

A área de coleta foi previamente delimitada por 10 piquetes, distribuídos em linha reta e distantes $5 \mathrm{~m}$ um do outro. Cada piquete identificava um ponto de coleta mensal. Em cada ponto de coleta foram retiradas 6 amostras, cada uma delas a $14 \mathrm{~cm}$ de profundidade. Posteriormente, as amostras foram divididas em 4 sub-amostras com as seguintes dimensões: Primeira camada $=0-3,5 \mathrm{~cm}$; Segunda camada $=3,5-7$ $\mathrm{cm}$; Terceira camada $=7-10,5 \mathrm{~cm}$ e Quarta camada $=10,5-14 \mathrm{~cm}$ de profundidade. Deste modo, para cada coleta mensal, foram obtidas 24 sub-amostras ( 4 x 6 amostras). A escolha dos 
piquetes foi feita aleatoriamente. No campo, usou-se um recipiente $(25,5 \mathrm{~cm}$ de altura e $10,5 \mathrm{~cm}$ de diâmetro) com uma tela plástica no fundo $e$, sobre esta, uma malha de tamanho e diâmetro menor, que possibilitava a saída dos animais, mas evitava a queda de solo da amostra. Neste recipiente, as amostras eram colocadas em posição invertida sobre a malha. Em seguida, cada recipiente era envolvido por um saco plástico e colocado em caixa de alumínio $(67 \mathrm{~cm}$ x $67 \mathrm{~cm}$ x 60 $\mathrm{cm})$, revestidas internamente com isopor, para evitar grandes variações de temperatura durante o transporte.

Para extração dos artrópodos do solo no laboratório, utilizou-se o método do KEMPSON et alii (1963)(Figuras 2a e 2b), modificado por ADIS (1987) para a região neotropical. Para que as amostras fossem introduzidas no aparelho do Kempson, usaram-se 2 recipientes de diferentes tamanhos: o recipiente menor (tipo meio balde) proveniente do campo e contendo a amostra de solo e outro recipiente maior tipo balde inteiro (capacidade 10 litros). O recipiente menor contendo a amostra foi colocado dentro do balde, ficando preso na parte mediana interna do mesmo (Figura 2b). No interior do balde, usou-se uma solução de ácido pícrico concentrado e água (1:3), como líquido fixador e conservador. o conjunto contendo a amostra (balde com líquido fixador e conservador + recipiente menor com amostra) foi colocado na bandeja suporte das amostras (Figura 2a, $\mathrm{K}$ ), no interior do aparelho de extração. 


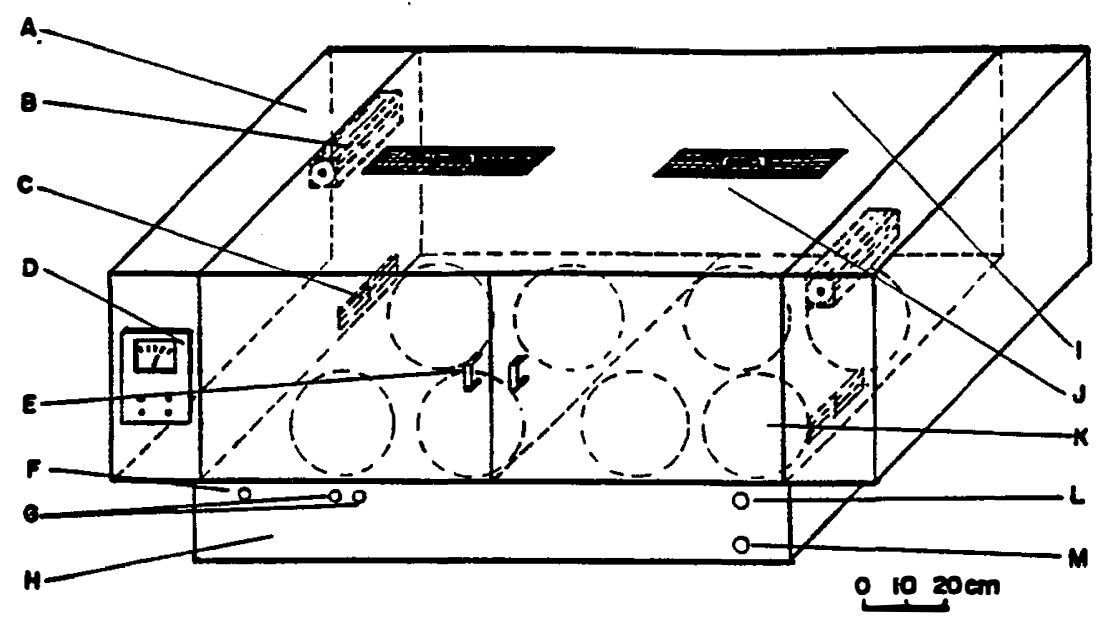

a

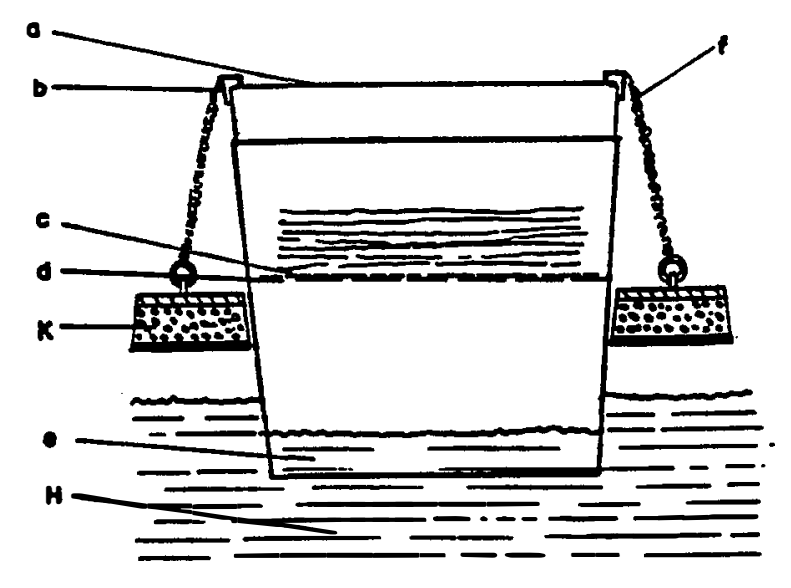

b

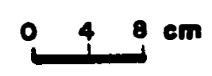

Figura 2a e b - Aparelho de extração de fauna de solo tipo Kempson/Mc-Fadyen. 2a): (A) compartimento lateral, (B) ventilador com entrada de ar, (C) saída de ar (D) regulador de temperatura, (E) portas, (F) entrada de água, (G) entrada e saída de água, (H) recipiente com água, (I) câmara de extração, (J) abertura de ar para controle da umidade, (K) bandeja suporte das amostras de solo, (L) fluxo superior de água (M) drenagem de água. 2b): Recipiente plástico para receber a amostra de solo; (a) cobertura, (b) recipiente, (c) tela de algodão, (d) tela de plástico (k), suporte da mostra, (e) agente preservativo, (H) água. Segundo ADIS (1987). 
Cada balde, contendo a amostra, foi coberto com um pano branco e preso por uma argola de borracha, a fim de evitar a saída dos animais maiores para o interior do aparelho. o tempo de permanência das amostras no interior do aparelho de Kempson variou de 12 a 14 dias. A temperatura e a umidade, no interior do aparelho, foram controladas na parte externa do mesmo.

Assim, aumentou-se gradativamente a temperatura na parte superior, enquanto que na parte inferior a temperatura foi diminuida gradativamente através de um sistema de refrigeração. Deste modo, os artrópodos foram induzidos a se deslocarem para baixo, em direção à parte mais úmida da amostra e conseqüentemente caindo na solução de ácido pícrico. A temperatura inicial da parte superior do aparelho foi de $27^{\circ} \mathrm{C}$, correspondendo à temperatura máxima mensal no solo da floresta segundo o esquema abaixo, proposto por ADIS (1987).

$\begin{array}{crrcr}\text { Dia } & \text { TS } & \text { TR } & \text { DT } & \text { V } \\ 1 & 27 & 21 & - & \text { F } \\ 2 & 31 & 17 & 1,0 & \text { F } \\ 3 & 35 & 13 & 1,0-1,5 & \text { F } \\ 4 & 39 & 09 & 2,0 & \text { F } \\ 5 & 43 & 06 & 2,0 & \text { F } \\ 6 & 47 & 06 & 2,5 & \text { SA } \\ 7 & 51 & 06 & 4,0 & \text { SA } \\ 8 & 55 & 06 & 8,0-10,0 & \text { SA } \\ 9 & 59 & 06 & 10,0 & \text { A } \\ 10 & 59 & 21 & 10,0 & \text { A } \\ 11 & 59 & - & - & \text { A } \\ 12 & 59 & - & - & \text { A } \\ 13 & 59 & - & - & \text { A } \\ 14 & 59 & - & - & \text { A }\end{array}$


TS = Temperatura na parte superior do aparelho $\left({ }^{\circ} \mathrm{C}\right)$

$\mathrm{TR}=$ Temperatura do sistema de refrigeração, na parte inferior do aparelho $\left({ }^{\circ} \mathrm{C}\right)$.

$\mathrm{DT}=$ Diferença de temperatura na parte superior e inferior das amostras de solo $\left({ }^{\circ} \mathrm{C}\right)$.

$\mathrm{V}$ = Abertura das partes de ventilação. $\mathrm{F}=$ Fechada; $\mathrm{SA}=$ Semi-aberta; $\mathrm{A}=$ Aberta .

o aumento na diferença de temperatura, entre a parte superior e a parte inferior do aparelho, causou uma secagem gradativa de cima para baixo na amostra. Isto possibilitou aos artrópodos se moveram de acordo com a camada de umidade que diminuía gradativamente no interior da mesma, e evitou, assim, uma secagem brusca e total, que resultaria na morte dos animais. A secagem total da amostra ocorreu após o oitavo dia.

Os artrópodos foram retirados do ácido pícrico e conservados em álcool $90 \%$, segundo o sistema de filtração proposto por ADIS (1979).

As 6 amostras retiradas por camada de solo representam aproximadamente $0,21 \mathrm{~cm}^{2}$ e a abundância foi expressa em valores calculados para $1 \mathrm{~m}^{2}$ e representada através do valor médio mensal (indivíduos $/ \mathrm{m}^{2} / \mathrm{mês}$ ) ou através do valor total (individuos $/ \mathrm{m}^{2}$ ).

\subsubsection{Fotoeclectores}

Segundo FUNKE (1971), os fotoeclectores são apropriados para extração quantitativa de artrópodos em todos os níveis tróficos nas áreas de troncos e copas de árvores, assim como, para captura de estágios de desenvolvimento que vivem no solo. Eles podem ser de dois tipos: a) Fotoeclector de solo. b) Fotoeclector de árvore. 
3.2.2.1 Fotoeclector de solo (E)

O fotoeclector de solo é também conhecido como armadilha de emergência, ou eclector de solo. É um tipo de armadilha utilizada normalmente, para captura de insetos emergentes (especialmente adultos de Pterygota), os quais completam o desenvolvimento larval no folhedo ou solo (FUNKE, 1971) e que apresentam fototropismo positivo e geotropismo negativo. O fotoeclector de solo também captura animais de outros habitats, tais como: região de tronco e copa. Os dados de captura com fotoeclectores de solo representam a abundância de emergência, a fenologia e a densidade de atividade de artrópodos em áreas fechadas (THIEDE, 1977). Neste estudo, o tipo de eclector utilizado foi semelhante ao descrito por FUNKE(1971), que consiste de uma parede quadrada ou arredondada de material plástico não transparente ("Trovidur"), cobrindo $1 \mathrm{~m}$ de solo e com 0,5 m de altura, com uma armação de metal, um teto em forma de pirâmide (Figura 3a) e totalmente revestida por um pano preto. o pano preto foi preso no ápice da armadilha por um anel de metal e um tubo plástico (diâmetro $=7,1 \mathrm{~cm}$ ). Sobre o tubo plástico, usou-se uma caixa transparente de polietileno $(12 \mathrm{~cm}$ de diâmetro e $9,5 \mathrm{~cm}$ de altura) como caixa coletora, que possibilitava a penetração de luz no interior da armadilha (Figura 3b). No interior da caixa de polietileno colocou-se - líquido fixador e conservador. Dentro de cada eclector de solo usou-se uma armadilha de fosso ("pitfall") com altura de $19,5 \mathrm{~cm}$ e diâmetro superior de $4,5 \mathrm{~cm}$ (Figura 3c), com uma solução de ácido pícrico e água (1:3). O material coletado nas armadilhas de fosso, e que geralmente representa menos que $1 \%$ da captura total (ADIS, 1981), não foi avaliado neste estudo. 
Foram utilizados 4 fotoeclectores de solo e foram feitas duas coletas mensais, ao longo do período não inundado. A primeira foi realizada entre os dias 14 e 16 de cada mês e a segunda entre os dias 29 e 02 do mês seguinte. o período de coleta dos fotoeclectores do solo foi de agosto/1987 a maio/1988 (período não inundado). 0 material coletado foi conservado em álcool $90 \%$

\subsubsection{Fotoeclector de árvore}

- fotoeclector de árvore utilizado foi semelhante ao descrito por FUNKE(1971), que consiste numa armadilha em forma de funil, feita de pano preto, cuja abertura inferior apresenta a forma de arco, através do qual foi fortemente presa ao redor do tronco. Na parte superior usou-se o recipiente coletor, transparente e de polietileno. Foram conectados 4 "funis" um ao outro (Figura $4 \mathrm{a}$ e 4b) e em seguida presos ao redor do tronco pelo arco inferior através de um arame, existente no interior do mesmo, e grampeado ao redor do tronco. o outro lado ficou projetado para a frente do tronco, dando o aspecto de um abajur. Na parte superior de cada funil, instalou-se o recipiente coletor com ácido pícrico semelhante ao usado nos fotoeclectores de solo.

\section{A - Fotoeclector de árvore direcionado para cima (BE†)}

A finalidade deste tipo de eclector de árvore é capturar os artrópodos migrantes do solo para a copa, que utilizam o tronco das árvores. Os dados de captura representam a densidade de atividade, especialmente a migração para cima de animais voadores e não voadores da região do tronco e fornece informações sobre a fenologia e ciclo de vida (FUNKE, 1971; ADIS, 1981). 
Foi utilizado 1 fotoeclector de árvore, com 4 funis de captura. A armadilha foi instalada em Virola surinamensis (Rol.) Wars. (Myristicaceae), conhecida regionalmente como ucuúba a uma altura de aproximadamente 3 metros, acima do nível máximo da enchente. Foram feitas 2 coletas mensais, durante o periodo de julho/1987 a junho/1988. O material coletado foi conservado em álcool $90 \%$

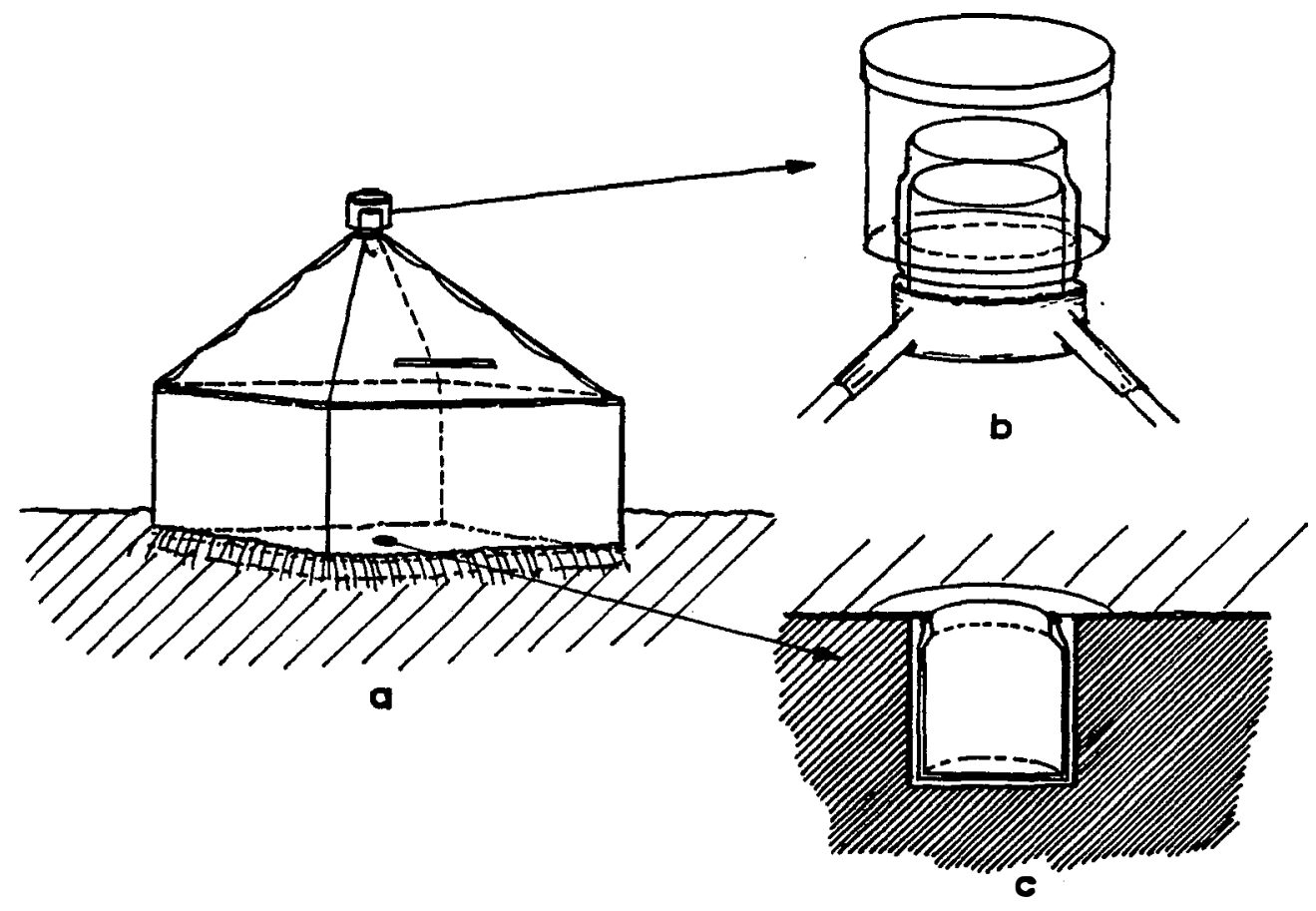

Figura 3a, b e c. Fotoeclector de solo e armadilha de fosso ("pitfall trap"). 3a) vista lateral; 3b) caixa coletora com tubos; 3c) armadilha de fosso. Segundo FUNKE (1971). 
B - Fotoeclector de árvore direcionado para baixo (BE $\downarrow$ )

Este tipo de eclector de árvore monitora a migração copa-solo de artrópodos não voadores e voadores. É o mesmo tipo de armadilha descrita anteriormente (BE $\uparrow$ ), porém instalada no sentido contrário segundo ADIS (1981) ou seja, a parte com o recipiente coletor foi direcionada para baixo, e a parte com a abertura em forma de arco foi direcionada para cima e presa com arame ao redor do tronco. Os 4 "funis" foram conectados um ao outro. A armadilha foi instalada em Hevea spruceana Muell (Euphorbiaceae), conhecida regionalmente como seringueira. A montagem da armadilha foi feita durante o período do nível mais alto do rio. o período de coleta dos artrópodos foi de julho/1987 a julho/1988. o material coletado foi conservado em álcool $90 \%$

\subsection{Material de estudo}

O material estudado foi classificado em grupos superiores (ordens e famílias) ou a nível de espécies. Os resultados e discussões dos grupos identificados a nível de família e espécies serão tratados em capítulos separados. A identificação a nível de espécie foi feita através, e/ou em colaboração com os seguintes taxonomistas:

Pseudoscorpiones - Dr. V. MAHNERT, Genebra, Suíça Symphyla - Dr. U. SCHELLER, Järpas, Suécia

Diplopoda - Dr. S. I. GOLOVATCH, Moscou, Rússia Meinertellidae - Dr. H. STURM, Hildesheim, Alemanha Os Pseudoscorpiones foram classificados em imaturos e adultos (machos e fêmeas). Dentre os imaturos foram determinados as protoninfas (P), deutoninfas (D) e tritoninfas $(T)$. 
Os Symphyla foram classificados como imaturos (8, 9 e 10 pares de pernas). Os estágios de subadultos (11 pares de pernas, sendo um par reduzido) e adultos (12 pares de pernas, sendo um par reduzido) foram determinados de acordo com CHARDARD (1947) e SCHELLER (1979).

Não é possível a identificação de diplópodos imaturos por espécie e, portanto, eles foram classificados como imaturos de $7,9,12,15,17,18$ segmentos e subadultos, na maioria com 19 segmentos. Os adultos, com 19 ou 20 segmentos, foram identificados de acordo com o gonópodo do macho. A identificação foi feita pelo próprio taxônomo, Dr. S.I. Golovatch).

Os Meinertellidae (Archaeognatha) foram classificados como imaturos, subadultos e adultos de acordo com o comprimento do corpo e da cápsula cefálica, segundo STURM \& ADIS (1984).

As famílias de coleópteros foram separadas em niveis tróficos, conforme os trabalhos de ERWIN \& SCOTT (1980), TRIHAS \& LEGAKIS (1991) e a identificação foi feita por comparação com a coleção de referência do Instituto MaxPlanck (Plön, Alemanha) e/ou através de chaves de identificação segundo BORROR et alii (1976).

Em relaçao a Coccoidea foram avaliadas as ninfas juntamente com as fêmeas adultas e separadas dos machos adultos alados.

A captura de ácaros e colêmbolas não foi avaliada.

\subsection{Termos ecológicos traduzidos}

Foi observado que alguns termos ecológicos na literatura alemã ainda não são utilizados em Português e portanto se fez necessário traduzi-los e explicá-los 
conforme SCHAEFER \& TISCHLER (1983).

3.4.1 Abundância de emergência ou densidade de emergência (Schlüpfabundanz ou Schlüpfdichte) - Diz respeito à quantidade de adultos alados por unidade de superficie ou volume.

3.4.2 Densidade de atividade (Aktivitätsdichte) - Refere-se ao número de indivíduos ou espécies que num determinado tempo e numa determinada área, se deslocam sobre uma superfície. 3.4.3 Freqüência de ocorrência (Häufigkeit) - É a quantidade de individuos de uma determinada espécie encontrados no mesmo tipo de biótopo de uma região. 3.4.4 Aparecimento (Apparenz) - É o surgimento temporal de um determinado estágio de desenvolvimento de uma espécie num determinado habitat e/ou biótopo.
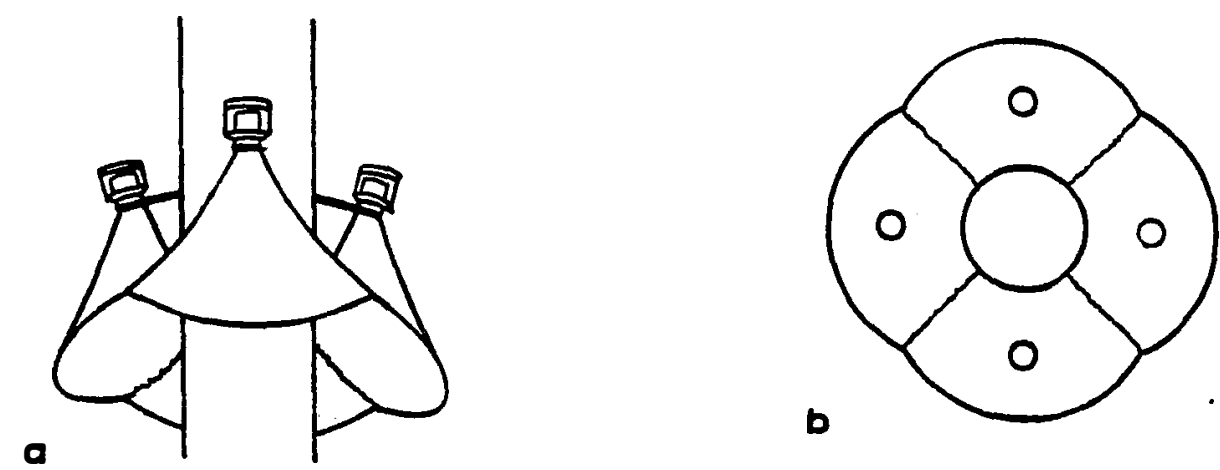

Figura 4a e b - Fotoeclector de árvore com quatro funis agrupados ao redor do tronco. 4a) vista lateral; 4b) vista de baixo (seção transversal do caule (centro) com pequenos círculos indicando respectivamente as caixas coletoras. Segundo FUNKE (1971). 


\section{RESULTADOS}

\subsection{PSEUDOSCORPIONES}

Foram coletados 650 Pseudoscorpiones na floresta inundada por água mista representando 4 espécies: Tyrannochthonius amazonicus Mahnert, 1979 (Chthoniidae); Pseudochthonius homodentatus Chamberlin, 1929 (Chthoniidae); Geogaripus amazonicus Mahnert, 1979 (Garypidae) e Pachyolpium irmgardae Mahnert, 1979 (Olpiidae). Do total de Pseudoscorpiones capturados, $35,6 \%$ foram coletados no solo, através do extrator Kempson, 27,4\% em fotoeclectores de solo, 14,9\% em fotoeclector de árvore direcionado para cima (BE $\uparrow$ ) e 22,1 \% em fotoeclector de árvore direcionado

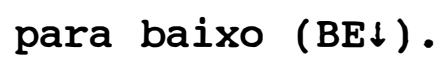

\subsubsection{Captura no solo com o método de Kempson}

Foram extraídos 231 Pseudoscorpiones ( $\approx 111$ indivíduos $/ \mathrm{m}^{2} / \mathrm{mês}$ ) através do método de Kempson. Dentre as espécies acima mencionadas, T. amazonicus, $P$. homodentatus $e$ $P$. irmgardae foram capturadas no solo. A maior abundância, ao longo do ano, ocorreu em fevereiro/1988, com 24,2\% do total de Pseudoscorpiones capturados ( $\approx 270$ indivíduos $/ \mathrm{m}^{2}$ ).

Com relação às estações anuais, os Pseudoscorpiones apresentaram um número médio mensal de 153 indivíduos $/ \mathrm{m}^{2}$ durante a estação chuvosa e de 48 indivíduos $/ \mathrm{m}^{2}$ na estação menos chuvosa (Apêndice 4 ).

Com relação à distribuição vertical no solo, os Pseudoscorpiones foram mais abundantes na primeira camada com $53,7 \%$ do total capturado ( $\approx 597$ indivíduos $\left./ \mathrm{m}^{2}\right), 27,7 \%$ $\left(\approx 308\right.$ individuos $\left./ \mathrm{m}^{2}\right)$ na segunda camada, $9,5 \%$ ( $\approx 106$ individuos $\left./ \mathrm{m}^{2}\right)$ na terceira camada e $9,1 \%(\approx 101$ 
individuos $/ \mathrm{m}^{2}$ ) foram capturados na quarta camada do solo (Apêndice 4).

T. amazonicus (Figura 5) foi a espécie mais abundante no solo com $95,2 \%$ do total capturado ( $\approx 106$ indivíduos $/ \mathrm{m}^{2} / \mathrm{mês}$ ) e foi a única espécie presente no subsolo mineral (Apêndice 4). A abundância média mensal na estação chuvosa foi de 146 indivíduos $/ \mathrm{m}^{2} / \mathrm{mês}$, enquanto que, na estação menos chuvosa capturou-se uma média mensal de 46 indivíduos $/ \mathrm{m}^{2} / \mathrm{mês}$. Do total capturado, $51,4 \%$ ( $\approx 544$ indivíduos $/ \mathrm{m}^{2}$ ) foi coletado na primeira camada do solo, $29,1 \%\left(\approx 308\right.$ individuos $\left./ \mathrm{m}^{2}\right)$ na segunda camada, $10,0 \%$ ( $\approx 106$ individuos $\left./ \mathrm{m}^{2}\right)$ na terceira camada e $9,5 \%$ ( $\approx 101$ indivíduos $/ \mathrm{m}^{2}$ ) foi capturado na quarta camada do solo (Figura 6). Imaturos foram capturados durante todo ano, e a maior atividade ocorreu durante o período chuvoso em fevereiro/1988 $\left(\approx 197\right.$ individuos $/ \mathrm{m}^{2}$ ) (Figura 5$)$. Protoninfas, foram mais abundantes na segunda camada do solo com $\approx 96$ individuos $/ \mathrm{m}^{2}$ )(Figura 6 ). Adultos foram mais abundantes durante o período chuvoso em janeiro/1988, com $\approx 72$ indivíduos $/ \mathrm{m}^{2}$ e em fevereiro/1988 com $\approx 67$ indivíduos $/ \mathrm{m}^{2}$ (Figura 7). Aproximadamente $20,9 \%$ da população capturada no solo foi representada por protoninfas, 23,2 por deutoninfas, $30,0 \%$ por tritoninfas, $13,6 \%$ por machos adultos e 12,3\% por fêmeas adultas (Apêndice 5).

Não foram obtidos resultados significativos nas correlações entre a distribuição de $T$. amazonicus ao longo do ano com os fatores abióticos locais (temperatura do ar, umidade relativa do ar e precipitação pluviométrica). Entretanto, foram obtidas correlações significativas entre a distribuição vertical no solo e a temperatura, pH e umidade do solo (Apêndice 3 ).

P. irmgardae também foi capturada somente na primeira camada do solo representando $4,8 \%$ do total coletado 
( $\approx 3$ indivíduos $/ \mathrm{m}^{2} / \mathrm{mês}$ ). Aproximadamente $50,0 \%$ foram imaturos e $50,0 \%$ foram adultos.

P. homodentatus (Figura 9) foi capturada apenas na primeira camada e representou 4,0\% do total de Pseudoscorpiones do solo ( $\approx 2$ individuos $\left./ \mathrm{m}^{2} / \mathrm{mês}\right)$. Aproximadamente $20 \%$ foram imaturos e $80 \%$ foram adultos.

\subsubsection{Captura no folhedo com fotoeclectores de solo}

Durante o período não inundado foram coletados no folhedo um total de 178 Pseudoscorpiones $(\approx 4$ indivíduos $\left./ \mathrm{m}^{2} / \mathrm{mês}\right)$. A espécie mais freqüente foi $T$. amazonicus (Figura 5 ) com $80,3 \%$ ( $\approx 4$ individuos $/ \mathrm{m}^{2} / \mathrm{mês}$ ), seguida de $P$. homodentatus (Figura 9$)$ com $12,4 \%(\approx 0,5$ indivíduos $\left./ \mathrm{m}^{2} / \mathrm{mês}\right)$ e $P$. irmgardae $\operatorname{com} 7,3 \%(\approx 0,3$ indivíduos $/ \mathrm{m}^{2} / \mathrm{mês}$ ) do total dos Pseudoscorpiones capturados. Toda a atividade dos Pseudoscorpiones no folhedo ocorreu durante o período chuvoso e nenhum indivíduo foi capturado durante o período menos chuvoso. o período de maior captura ocorreu em janeiro/1988 com $38,2 \%$ ( $\approx 17$ indivíduos $/ \mathrm{m}^{2}$ ) e em março/1988 com $39,7 \%$ ( $\approx 18$ indivíduos $/ \mathrm{m}^{2}$ ) (Apêndice 6).

T. amazonicus foi capturada somente durante o período de janeiro a março/1988 (Figura 8). A maior abundância ocorreu em março/1988 com $47,6 \%$ do total capturado $\left(\approx 17\right.$ individuos $/ \mathrm{m}^{2}$ ). Aproximadamente $0,7 \%$ de $T$. amazonicus capturado no folhedo da floresta inundada por água mista foi representada por deutoninfas, 95,8 \% por tritoninfas, $0,7 \%$ por machos adultos e $2,8 \%$ por fêmeas adultas (Figura 8). Protoninfas não foram capturadas no folhedo (Apêndice 7).

P. homodentatus também foi capturada somente 
durante a época chuvosa de janeiro a março/1988 (Figuras 9 e 10). A abundância foi baixa, sendo maior em janeiro com $59,1 \%$ do total capturado ( $\approx 3$ individuos $/ \mathrm{m}^{2}$ ). Aproximadamente $22,7 \%$ da população de $P$. homodentatus capturada no folhedo foi representada por deutoninfas, $9 \%$ por tritoninfas, $63,6 \%$ por machos adultos e $4,5 \%$ por fêmeas adultas. Protoninfas não foram capturadas com fotoeclectores de solo (Figura 10, Apêndice 8).

P. irmgardae foi capturada durante a estação chuvosa, porém o número de individuos foi baixo $(\mathrm{n}=13)$. Do total capturado, $46,2 \%$ foi representado por imaturos e $53,8 \%$ por adultos.

4.1.3 Capturas nos troncos com fotoeclectores de árvores

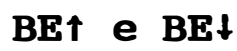

Durante a migração vertical solo-copa, coletaram-se 97 Pseudoscorpiones no tronco, através de fotoeclectores direcionado para cima BE $\uparrow$. A espécie capturada em maior número foi $P$. homodentatus com $57,7 \%$, seguida de T. amazonicus com $34,0 \%, P$. irmgardae com $6,2 \%$ e $G$. amazonicus com 2,1\% do total coletado (Apêndice 9). Do total de Pseudoscorpiones capturado no tronco, coletaram-se em média $\approx 14$ indivíduos/mês durante a estação chuvosa, enquanto que, na estação menos chuvosa coletaram-se em média 2 individuos/mês. o período de maior captura ocorreu em fevereiro/1988 ( $n=25)$.

P. homodentatus foi capturada somente durante a estação chuvosa e no início do período menos chuvoso. 0 período de maior captura ocorreu em maio/1988, antes da inundação da floresta $(n=21)$. Aproximadamente $32,2 \%$ da população de $P$. homodentatus durante a migração solo-copa foi representada por deutoninfas, 19,6\% por tritoninfas, 19,6\% 
por machos adultos e 28,6 por fêmeas adultas. Protoninfas não foram capturadas com fotoeclectores BE $\uparrow$ (Figura 11a, Apêndice 10) .

T. amazonicus também foi capturada somente durante a estação chuvosa no período de janeiro a maio/1988 (período não inundado). A maior captura ocorreu em fevereiro/1988. Aproximadamente $93,0 \%$ da população de $T$. amazonicus coletada através de fotoeclectores BE $\uparrow$ foi representada por tritoninfas. Não foram capturadas deutoninfas, machos e fêmeas adultos (Figura 12a, Apêndice 11).

Durante a migração vertical copa-solo coletaram-se 144 Pseudoscorpiones através de fotoeclectores de árvore $\mathrm{BE} \downarrow$. A espécie capturada em maior número foi $P$. homodentatus com $83,3 \%$, seguida por T. amazonicus com $15,3 \%$ e G. amazonicus com $1,4 \%$ do total capturado. Durante a estação chuvosa capturaram-se em média 18 indivíduos/mês, enquanto que, na estação menos chuvosa coletaram-se em média 6 individuos/mês. O maior número de indivíduos foi coletado em março/1988, no período não inundado $(n=36)$ (Apêndice 12 ) •

P. homodentatus foi coletada durante toda a estação chuvosa (período não inundado) e início da estação menos chuvosa (período inundado). o período de maior captura ocorreu em março/1988 $(n=35)$. Aproximadamente $6,7 \%$ da população de $P$. homodentatus capturada na área de estudo foi representada por deutoninfas, $10,0 \%$ por tritoninfas, $28,3 \%$ por machos adultos e 55,0 \% por fêmeas adultas. Protoninfas não foram coletadas em fotoeclector BE $\downarrow$ (Figura 11b, Apêndice 10).

T. amazonicus foi capturada em número baixo, durante a estação menos chuvosa (período não inundado) apresentando uma média de 3 indivíduos/mês. Aproximadamente 
$50,0 \%$ da população de $T$. amazonicus $(n=22)$ capturada durante a migração copa-solo foi representada por imaturos (a maioria tritoninfas), $31,8 \%$ por machos adultos e 18,2 por fêmeas adultas. Protoninfas não foram coletadas em fotoeclector BE $\downarrow$ (Figura 12b, Apêndice 11). 
Ind.

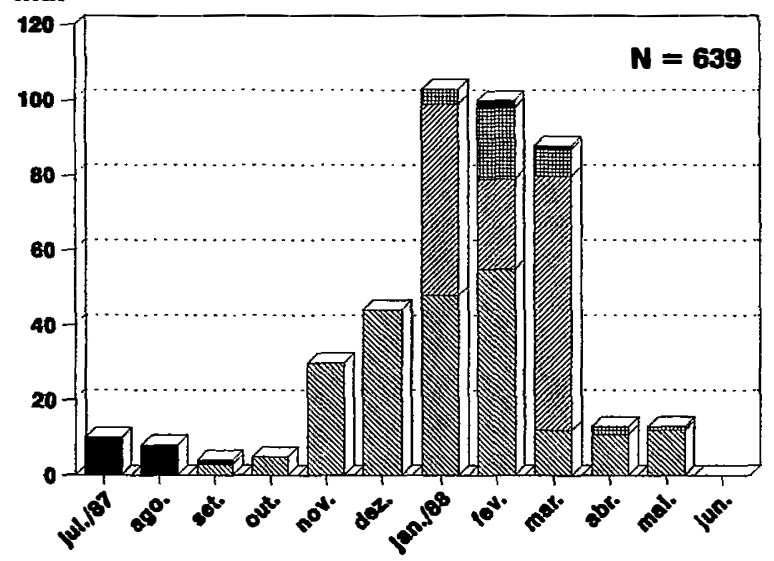

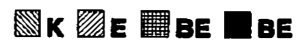

Figura 5 - Captura mensal de Tyrannochthonius amazonicus Mahnert, 1979 (Chthoniidae, Pseudoscorpiones), nos diferentes tipos de armadilhas, na floresta inundada por água mista, no período de julho/1987 a junho/1988. $\mathrm{K}=$ método de Kempson. $\mathrm{BE} \uparrow=$ fotoeclector de árvore direcionado para cima. BE $\downarrow$ = fotoeclector de árvore direcionadao para baixo.

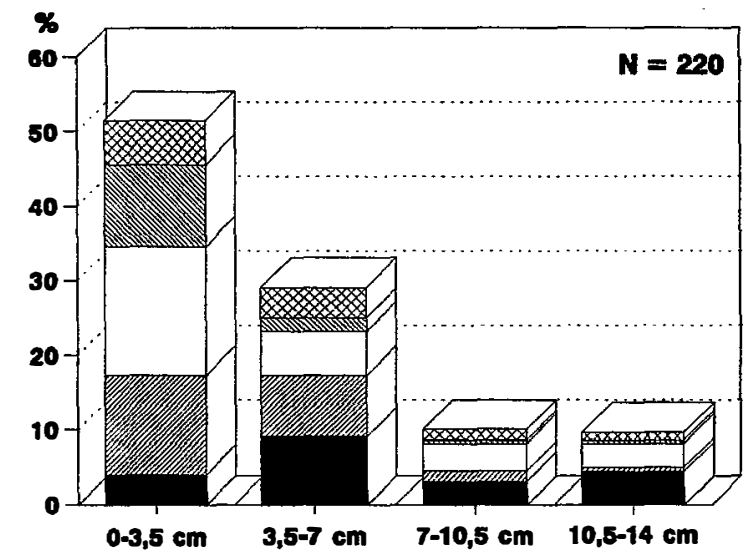

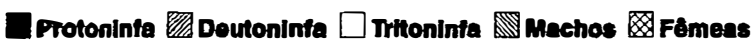

Figura 6 - Abundância vertical de Tyrannochthonius amazonicus Mahnert, 1979 (Chthoniidae, Pseudoscorpiones), nas diferentes camadas do solo, na floresta inundada por água mista, no período de agosto/1987 a maio/1988. Coleta com o método de Kempson. 


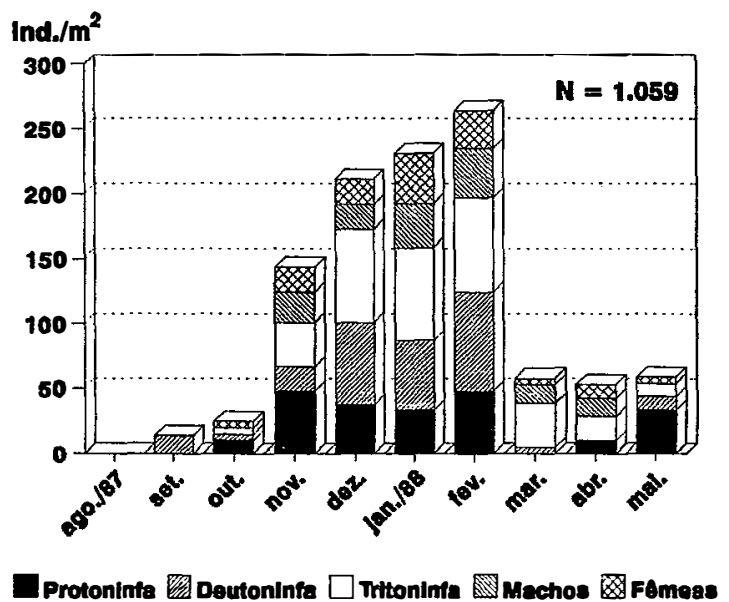

Figura 7 - Captura mensal no solo dos estágios de desenvolvimento de Tyrannochthonius amazonicus Mahnert, 1979 (Chthoniidae, Pseudoscorpiones), na floresta inundada por água mista, no período de agosto/1987 a maio/1988. Coleta com o método de Kempson.

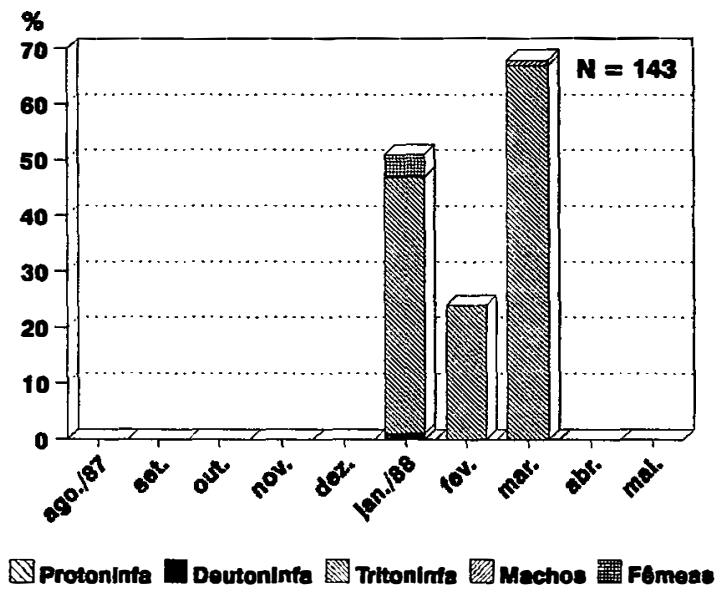

Figura 8 - Captura mensal no folhedo dos estágios de desenvolvimento de Tyrannochthonius amazonicus Mahnert, 1979 (Chthoniidae, Pseudoscorpiones), na floresta inundada por água mista, no período de agosto/1987 a maio/1988. Coleta com fotoeclectores de solo. 


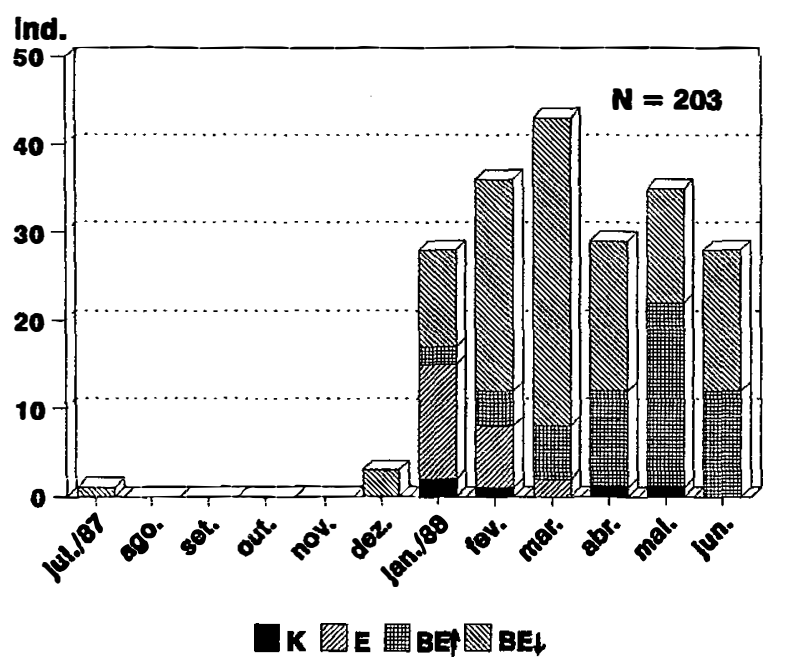

Figura 9 - Captura mensal de Pseudochthonius homodentatus Chamberlin, 1929 (Chthoniidae, Pseudoscorpiones), nos diferentes tipos de armadilhas, na floresta inundada por água mista, no período de julho/1987 a junho/1988. $\mathrm{K}=$ método de Kempson. $\mathrm{E}=$ fotoeclectores de solo. BE $\uparrow=$ fotoeclector de árvore direcionado para cima. $\mathrm{BE} \downarrow=$ fotoeclector de árvore direcionado para baixo.

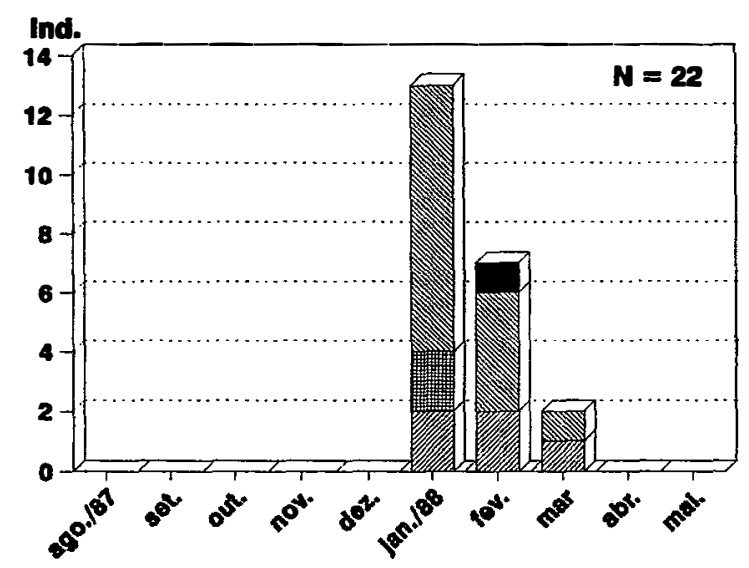

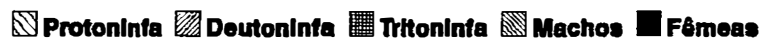

Figura 10 - Captura mensal no folhedo dos estágios de desenvolvimento de Pseudochthonius homodentatus Chamberlin, 1929 (Chthoniidae, Pseudoscorpiones), na floresta inundada por água mista, no período de agosto/1987 a maio/1988. Coleta com fotoeclectores de solo. 


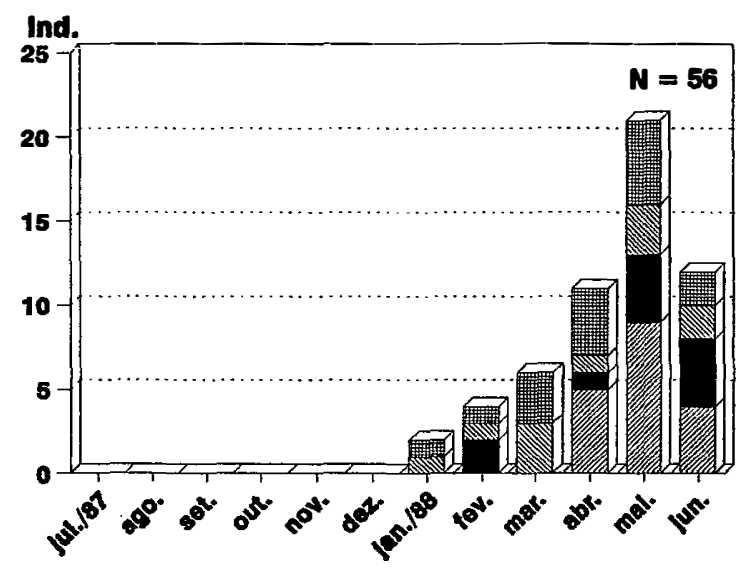

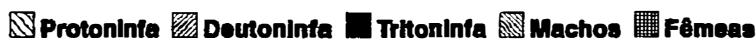

A

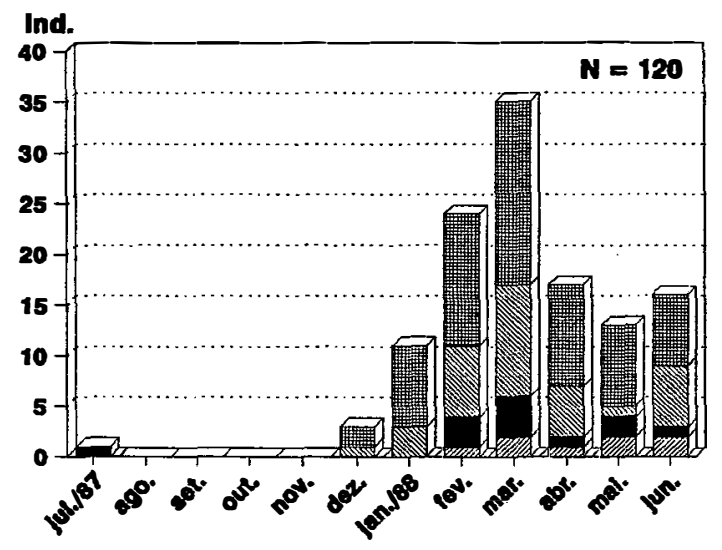

$\square$ Protonimfa

B

Figura 11A, B - Captura mensal dos estágios de desenvolvimento de Pseudochthonius homodentatus Chamberlin, 1929 (Chthoniidae Pseudoscorpiones) na floresta inundada por água mista, no período de julho/1987 a junho/1988. $A=$ Coleta com fotoeclector de

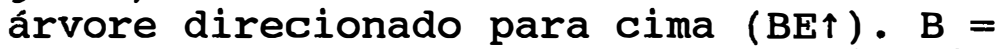
Coleta com fotoeclector de árvore direcionado

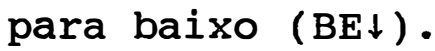




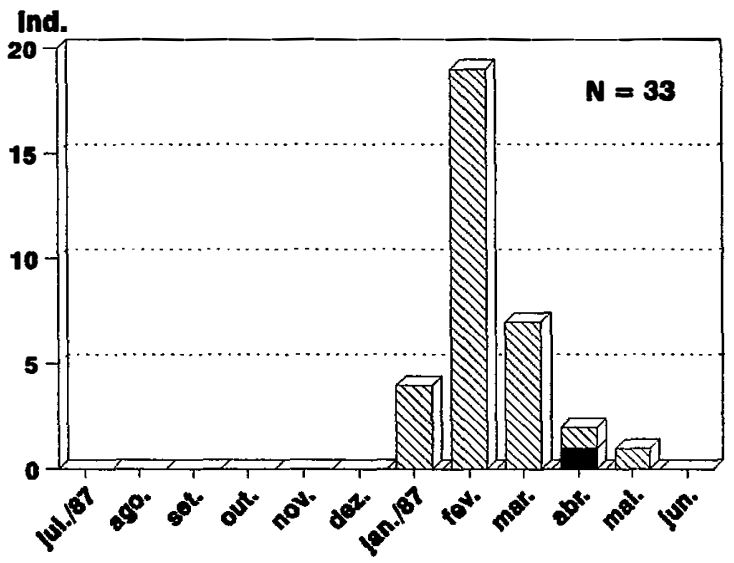

Protoninfa

A

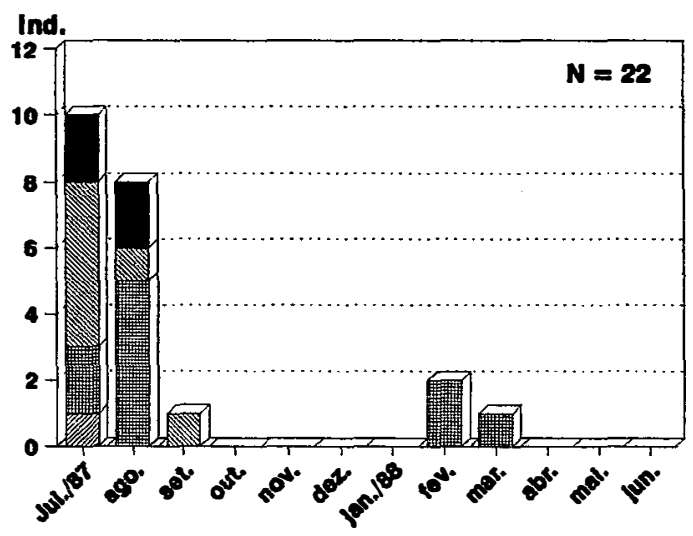

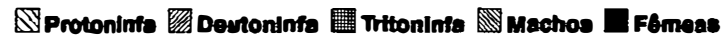

B

Figura 12A, B - Captura mensal dos estágios de desenvolvimento de Tyrannochthonius amazonicus Mahnert, 1979 (Chthoniidae, Pseudoscorpiones), na floresta inundada por água mista, no período de julho/1987 a junho/1988. $A=$ Coleta com fotoeclector de

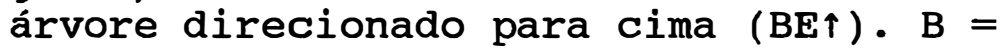
Coleta com fotoeclector de árvore direcionado

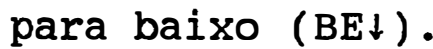




\section{2 CHILOPODA}

Foi capturado um total de 263 Chilopoda na floresta inundada por água mista, dos quais $54,8 \%(n=144)$ foi coletado no solo, $5,3 \%(\mathrm{n}=14)$ no folhedo, $7,2 \%(\mathrm{n}=$ 19) no tronco, durante a migração para cima, com fotoeclector $\mathrm{BE} \uparrow$ e $32,7 \%(\mathrm{n}=86)$, durante a migração para baixo com fotoeclector arboreo (BE $\downarrow$ ). Do total capturado, $38,8 \%$ foi representado por Geophilomorpha, 33,8 \% por Lithobiomorpha e $27,4 \%$ por Scolopendromorpha. Apenas os Geophilomorpha foram identificados a nível de espécie.

\subsubsection{Geophilomorpha}

Foram capturados 102 indivíduos na área experimental, sendo que $45,0 \%$ foi coletado no solo, $2,0 \%$ no folhedo, $5,9 \%$ no tronco com fotoeclector de árvore

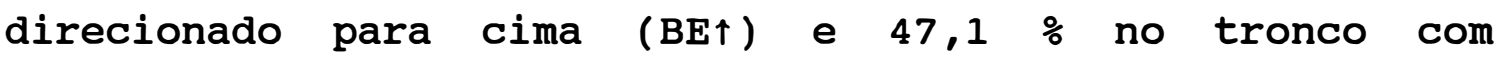
fotoeclector de árvore direcionado para baixo (BE $\downarrow$ ). Dentre os Geophilomorpha capturados identificaram-se 5 espécies, sendo que, duas espécies novas e um gênero novo: Pectiniunguis ascendens Pereira, Minelli \& Barbieri, 1994; Ribautia centralis (Silvestri, 1907); Geophilidae n.sp.; Schendylidae n.g., Schendylurus n. sp. (Figura 13). Devido ao baixo número capturado, as novas espécies da família Schendylidae foram mencionadas juntas como schendylidae n.spp. (Apêndice 13).

4.2.1.1 Captura no solo com o método de Kempson

Dentre as espécies de Geophilomorpha capturadas no solo, 39,1\% foi representado por $P$. ascendens, $32,6 \%$ por Schendylidae $n$. spp., $17,4 \%$ por $R$. centralis e 
$10,9 \%$ por Geophilidae n. sp.. A maior frequência de ocorrência ocorreu nos primeiros $7 \mathrm{~cm}$ de profundidade do solo (Figura 13). O período de maior abundância ocorreu seis semanas após a inundação, durante o período menos chuvoso (setembro/1987), com $30,5 \%$ do total capturado $(\approx 67,4$ individuos $/ \mathrm{m}^{2}$ ) (Figura 14). Com relação às estações anuais, coletaram-se uma média mensal de $\approx 23$ indivíduos $/ \mathrm{m}^{2} / \mathrm{mês}$ durante a estação menos chuvosa e uma média mensal de $\approx 21$ individuos $/ \mathrm{m}^{2} / \mathrm{mês}$ durante a estação chuvosa. Os dados de captura das espécies, nas diferentes camadas do solo, foram registrados (Apêndice 13 ).

Do total de Geophilomorpha capturado, 43,5 $\%\left(\approx 10\right.$ indivíduos $\left./ \mathrm{m}^{2} / \mathrm{mês}\right)$ foi representado por imaturos, 8,7 $\% \quad\left(\approx 2\right.$ indivíduos $/ \mathrm{m}^{2} / \mathrm{mês}$ por subadultos, $8,7 \% \quad(\approx 2$ individuos $\left./ \mathrm{m}^{2} / \mathrm{mês}\right)$ por machos adultos, $23,9 \%(\approx 5$ individuos $/ \mathrm{m}^{2} / \mathrm{mês}$ ) por fêmeas adultas. Para os restantes $15,2 \%$ não foi determinado o estágio de desenvolvimento. A distribuição de Geophilomorpha, no solo, por estágios de desenvolvimento foi representada (Figura 14 Apêndice 14).

$P$. ascendens foi a espécie mais abundante no solo e apresentou uma média mensal de $\approx 9$ indivíduos $/ \mathrm{m}^{2} / \mathrm{mês}$. A maior abundância ocorreu durante a estação menos chuvosa com uma média mensal de $\approx 14$ indivíduos $/ \mathrm{m}^{2} / \mathrm{mês}$, enquanto que, a estação chuvosa apresentou uma média mensal de $\approx 5$ individuos $/ \mathrm{m}^{2} /$ mês. Ao longo do ano, a maior abundância ocorreu seis semanas após a inundação (setembro/1987), com 53 indivíduos $/ \mathrm{m}^{2}$ (Figura 15). Na área experimental, P. ascendens foi capturada apenas na camada de $0-7 \mathrm{~cm}$ de profundidade no solo (Figura 13). Aproximadamente $66,7 \%$ do total capturado foi representado por imaturos, $5,6 \%$ por subadultos, $5,5 \%$ por machos adultos, 11,1\% por fêmeas adultas, e 11,1 $\%$ não foi identificado (Apêndice 14). 
Schendylidae n.spp. apresentou uma média mensal de $\approx 7$ indivíduos $/ \mathrm{m}^{2} /$ mês. O período de maior abundância ocorreu em dezembro/1987 com $\approx 34$ indivíduos $/ \mathrm{m}^{2}$. A maior abundância foi durante a estação chuvosa, com uma média mensal de $\approx 10$ indivíduos $/ \mathrm{m}^{2} / \mathrm{mês}$, enquanto que a estação menos chuvosa apresentou uma média mensal de $\approx 4$ indivíduos $/ \mathrm{m}^{2} / \mathrm{mês}$. Aproximadamente $33,3 \%$ dos indivíduos capturados foram representados por imaturos, $6,7 \%$ por subadultos, $26,6 \%$ por machos adultos, $20,0 \%$ fêmeas adultas e $13,4 \%$ não foi identificado (Apêndice 14).

Ribautia centralis foi pouco abundante no solo. Foi capturada uma média mensal de $\approx 4$ indivíduos $/ \mathrm{m}^{2} / \mathrm{mês}$. Aproximadamente $37,5 \%$ dos indivíduos capturados foram representados por imaturos, 50,0\% por fêmeas adultas e $12,5 \%$ não foi indentificado (Apêndice 14).

Geophilidae n. sp. foi pouco capturado no solo, em média apenas $\approx 2$ indivíduos $/ \mathrm{m}^{2} / \mathrm{mês}$. Aproximadamente $20,0 \%$ dos indivíduos extraídos do solo foram representados por subadultos e $40,0 \%$ por adultos.

4.2.1.2 Captura no folhedo com fotoeclectores de solo

Dentre os Geophilomorpha capturados, apenas dois indivíduos adultos ( 1 macho e 1 fêmea) de $P$. scandens foram capturados no folhedo através de fotoeclectores de solo e durante o período chuvoso.

\subsubsection{Captura nos troncos com fotoeclectores de árvores BEt e BE $\downarrow$}

Durante a migração do solo para a copa, capturaram-se apenas 4 indivíduos adultos de $P$. ascendens e 2 individuos adultos de $R$. centralis. 
Durante a migração da copa para o solo, coletaram-se um total de 48 individuos sendo que, 75,0\% foram representados por $R$. centralis, 20,8\% por Geophilidae n.sp., 2,1\% por Schendylidae n.spp. e 2,1\% por $P$. ascendens (Apêndice 15).

A freqüência de ocorrência $R$. centralis foi maior no início do período não inundado (agosto/1987) com $83,8 \%$ do total capturado. Aproximadamente $2,8 \%$ foi representado por subadultos, $38,9 \%$ por machos adultos, $55,5 \%$ por fêmeas adultas e $2,8 \%$ não foi identificado (Apêndice 15).

A freqüência de ocorrência de Geophilidae n.sp. foi maior no início do periodo não inundado (julho e agosto/1987, com respectivamente $30,0 \%$ e $30,0 \%$ do total capturado). Aproximadamente $30,0 \%$ foi representado por machos adultos, $30,0 \%$ por fêmeas adultas e 40,0\% não foi identificado.

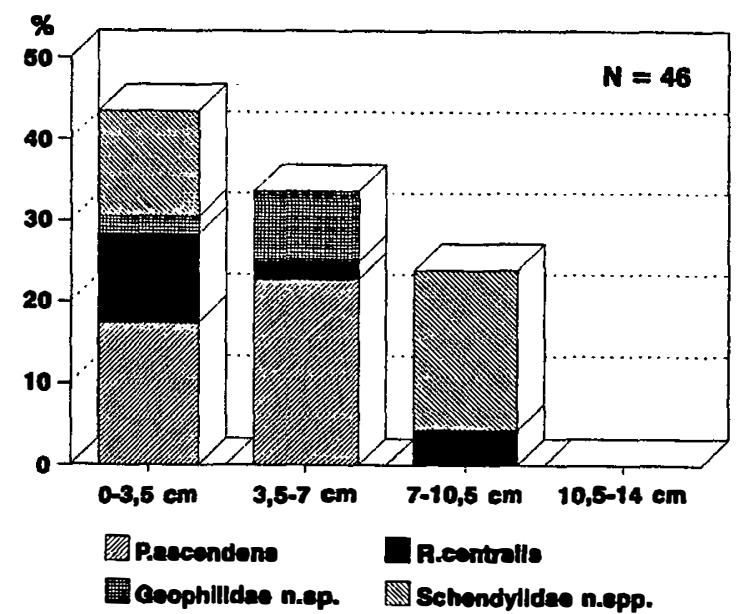

Figura 13 - Distribuição de Geophilomorpha (Chilopoda) nas diferentes camadas do solo, na floresta inundada por água mista, no período de agosto/1987 a maio/1988. Captura com o método de Kempson. 


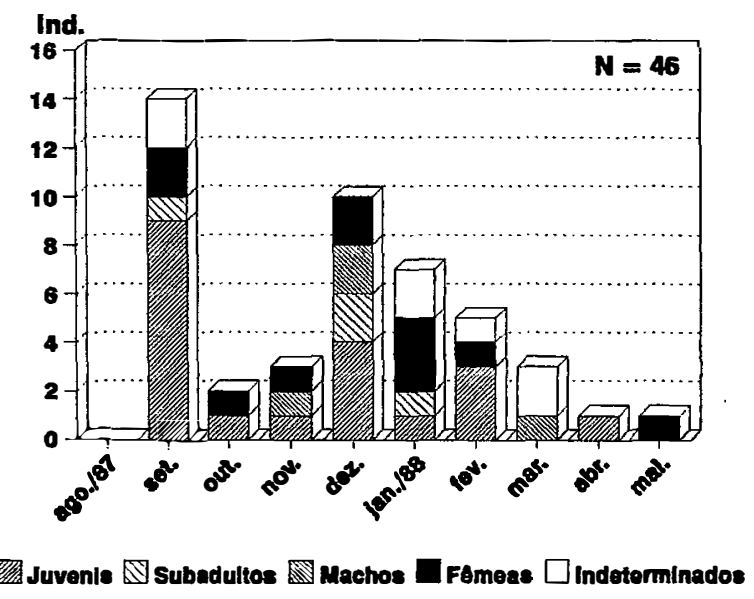

Figura 14 - Captura mensal no solo dos estágios de desenvolvimento de Geophilomorpha (Chilopoda), na floresta inundada por água mista, no periodo de agosto/1987 a maio/1988. Coleta com o método de Kempson.

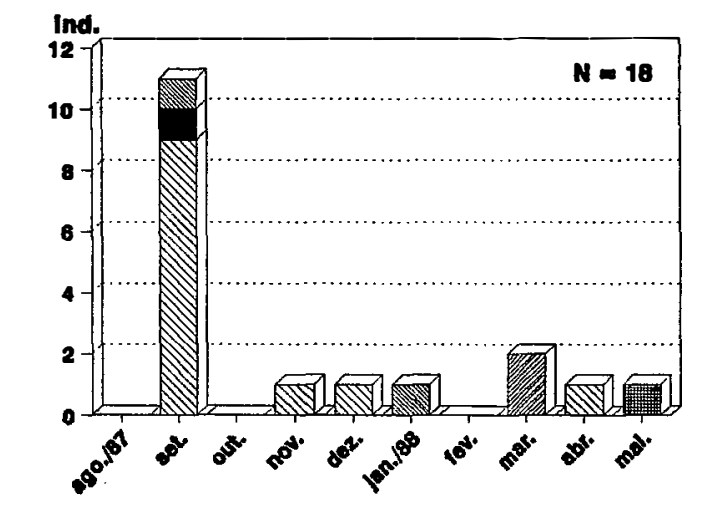

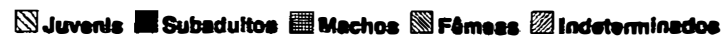

Figura 15 - Captura mensal no solo dos estágios de desenvolvimento de Pectiniunguis ascendens Pereira, Minelli \& Barberi, 1993 (Geophilomorpha, Chilopoda), na floresta inundada por água mista, no período de agosto/1987 a maio/1988. Coleta com o método de Kempson. 


\subsection{DIPLOPODA}

Foram coletados 3.607 diplópodos durante 0 período de estudo. o maior número foi encontrado no solo com $60,7 \%$ do total coletado $(n=2.188)$. No tronco, foram coletados $20,5 \%$ durante a migração para baixo com fotoeclector arbóreo $(B E \downarrow)$, enquanto que $13,9 \%$ foram coletados durante a migração para cima (fotoeclector arbóreo $B E \uparrow)$. No folhedo, apenas $4,9 \%(n=175)$ foram coletados através de fotoeclectores de solo. Do total de diplópodos capturados foram identificados 5 espécies na floresta inundada por água mista, das quais três são espécies novas: Phaneromerium distinctum n.sp. Golovatch, 1994; Fuhrmannodesmus rhinocerus n.sp. Golovatch, 1994; Moojenodesmus pumilus Schubart, 1943; Moojenodesmus wellingtoni n. sp. Golovatch, 1994 (Fuhrmannodesmidae) e Muyudesmus obliteratus Kraus, 1960 (Pyrgodesmidae).

\subsubsection{Captura no solo com o método de Kempson}

Foram coletados um total de 2.188 individuos ( 1053 indivíduos $/ \mathrm{m}^{2} / \mathrm{mês}$ ) no solo, cujos grupos mais abundantes foram distribuídos nas seguintes ordens: Polyxenida, familia Polyxenidae com $77,9 \%$ do total capturado ( $\approx 820$ indivíduos $\left./ \mathrm{m}^{2} / \mathrm{mês}\right)$; Polydesmida, familia Fuhrmannodesmidae com $19,9 \%$ ( $\approx 208$ indivíduos $\left./ \mathrm{m}^{2} / \mathrm{mês}\right)$ e $4,2 \%$ do restante foi representado por outros Polydesmida (Pyrgodesmidae e Paradoxomatidae), Siphonophorida (Siphonophoridae), Stemmiulida (Stemmiulidae) e Spirostreptida (Spirostreptidae). Durante o ano, a maior captura ocorreu na estação chuvosa com uma abundância média mensal de $\approx 1.641$ individuos $/ \mathrm{m}^{2} / \mathrm{mês}$. A maior atividade ocorreu duas semanas antes da inundação com $\approx 2.242$ indivíduos $/ \mathrm{m}^{2} / \mathrm{mês}$ 
(Apêndice 16).

Com relação à distribuição vertical no solo, os diplópodos foram mais abundantes na primeira camada do que no subsolo mineral, representando $65,3 \%$ do total capturado $\left(\approx 6.871\right.$ individuos $\left./ \mathrm{m}^{2}\right)$.

Ao longo do ano, a maior abundância dos Polyxenidae ocorreu durante 0 período chuvoso com uma abundância média mensal de $\approx 844$ indivíduos $/ \mathrm{m}^{2} / \mathrm{mês}$ (Figura 16a). Nenhum indivíduo foi capturado em agosto/1987 (início do período não inundado). No que diz respeito à distribuição vertical, a maior abundância ocorreu na primeira camada do solo $\left(62,7 \%\right.$ do total, $\approx 5.144$ indivíduos $/ \mathrm{m}^{2}$ ) (Figura $16 \mathrm{~b}$ ). Não foi possível fazer a determinação das espécies e dos estágios imaturos e adultos de Polyxenidae; no entanto, observou-se grande quantidade de imaturos nas amostras.

Os Fuhrmannodesmidae foram o segundo grupo mais abundante no solo com 19,9\% do total capturado. Durante - período de estudo a maior densidade populacional ocorreu duas semanas antes da inundação (maio/1988) com $\approx 1.121$ indivíduos $/ \mathrm{m}^{2}$ (Figura 17). Com relação à distribuição vertical, a maior abundância ocorreu na primeira camada do solo com $74,1 \%$ do total coletado ( $\approx 1.545$ individuos $/ \mathrm{m}^{2}$ ) (Figura 18). Dentre os indivíduos capturados no solo foram identificados adultos de Moojenodesmus pumilus e Moojenodesmus wellingtoni $n$. sp..

Para os imaturos não foi possivel fazer a determinação por espécies, sendo feita apenas a determinação por estágios através da contagem do número de segmentos. Os imaturos que se encontravam quebrados, e sendo impossível fazer a contagem dos segmentos, considerou-se a parte anterior do corpo como um individuo, posteriormente classificados como "indeterminados". Dentre os estágios de Fuhrmannodesmidae no solo (M. wellingtoni e M. pumilus), aproximadamente $96,3 \%$ 
foram imaturos e $3,7 \%$ foram adultos. A maior atividade no solo ocorreu duas semanas antes da inundação (Figura 19), e a maior abundância foi apresentada pelos primeiros estágios com 7 e 9 segmentos (Figura 20). Ambos estágios representaram $44,1 \%$ do total capturado (Apêndice 18).

Foram obtidas correlações significativas entre a distribuição vertical no solo e os fatores abióticos locais (temperatura, umidade e $\mathrm{pH}$ do solo) para Polyxenidae e Fuhrmannodesmidae durante o mês de março/1988 (Apêndice 3).

\subsubsection{Captura no folhedo com fotoeclectores de solo}

Foram capturados 175 individuos no folhedo, e a maior abundância ocorreu durante a estação chuvosa com uma abundância média mensal de $\approx 38$ indivíduos $/ \mathrm{m}^{2} / \mathrm{mês}$. Na estação menos chuvosa foram capturados em média $\approx 5$ individuos $/ \mathrm{m}^{2} / \mathrm{mês}$. A maior abundância foi antes da inundação, em maio/1988, com $24,6 \%$ do total capturado ( $\approx 11$ individuos $/ \mathrm{m}^{2}$ ).

Dentre os diplópodos capturados no folhedo, a maior abundância foi de Polyxenida (Polyxenidae) e Polydesmida (Fuhrmannodesmidae). Do total capturado os Polyxenidae representaram $73,1 \% 21,1 \%$ foi representado por Fuhrmannodesmidae e 5,8 $\%$ foi representado por outros Polydesmida (Pyrgodesmidae), stemmiulida (Stemmiulidae) e Spirobolida (Apêndice 19). A distribuição das principais familias de Diplopoda capturadas no folhedo foi representada na Figura 21.

Os Polyxenidae foram mais abundantes durante a estação chuvosa, com uma abundância média mensal de $\approx 28$ indivíduos $/ \mathrm{m}^{2} / \mathrm{mês}$. Na estação menos chuvosa a abundância média mensal foi de $\approx 4$ indivíduos $/ \mathrm{m}^{2} /$ mês. A maior densidade populacional dos Polyxenidae ocorreu em janeiro/1988 com $21,7 \%$ do total capturado ( $\approx 9$ individuos $/ \mathrm{m}^{2}$ ) (Figura 16a). 
A maior atividade dos Fuhrmannodesmidae no folhedo também ocorreu durante o período chuvoso com uma abundância média mensal de $\approx 5$ indivíduos $/ \mathrm{m}^{2} / \mathrm{mês.} \mathrm{A} \mathrm{maior}$ atividade ocorreu duas semanas antes da inundação, com $86,5 \%\left(\approx 8\right.$ individuos $\left./ \mathrm{m}^{2}\right)$ (Figura 17). As espécies capturadas foram Moojenodesmus pumilus e Moojenodesmus wellingtoni, e os estágios imaturos e adultos foram determinados (Figura 22 , Apêndice 20). Do total coletado, a maior abundância foi dos imaturos com 17 e 18 segmentos representando respectivamente $27,1 \%$ e $21,6 \%$. As fêmeas adultas representaram $2,7 \%$ do total coletado. Não foram capturados, imaturos com 7, 9 segmentos e machos adultos em fotoeclectores de solo (Figura 22 ).

Os Pyrgodesmidae foram pouco abundantes no folhedo. Coletaram-se apenas quatro exemplares de Muyudesmus obliteratus, durante o período chuvoso.

\subsubsection{Captura nos troncos com fotoeclector de árvore (BEt e BE $\downarrow$ )}

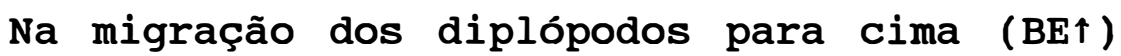
coletaram-se um total de 503 individuos, cuja ordem mais abundante foi Polydesmida, representando $91,2 \%$ do total coletado e classificados em duas famílias: Fuhrmannodesmidae e Pyrgodesmidae. Do total capturado, 78,9 foi representado por Fuhrmannodesmidae, $12,3 \%$ por Pyrgodesmidae e sendo $8,8 \%$ representado pelas ordens Polyxenida (Polyxenidae), Spirostreptida (Spirostreptidae), stemmiulida (Stemmiulidae) e Siphonophorida (Siphonophoridae). o período de maior captura dos diplópodos, durante a migração para cima (BE $\uparrow$ ), ocorreu durante a época chuvosa (período não inundado) com $97,6 \%$ do total capturado. No período menos chuvoso coletaram-se apenas $2,4 \%$ do total. A maior atividade ocorreu 
duas semanas antes da inundação (maio/1988) com 59,4\% do total (Apêndice 21). A distribuição das principais famílias de diplópodos, capturadas ao longo do ano, com fotoeclector de árvore $B E \uparrow$ foram ilustradas (Figura 23).

Os diplópodos adultos capturados durante a migração para cima ( $\mathrm{BE} \uparrow$ ) foram representados na maioria por Moojenodesmus pumilus (Fuhrmannodesmidae, Polydesmida). Apenas 1 adulto de $P$. distinctum foi capturado em setembro/1987. M. pumilus foi coletada somente durante a época chuvosa. o maior número de capturas ocorreu duas semanas antes da inundação com $68,0 \%$ do total coletado (Figura 24a). Os imaturos representaram $67,4 \%$ e os adultos, $12,6 \%$. Não foram coletados os estágios com 7 e 9 segmentos (Figura 24b).

Pyrgodesmidae foi a segunda familia mais abundante coletada em fotoeclector de árvore durante a migração para cima ( $B E \uparrow)$. A única espécie presente foi Muyudesmus obliteratus. o periodo de maior atividade ocorreu durante a época chuvosa com $87,0 \%$ do total capturado antes e no início do período não inundado (Figura 25a). Dentre os imaturos coletados, $22,6 \%$ eram do último estágio de desenvolvimento com 19 segmentos. Não foram coletados os primeiros estágios imaturos com 7 e 9 segmentos (Figura 25b, Apêndice 23).

Em fotoeclectores direcionados para baixo $(B E \downarrow)$ coletaram-se um total de 741 individuos, pertencentes na maioria a ordem Polydesmida, representando 89,8\% do total coletado e classificados em duas familias: Fuhrmannodesmidae e Pyrgodesmidae. Do total capturado, Fuhrmannodesmidae representou $79,8 \%$, Pyrgodesmidae $10,0 \%$, e $11,1 \%$ foi representado pelas ondens: Polyxenida (Polyxenidae); Stemmiulida (Stemmiulidae); Siphonophorida (Siphonophoridae) e Spirostreptida. A distribuição dos diplópodos ao longo do 
ano apresentou períodos de maior abundância: 41,2 do período chuvoso e $39,7 \%$ no início da época menos chuvosa (Apêndice 24). A distribuição, ao longo do ano, das principais familias de Diplopoda, capturadas em fotoeclector de árvore direcionado para baixo (BE $\downarrow$ ) foi ilustrada (Figura 26).

Fuhrmannodesmus rhinocerus foi coletada na maioria em fotoeclectores de árvore BE $\downarrow$. Alguns indivíduos adultos também foram coletados no solo através do aparelho de extração Kempson. Adultos de $F$. rhinocerus foram os únicos Fuhrmannodesmidae capturados em eclectores BE $\downarrow$ e coletados somente no final do periodo chuvoso com $51,8 \%$ do total (maio/1988) e no início do período menos chuvoso com $47,2 \%$ (junho/1988)(Figura 27a). A maioria dos imaturos coletados pertenciam aos últimos estágios com 17,18 e 19 segmentos. Os estágios iniciais com 7 e 9 segmentos não foram coletados (Figura 27b, Apêndice 25).

Muyudesmus obliteratus foi a única espécie representante dos Pyrgodesmidae capturada em armadilha BE $\downarrow$. O período de maior atividade ocorreu durante a época chuvosa com 78,3 \% do total capturado e no início da época menos chuvosa com 20,3 \% do total (Figura 25a). A maioria dos imaturos coletados pertencia aos últimos estágios de 18 e 19 segmentos com respectivamente 27,0 e $23,0 \%$ do total capturado (Figura 25b, Apêndice 26). 


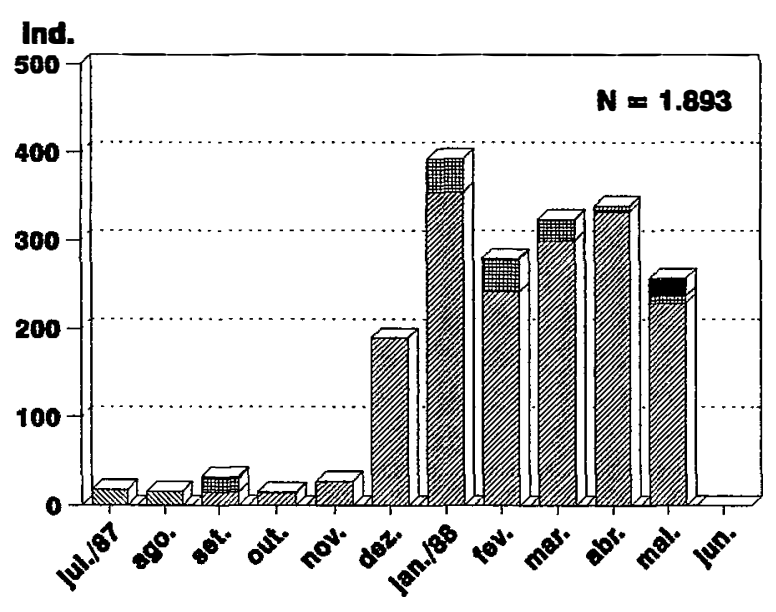

שK

A

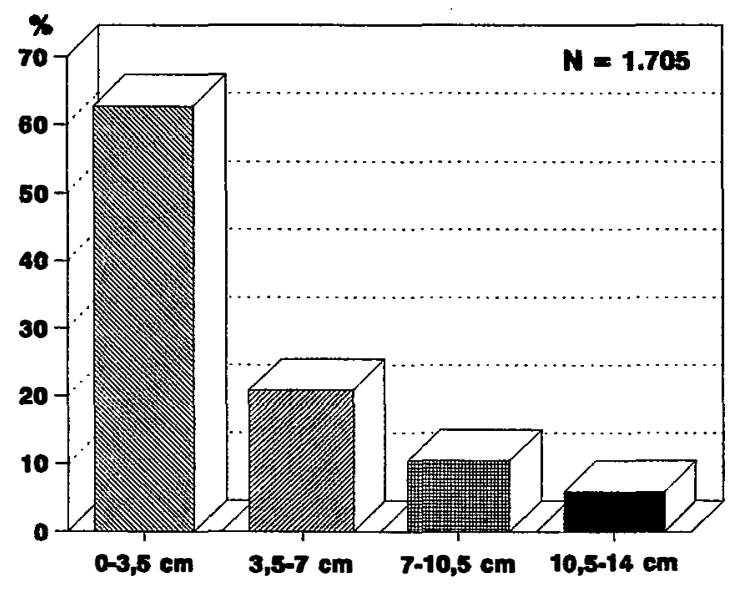

B

Figura 16A, B - Captura mensal e distribuição nas diferentes camadas do solo de Polyxenidae (Polyxenida, Diplopoda), na floresta inundada por água mista, no período de julho/1987 a junho/1988. $A$ = Captura com o método de Kempson ( $K)$, fotoeclectores de solo (E), fotoeclector de árvore direcionado para cima (BE $\uparrow$ ) e fotoeclector de árvore direcionado para baixo $(\mathrm{BE} \downarrow) . \mathrm{B}=$ Distribuição vertical no solo. 


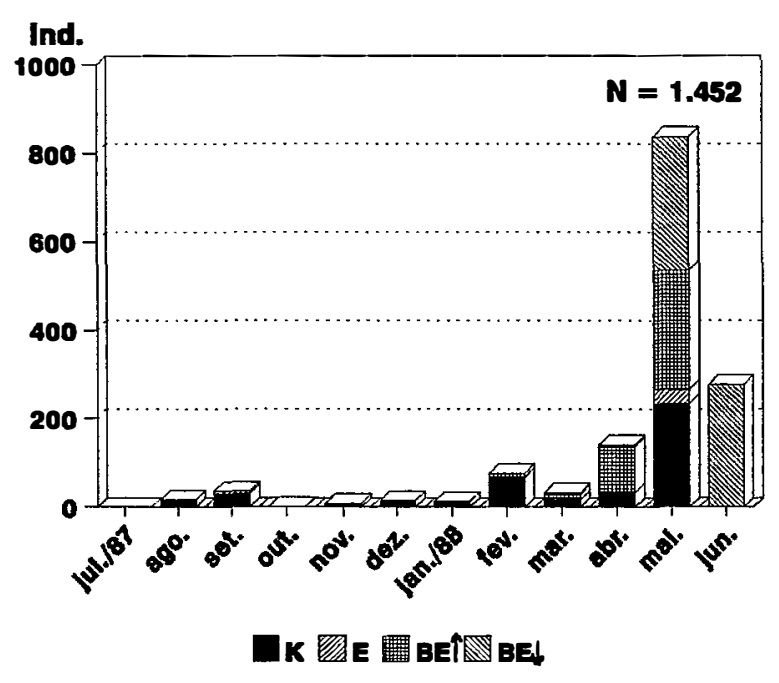

Figura 17 - Captura mensal de Fuhrmannodesmidae (Polydesmida, Diplopoda), nos diferentes tipos de armadilhas, na floresta inundada por água mista, no periodo de julho/1987 a junho/1988. $\mathrm{K}=$ método de Kempson; $\mathrm{E}=$ fotoeclectores de solo; $\mathrm{BE} \uparrow=$ fotoeclector de árvore direcionado para cima e $\mathrm{BE} \downarrow=$ fotoeclector de árvore direcionado para baixo.

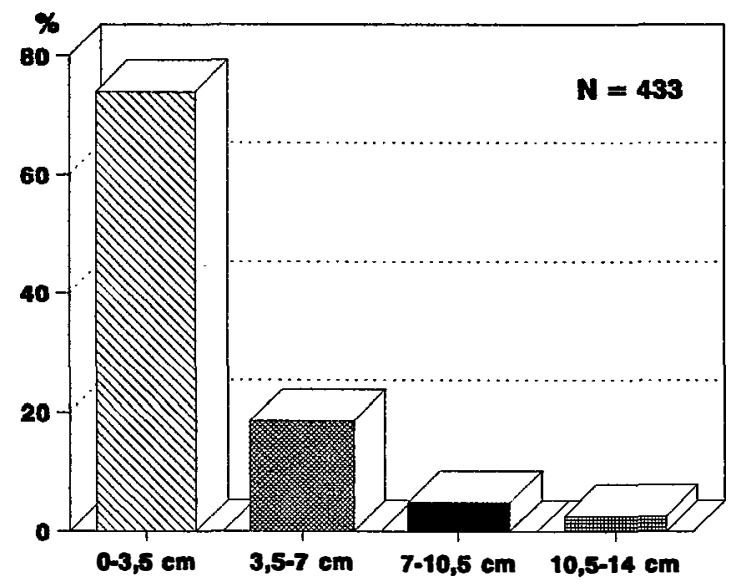

Figura 18 - Distribuição vertical de Moojenodesmus wellingtoni n.sp. Golovatch, 1994 e Moojenodesmus pumilus Schubart, 1943 (Fuhrmannodesmidae, Diplopoda), nas diferentes camadas do solo, na floresta inundada por água mista, no periodo de agosto/1987 a maio/1988. Captura com o método de Kempson. 


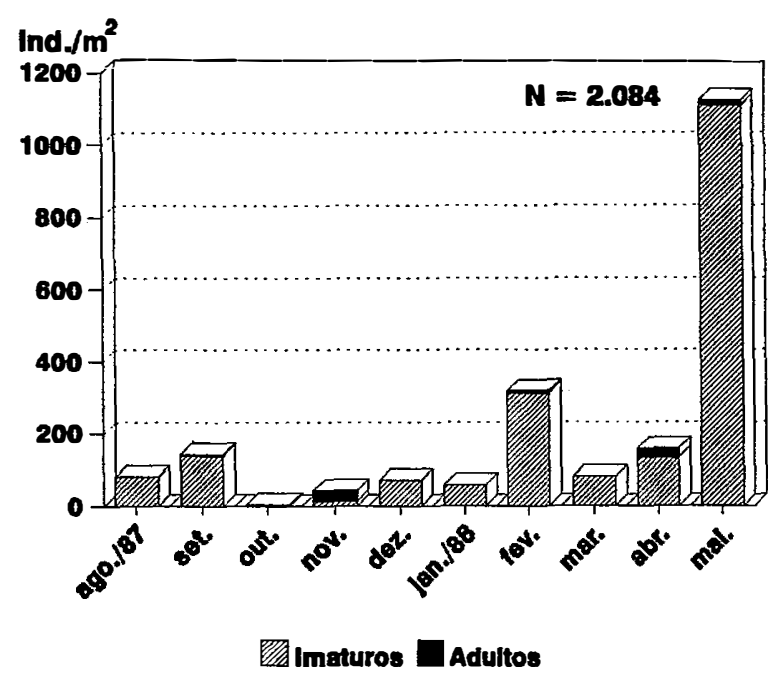

Figura 19 - Captura mensal de imaturos e adultos de Moojenodesmus wellingtoni n.sp. Golovatch 1994 e Moojenodesmus pumilus Schubart, 1943 (Fuhrmannodesmidae, Diplopoda), na floresta inundada por água mista, no período de agosto/1987 a maio/1988. Coleta com o método de Kempson.

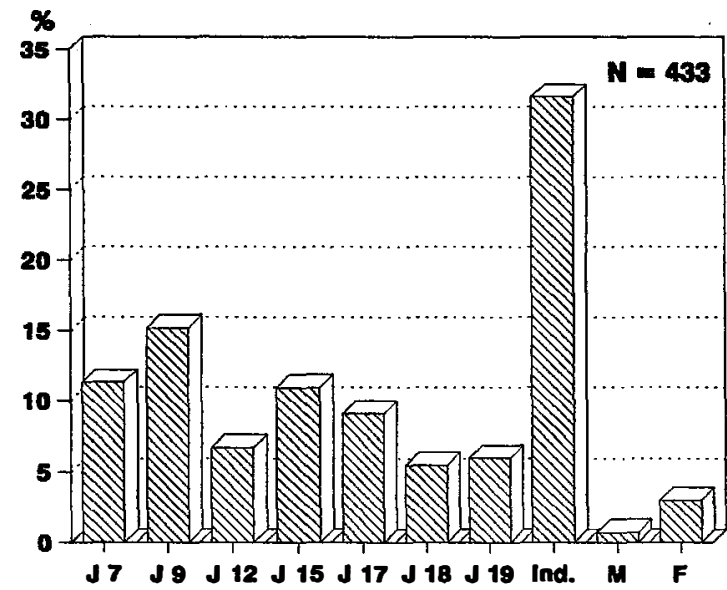

Figura 20 - Distribuição vertical dos estágios de desenvolvimento de Moojenodesmus wellingtoni n.sp. Golovatch, 1994 e Moojenodesmus pumilus Schubart, 1943 (Fuhrmannodesmidae, Diplopoda), na floresta inundada por água mista, no período de agosto/1987 a maio/1988. Captura com o método de Kempson. 


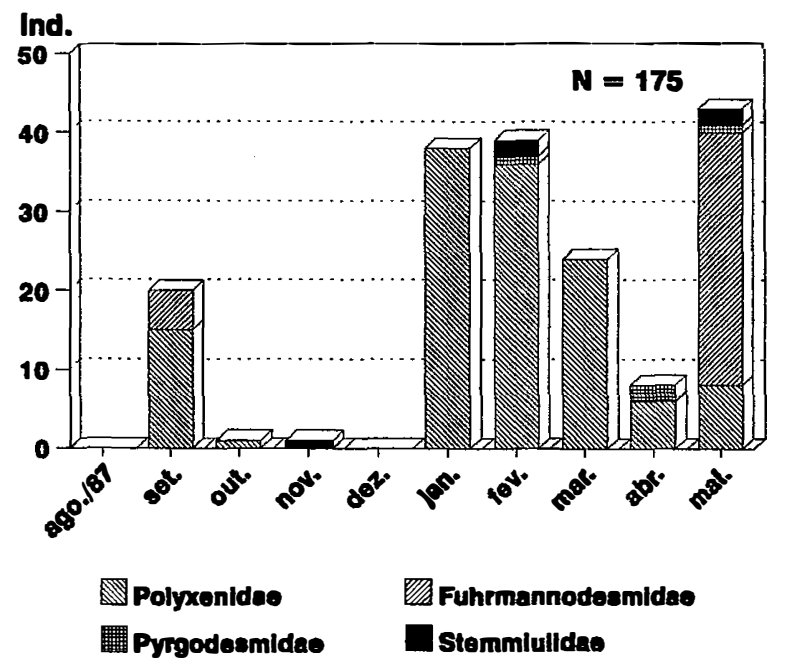

Figura 21 - Captura mensal das familias mais abundantes de Diplopoda, no folhedo, na floresta inundada por água mista, no período de agosto/1987 a maio/1988. Coleta com fotoeclectores de solo.

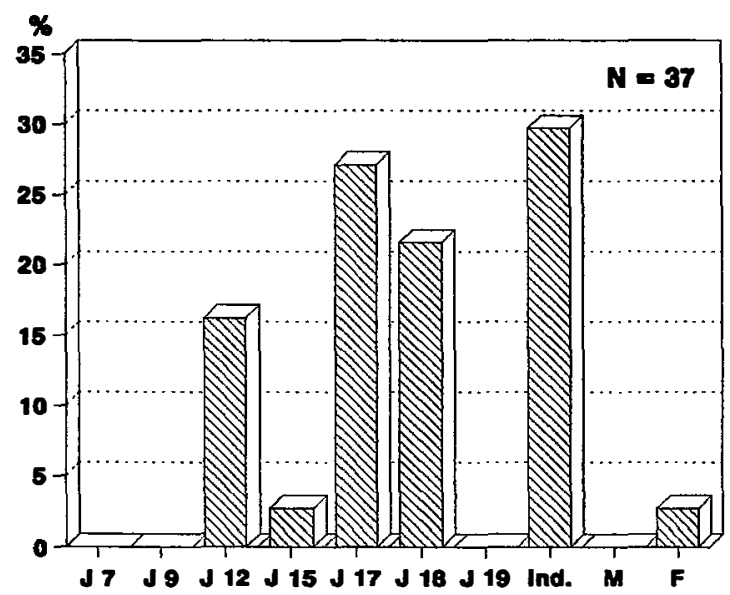

Figura 22 - Abundância dos estágios de desenvolvimento, no folhedo, de Moojenodesmus wellingtoni n.sp. Golovatch, 1994 e Moojenodesmus pumilus Schubart, 1943 (Fuhrmannodesmidae, Diplopoda), na floresta inundada por água mista, no período de agosto/1987 a maio/1988. Captura com fotoeclectores de solo. 


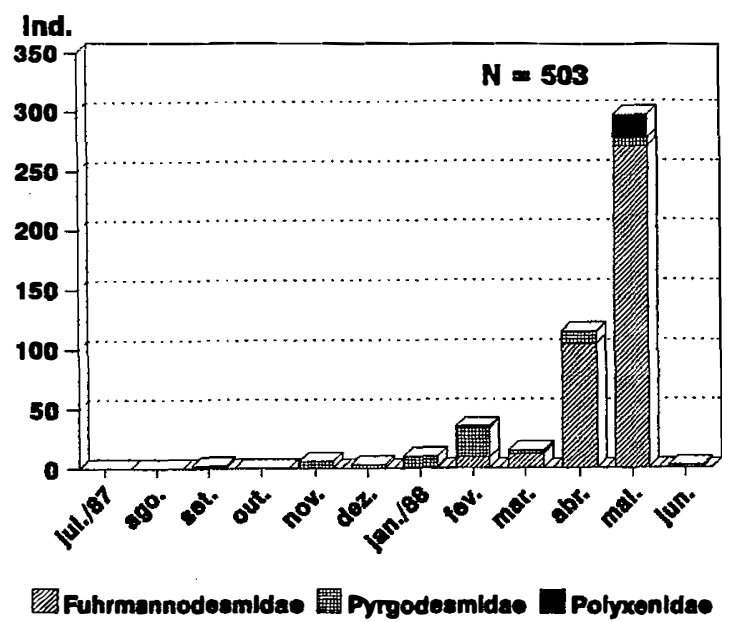

Figura 23 - Captura mensal das principais famílias de Diplopoda, no tronco, na floresta inundada por água mista, no período de julho/1987 a junho/1988. Coleta com fotoeclector de árvore direcionado para cima (BE $\uparrow$ ). 


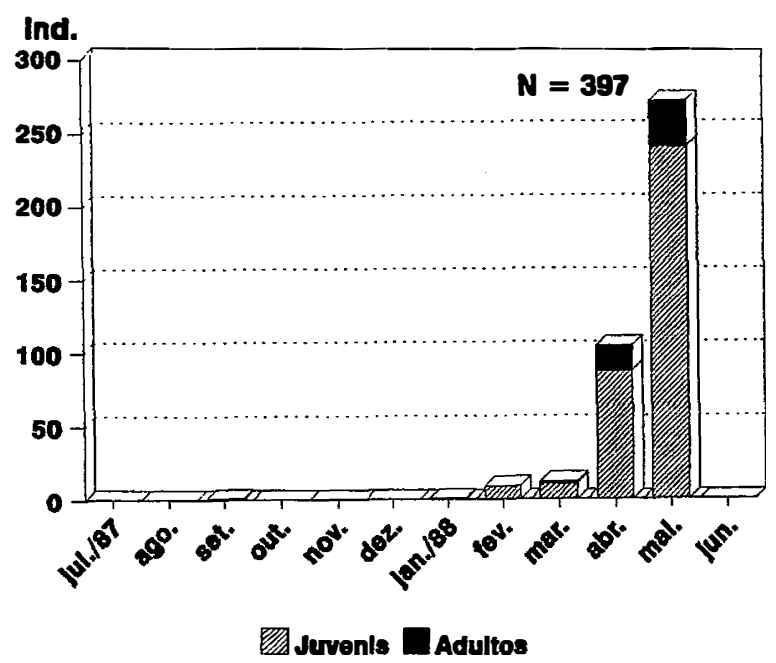

A

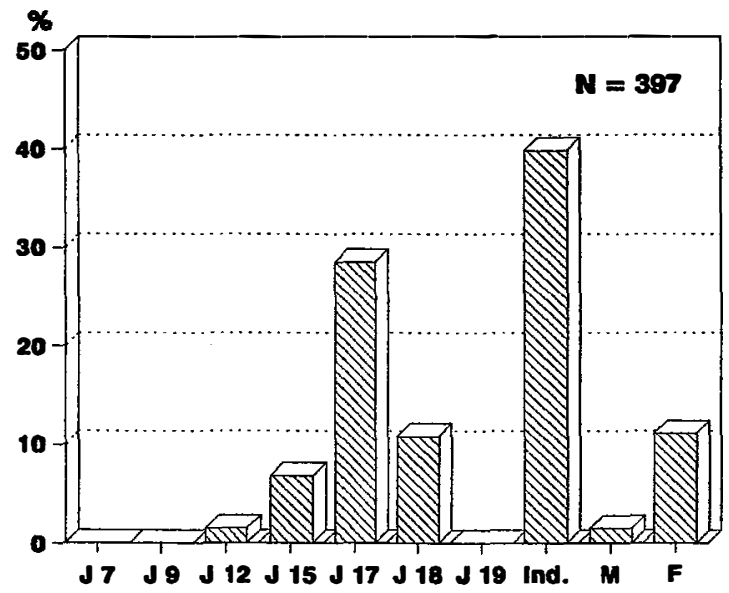

B

Figura 24A, B - Captura mensal de imaturos e adultos de Moojenodesmus pumilus Schubart, 1943 (Fuhrmannodesmidae, Diplopoda), no tronco, na floresta inundada por água mista, no período de julho/1987 a junho/1988. Coleta com fotoeclector de árvore direcionado para cima $(B E \uparrow) . A=$ Captura mensal de imaturos $e$ adultos. $\mathrm{B}=$ Frequência de ocorrência dos estágios de desenvolvimento. 


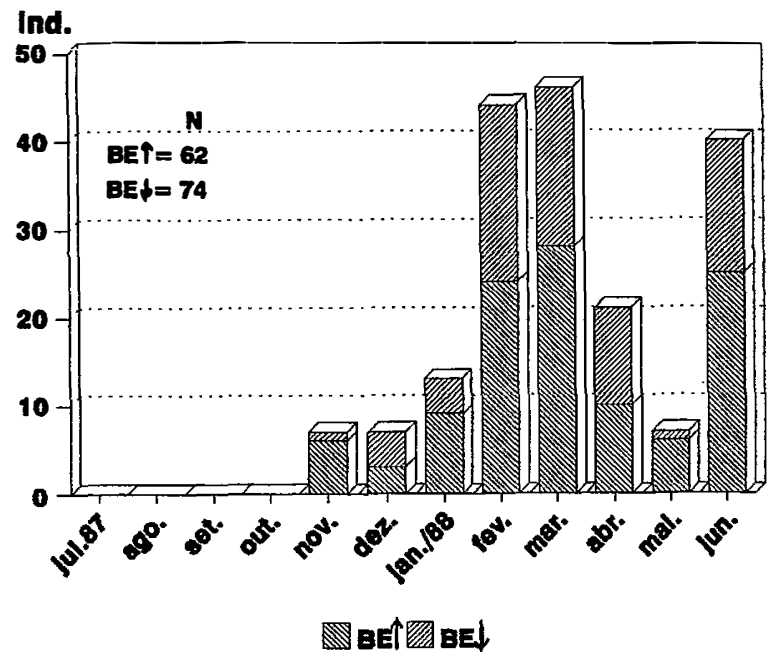

A

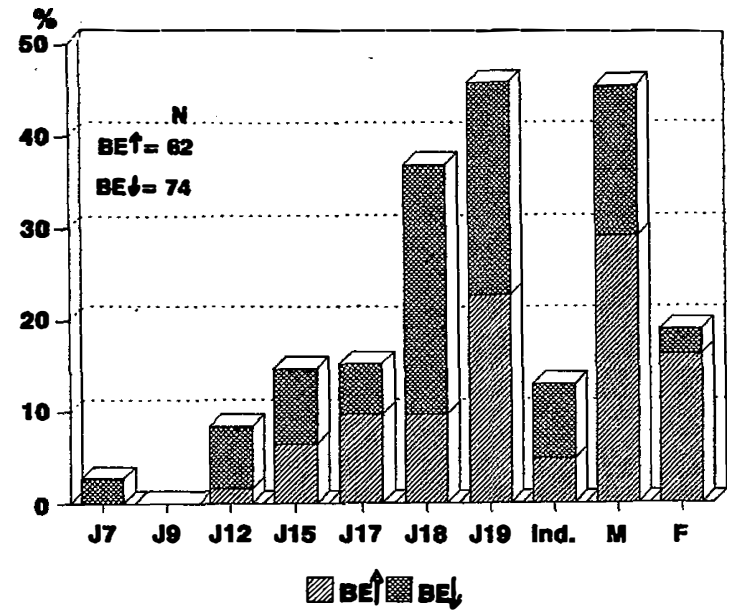

B

Figura 25 A, B - Captura mensal dos estágios de desenvolvimento de Muyudesmus obliteratus Schubart, 1943 (Pyrgodesmidae, Diplopoda), nos troncos, na floresta inundada por água mista, no período de julho/1987 a junho/1988. Coleta com fotoeclectores de árvores direcionado para cima ( $\mathrm{BE} \uparrow)$ e para baixo ( $\mathrm{BE} \downarrow)$. $\mathrm{A}=$ Captura mensal. $\mathrm{B}=$ Frequência de ocorrência dos estágios de desenvolvimento. 


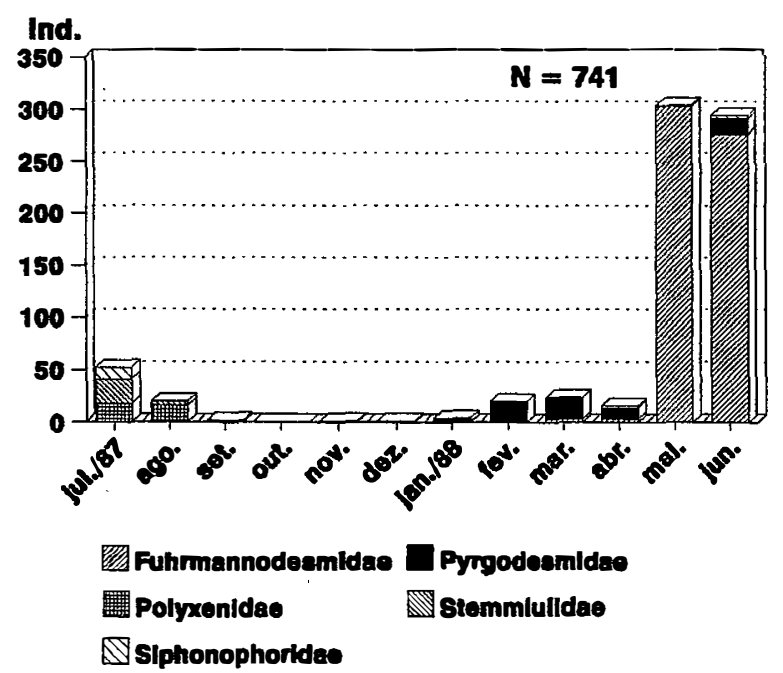

Figura 26 - Captura mensal das principais famílias de Diplopoda, no tronco, na floresta inundada por água mista, no periodo de julho/1987 a junho/1988. Captura com fotoeclector de árvore direcionado para baixo (BE $\downarrow$ ). 


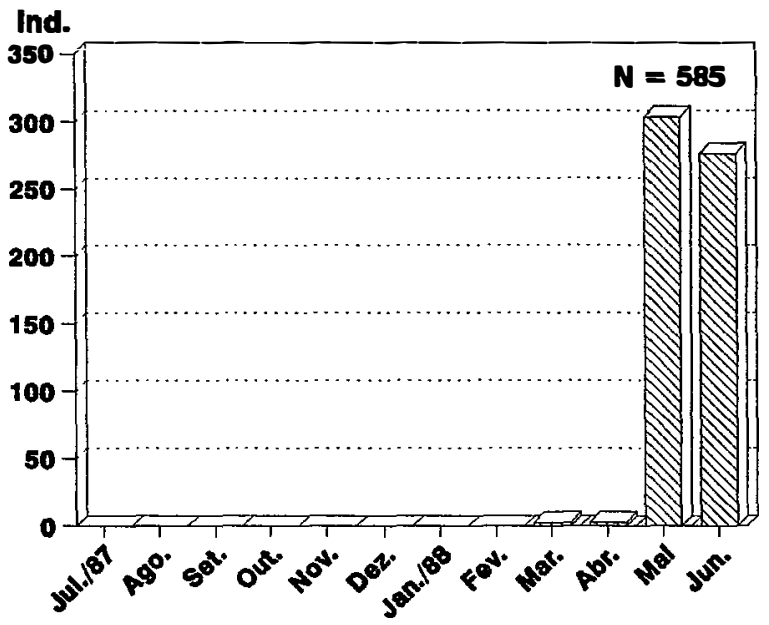

A

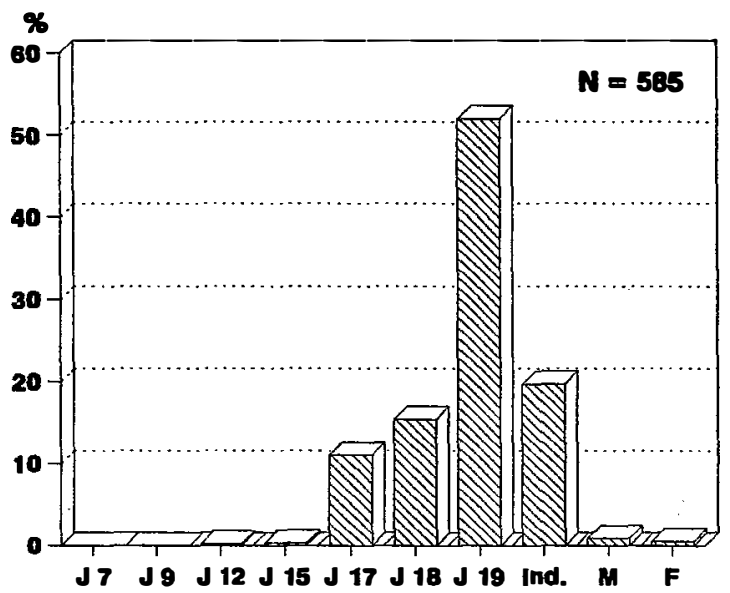

B

Figura 27A, B - Captura mensal dos estágios de desenvolvimento de Fuhrmannodesmus rhinocerus n.sp. Golovatch, 1994 (Fuhrmannodesmidae, Diplopoda), no tronco, na floresta inundada por água mista, no período de julho/1987 a junho/1988. Captura com fotoeclector direcionado para baixo $(B E \downarrow) . A=$ Captura mensal. $B=$ Freqüência de ocorrência dos estágios de desenvolvimento. 


\subsection{SYMPHYLA}

Foi capturado um total de 2.672 Symphyla, dos quais $86,7 \%$ foram classificados em espécies e em estágios de desenvolvimento. o restante do material foi danificado, e, portanto, não foi possível fazer a identificação. Do total identificado, a maioria era de juvenis $(47,7 \%$ do total capturado; $n=1.105), \quad 38,9 \%$ eram adultos $(n=899)$ e $13,5 \%$ eram subadultos $(n=312)$. As espécies capturadas na área foram: Ribautiella amazonica Scheller, 1984; Symphylella adisi Scheller, 1989 (Scolopendrellidae) e Hanseniella arborea Scheller, 1979 (Scutigerellidae).

\subsubsection{Captura no solo com o método de Kempson}

Coletaram-se um total de 2.311 symphyla no solo, dos quais $95,3 \%$ foram identificados em espécies e estágios de desenvolvimento. A abundância dos symphyla no solo foi maior durante o período não inundado e nos primeiros $7 \mathrm{~cm}$ de profundidade. A maior densidade populacional registrada foi durante o período menos chuvoso com $\approx 1.886$ individuos $/ \mathrm{m}^{2}$ (outubro/1987), e a mais baixa foi registrada no início do período não inundado com $\approx 255$ indivíduos $/ \mathrm{m}^{2}$ (agosto/1987). A abundância média dos symphyla na floresta inundada por água mista foi de $\approx 1.060$ indivíduos $/ \mathrm{m}^{2} / \mathrm{mês}$ (Apêndice 27) .

A abundância de $R$. amazonica foi mais alta $\left(52,2 \%\right.$ do total capturado; em média $\approx 553$ indivíduos $/ \mathrm{m}^{2} /$ mês), quando comparada com $H$. arborea $(39,8 \%$ i em média $\approx 421$ indivíduos $\left./ \mathrm{m}^{2} / \mathrm{mês}\right)$ e $S$. adisi $(8,0 \%$ em média $\approx 85$ indivíduos $/ \mathrm{m}^{2} / \mathrm{mês}$ ).

R. amazonica foi mais abundante nos primeiros $7 \mathrm{~cm}$ de profundidade do solo (Figura 28a). Aproximadamente 
$63,1 \%$ de $R$. amazonica na floresta inundada por água mista foi representada por juvenis, $11,5 \%$, por subadultos $e$ $23,3 \%$, por adultos. A distribuição dos estágios juvenis e adultos foi representada na Figura 28b. Ao longo do ano, a maior abundância ocorreu durante o mês de outubro/1987 com $\approx 1.506$ indivíduos $/ \mathrm{m}^{2}$, enquanto que a menor atividade ocorreu duas semanas antes da inundação (maio/1988) com $\approx 106$ indivíduos $/ \mathrm{m}^{2}$ (Figuras 29a e 29b).

A distribuição de $S$. adisi foi mais homogênea nas diferentes camadas do solo e a maior abundância ocorreu na camada de 10,5 a $14 \mathrm{~cm}$ de profundidade (Figura 30a). Aproximadamente $65,3 \%$ da população foi representada por imaturos, $11,4 \%$, por subadultos e 19,9\%, por adultos. A distribuição dos estágios imaturos e adultos foi ilustrada (Figura 30b). A maior abundância no solo ocorreu em fevereiro/1988 com $\approx 332$ indivíduos $/ \mathrm{m}^{2}$. A densidade populacional foi mais baixa duas semanas antes da inundação da floresta (maio/1988) com 5 indivíduos $/ \mathrm{m}^{2}$ (Apêndice 28). A distribuição ao longo do ano e nas diferentes camadas do solo foram ilustradas (Figuras $31 a$ e 31b).

H. arborea foi mais abundante nos primeiros 7 $\mathrm{cm}$ de profundidade do solo, com 90,2\% do total capturado (Figura 32a). Aproximadamente $49,0 \%$ da população capturada no solo, durante o período não inundado, foi representada por adultos, 30,2\%, por juvenis e $17,0 \%$, por subadultos. A distribuição dos estágios imaturos e adultos foi ilustrada (Figura 32b). O período de maior abundância ocorreu dez semanas antes da inundação (abril/1988) com $\approx 1.015$ individuos $/ \mathrm{m}^{2}$. A densidade populacional foi mais baixa no início do período não inundado (agosto/1987) com $\approx 14$ indivíduos $/ \mathrm{m}^{2}$. A distribuição ao longo do ano e nas camadas do solo foram ilustradas (Figuras 33a e 33b). 
4.4.2 Captura no folhedo com fotoeclectores de solo

H. arborea foi a única espécie capturada no folhedo ( $n=170)$ e ocorreu somente durante a estação chuvosa. o período de maior abundância foi registrado em março/1988 com $\approx 19$ indivíduos $/ \mathrm{m}^{2}$ (Apêndice 29).

4.4.3 Captura nos troncos com fotoeclectores de árvores (BE† e BE $\downarrow$ )

Dentre as espécies de Symphyla existentes na área experimental, apenas $H$. arborea foi coletada em fotoeclector de árvores $(n=72)$. Na captura em fotoeclector direcionado para cima ( $\mathrm{BE} \uparrow), H$. arborea foi coletada somente durante a época chuvosa, no período não inundado (de fevereiro a maio/1988). A maior densidade ocorreu durante 0 mês de março/1988, com $59,7 \%$ do total capturado (Apêndice 30).

Na captura em fotoeclector direcionado para baixo $(\mathrm{BE} \downarrow), H$. arborea foi coletada somente durante a época menos chuvosa ( $\mathrm{n}=50)$, no final do período inundado (julho/1987), com 98,0\% do total capturado (Apêndice 30). 


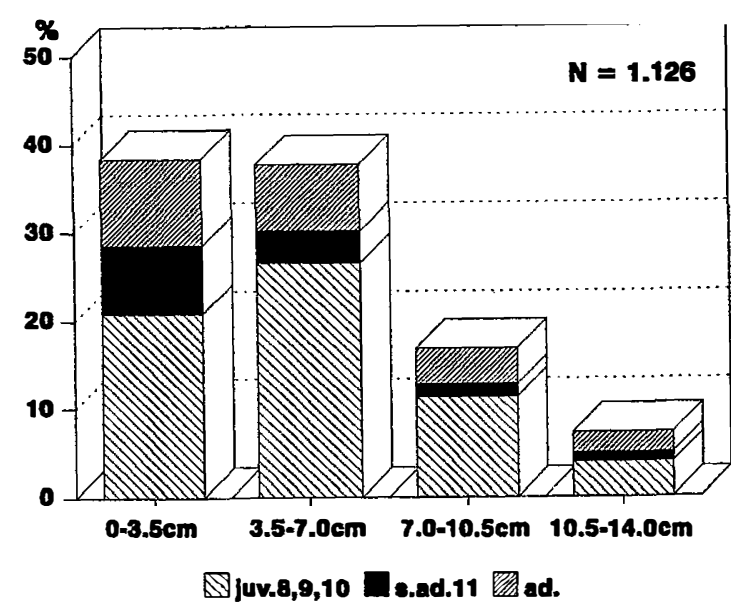

A

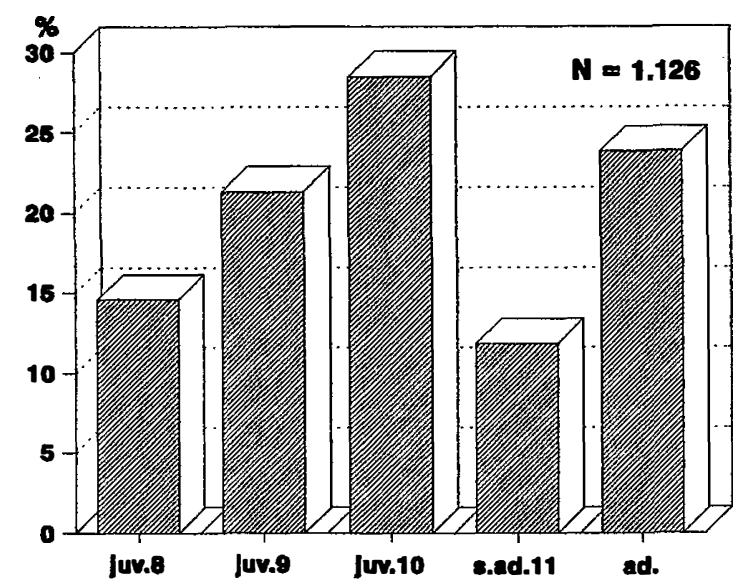

B

Figura 28A, B - Abundância vertical e estágios de desenvolvimento de Ribautiella amazonica Scheller, 1984 (Scolopendrellidae, Symphyla), no solo da floresta inundada por água mista, no período de agosto/1987 a maio/1988. Captura com o método de Kempson. $A=$ Abundância vertical. $B=$ Abundância por estágios de desenvolvimento. 


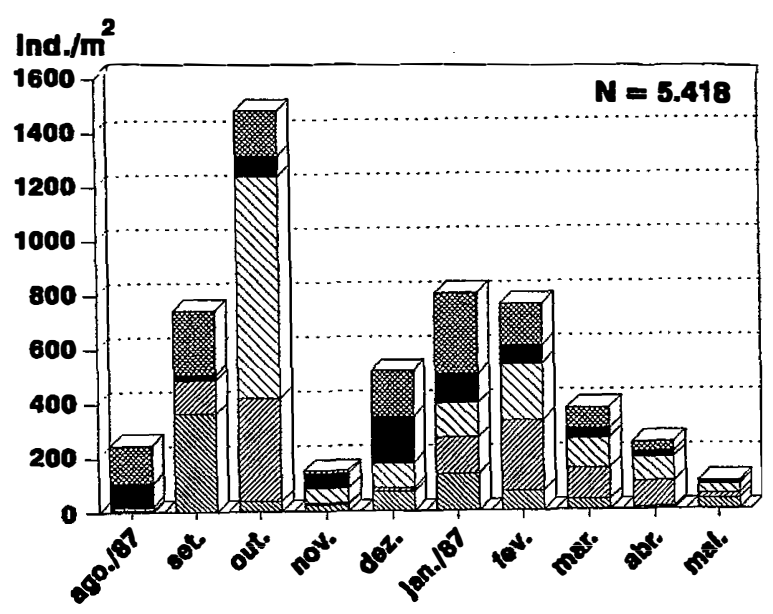

$\mathbb{\mathbb { N }}$ Juv.8

A

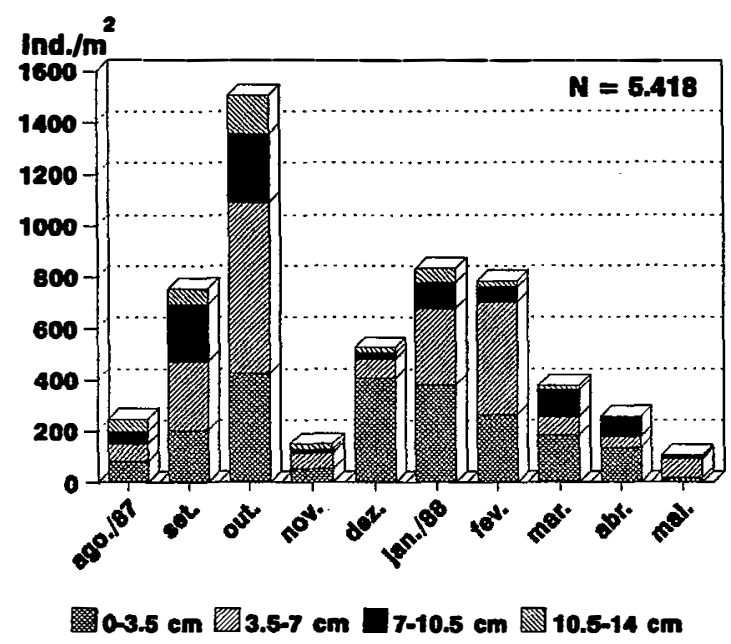

B

Figura 29A, B - Captura mensal dos estágios de desenvolvimento e distribuição vertical de Ribautiella amazonica Scheller, 1984

(Scolopendrellidae, Symphyla), no solo, na floresta inundada por água mista, no período de agosto/1987 a maio/1988. Coleta com o método do Kempson. $\mathrm{A}=$ Abundância mensal por estágios de desenvolvimento. $\mathrm{B}=$ Abundância vertical. 


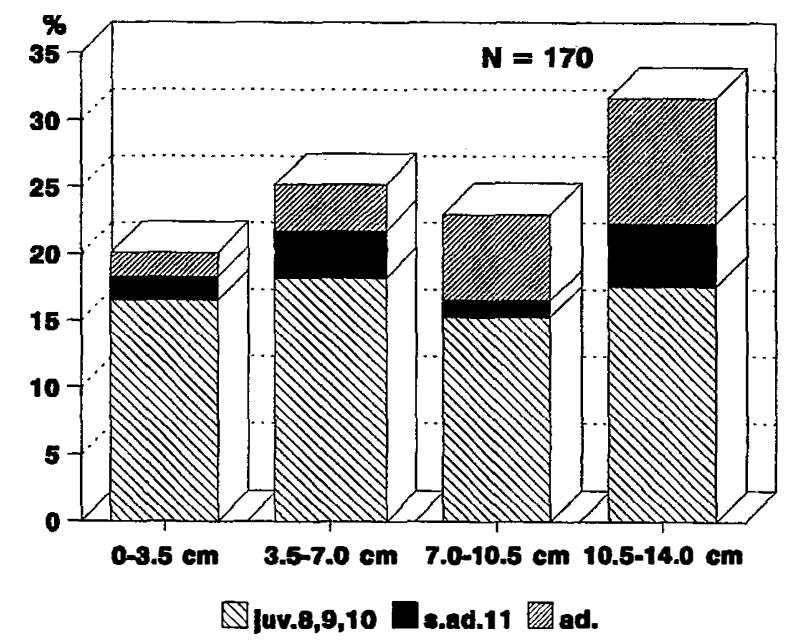

A

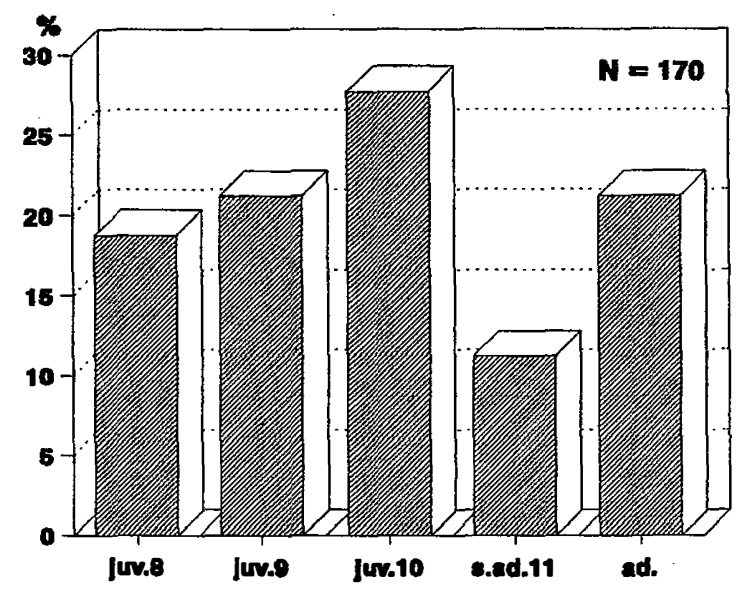

B

Figura 30A, B - Abundância vertical e estágios de desenvolvimento de symphylella adisi Scheller, 1989 (Scolopendrellidae, Symphyla), no solo, na floresta inundada por água mista, no período de agosto/1987 a maio/1988. Coleta com 0 método do Kempson. $A=$ Abundância vertical. $\mathrm{B}=$ Abundância por estágios de desenvolvimento. 


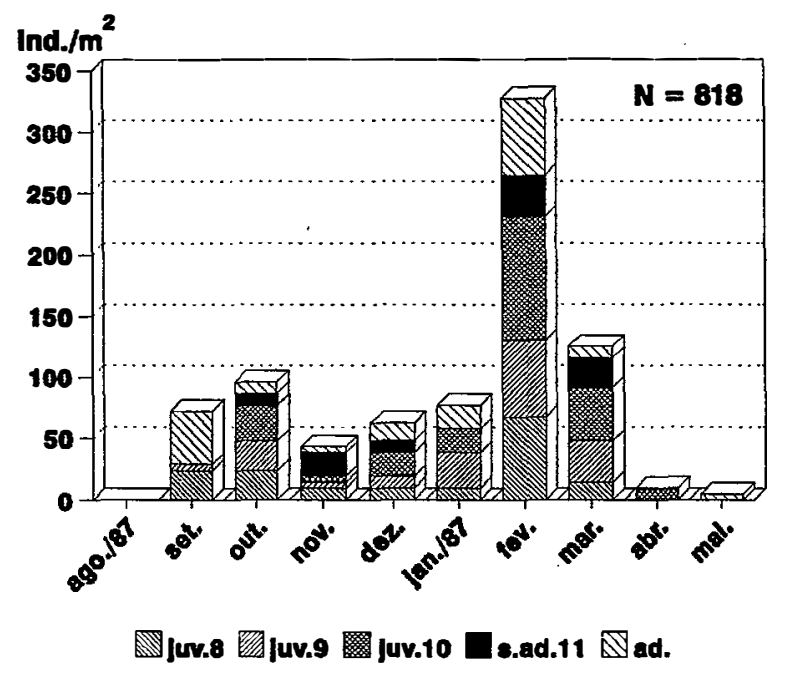

A

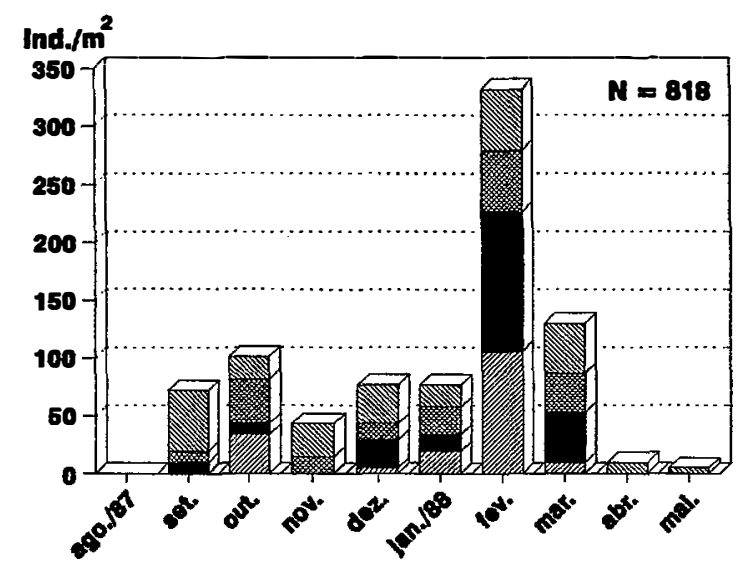

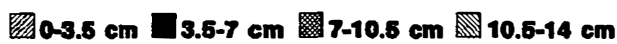

B

Figura 31A, B - Captura mensal dos estágios de desenvolvimento e distribuição vertical de Symphylella adisi Scheller, 1989

(Scolopendrellidae, Symphylla), no solo, na floresta inundada por água mista, no período de agosto/1987 a maio/1988. Coleta com o método de Kempson. $A=$ Abundância mensal por estágios de desenvolvimento. $\mathrm{B}=$ Abundância vertical. 


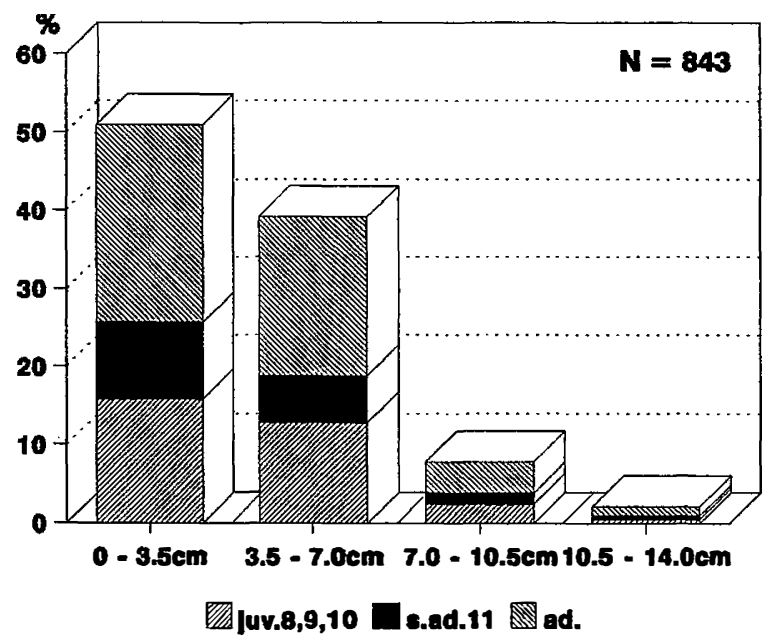

A

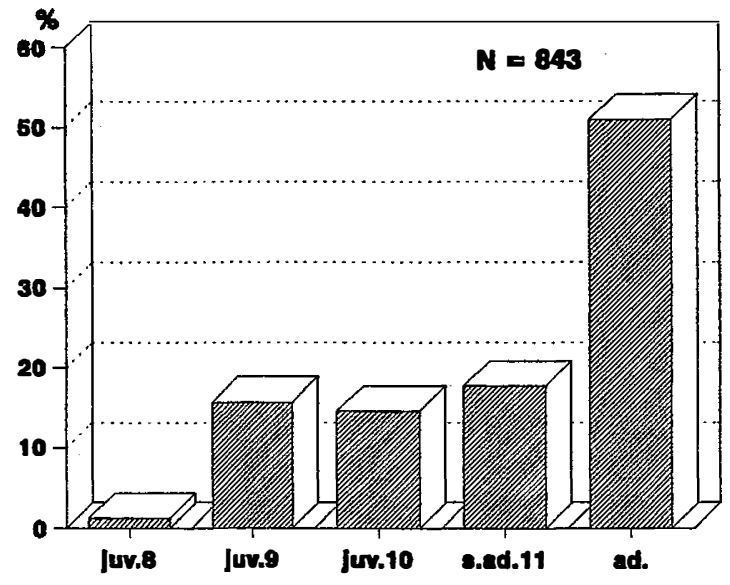

B

Figura 32A, B - Abundância vertical e estágios de desenvolvimento de Hanseniella arborea Scheller, 1979 (Scutigerellidae, Symphyla), no solo, na floresta inundada por água mista, no período de agosto/1987 a maio/1988. Coleta com o método de Kempson. $A=$ Abundância vertical. $\mathrm{B}=$ Abundância por estágios de desenvolvimento. 


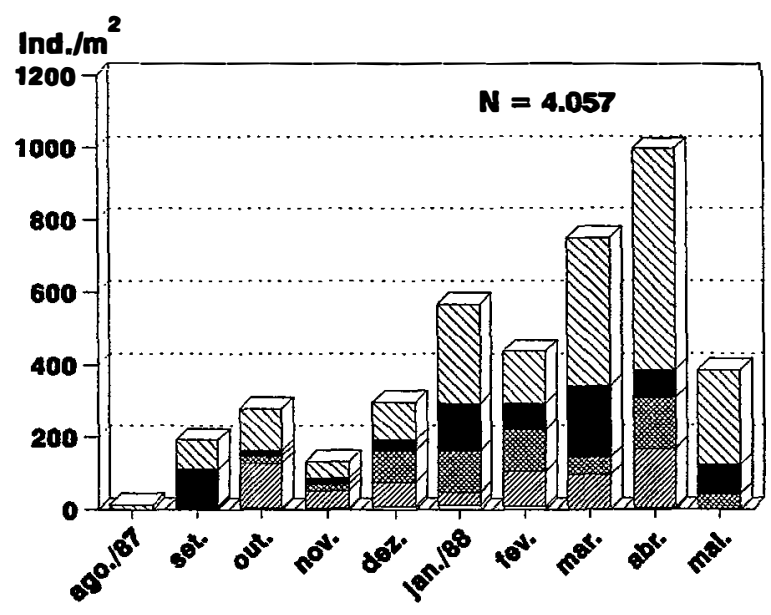

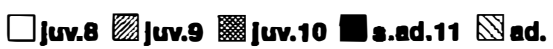

A

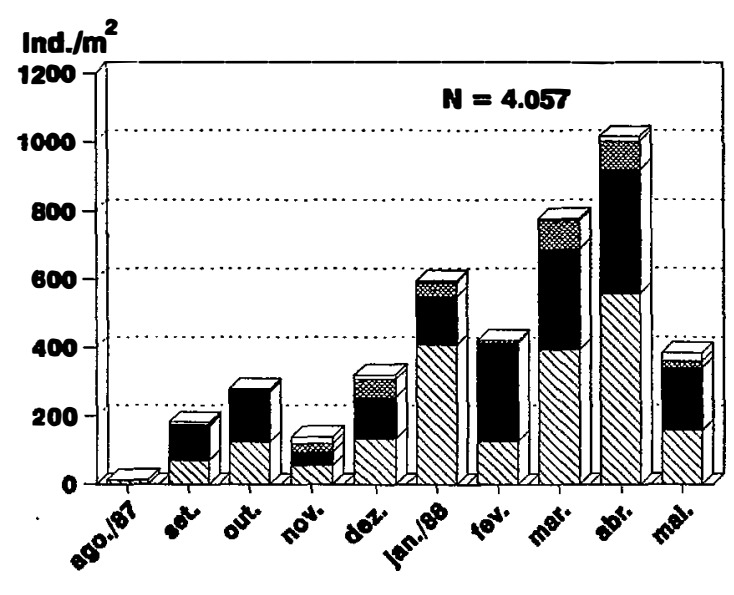

$\mathbb{Q} 0-3.5 \mathrm{~cm} \square_{3.5-7} \mathrm{~cm}$ 7-10.5 cm $\square$ 10.5-14 cm

B

Figura 33A, B - Captura mensal dos estágios de desenvolvimento e distribuição de Hanseniella arborea Scheller, 1979 (Scutigerellidae, Symphyla), no solo, na floresta inundada por água mista, no período de agosto/1987 a maio/1988. Coleta com o método de Kempson. A = Abundância mensal por estágios de desenvolvimento. $\mathrm{B}=$ Abundância vertical. 
4.5 ARCHAEOGNATHA (Microcoryphia)

Dentre os Archaeognatha capturados ( $n=145)$, $37,2 \%(n=54)$ foram coletados em fotoeclectores de árvores

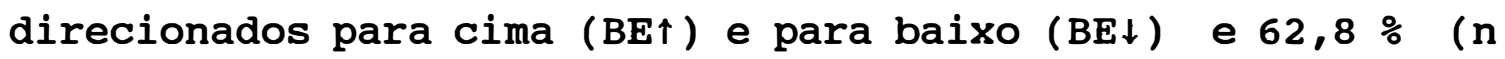
= 91) em fotoeclectores de solo. Nenhum individuo foi coletado no solo com o método de Kempson (Apêndices 31 e 32).

\subsubsection{Captura no folhedo com fotoeclectores de solo}

Do total de Archaeognatha capturados com armadilhas de fotoeclectores de solo, coletaram-se apenas individuos pertencentes à familia Meinertellidae (em média $\approx 13,5$ individuos $\left./ \mathrm{m}^{2} / \mathrm{mês}\right)$. As espécies capturadas foram Neomachilellus scandens Wygodzinsky, $1978(\mathrm{n}=31)$; Meinertellus adisi Sturm, 1983 ( $\mathrm{n}=114)$ e Neomachilellus adisi Wygodzinsky, $1978(\mathrm{n}=1)$. A época de maior abundância ocorreu durante o período menos chuvoso com $79,6 \%$ do total capturado. A maior densidade populacional ocorreu no início do período não inundado com 4 indivíduos $/ \mathrm{m}^{2}$ (agosto/1987) (Apêndice 31).

Aproximadamente $45,2 \%$ da população de Neomachilellus scandens foi representada por imaturos, e 54,8\%, por adultos. A distribuição dos imaturos $e$ adultos de $N$. scandens, no folhedo, foi baseada nas medições do comprimento da cabeça (Figura 34a). A maior abundância ocorreu durante - período menos chuvoso com 87,1 \% do total capturado. A maior densidade populacional ocorreu no início do período não inundado (agosto/1987) com aproximadamente 45,2 \% do total (Figura 34b). O período menos chuvoso foi representado por $12,9 \%$. Os imaturos ocorreram somente no início do período não inundado.

No que diz respeito a Meinertellus adisi, 
aproximadamente $87,0 \%$ dos indivíduos coletados foram representados por imaturos, e $13,0 \%$, por adultos. A distribuição de imaturos e adultos de $M$. adisi no folhedo foi baseada nas medições do comprimento da cabeça (Figura 35a) e os imaturos coletados foram mais jovens do que aqueles capturados nos troncos. Com relação às estações anuais, $M$. adisi foi mais abundante durante a estação menos chuvosa com $69,6 \%$, enquanto que na estação chuvosa capturaram-se $30,4 \%$ do total. Ao longo do ano, a maior abundância ocorreu durante 0 mês de outubro/1987, com $62,6 \%$ do total capturado (Figura 35b).

Com relação a Neomachilellus adisi, apenas um exemplar (fêmea) foi capturado durante a época de coleta, através de fotoeclectores de solo, em janeiro/1988.

\subsubsection{Captura nos troncos com fotoeclectores de

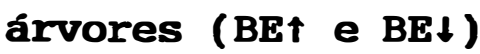

Nos troncos, capturaram-se apenas Meinertellus adisi. Na captura em direção para cima coletaram-se um total de 88 indivíduos em fotoeclector de árvore direcionado para cima ( $B E \uparrow$ ), enquanto que apenas 3 indivíduos foram capturados em fotoeclector de árvore direcionado para baixo (BE $\downarrow$ ) (Apêndice 32). Aproximadamente $63,7 \%$ dos indivíduos capturados foram imaturos e $36,3 \%$ foram adultos. A distribuição de imaturos e adultos de $M$. adisi, no tronco, foi baseada nas medições do comprimento da cabeça. Os imaturos capturados apresentaram um tamanho máximo de $3,7 \mathrm{~cm}$ de comprimento da cabeça (Figura 36a). A maior freqüência ocorreu durante 0 período chuvoso com $61,4 \%$ do total capturado, enquanto que no período menos chuvoso capturaramse $38,6 \%$ do total. A maior densidade populacional ocorreu em fevereiro/1988 com $20,9 \%$ do total coletado (Figura 36h) 


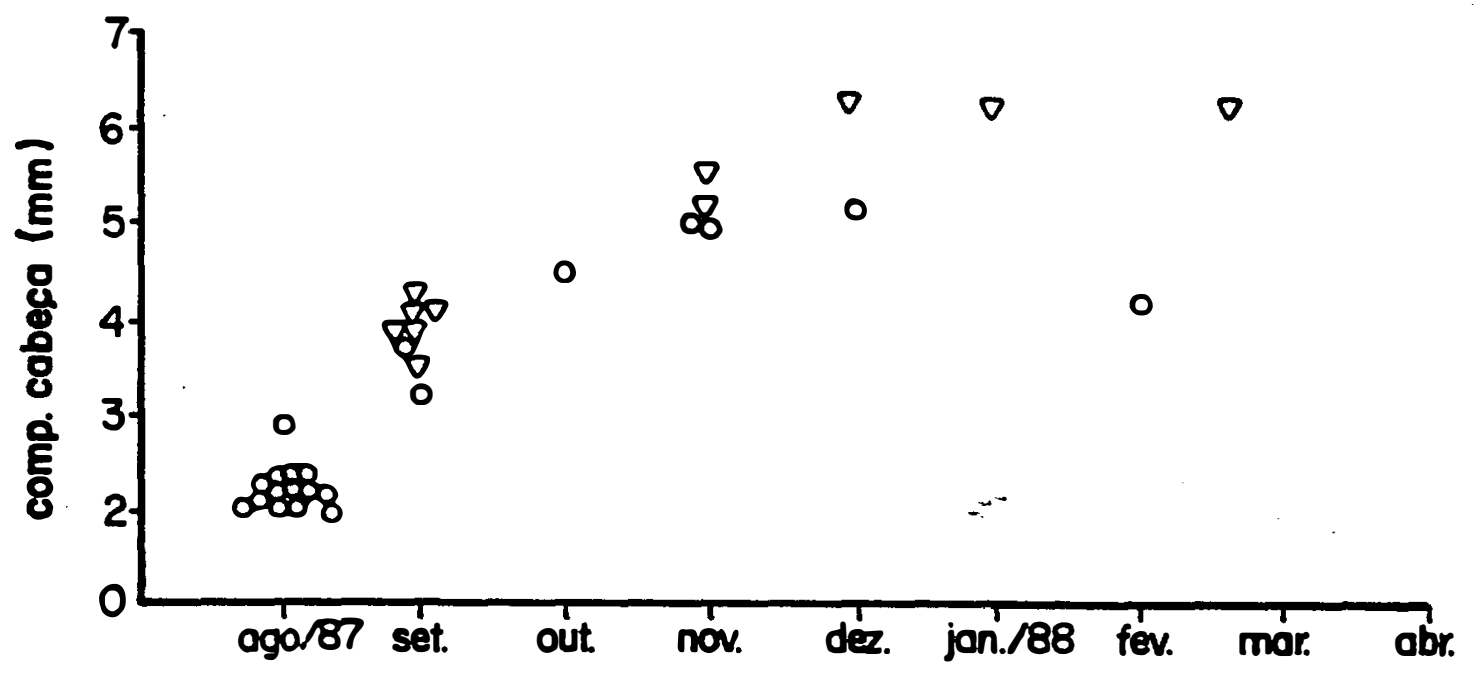

o Imaturos

口 Maçhos

○ Fêmeas

A

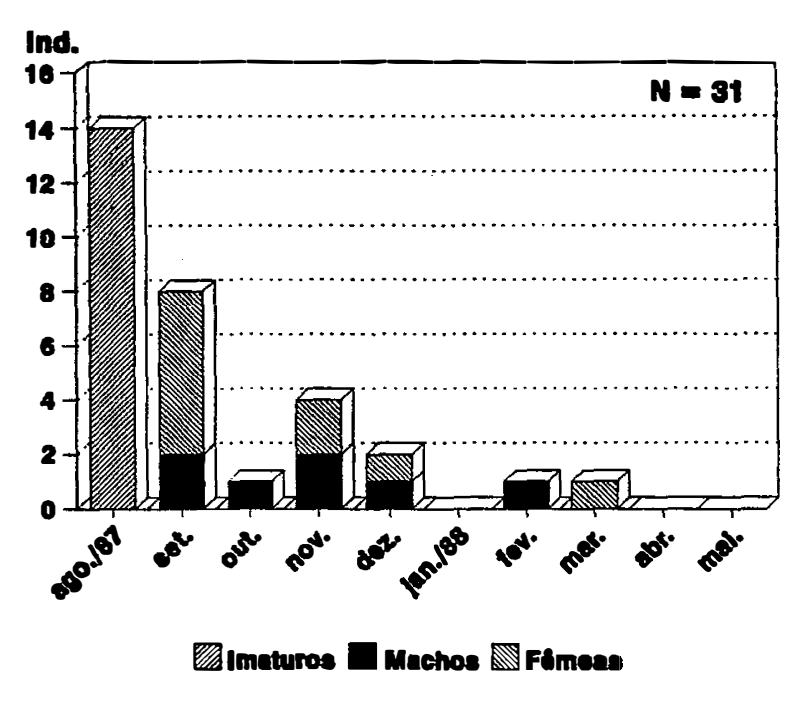

Figura 34A,B - Captura mensal dos estágios de desenvolvimento de Neomachilellus scandens Wygodzinsky, 1978 (Meinertellidae, Archaeognatha), no folhedo, na floresta inundada por água mista, no período de agosto/1987 a maio/1988. Coleta com fotoeclectores de solo. $A=$ Freqüência de ocorrência dos estágios de desenvolvimento. Dados de medições do comprimento da cabeça e datas de captura. $\mathrm{B}=$ Captura mensal . 


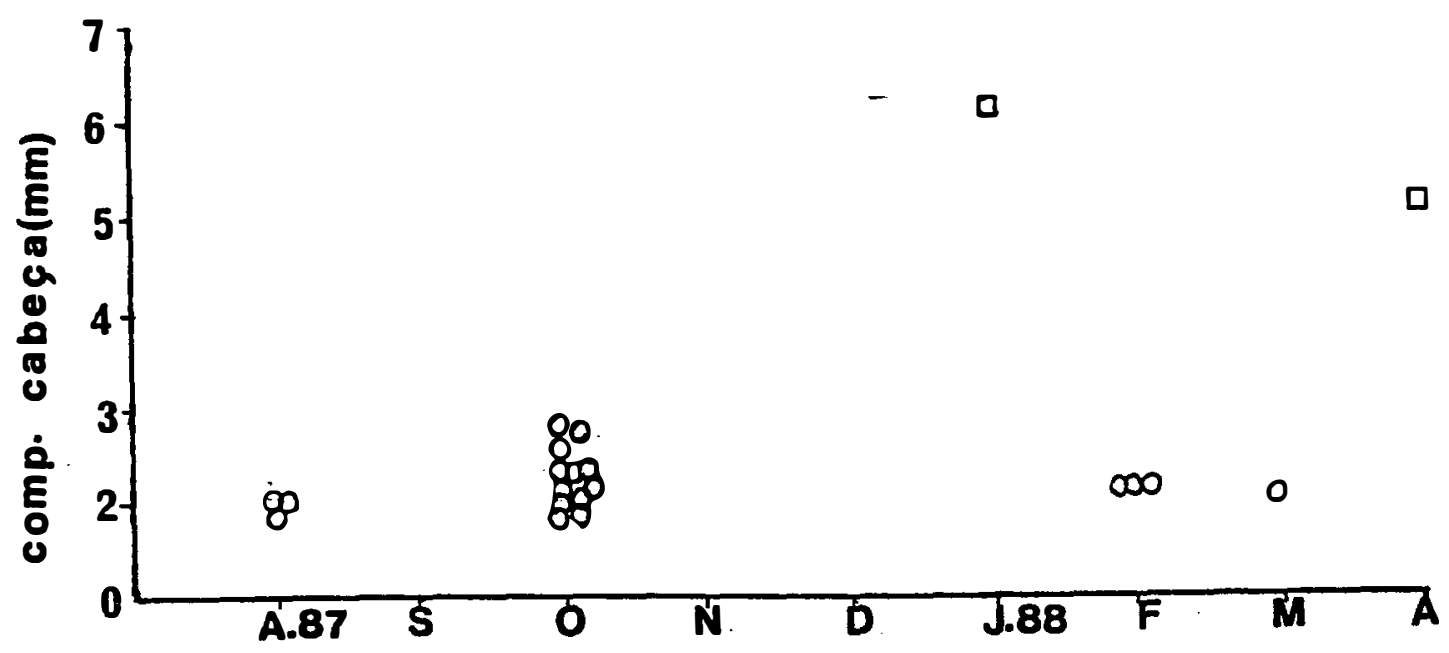

A.

oimaturos omachos ofêmeas

A

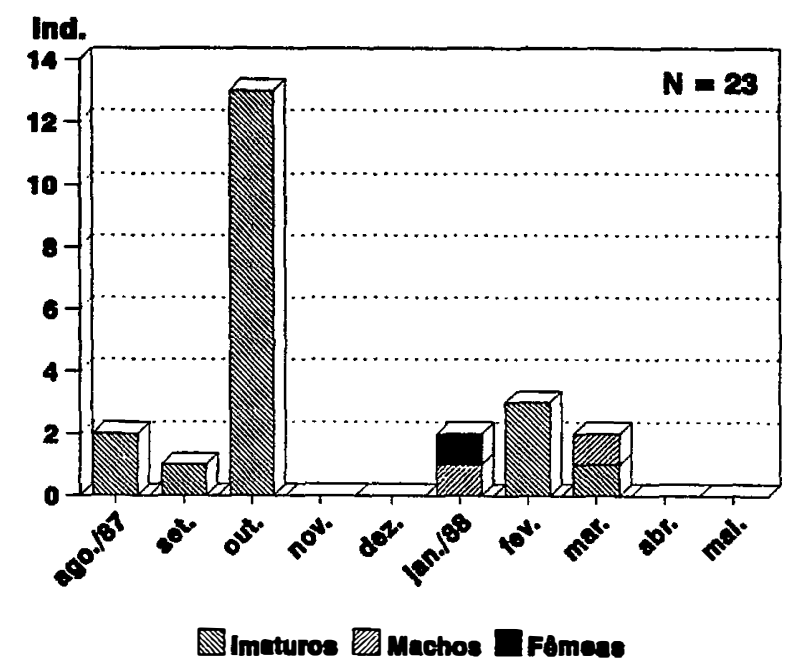

B

Figura 35A, B - Captura mensal dos estágios de desenvolvimento de Meinertellus adisi Wygodzinsky, 1978 (Meinertellidae, Archaeognatha), no folhedo, da floresta inundada por água mista, no período de agosto/1987 a maio/1988. Coleta com fotoeclectores de solo. A = Freqüência de ocorrência dos estágios de desenvolvimento. Dados de medições do comprimento da cabeça e datas de captura. $\mathrm{B}=$ Captura mensal. 


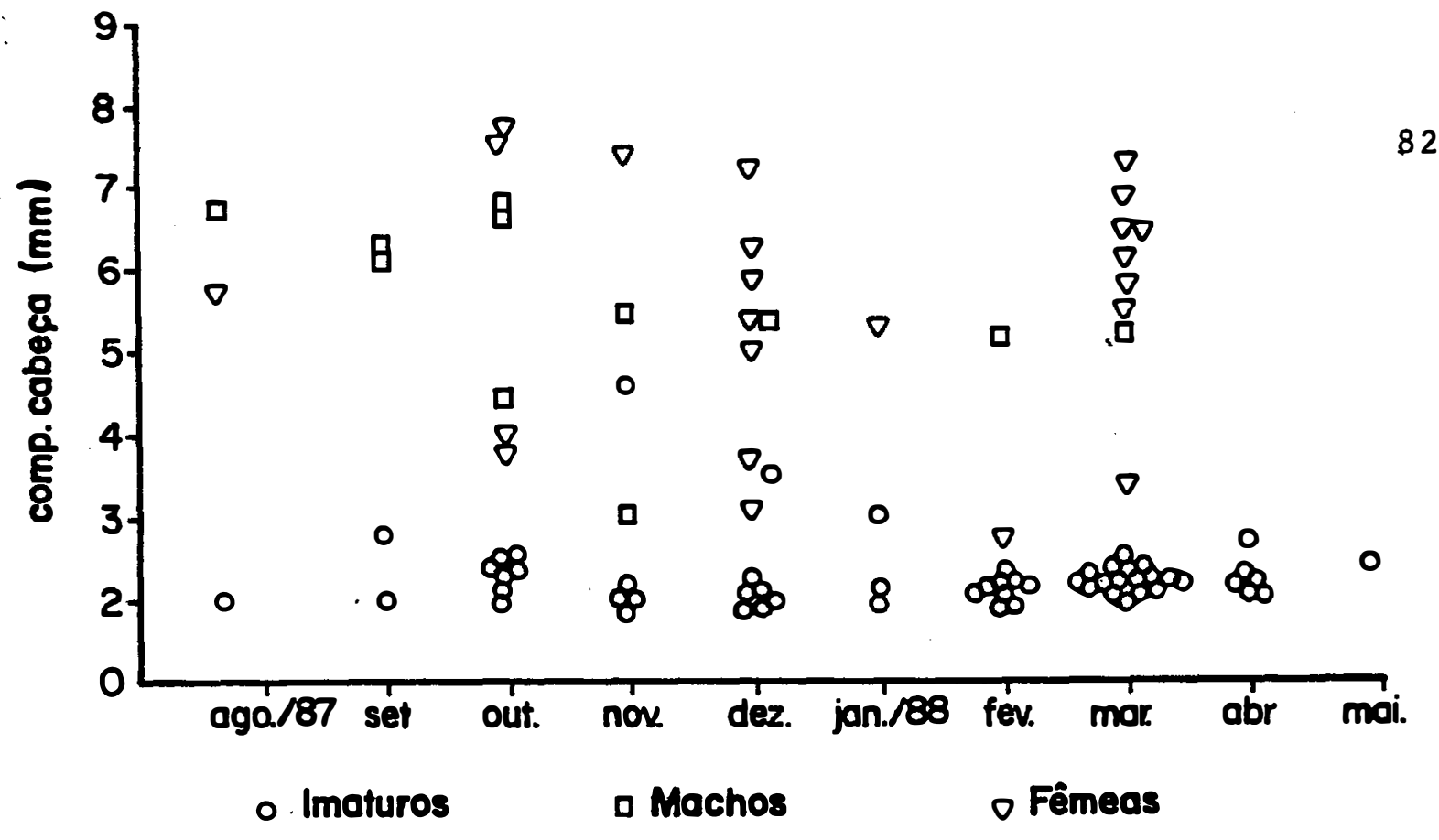

A

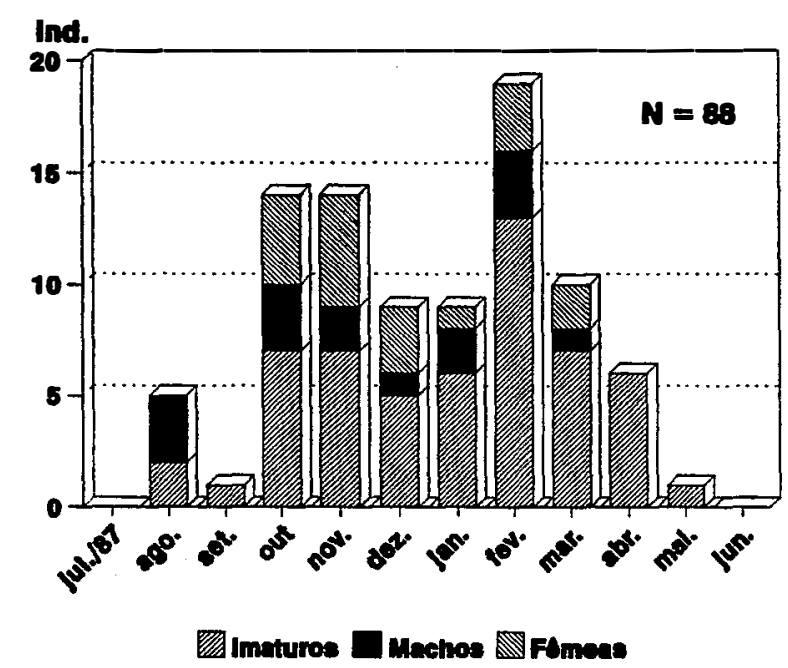

B

Figura 36A, B - Captura mensal dos estágios de desenvolvimento de Meinertellus adisi Wigodzinsky, 1978 (Meinertellidae, Archaeognatha), em fotoeclector direcionado para cima ( $\mathrm{BE} \uparrow)$, na floresta inundada por água mista, no período de julho/1987 a junho/1988. A = Freqüência de ocorrência dos estágios de desenvolvimento. Dados de medições do comprimento da cabeça e datas de captura. $\quad$ B = Captura mensal. 
4.6 COLEOPTERA

Foram coletados 7.914 coleópteros (adultos) na área experimental. O maior número de indivíduos foi obtido em fotoeclectores de solo com $77,1 \%$ do total capturado. No solo foram capturados $10,9 \%$ do total, através do método de Kempson. No tronco capturaram-se 8,1\% em fotoeclector de árvore direcionado para baixo ( $\mathrm{BE} \downarrow$ ), enquanto que na direção para cima coletaram-se apenas $3,9 \%$

\subsubsection{Captura no solo com o método de Kempson}

Coletaram-se um total de 865 coleópteros (adultos) ( $\approx 416$ indivíduos $\left./ \mathrm{m}^{2} / \mathrm{mês}\right)$, na camada de 0 a $14 \mathrm{~cm}$ de profundidade no solo dos quais $91 \%$ foram identificados a nível de familia. A maior abundância foi na primeira camada do solo (Figura 37a). Ao longo do ano, a maior densidade populacional foi observada no início da inundação ( $\approx 481$ indivíduos $/ \mathrm{m}^{2}$ ), em agosto/1987 e no final da inundação ( $\approx 986$ individuos $/ \mathrm{m}^{2}$ ), em maio/1988 (Figura 37b).

ERWIN \& SCOTT (1980) e ERWIN (1983) classificaram os coleópteros de acordo com o nível trófico de cada familia. Seguindo esta classificação, ilustrou-se a distribuição das familias de coleópteros coletadas neste trabalho (Tabelas $1,2,3$ e 4 ).

No solo, os predadores foram mais abundantes com $\approx 289$ individuos $/ \mathrm{m}^{2} /$ mês, seguidos de fungívoros com $\approx 86$ individuos $/ \mathrm{m}^{2} /$ mês e herbivoros com $\approx 3$ indivíduos $/ \mathrm{m}^{2} / \mathrm{mês}$.

Do total de coleópteros (adultos), foram capturados em média $\approx 532$ indivíduos $/ \mathrm{m}^{2} / \mathrm{mês}$ durante a época chuvosa (dezembro/1987 a maio/1988), e $\approx 242$ indivíduos $/ \mathrm{m}^{2} / \mathrm{mês}$ durante a época menos chuvosa. Na época chuvosa os predadores foram dominantes ( $\approx 361$ individuos $\left./ \mathrm{m}^{2} / \mathrm{mês}\right)$, seguidos pelos 
fungívoros $\left(\approx 123\right.$ individuos $\left./ \mathrm{m}^{2} / \mathrm{mês}\right)$ e herbivoros $(\approx 4$ indivíduos $/ \mathrm{m}^{2} / \mathrm{mês}$ ) (Tabela 1 ).

Os coleópteros (adultos) apresentaram a seguinte distribuição vertical no solo: primeira camada = $70,3 \%$ do total capturado $\left(\approx 2.926\right.$ indivíduos $\left./ \mathrm{m}^{2}\right)$; segunda camada $=17,8 \%\left(\approx 741\right.$ individuos $\left./ \mathrm{m}^{2}\right) ;$ terceira camada $=$ $6,0 \%\left(\approx 250\right.$ individuos $\left./ \mathrm{m}^{2}\right)$ e quarta camada $=5,9 \%(\approx 245$ individuos $/ \mathrm{m}^{2}$ ) (Figura $37 \mathrm{a}$ ).

No total de 8 famílias determinadas (Apêndice $33)$, as mais abundantes foram: Staphylinidae, com $36,0 \%$ $\left(\approx 1.496\right.$ individuos $\left./ \mathrm{m}^{2}\right) ;$ Carabidae, com $31,9 \%(\approx 1.328$ indivíduos $\left./ \mathrm{m}^{2}\right)$ e Pselaphidae, com $17,5 \%$ ( $\approx 727$ individuos $\left./ \mathrm{m}^{2}\right)$. Os $5,5 \%$ restantes $\left(\approx 231\right.$ individuos $/ \mathrm{m}^{2}$ ) foram representados pelas famílias: Ptiliidae, Scydmaenidae, Scolytidae, Scarabaeidae e Curculionidae. A maior frequência de ocorrência em Staphylinidae ocorreu na primeira camada do solo (Figura 37a). Ao longo do ano a abundância foi maior no início do período não inundado $\left(\approx 318\right.$ indivíduos $\left./ \mathrm{m}^{2}\right)$ e no final deste período $\left(\approx 462\right.$ indivíduos $\left./ \mathrm{m}^{2}\right)$. Carabidae também apresentou uma alta abundância na primeira camada do solo e foi dominante nas camadas subseqüentes (Figura 37a). Ao longo do ano, a maior abundância ocorreu no final do período não inundado, com $\approx 308$ indivíduos $/ \mathrm{m}^{2}$. o período de maior captura de Pselaphidae ocorreu em março/1988 ( $\approx 164$ indivíduos $\left./ \mathrm{m}^{2}\right)$ e na camada superior do solo (Figura 37a).

Foram coletadas 540 larvas de coleópteros ( $\approx 260$ indivíduos $/ \mathrm{m}^{2} /$ mês). Ao longo do ano, a maior abundância ocorreu no início do período não inundado ( $\approx 452$ indivíduos $/ \mathrm{m}^{2}$, agosto/1987). O número de larvas foi maior que - número de adultos no início do período não inundado' e diminuiu gradativamente no final (Figura 37b).

Com relação à distribuição vertical, as larvas foram mais abundantes na primeira camada do solo com 71,1\% 
do total capturado $\left(\approx 1.848\right.$ individuos $/ \mathrm{m}^{2}$ ) (Apêndices $34 \mathrm{e}$ 37). Somente no mês de dezembro/1987, a abundância das larvas foi maior na segunda do que na primeira camada do solo (Figura 38).

No que diz respeito às estações do ano, as larvas foram mais abundantes durante o período menos chuvoso $\left(\approx 307\right.$ individuos $\left./ \mathrm{m}^{2} / \mathrm{mês}\right)$ do que no periodo chuvoso ( $\approx 229$ individuos $/ \mathrm{m}^{2} / \mathrm{mês}$ ).

Foram obtidas correlações significativas entre a distribuição vertical no solo e os fatores abióticos locais (temperatura, pH e umidade do solo) com larvas e adultos (captura total de coleópteros) e com as familias Carabidae, Staphylinidae e Pselaphidae durante o mês de março/1988. Para os carabideos adultos, por exemplo, foram obtidos resultados significativos durante o período de fevereiro a maio/1988, enquanto que para as larvas foi durante o período de setembro a novembro/1987 e de janeiro a março/1988 (Apêndice 3).

\subsubsection{Captura no folhedo com fotoeclectores de solo}

Dentre os coleópteros (adultos) capturados no folhedo $(n=6.105), 89,3 \%$ foram identificados a nível de familia, e as mais abundantes foram: staphylinidae, com $41,2 \%$ do total de coleópteros capturados ( $\approx 630$ individuos $\left./ \mathrm{m}^{2}\right)$; Carabidae, $\operatorname{com} 15,7 \%\left(\approx 240\right.$ individuos $\left./ \mathrm{m}^{2}\right)$ e Pselaphidae, $\operatorname{com} 8,3 \%\left(\approx 127\right.$ individuos $\left./ \mathrm{m}^{2}\right)$. Os $24,2 \%$ dos individuos restantes ( $\approx 367$ individuos $/ \mathrm{m}^{2}$ ) foram representados por Chrysomelidae, Curculionidae, Scolytidae, Hydrophilidae, Scydmaenidae, Ptiliidae, Nitidulidae, Elateridae, Scarabaeidae, Psephenidae, Cerambycidae, Brentidae, Phengodidae, Endomychidae e Cicindelidae (Apêndice 38 ).

Durante a estação menos chuvosa a abundância média foi de $\approx 187$ indivíduos $/ \mathrm{m}^{2} /$ mês $e$, a abundância máxima 
foi observada em agosto/1987 com $\approx 443$ indivíduos $/ \mathrm{m}^{2}(29,1 \%$ da captura total). Durante a estação menos chuvosa, a abundância média foi menor ( $\approx 130$ indivíduos $\left./ \mathrm{m}^{2} / \mathrm{mês}\right)$, com a abundância máxima observada em maio $\left(\approx 352\right.$ indivíduos $/ \mathrm{m}^{2}$; $23,1 \%$ da captura total) (Apêndice 38).

No que diz respeito ao nível trófico do total dos coleópteros (adultos) capturados, os predadores foram dominantes ( $\approx 90$ indivíduos $/ \mathrm{m}^{2} / \mathrm{mês}$ ), seguidos por fungívoros ( $\approx 22$ indivíduos $/ \mathrm{m}^{2} / \mathrm{mês}$ ), herbívoros ( $\approx 19$ indivíduos $/ \mathrm{m}^{2} / \mathrm{mês}$ ) e necrófagos ( $\approx 5$ indivíduos $/ \mathrm{m}^{2} / \mathrm{mês;} \mathrm{Tabela} 2$ ). Durante a estação menos chuvoosa a abundância dos predadores foi $\approx 115$ indivíduos $/ \mathrm{m}^{2} / \mathrm{mês;}$ herbivoros, $\approx 28$ indivíduos $/ \mathrm{m}^{2} / \mathrm{mês}$; fungivoros, $\approx 21$ individuos $/ \mathrm{m}^{2} / \mathrm{mês} e$, necrófagos, $\approx 12$ indivíduos $/ \mathrm{m}^{2} / \mathrm{mês}$. Na estação chuvoṣa os predadores também foram dominantes, com $\approx 73$ indivíduos $/ \mathrm{m}^{2} /$ mês; seguidos pelos fungívoros, com $\approx 22$ individuos $/ \mathrm{m}^{2} / \mathrm{mês;} \mathrm{herbivoros,} \mathrm{com} \mathrm{\approx 14}$ indivíduos $/ \mathrm{m}^{2} / \mathrm{mês}$ ) $e$, necrófagos com $\approx 0,1$ indivíduos $/ \mathrm{m}^{2} / \mathrm{mês}$ (Tabela 2). As larvas de coleópteros capturadas no folhedo, apresentaram uma abundância média maior durante a estação menos chuvosa, com $\approx 98$ indivíduos $/ \mathrm{m}^{2} / \mathrm{mês}$ e $\approx 6$ indivíduos $/ \mathrm{m}^{2} / \mathrm{mês}$ na estação chuvosa.

\subsubsection{Captura nos troncos com fotoeclectores de árvore} BEt e BE $\downarrow$

Em fotoeclectores direcionados para cima ( $B E \uparrow)$, foram capturados 303 coleópteros (adultos), dos quais $88,4 \%$ foram identificados a nível de família, sendo as mais freqüentes: Scolytidae $(43,6 \%)$, Curculionidae $(16,8 \%)$ e Staphylinidae $(6,6 \%)$. Os $21,4 \%$ restantes foram representados pelas familias: Carabidae, Chrysomelidae, Scydmaenidae, Ptiliidae, Pselaphidae, Cerambycidae, Elateridae, Brentidae, Scarabaeidae e Lampyridae (Apêndice 
7)

Com referência aos niveis tróficos,

predominaram os fungívoros $(n=144)$, seguidos pelos herbivoros $(n=73)$ e predadores $(n=50)$. A maior densidade de atividade ocorreu durante a época chuvosa com uma média de 39 indivíduos/mês, enquanto que na época menos chuvosa capturaram-se uma média de 12 indivíduos/mês. Na estação chuvosa os fungívoros $(n=142)$ foram mais freqüentes, seguidos pelos predadores $(n=41)$ e herbívoros $(n=25)$, enquanto que na estação menos chuvosa predominaram os herbivoros ( $n=48)$, seguidos pelos predadores $(n=9)$ e fungívoros $(n=2)$ ( Tabela 3 ). Ao longo do ano, o período de maior captura ocorreu em março/1988 com $36,3 \%$ do total.

$\mathrm{Na}$ captura com fotoeclector direcionado para baixo ( $B E \downarrow)$, coletaram-se um total de 641 indivíduos. As 10 famílias identificadas representaram $84,4 \%$ da captura, sendo as mais freqüentes: Carabidae, $\operatorname{com} 46,6 \%$ do total coletado; Staphylinidae, com $12,8 \%$ e Ptiliidae com $5,6 \%$ Os $19,4 \%$ restantes foram representados pelas familias: Pselaphidae, Scolytidae, Scarabaeidae, Curculionidae, scydmaenidae, Brentidae e Cerambycidae (Apêndice 40).

Com relação aos níveis tróficos, o grupo mais freqüente foi $\circ$ dos predadores $(n=391)$, seguido pelos fungívoros $(n=106)$ e herbívoros $(n=42)$. Esta freqüência foi semelhante nas duas estações, durante todo o período de coleta. Com relação às estações anuais, os coleópteros foram capturados em maior número durante a estação menos chuvosa com uma média de 73 indivíduos/mês (Tabela 4). Na época chuvosa capturaram-se em média 34 indivíduos/mês. Os meses com maior densidade de atividade foram julho e agosto/1987.

As famílias capturadas em maior número, com os diversos tipos de armadilhas, foram represertadas em figuras separadas: Staphylinidae (Figura 39); Carabidae 
(Figura 40a); Pselaphidae (Figura 40b); Chrysomelidae (Figura 41a); Scolytidae (Figura 41b); Curculionidae (Figura 42a); Ptiliidae (Figura 42b) e Scydmaenidae (Figura 43). 


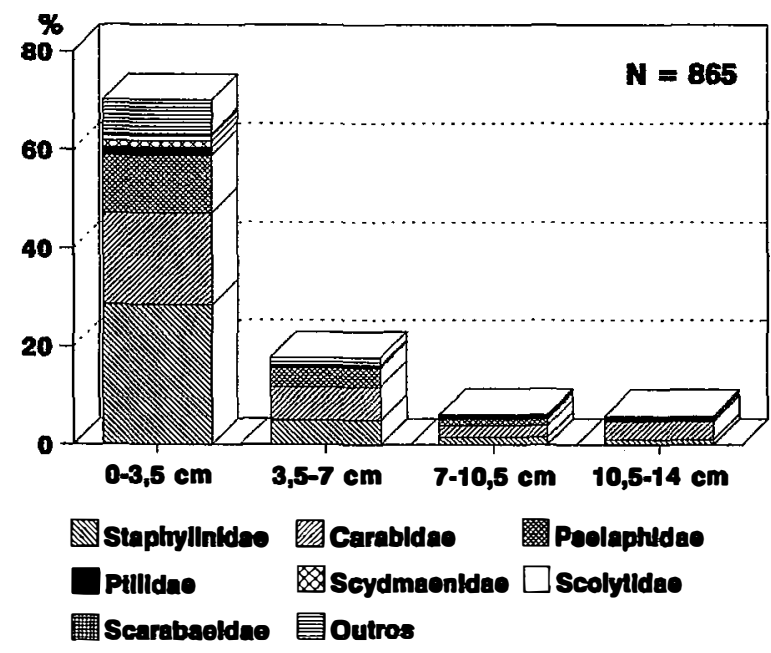

A

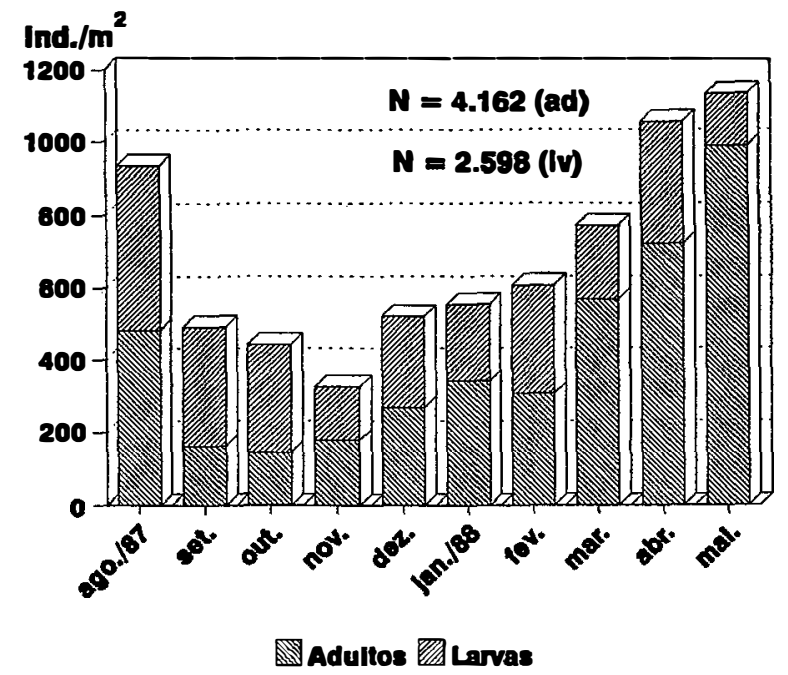

B

Figura 37A, B - Abundância vertical de Coleoptera adultos (famílias) e captura mensal de adultos e larvas, no solo, na floresta inundada por água mista, no período de agosto/1987 a maio/1988. Coleta com o método de Kempson. $\mathrm{A}=$ Abundância vertical $. \mathrm{B}=$ Captura mensal de adultos e larvas. 


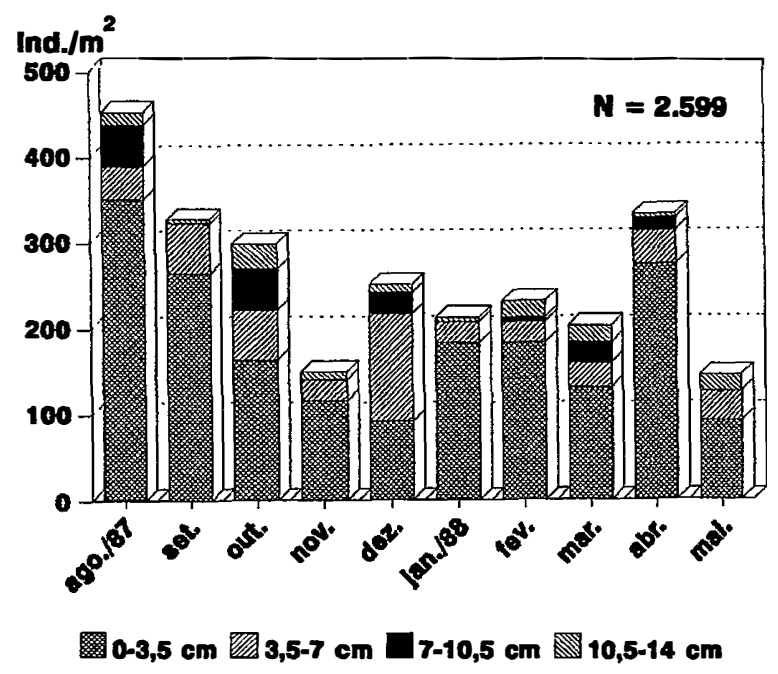

Figura 38 - Abundância vertical de larvas de Coleoptera, no solo, na floresta inundada por água mista, no período de agosto/1987 a maio/1988. $\mathrm{K}=$ método de Kempson; $\mathrm{E}=$ fotoeclecotres de solo; $\mathrm{BE} \uparrow=$ fotoeclector de árvore direcionado para cima. BE $\downarrow$ = fotoeclector de árvore direcionado para baixo.

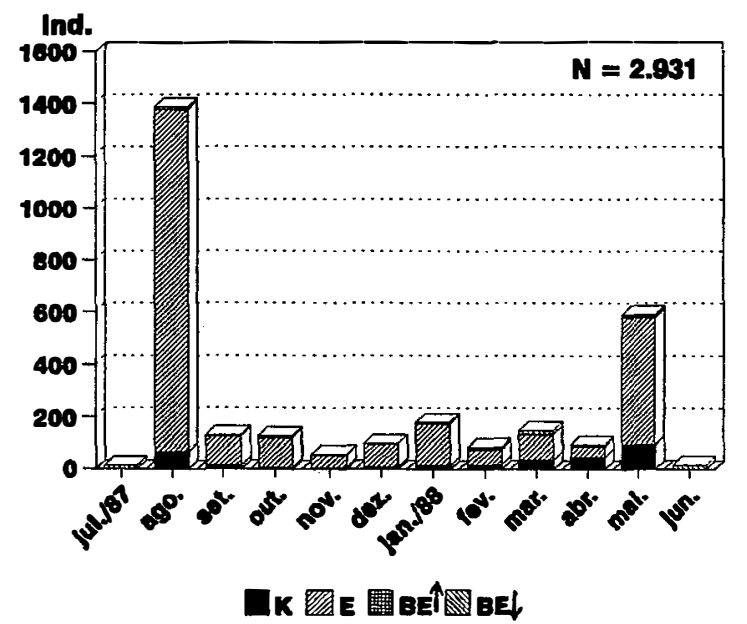

Figura 39 - Captura mensal de Staphylinidae (Coleoptera), nos diferentes tipos de armadilhas, na floresta inundada por água mista, no período de julho/1987 a junho/1988. $\mathrm{K}=$ método de Kempson; $\mathrm{E}=$ fotoeclectores de solo; $\mathrm{BE} \uparrow=$ fotoeclector de árvore direcionado para cima. $\mathrm{BE} \downarrow=$ fotoeclector de árvore direcionado para baixo. 


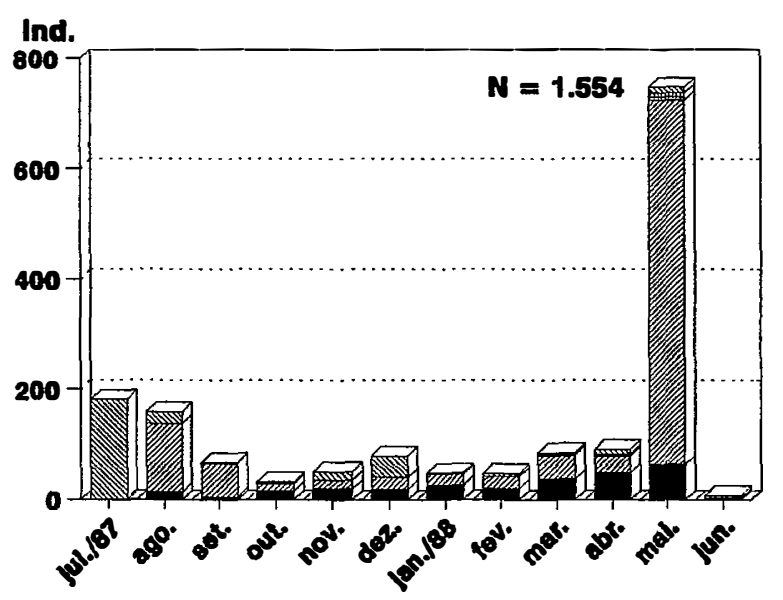

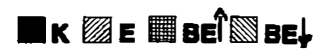

A

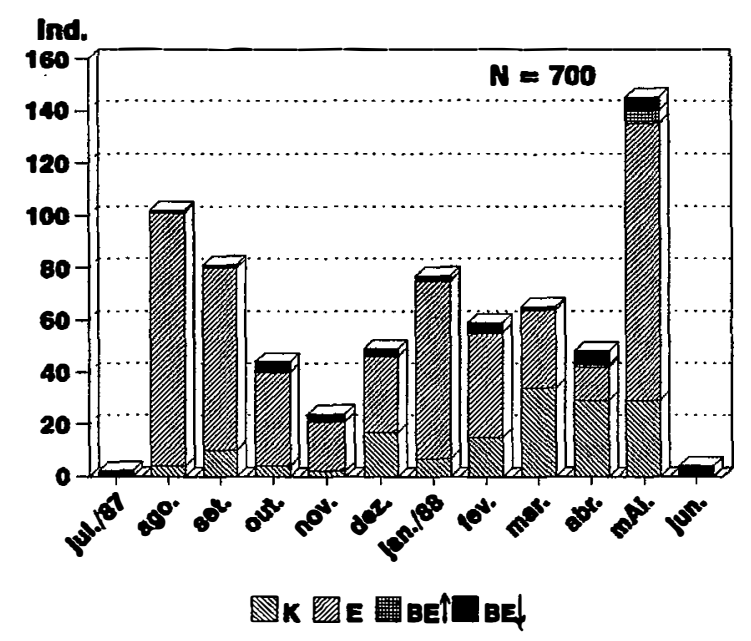

B

Figura 40A, B - Captura mensal de Carabidae e Pselaphidae (Coleoptera), nos diferentes tipos de armadilhas, na floresta inundada por água mista, no período de julho/1987 a junho/1988. $\mathrm{K}=$ método de Kempson; $\mathrm{E}=$ fotoeclectores de solo; $B E \uparrow=$ fotoeclector de árvore direcionado para cima e $\mathrm{BE} \downarrow$ = fotoeclector de árvore direcionado para baixo. $\mathrm{A}=$ Carabidae. $\mathrm{B}=$ Pselaphidae. 


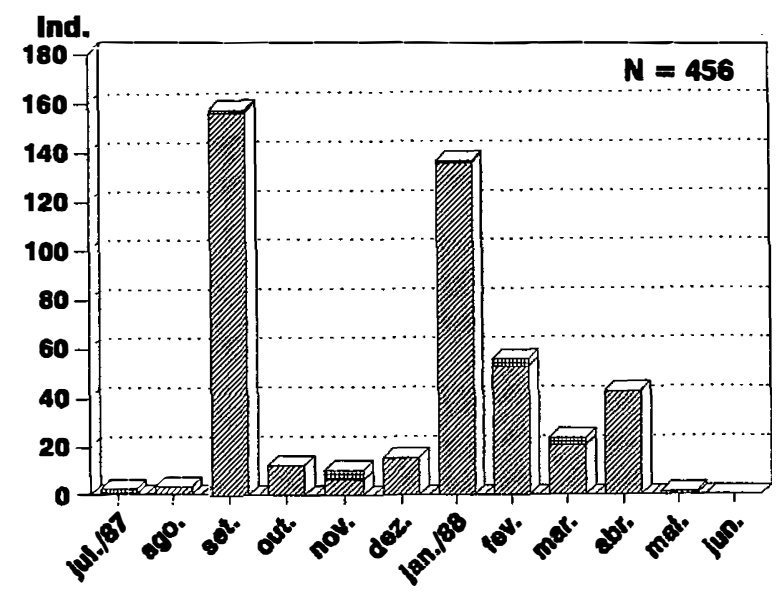

DK Y

A

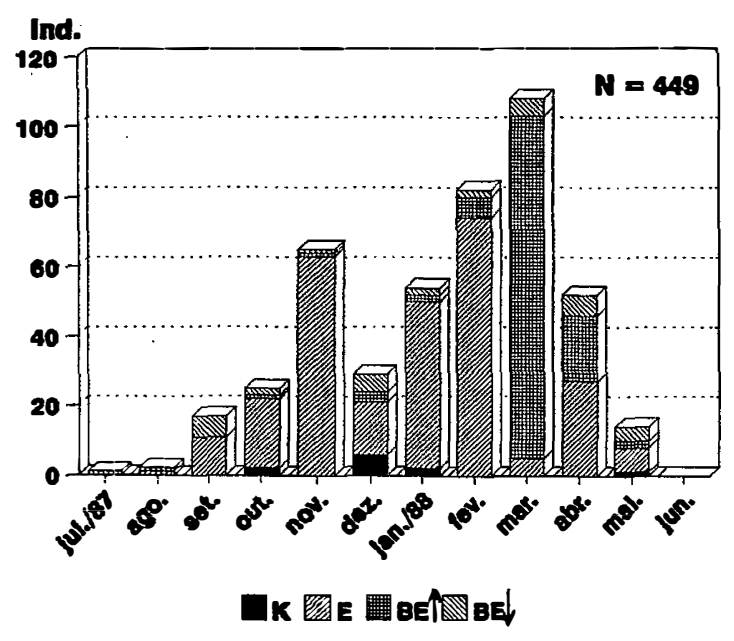

B

Figura 41A, B - Captura mensal de Chrysomelidae e Scolytidae (Coleoptera), nos diferentes tipos de armadilhas, na floresta inundada por água mista, no período de julho/1987 a junho/1988. $\mathrm{K}=$ método de Kempson; $\mathrm{E}$ = fotoeclectores de solo; $\mathrm{BE} \uparrow=$ fotoeclector de árvore direcionado para cima e $\mathrm{BE} \downarrow$ = fotoeclector de árvore direcionado para baixo. $\mathrm{A}=$ Chrysomelidae. $\mathrm{B}=$ Scolytidae. 


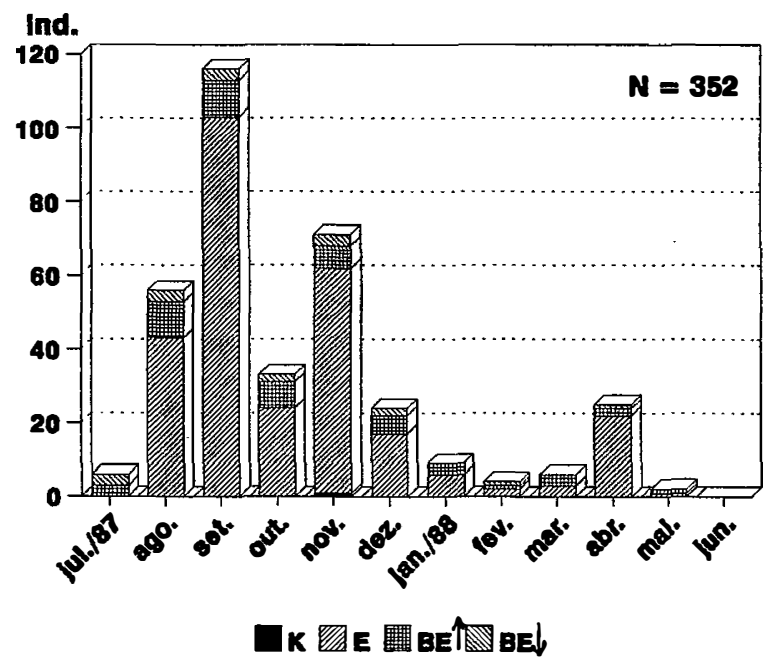

A

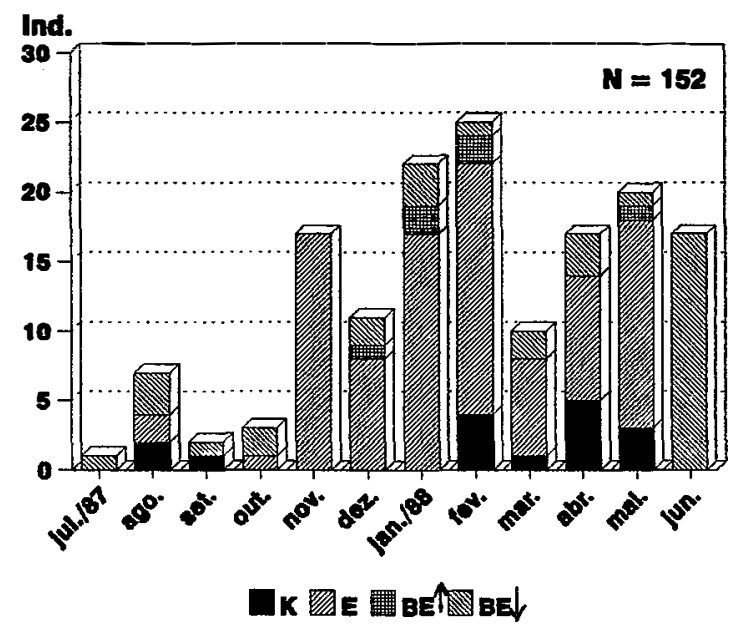

B

Figura 42A, B - Captura mensal de Curculionidae e Ptiliidae (Coleoptera), nos diferentes tipos de armadilhas, na floresta inundada por água mista, no período de julho/1987 a junho/1988. $\mathrm{K}=$ método do Kempson; $\mathrm{E}=$ fotoeclectores de solo; $\mathrm{BE} \uparrow=$ fotoeclector de árvore direcionado para cima e $\mathrm{BE} \downarrow$ = fotoeclector de árvore direcionado para baixo. $\mathrm{A}=$ Curculionidae. $\mathrm{B}=$ Ptiliidae. 


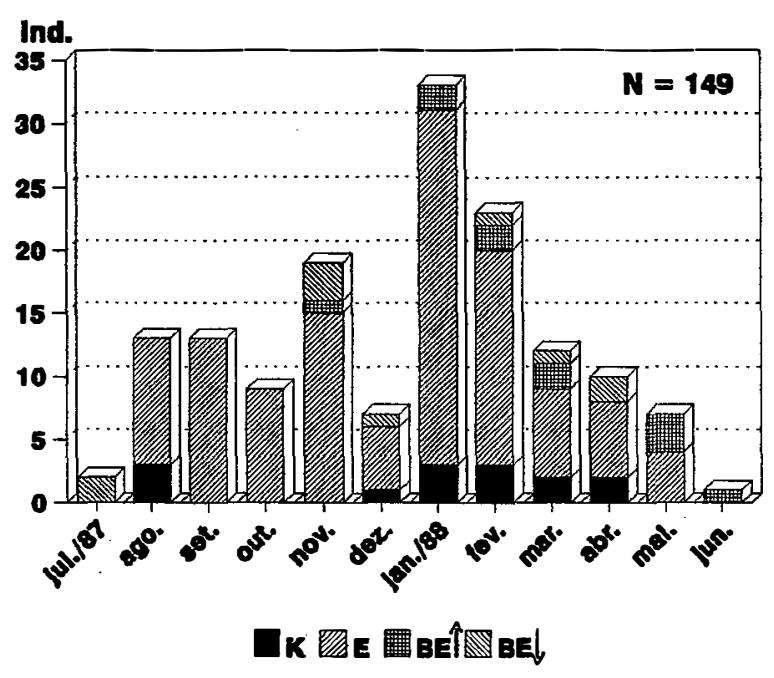

Figura 43 - Captura mensal de Scydmaenidae (Coleoptera), nos diferentes tipos de armadilhas, na floresta inundada por água mista, no período de julho/1987 a junho/1988. $\mathrm{K}=$ método de Kempson; $\mathbf{E}=$ fotoeclectores de solo; $\mathrm{BE} \uparrow=$ fotoeclector de árvore direcionado para cima e $\mathrm{BE} \downarrow$ = fotoeclector de árvore direcionado para baixo. 
Tabela 01 - Captura de Coleoptera (famílias) por estações sazonais e classificação em níveis tróficos, de 0 a $14 \mathrm{~cm}$ de profundidade no solo, no período de agosto/1987 a maio/1988, na floresta inundada do Lago Janauari (número total de captura, abundância (individuos $/ \mathrm{m}^{2} / \mathrm{mês}$ ), percentagem $(\%)$, média e desvio padrão (S)) . Est. 1 = estação menos chuvosa. Est. 2 = estação chuvosa.

\begin{tabular}{|c|c|c|c|c|c|c|c|}
\hline Grupos Tróficos & Est.1 & Est.2 & Total & $\%$ & Ind./m²/mês & Média & $\mathrm{S}$ \\
\hline \multicolumn{8}{|l|}{ 1- HERBIVOROS } \\
\hline Curculionidae & 1 & 0 & 1 & 0,1 & 0,5 & 0,1 & 0,3 \\
\hline Scarabaeidae & 1 & 5 & 6 & 0,7 & 2,9 & 0,6 & 1,1 \\
\hline Subtotal & 2 & 5 & 7 & 100,0 & 3,4 & & \\
\hline$\%$ & 28,6 & 71,4 & & & & & \\
\hline Ind. $/ \mathrm{m}^{2} / \mathrm{mês}$ & 2,4 & 4,0 & & & & & \\
\hline \multicolumn{8}{|l|}{ 2- FUNGIVOROS } \\
\hline Pselaphidae & 20 & 131 & 151 & 17,5 & 72,7 & 15,1 & 11,8 \\
\hline Ptiliidae & 3 & 13 & 16 & 1,8 & 7,7 & 1,6 & 1,8 \\
\hline Scolytidae & 2 & 9 & 11 & 1,3 & 5,3 & 1,1 & 1,9 \\
\hline Subtotal & 25 & 153 & 178 & 100,0 & 85,6 & & \\
\hline$\%$ & 14,0 & 86,0 & & & & & \\
\hline Ind./m²/mês & 30,1 & 122,7 & & & & & \\
\hline \multicolumn{8}{|l|}{ 3- PREDADORES } \\
\hline Carabidae & 57 & 219 & 276 & 31,9 & 132,8 & 27,6 & 17,9 \\
\hline Staphylinidae & 91 & 220 & 311 & 36,0 & 149,6 & 31,1 & 30,5 \\
\hline Scydmaenidae & 3 & 11 & 14 & 1,6 & 6,7 & 1,4 & 1,3 \\
\hline Subtotal & 151 & 450 & 601 & 100,0 & 289,2 & & \\
\hline$\%$ & 25,1 & 74,9 & & & & & \\
\hline Ind./m²/mês & 181,6 & 360,9 & & & & & \\
\hline Indeterminados & 23,0 & 56,0 & 79,0 & 9,1 & 38,0 & 7,9 & 5,2 \\
\hline Total (1)+(2)+(3) & 201 & 664 & 865 & 100,0 & 416,2 & 86,5 & 57,1 \\
\hline$\%$ & 23,2 & 76,8 & & & & & \\
\hline Ind./ $/ \mathrm{m}^{2} / \mathrm{mês}$ & 241,8 & 532,5 & & & & & \\
\hline
\end{tabular}


Tabela 02 - Captura de Coleoptera (famílias) no folhedo, por estações sazonais e classificação em niveis tróficos, no período de agosto/1987 a maio/1988, na floresta inundada do Lago Janauari (número total de captura, abundância (individuos $/ \mathrm{m}^{2} / \mathrm{mês}$ ), percentagem $(\%)$, média $e$ desvio padrão (S)). Est.1 = estação menos chuvosa. Est. 2 = estação chuvosa.

\begin{tabular}{|c|c|c|c|c|c|c|c|}
\hline Grupos Tróficos & Est.1 & Est.2 & Total & $\%$ & Ind. $/ \mathrm{m}^{2} / \mathrm{mês}$ & Média & $s$ \\
\hline \multicolumn{8}{|l|}{ 1- HERBIVOROS } \\
\hline Cerambycidae & 2 & 2 & 4 & 0,1 & 0,1 & 0,4 & 0,7 \\
\hline Chrysomelidae & 177 & 265 & 442 & 7,2 & 11,0 & 44,2 & 56,1 \\
\hline Curculionidae & 231 & 51 & 282 & 4,6 & 7,0 & 28,2 & 32,7 \\
\hline Elateridae & 21 & 7 & 28 & 0,5 & 0,7 & 2,8 & 3,8 \\
\hline Scarabaeidae & 16 & 8 & 24 & 0,4 & 0,6 & 2,4 & 2,0 \\
\hline Subtotal & 447 & 333 & 780 & 100,0 & 19,5 & & \\
\hline$\%$ & 57,3 & 42,7 & & & & & \\
\hline Ind. $/ \mathrm{m}^{2} / \mathrm{mês}$ & 27,9 & 13,8 & & & & & \\
\hline \multicolumn{8}{|l|}{ 2- NECROFAGOS } \\
\hline Hydrophilidae & 146 & $\mathbf{0}$ & 146 & 2,4 & 3,6 & 14,6 & 46,2 \\
\hline Nitidulidae & 40 & 3 & 43 & 0,7 & 1,1 & 4,3 & 10,2 \\
\hline Subtotal & 186 & 3 & 189 & 100,0 & 4,7 & & \\
\hline$\%$ & 98,0 & 2,0 & & & & & \\
\hline Ind./m²/mês & 11,6 & 0,1 & & & & & \\
\hline \multicolumn{8}{|l|}{ 3- FUNGIVOROS } \\
\hline Endomychidae & 1 & 0 & 1 & $<0,1$ & 0,0 & 0,1 & 0,3 \\
\hline Pselaphidae & 222 & 286 & 508 & 8,3 & 12,7 & 50,8 & 32,5 \\
\hline Ptillidae & 20 & 74 & 94 & 1,5 & 2,3 & 9,4 & 7,0 \\
\hline Scolytidae & 95 & 176 & 271 & 4,4 & 6,8 & 27,1 & 25,7 \\
\hline Subtotal & 338 & 536 & 874 & 100,0 & 21,8 & & \\
\hline$\%$ & 38,7 & 61,3 & & & & & \\
\hline Ind./m²/mês & 21,1 & 22,3 & & & & & \\
\hline \multicolumn{8}{|l|}{ 4- PREDADORES } \\
\hline Carabidae & 213 & 748 & 961 & 15,7 & 24,0 & 96,1 & $>150$ \\
\hline Cicindelidae & 1 & 0 & 1 & $<0,1$ & 0,0 & 0,1 & 0,3 \\
\hline Phengodidae & 0 & 2 & 2 & $<0,1$ & 0,0 & 0,2 & 0,4 \\
\hline Scydmaenidae & 47 & 67 & 114 & 1,9 & 2,8 & 11,4 & 7,3 \\
\hline Staphylinidae & 1587 & 931 & 2518 & 41,2 & 62,9 & 251,8 & $>150$ \\
\hline Subtotal & 1848 & 1748 & 3596 & 100,0 & 89,8 & & \\
\hline$\%$ & 51,4 & 48,6 & & & & & \\
\hline Ind./ $/ \mathrm{m}^{2} / \mathrm{mês}$ & 115,5 & 72,8 & & & & & \\
\hline \multicolumn{8}{|l|}{ 5- OUTROS } \\
\hline Psephenidae & 0 & 15 & 15 & 0,2 & 0,4 & 1,5 & 4,7 \\
\hline Brentidae & 2 & 0 & 2 & $<0,1$ & 0,0 & 0,2 & 0,4 \\
\hline Subtotal & 2 & 15 & 17 & 100,0 & 0,4 & & \\
\hline$\%$ & 11,8 & 88,2 & & & & & \\
\hline Ind. $/ \mathrm{m}^{2} / \mathrm{mês}$ & 0,1 & 0,6 & & & & & \\
\hline Indeterminados & 168 & 481 & 649 & 10,6 & 162,3 & 64,9 & 44,2 \\
\hline Total $(1)+(2)+(3)+(4$ & 2989,0 & 3116,0 & 6105,0 & 100,0 & 1526,3 & 610,0 & $>150$ \\
\hline$\%$ & 490 & 51,0 & 100,0 & & & & \\
\hline Ind./m²/mês & 186,8 & 129,8 & & & & & \\
\hline
\end{tabular}


Tabela 03 - Captura de Coleoptera (famílias) em fotoeclector direcionado para cima (BE $\uparrow$ ) por estações sazonais e classificação em niveis tróficos, no periodo de julho/1987 a junho/1988, na floresta inundada do Lago Janauari (número total de captura, percentagem (\%), média e desvio padrão (S)). Est.1 = estação menos chuvosa. Est. 2 = estação chuvosa.

\begin{tabular}{|c|c|c|c|c|c|c|}
\hline Grupos Tróficos & Est. 1 & Est. 2 & Total & $\%$ & Média & $\mathbf{S}$ \\
\hline \multicolumn{7}{|l|}{ 1- HERBIVOROS } \\
\hline Cerambycidae & 1 & 3 & 4 & 1,3 & 0,3 & 0,5 \\
\hline Chrysomelidae & 7 & 7 & 14 & 4,6 & 1,2 & 1,5 \\
\hline Curculionidae & 36 & 15 & 51 & 16,8 & 4,3 & 3,4 \\
\hline Elateridae & 3 & 0 & 3 & 1,0 & 0,3 & 0,6 \\
\hline Scarabaeidae & 1 & 0 & 1 & 0,3 & $<0,1$ & 0,3 \\
\hline Subtotal & 48 & 25 & 73 & & & \\
\hline$\%$ & 65,8 & 34,2 & & & & \\
\hline \multicolumn{7}{|l|}{ 2- FUNGIVOROS } \\
\hline Pselaphidae & 0 . & 6 & 6 & 2,0 & 0,5 & 1,4 \\
\hline Ptiliidae & 0 & 6 & 6 & $\quad 2,0$ & 0,5 & 0,8 \\
\hline Scolytidae & 2 & 130 & 132 & 43,6 & 11,0 & 27,9 \\
\hline Subtotal & 2 & 142 & 144 & & & \\
\hline$\%$ & 1,4 & 98,6 & & & & \\
\hline \multicolumn{7}{|l|}{ 3- PREDADORES } \\
\hline Carabidae & 4 & 14 & 18 & 6,0 & 1,5 & 3,7 \\
\hline Lampyridae & 0 & 1 & 1 & 0,3 & $<0,1$ & 0,3 \\
\hline Scydmaenidae & 2 & 9 & 11 & 3,6 & 0,9 & 1,1 \\
\hline Staphylinidae & 3 & 17 & 20 & 6,6 & 1,7 & 2,4 \\
\hline Subtotal & 9 & 41 & 50 & & & \\
\hline$\%$ & 18,0 & 82,0 & & & & \\
\hline \multicolumn{7}{|l|}{ 4- OUTROS } \\
\hline Brentidae & 1 & 0 & 1 & 0,3 & $<0,1$ & 0,3 \\
\hline Subtotal & 1 & 0 & 1 & & & \\
\hline$\%$ & 100,0 & 0,0 & & & & \\
\hline Indeterminados & 11 & 24 & 35 & 11,6 & 2,9 & 2,2 \\
\hline Total $(1)+(2)+1$ & 71 & 232 & 303 & 100,0 & 25,5 & 28,0 \\
\hline$\%$ & 23,4 & 76,6 & 100,0 & & & \\
\hline
\end{tabular}


Tabela 04 - Captura de Coleoptera (famílias) em fotoeclector direcionado para baixo (BE $\downarrow$ ), por estações sazonais e classificação em níveis tróficos, no periodo de julho/1987 a junho/1988, na floresta inundada do Lago Janauari (número total de captura, percentagem (\%), média e desvio padrão (S)). Est. I = estação menos chuvosa. Est. 2 = estação chuvosa.

\begin{tabular}{|c|c|c|c|c|c|c|}
\hline Grupos Tróficos & Est. 1 & Est.2 & Total & $\%$ & Média & $\mathrm{S}$ \\
\hline \multicolumn{7}{|l|}{ 1- HERBIVOROS } \\
\hline Cerambycidae & 1 & 0 & 1 & 0,2 & $<0,1$ & 0,3 \\
\hline Curculionidae & 14 & 4 & 18 & 2,8 & 1,5 & 1,3 \\
\hline Scarabaeidae & 12 & 11 & 23 & 3,6 & 1,9 & 3,0 \\
\hline Subtotal & 27 & 15 & 42 & & & \\
\hline$\%$ & 64,3 & 35,7 & & & & \\
\hline \multicolumn{7}{|l|}{ 2- FUNGIVOROS } \\
\hline Pselaphidae & 15 & 20 & 35 & 5,5 & 2,9 & 1,5 \\
\hline Ptiliidae & 24 & 12 & 36 & 5,6 & 3,0 & 4,5 \\
\hline Scolytidae & 11 & 24 & 35 & 5,5 & 2,9 & 2,2 \\
\hline Subtotal & 50 & 56 & 106 & & & \\
\hline$\%$ & 47,2 & 52,8 & & & & \\
\hline \multicolumn{7}{|l|}{ 3- PREDADORES } \\
\hline Carabidae & 229 & 70 & 299 & 46,6 & 24,9 & 50,3 \\
\hline Scydmaenidae & 5 & 5 & 10 & 1,5 & 0,8 & 1,0 \\
\hline Staphylinidae & 52 & 30 & 82 & 12,8 & 6,8 & 4,9 \\
\hline Subtotal & 286 & 105 & 391 & & & \\
\hline$\%$ & 73,1 & 26,9 & & & & \\
\hline \multicolumn{7}{|l|}{ 4- OUTROS } \\
\hline Brentidae & 2 & 0 & 2 & & 0,2 & 0,4 \\
\hline$\%$ & 100,0 & 0,0 & & & & \\
\hline Indeterminados & 74 & 26 & 100 & 15,6 & 8,3 & 7,8 \\
\hline Total $(1)+(2)+1$ & 439 & 202 & 641 & 100,0 & 53,4 & 52,1 \\
\hline$\%$ & 68,5 & 31,5 & 100,0 & & & \\
\hline
\end{tabular}


4.7 RESULTADO GERAL A NÍVEL DE GRANDES GRUPOS

CAPTURADOS, NO SOLO, NO FOLHEDO E NOS TRONCOS.

Foram capturados 111.921 Arthropoda na floresta inundada por água mista, sendo que, 14,5\% foram coletados com 0 aparelho de extração Kempson, 63,7\% com fotoeclectores de solo, 15,9\% com fotoeclectores de árvores $\mathrm{BE} \uparrow$ e 5,9 \% com fotoeclectores BE $\downarrow$. (Apêndices $41,46,47$ e 48 ).

4.7.1 Captura no solo com método de Kempson

Foram capturados um total de 16.189 artrópodos, classificados em 25 grupos e os mais abundantes foram: Formicidae com $23,9 \%$ do total capturado ( $\approx 18.627$ individuos $\left./ \mathrm{m}^{2}\right)$, seguido por symphyla, 14,3\% ( 11.120 indivíduos $\left./ \mathrm{m}^{2}\right)$, Diplopoda $13,5 \%$ ( $\approx 10.529$ indivíduos $\left./ \mathrm{m}^{2}\right)$, Araneae $8,6 \%\left(\approx 6.698\right.$ individuos $\left./ \mathrm{m}^{2}\right)$, Japygidae $5,5 \%(\approx 4.283$ individuos $\left./ \mathrm{m}^{2}\right), \quad$ Coleoptera (adultos) $5,3 \%(\approx 4.162$ individuos $\left./ \mathrm{m}^{2}\right)$, Pauropoda $5,0 \%\left(\approx 3.898\right.$ individuos $\left./ \mathrm{m}^{2}\right)$, Coccoidea (ninfas) $5,0 \%\left(\approx 3.869\right.$ individuos $\left./ \mathrm{m}^{2}\right)$, Coleoptera (larvas) $3,3 \%\left(\approx 2.598\right.$ indivíduos $\left./ \mathrm{m}^{2}\right)$, Isoptera com $2,9 \%$ $\left(\approx 2.233\right.$ indivíduos $\left./ \mathrm{m}^{2}\right)$ e $12,7 \%$ foi representado por outros grupos menos abundantes (Apêndice 41 ). Os principais grupos de artrópodos capturados no solo foram representados (Figura 44). O período de maior abundância, no solo, ocorreu duas semanas antes da inundação (maio/1988) com $14,7 \%$ do total capturado $\left(\approx 11.472\right.$ indivíduos $\left./ \mathrm{m}^{2}\right)$, enquanto que, a menor abundância ocorreu no início do período não inundado com $4,6 \%\left(\approx 3.585\right.$ indivíduos $\left./ \mathrm{m}^{2}\right)$. Com relação às estações anuais, a abundância média mensal dos artrópodos no solo, de 0 a 14 cm de profundidade, foi maior durante a estação chuvosa (de 
dezembro/1987 a maio/1988, $\approx 9.732$ indivíduos $/ \mathrm{m}^{2} / \mathrm{mês}$ ), do que durante a estação menos chuvosa (de agosto a novembro/1987, $\approx 4.877$ indivíduos $/ \mathrm{m}^{2} /$ mês) (Apêndice 41 ).

Com relação a distribuição vertical, 60,2\% dos artrópodos foram capturados na primeira camada do solo, $23,5 \%$ na segunda camada, $9,8 \%$ na terceira camada e 6,5\% foi capturado na quarta camada do solo (Figura 45).

Na primeira camada capturaram-se um total de 9.752 Arthropoda, sendo que o grupo mais abundante foi Formicidae com $32,0 \%$ do total capturado $(\approx 15.023$ indivíduos $\left./ \mathrm{m}^{2}\right)$, seguido por Diplopoda com $14,6 \%$ ( $\approx 6.871$ indivíduos $\left./ \mathrm{m}^{2}\right)$, symphyla $10,1 \%\left(\approx 4.730\right.$ individuos $\left./ \mathrm{m}^{2}\right)$, Coleoptera (adultos) $6,2 \%\left(\approx 2.926\right.$ individuos $\left./ \mathrm{m}^{2}\right)$, Araneae $5,7 \%\left(\approx 2.695\right.$ indivíduos $\left./ \mathrm{m}^{2}\right)$, coleoptera (larvas) $3,9 \%$ $\left(\approx 1.848\right.$ individuos $\left./ \mathrm{m}^{2}\right)$, Pauropoda $3,6 \%$ ( $\approx 1.699$ individuos $\left./ \mathrm{m}^{2}\right)$, Isoptera $3,6 \div\left(\approx 1.675\right.$ individuos $\left./ \mathrm{m}^{2}\right)$, Diptera (larvas) $3,2 \%\left(\approx 1.501\right.$ indivíduos $\left./ \mathrm{m}^{2}\right)$, Japygidae $3,2 \%\left(\approx 1.496\right.$ indivíduos $\left./ \mathrm{m}^{2}\right)$ e $13,9 \%$ foi representado por outros grupos menos abundantes (Apêndice 42 ). Ao longo do ano a maior abundância ocorreu em maio/1988, duas semanas antes da inundação, com $17,8 \%$ do total coletado ( $\approx 8.354$ indivíduos $\left./ \mathrm{m}^{2}\right)$, enquanto que o período de menor abundância ocorreu em novembro/1887 com $4,2 \%$ ( $\approx 1.987$ indivíduos $\left./ \mathrm{m}^{2}\right)$. Com relação as estações anuais a abundância média mensal dos artrópodos, na primeira camada do solo, foi maior durante a estação chuvosa ( $\approx 9.205$ individuos $/ \mathrm{m}^{2} / \mathrm{mês}$ ) do que na estação menos chuvosa ( $\approx 2.526$ indivíduos $/ \mathrm{m}^{2} / \mathrm{mês}$ ) (Apêndice 42 ).

$\mathrm{Na}$ segunda camada do solo, coletaram-se um total de 3.796 Arthropoda, sendo que o grupo mais abundante foi Symphyla com $24,0 \%$ do total capturado ( $\approx 4.379$ indivíduos $\left./ \mathrm{m}^{2}\right)$, Formicidae $13,1 \%\left(\approx 2.387\right.$ indivíduos $\left./ \mathrm{m}^{2}\right)$, Araneae $12,9 \%\left(\approx 2.363\right.$ indivíduos $\left./ \mathrm{m}^{2}\right)$, Diplopoda $11,6 \%$ $\left(\approx 2.127\right.$ indivíduos $\left./ \mathrm{m}^{2}\right)$, Coccoidea (ninfas) $7,8 \%(\approx 1.429$ 
individuos $\left./ \mathrm{m}^{2}\right)$, Japygidae $7,4 \div\left(\approx 1.362\right.$ individuos $\left./ \mathrm{m}^{2}\right)$, Pauropoda $6,9 \%\left(\approx 1.261\right.$ individuos $\left./ \mathrm{m}^{2}\right)$, Coleoptera (adultos) $4,1 \%\left(\approx 741\right.$ indivíduos $\left./ \mathrm{m}^{2}\right)$, Coleoptera (larvas) $2,5 \%(\approx 452$ individuos $\left./ \mathrm{m}^{2}\right)$, Pseudoscorpiones $1,7 \%\left(\approx 308\right.$ indivíduos $\left./ \mathrm{m}^{2}\right)$ e $8,0 \%$ foi representado por outros grupos menos abundantes (Apêndice 43). O período de maior captura ocorreu no início da estação chuvosa (dezembro/1987), com 23,0 \% do total capturado $\left(\approx 4.206\right.$ indivíduos $\left./ \mathrm{m}^{2}\right)$, enquanto que, a menor captura ocorreu durante o período menos chuvoso, em agosto/1987, com $2,3 \%$ do total capturado ( $\approx 414$ indivíduos $\left(\mathrm{m}^{2}\right)$. No que diz respeito as estações anuais a abundância média mensal, na segunda camada do solo, foi maior durante a estação chuvosa ( $\approx 2.235$ indivíduos $\left./ \mathrm{m}^{2} / \mathrm{mês}\right)$, do que na estação menos chuvosa $\left(\approx 1.214\right.$ indivíduos $/ \mathrm{m}^{2} / \mathrm{mês}$ ) (Apêndice 43).

Na terceira camada do solo, coletaram-se um total de 1.582 Arthropoda, sendo que a maior abundância foi de Symphyla com $16,4 \%$ do total capturado ' $\approx 1.251$ individuos $\left./ \mathrm{m}^{2}\right)$, seguido de Araneae $13,3 \%(\approx 1.010$ indivíduos $\left./ \mathrm{m}^{2}\right)$, Diplopoda $12,9 \%$ ( $\approx 986$ indivíduos $\left./ \mathrm{m}^{2}\right)$, Formicidae $10,8 \%$ ( $\approx 823$ individuos $\left./ \mathrm{m}^{2}\right)$, Japygidae $10,2 \%$ $\left(\approx 779\right.$ individuos $\left./ \mathrm{m}^{2}\right)$, Coccoidea (ninfas) $9,4 \%$ ( $\approx 717$ individuos $/ \mathrm{m}^{2}$, Isoptera $4,0 \%$ ( $\approx 303$ indivíduos $\left./ \mathrm{m}^{2}\right)$, Coleoptera (adultos) 3,3\%( 2250 individuos $\left./ \mathrm{m}^{2}\right)$, Psocoptera $2,3 \%\left(\approx 173\right.$ indivíduos $\left./ \mathrm{m}^{2}\right)$, Coleoptera (larvas) $2,1 \%$ ( 164 indivíduos $/ \mathrm{m}^{2}$ ) e $15,3 \%$ foi representado por outros grupos menos abundantes (Apêndice 44). Ao longo do ano a maior abundância ocorreu durante a estação chuvosa (janeíro/1988) com $17,4 \%$ do total capturado $\left(\approx 1.323\right.$ individuos $\left./ \mathrm{m}^{2}\right)$ e a menor abundância também ocorreu durante a estação chuvosa (abril/1988) com $7,2 \%$ do total capturado ( $\approx 549$ indivíduos $/ \mathrm{m}^{2}$ ). A abundância média mensal, na terceira camada do solo, foi semelhante na estação chuvosa ( $\approx 790$ 
indivíduos $\left./ \mathrm{m}^{2} / \mathrm{mês}\right)$, quando comparada com a estação menos chuvosa ( $\approx 721$ indivíduos $/ \mathrm{m}^{2} / \mathrm{mês}$ ) (Apêndice 44 ).

Na quarta camada do solo, coletaram-se um total de 1.059 Arthropoda. A maior abundância foi de Symphyla com $14,9 \%$ do total capturado $\left(\approx 760\right.$ indivíduos $\left./ \mathrm{m}^{2}\right)$ seguido por Japygidae $12,6 \%$ ( $\approx 645$ indivíduos $\left./ \mathrm{m}^{2}\right)$, Araneae $12,3 \%$ $\left(\approx 630\right.$ indivíduos $\left./ \mathrm{m}^{2}\right)$, Diplopoda $10,7 \%$ ( $\approx 544$ indivíduos $\left./ \mathrm{m}^{2}\right)$, Coccoidea (ninfas) $10,7 \%\left(\approx 544\right.$ indivíduos $\left./ \mathrm{m}^{2}\right)$, Pauropoda $8,2 \%\left(\approx 419\right.$ individuos $\left./ \mathrm{m}^{2}\right), \quad$ Formicidae $7,7 \%(\approx 395$ individuos $\left./ \mathrm{m}^{2}\right)$, Isoptera $3,8 \%$ ( $\approx 192$ individuos $\left./ \mathrm{m}^{2}\right)$, Coleoptera (larvas) $2,6 \%\left(\approx 135\right.$ indivíduos $\left./ \mathrm{m}^{2}\right)$, Coccoidea (adultos) $2,5 \%$ ( $\approx 125$ indivíduos $\left./ \mathrm{m}^{2}\right)$ e $14 \%$ foi representado por outros grupos menos abundantes (Apêndice 45). Ao longo do ano, o período de maior abundância ocorreu em janeiro/1988 com $18,8 \%\left(\approx 958\right.$ individuos $\left./ \mathrm{m}^{2}\right)$, enquanto que, a menor abundância ocorreu em agosto/1988 com $5,3 \%$ ( $\approx 269$ individuos $/ \mathrm{m}^{2}$ ). A abundância média mensal dos artrópodos, na quarta camada do solo, foi maior durante a estação chuvosa ( $\approx 573$ indivíduos $/ \mathrm{m}^{2} / \mathrm{mês}$ ) que durante a estação menos chuvosa ( $\approx 415$ indivíduos $/ \mathrm{m}^{2} / \mathrm{mês}$ ) (Apêndice 45 ).

Foram obtidas correlações significativas, com abundância dos grupos ao longo do ano e a precipitação pluviométrica e entre a distribuição vertical no solo e a umidade, a temperatura, $\mathrm{opH}$ e o teor de silte e argila do solo (Apêndice 3 ).

Do total de artrópodos capturado, $24,4 \%$ foi Hymenoptera. Dentre os Hymenoptera, Formicidae foi o grupo mais abundante no solo. A maior abundância ocorreu durante a estação chuvosa, com $\approx 2.690$ indivíduos $/ \mathrm{m}^{2}$. A abundância na estação menos chuvosa foi de $\approx 622$ indivíduos $/ \mathrm{m}^{2}$. Aproximadamente $80,7 \%\left(\approx 15.023\right.$ indivíduos $\left./ \mathrm{m}^{2}\right)$ foi capturado na primeira camada do solo, $12,8 \%\left(\approx 2.387\right.$ indivíduos $\left./ \mathrm{m}^{2}\right)$ na segunda, 4,4\%( 2823 indivíduos $\left./ \mathrm{m}^{2}\right)$ na terceira e $2,1 \%$ ( $\approx 395$ 
individuos $/ \mathrm{m}^{2}$ ) na quarta camada do solo.

A abundância média mensal de Araneae foi de $\approx 962$ indivíduos $/ \mathrm{m}^{2} /$ mês na estação chuvosa e 232 individuos $/ \mathrm{m}^{2} /$ mês na estação menos chuvosa. Aproximadamente $40,2 \%\left(\approx 2.695\right.$ individuos $\left./ \mathrm{m}^{2}\right)$ foi capturado na primeira camada do solo, $35,3 \%\left(\approx 2.363\right.$ individuos $\left./ \mathrm{m}^{2}\right)$ na segunda camada, $15,1 \%\left(\approx 1.010\right.$ individuos $\left./ \mathrm{m}^{2}\right)$ na terceira camada $e$ $9,4 \%\left(\approx 630\right.$ individuos $\left./ \mathrm{m}^{2}\right)$ na quarta camada do solo.

A abundância média mensal de Japygidae durante a estação chuvosa foi de $\approx 67$ individuos $/ \mathrm{m}^{2} / \mathrm{mês}$, enquanto que na estação menos chuvosa foi de $\approx 122$ indivíduos $/ \mathrm{m}^{2} / \mathrm{mês}$. Eles foram capturados em todas as camadas do solo nas seguintes proporções: $34,9 \%\left(\approx 1.496\right.$ indivíduos $\left./ \mathrm{m}^{2}\right)$ na primeira camada, $31,8 \%\left(\approx 1.362\right.$ individuos $\left./ \mathrm{m}^{2}\right)$ na segunda, $18,2 \%(\approx 779$ individuos $\left./ \mathrm{m}^{2}\right)$ na terceira e $15,1 \%\left(\approx 645\right.$ individuos $\left./ \mathrm{m}^{2}\right)$ na quarta camada do solo.

A abundância média mensal de Pauropoda foi de $\approx 439$ indivíduos $/ \mathrm{m}^{2} /$ mês na estação chuvosa e $\approx 316$ indivíduos $/ \mathrm{m}^{2} /$ mês na estação menos chuvosa. Do total capturado, $43,6 \%\left(\approx 1.699\right.$ individuos $\left./ \mathrm{m}^{2}\right)$ foram coletados na primeira camada do solo, $32,4 \%\left(\approx 1.261\right.$ individuos $\left./ \mathrm{m}^{2}\right)$ na segunda, $13,3 \%\left(\approx 520\right.$ individuos $\left./ \mathrm{m}^{2}\right)$ na terceira e $10,7 \%$ $\left(\approx 419\right.$ indivíduos $/ \mathrm{m}^{2}$ ) na quarta camada do solo.

Do total de artrópodos capturados, aproximadamente $6,2 \%$ foi Homoptera. Dentre os Homoptera, 0 grupo mais abundante foi de ninfas de coccoidea cuja abundância média mensal foi semelhante na estação chuvosa, com $\approx 396$ indivíduos $/ \mathrm{m}^{2} /$ mês, quando comparada com a estação menos chuvosa, com $\approx 373$ individuos $/ \mathrm{m}^{2} / \mathrm{mês}$. Do total capturado, $30,5 \%\left(\approx 1.179\right.$ individuos $\left./ \mathrm{m}^{2}\right)$ foi coletado na primeira camada do solo, 36,9\%( $\approx 1.429$ individuos $\left./ \mathrm{m}^{2}\right)$ na segunda camada, $18,5 \%\left(\approx 717\right.$ individuos $\left./ \mathrm{m}^{2}\right)$ na terceira camada e $14,1 \%\left(\approx 543\right.$ individuos $\left./ \mathrm{m}^{2}\right)$ na quarta camada do 
solo.

A abundância média mensal de Isoptera foi de $\approx 243$ indivíduos $/ \mathrm{m}^{2} /$ mês durante a estação chuvosa e $\approx 194$ indivíduos $/ \mathrm{m}^{2} /$ mês durante a estação menos chuvosa. o maior número de indivíduos foi coletado na primeira camada do solo com $75,0 \%\left(\approx 1.675\right.$ indivíduos $\left./ \mathrm{m}^{2}\right)$ do total capturado, enquanto que, nas camadas subseqüentes coletaram-se $2,8 \%$ $\left(\approx 63\right.$ individuos $\left./ \mathrm{m}^{2}\right)$ na segunda camada, $13,6 \%$ ( $\approx 303$ indivíduos $\left./ \mathrm{m}^{2}\right)$ na terceira e $8,6 \%\left(\approx 192\right.$ indivíduos $\left./ \mathrm{m}^{2}\right)$ na quarta camada do solo.

Foram capturados adultos e larvas de Diptera no solo, sendo que $2,6 \%$ foram adultos e 2,2 foram larvas. Dentre os adultos, Cecidomyiidae foi coletado em maior número e apresentou uma abundância média mensal de $\approx 162$ indivíduos $/ \mathrm{m}^{2} / \mathrm{mês}$ na estação menos chuvosa e $\approx 86$ indivíduos $/ \mathrm{m}^{2} / \mathrm{mês}$ na estação chuvosa. Ao longo do ano a maior abundância foi em setembro/1987 com $\approx 313$ individuos $/ \mathrm{m}^{2}$. A abundância média mensal das larvas de Diptera na estação menos chuvosa foi de $\approx 180$ individuos $/ \mathrm{m}^{2} / \mathrm{mês}$, enquanto que na estação chuvosa foi de $\approx 169$ indivíduos $/ \mathrm{m}^{2} / \mathrm{mês}$. 0 período de maior captura foi em abril/1988 com $\approx 346$ individuos $/ \mathrm{m}^{2}$. Aproximadamente $86,5 \%$ das larvas $\left(\approx 1.501\right.$ individuos $\left./ \mathrm{m}^{2}\right)$ foi capturado na primeira camada do solo, $9,1 \%$ ( $\approx 159$ individuos $\left./ \mathrm{m}^{2}\right)$ na segunda, $3,0 \%\left(\approx 53\right.$ individuos $\left./ \mathrm{m}^{2}\right)$ na terceira e $1,4 \%\left(\approx 24\right.$ individuos $\left./ \mathrm{m}^{2}\right)$ na quarta camada do solo.

A abundância média mensal de Thysanoptera foi de $\approx 63$ indivíduos $/ \mathrm{m}^{2} /$ mês na estação chuvosa e de $\approx 99$ indivíduos $/ \mathrm{m}^{2} /$ mês na estação menos chuvosa. A maior densidade populacional no folhedo ocorreu em outubro/1987 com 236 indivíduos $/ \mathrm{m}^{2}$. Aproximadamente $79,5 \%$ ( $\approx 616$ indivíduos $/ \mathrm{m}^{2}$ ) foi capturado na primeira camada do solo, $14,9 \%$ ( $\approx 115$ individuos $\left./ \mathrm{m}^{2}\right)$ na segunda, $2,5 \%\left(\approx 19\right.$ individuos $\left./ \mathrm{m}^{2}\right)$ na 
terceira e $3,1 \%\left(\approx 24\right.$ indivíduos $\left./ \mathrm{m}^{2}\right)$ na quarta camada do solo.

A abundância média mensal de Psocoptera foi de $\approx 49$ indivíduos $/ \mathrm{m}^{2} /$ mês na estação menos chuvosa e $\approx 22$ indivíduos $/ \mathrm{m}^{2} /$ mês na estação chuvosa. No solo, $21,7 \%$ ( $\approx 2$ individuos $/ \mathrm{m}^{2}$ ) foram capturados na primeira camada, 11,6\% $\left(\approx 38\right.$ indivíduos $\left./ \mathrm{m}^{2}\right)$ na segunda, $52,2 \%\left(\approx 173\right.$ indivíduos $\left./ \mathrm{m}^{2}\right)$ na terceira e $14,5 \%\left(\approx 48\right.$ indivíduos $\left./ \mathrm{m}^{2}\right)$ na quarta camada do solo. A maior densidade populacional ocorreu em dezembro com $\approx 178$ indivíduos $/ \mathrm{m}^{2}$. 


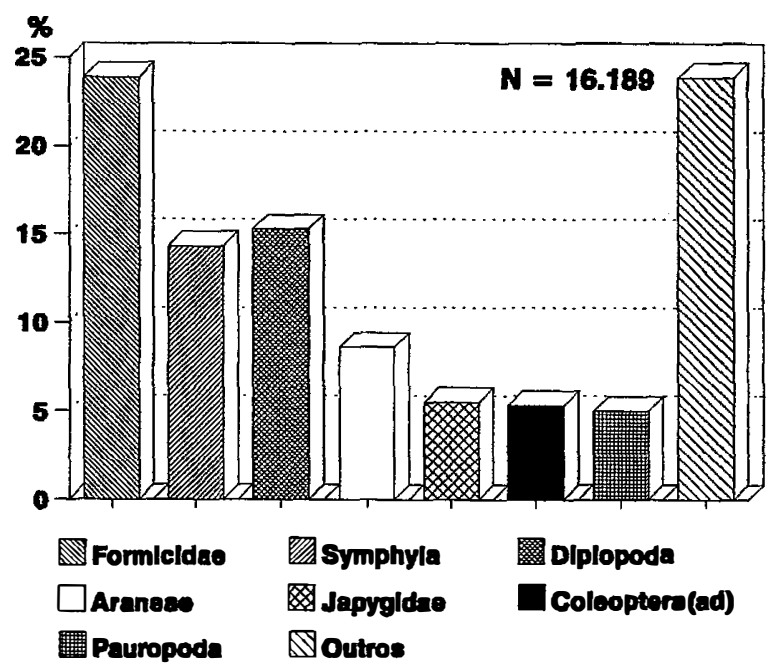

Figura 44 - Abundância dos grupos de Arthropoda, capturados em a maior número, no solo, na floresta inundada por água mista, no período de agosto/1987 a maio/1988. Coleta com o método do Kempson.

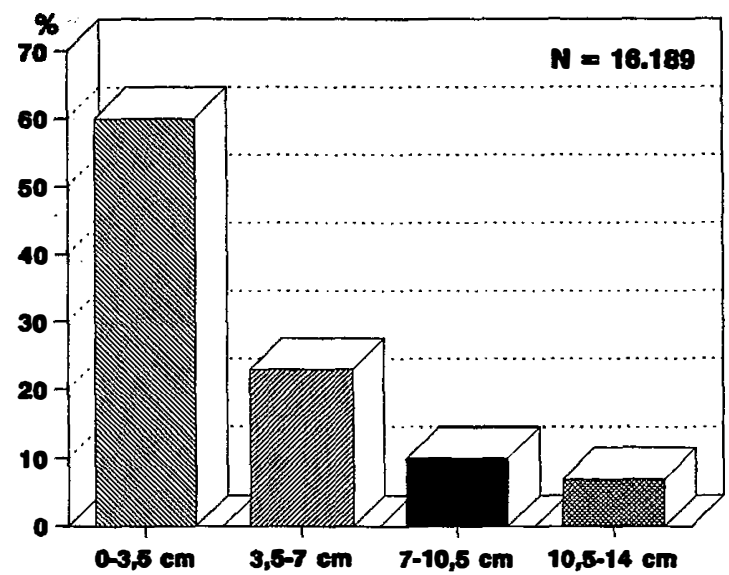

Figura 45 - Abundância vertical dos grupos de Arthropoda, nas diferentes camadas do solo, na floresta inundada por água mista, no periodo de agosto/1987 a maio/1988. Coleta com o método de Kempson. 
4.7.2 Captura no folhedo com fotoeclectores de solo

Foi coletado um total de 71.270 Arthropoda, distribuídos em 25 grupos, sendo que Diptera (adultos) foi o grupo mais freqüente, representando $63,5 \%$ do total capturado ( $\approx 11.324$ indivíduos $/ \mathrm{m}^{2}$ ), seguido por Hymenoptera (na maioria microhimenópteros) com $12,1 \%\left(\approx 2.162\right.$ indivíduos $\left./ \mathrm{m}^{2}\right)$, Coleoptera (adultos) $8,6 \%\left(\approx 1.526\right.$ individuos $\left./ \mathrm{m}^{2}\right)$, Araneae $5,3 \%\left(\approx 946\right.$ indivíduos $\left./ \mathrm{m}^{2}\right), \quad$ Formicidae $3,3 \%$ ( $\approx 592$ individuos $\left./ \mathrm{m}^{2}\right)$, Thysanoptera $2,5 \%\left(\approx 441\right.$ indivíduos $\left./ \mathrm{m}^{2}\right)$, Homoptera adultos (exceto Coccoidea) $1,0 \%$ ( $\approx 183$ individuos $/ \mathrm{m}^{2}$ ) e 3,7 foi representado por outros grupos de artrópodos menos freqüentes (Apêndice 46). Ao longo do ano a maior captura ocorreu durante o período menos chuvoso (outubro/1987) com 24,4\% do total capturado (4.344 indivíduos $\left./ \mathrm{m}^{2}\right)$, enquanto que a menor captura ocorreu durante o período chuvoso com $4,1 \%$ do total ( $\approx 731$ individuos $/ \mathrm{m}^{2}$ ). A densidade média mensal foi maior durante a estação menos chuvosa ( $\approx 2.522$ indivíduos $\left./ \mathrm{m}^{2} / \mathrm{mês}\right)$, do que durante a estação chuvosa $\left(\approx 1.288\right.$ indivíduos $/ \mathrm{m}^{2} / \mathrm{mês}$ ) (Apêndice 46 ).

No que diz respeito à freqüência dos artrópodos no folhedo, 63,5 foi representado por Diptera adultos e 0,1\% por larvas. Nematocera foi o grupo mais abundante com $59,8 \%$ do total capturado ( $\approx 10.670$ indivíduos $\left./ \mathrm{m}^{2}\right)$, enquanto que, $3,7 \%\left(\approx 654\right.$ indivíduos $\left./ \mathrm{m}^{2}\right)$ foi representado por Brachycera. A abundância média mensal de Cecidomyiidae durante a estação chuvosa foi somente $\approx 449$ indivíduos $/ \mathrm{m}^{2}$, enquanto que, na estação menos chuvosa, foi $\approx 1.440$ indivíduos $/ \mathrm{m}^{2}$. Ao longo do ano a maior densidade populacional ocorreu em outubro/1987, com um total de $\approx 2.974$ indivíduos $/ \mathrm{m}^{2}$. A abundância média mensal de sciaridae foi maior durante a estação chuvosa com $\approx 80$ indivíduos $/ \mathrm{m}^{2} / \mathrm{mês}$, que durante a estação menos chuvosa com $\approx 46$ 
indivíduos $/ \mathrm{m}^{2} / \mathrm{mês}$. O período de maior captura ocorreu em outubro/1987 com $\approx 151$ individuos $/ \mathrm{m}^{2}$.

Dentre os Hymenoptera, Formicidae foi o grupo freqüente, apresentando uma densidade média mensal de $\approx 63$ indivíduos $/ \mathrm{m}^{2} /$ mês na estação chuvosa e $\approx 54$ indivíduos $/ \mathrm{m}^{2} / \mathrm{mês}$ na estação menos chuvosa. A maior densidade populacional ocorreu em maio/1988 com $\approx 302$ indivíduos $/ \mathrm{m}^{2}$. Com relação aos outros Hymenoptera (na maioria microhimenópteros) a densidade média mensal, na estação chuvosa foi $\approx 102$ individuos $/ \mathrm{m}^{2}$, enquanto que, na estação menos chuvosa, foi 387 individuos $/ \mathrm{m}^{2}$. A maior captura ocorreu em setembro/1987 com $\approx 891$ individuos $/ \mathrm{m}^{2}$.

A maior densidade populacional de Araneae foi em maio/1988 com $\approx 504$ indivíduos $/ \mathrm{m}^{2}$. A densidade média mensal foi maior durante 0 período chuvoso com $\approx 126$ indivíduos $/ \mathrm{m}^{2} / \mathrm{mês}$ do que no período menos chuvoso com $\approx 47$ indivíduos $/ \mathrm{m}^{2} / \mathrm{mês}$.

A densidade média mensal de Thysanoptera foi maior durante a estação menos chuvosa com $\approx 90$ indivíduos $/ \mathrm{m}^{2} / \mathrm{mês}$, enquanto que na estação chuvosa foi de $\approx 14$ individuos $/ \mathrm{m}^{2} /$ mês. A maior captura ocorreu em outubro/1987 com $\approx 236$ indivíduos $/ \mathrm{m}^{2}$.

Do total de artrópodos capturados no folhedo, $1,8 \%$ foi representado por Homoptera e dentre eles, Coccoidea (adultos) apresentou uma densidade média mensal que variou entre 8 e 10 indivíduos $/ \mathrm{m}^{2} / \mathrm{mês}$, da estação menos chuvosa à estação chuvosa. A maior captura durante o ano ocorreu em janeiro/1988 com $\approx 42$ individuos $/ \mathrm{m}^{2}$. Ninfas foram capturadas somente durante a época menos chuvosa com uma densidade média mensal de 1 indivíduo $/ \mathrm{m}^{2} / \mathrm{mês}$. 0 período de sua maior densidade foi em setembro/1987 com $\approx 4$ indivíduos $/ \mathrm{m}^{2}$.

A densidade média mensal de Isopoda foi maior 
no período chuvoso com $\approx 8$ indivíduos $/ \mathrm{m}^{2} / \mathrm{mês}$ que no período menos chuvoso com $\approx 0,3$ indivíduos $/ \mathrm{m}^{2} / \mathrm{mês}$. A maior captura foi em maio/1988 com $\approx 46$ indivíduos $/ \mathrm{m}^{2}$.

Psocoptera apresentaram uma densidade média mensal de $\approx 4$ indivíduos $/ \mathrm{m}^{2} /$ mês na estação chuvosa e de $\approx 3$ indivíduos $/ \mathrm{m}^{2} / \mathrm{mês}$ na estação menos chuvosa. A maior captura ocorreu em dezembro/1987 com $\approx 11$ indivíduos $/ \mathrm{m}^{2}$.

4.7.3 Captura nos troncos com fotoeclectores de árvores BEt e BE $\downarrow$

Em fotoeclector de árvore direcionado para cima ( $B E \uparrow$ ) foram capturados 17.906 artrópodos e classificados em 28 grupos. A maior densidade foi registrada durante à estação menos chuvosa (de julho a novembro/1987 e junho/1988), com 64,9\% do total capturado ( $n=11.619)$, enquanto que na estação chuvosa (de dezembro/1987 a maio/1988) coletaram-se $35,1 \%(n=6.287)$. Diptera foi 0 grupo dominante com 50,3 $\%$ do total capturado, seguido por Formicidae 25,7\%, Araneae 4,3\%, Psocoptera 3,4\%, Diplopoda $2,8 \%$ Grylloidea $1,8 \%$, Coleoptera adultos $1,7 \%$, Isopoda $1,5 \%$ e $9,2 \%$ foi representado por outros grupos menos freqüentes (Apêndice 47). Ao longo do ano, a maior captura mensal ocorreu no final da inundação, durante o período menos chuvoso (julho/1987), com $46,5 \%$ do total capturado. A menor captura mensal ocorreu no início da inundação, também durante o período menos chuvoso, (junho/1988), com $1,5 \%$ do total capturado.

Do total de artrópodos capturados, Diptera (adultos) foi o grupo dominante $(50,3 \%$ do total), sendo que, $45,2 \%$ foi representado por Brachycera. A maior ocorrência foi no final do período não inundado (julho/1987) com 
$44,9 \%$ do total capturado. Com relação às estações anuais, a maior ocorrência de Brachycera foi durante a estação menos chuvosa com $99,5 \%$ do total capturado e 0,5\% na estação chuvosa. Dentre os Nematocera $(5,1 \%$ dos artrópodos capturados), Cecidomyiidae ocorreu em maior número, representando $2,6 \%$ do total de artrópodos coletado. A ocorrência durante à estação menos chuvosa com $57,0 \%$ do total de Cecidomyiidae coletado foi semelhante à da estação menos chuvosa, com $43,0 \%$

Dentre os Hymenoptera capturados ( $n=4.778$ ),

$96,2 \%$ foi representado por Formicidae e a maior ocorrência foi durante a estação chuvosa com $59,5 \%$ do total, enquanto que, 40,5 \% foi coletado na estação menos chuvosa.

A maior ocorrência de Araneae $(n=772)$ foi durante à estação chuvosa com 55,3\% do total capturado e $44,7 \%$ na estação menos chuvosa. A maior captura foi em maio/1988 ( $n=206)$.

Psocoptera ( $n=604$ ) foram capturados em maior número durante à estação chuvosa com $68,2 \%$ do total coletado e 31,2 foi capturado durante à estação menos chuvosa. Ao longo do ano a maior ocorrência foi em janeiro/1988 ( $n=145)$.

Os Orthoptera $(n=421)$ representaram $2,4 \%$ dentre os artrópodos coletados e $1,7 \%$ foi representado por ninfas de Grylloidea. Aproximadamente $63,8 \%$ das ninfas foi capturado durante à estação chuvosa e 36,2 \% durante à estação menos chuvosa. Ao longo do ano a maior ocorrência foi em janeiro/1988 $(n=52)$.

A maior densidade de atividade de Isopoda ( $\mathrm{n}$ = 271) foi durante à estação chuvosa representando $98,5 \%$ do total, enquanto que, $1,5 \%$ foi coletado na estação menos chuvosa. Ao longo do ano, o período de maior captura foi em maio/1988 com $95,9 \%(n=260)$. 
Em fotoeclector direcionado para baixo (BE $\downarrow$ ) foram capturados 6.556 Arthopoda representando 24 grupos. 0 grupo dominante foi Diptera com $24,9 \%$ do total, seguido por Isopoda com $16,5 \%$, Formicidae $14,4 \%$, Diplopoda 11,3\%, Coleoptera adultos $9,8 \%$, Araneae $8,0 \%$ larvas de Coleoptera $3,1 \%$, Pseudoscorpiones $2,2 \%$ e $11,5 \%$ foi representado por outros grupos menos freqüentes (Apêndice 48). O mês onde se obteve a maior captura, durante o período de estudo, foi junho/1988, no início da inundação, durante à época menos chuvosa, com $27,2 \%$ do total capturado. 0 mês onde se obteve a menor captura foi outubro/1987, durante o período não inundado e menos chuvoso, $\operatorname{com} 2,8 \%$ do total. Com relação às estações anuais, 58,0 \% dos artrópodos foi capturado durante à estação menos chuvosa, enquanto que, $42,0 \%$ foi capturado durante à estação chuvosa (Apêndice 48 ).

Do total de artrópodos capturado, $24,9 \%$ foi representado por Diptera $(\mathrm{n}=1.633)$, dos quais $12,4 \%$ adultos e $12,5 \%$ larvas. Dentre os Diptera adultos, Cecidomyiidae foi a família capturada em maior número. 0 período de maior ocorrência foi durante à estação chuvosa, com $68,9 \%$ do total de adultos capturado, enquanto que $31,1 \%$ foi capturado durante à estação menos chuvosa.

A maior densidade de atividade de Isopoda ( $\mathrm{n}$ =1.083) ocorreu durante a estação menos chuvosa com $64,7 \%$ do total capturado e $32,7 \%$ foi capturado durante a estação chuvosa. O mês com a maior densidade populacional foi em junho/1988 ( $n=694)$.

Hymenoptera representaram $15,1 \%$ da captura total ( $n=991)$, e a maioria foi Formicidae $(14,4 \%)$. A ocorrência durante a estação chuvosa foi de $52,6 \%$ do total, enquanto que na estação menos chuvosa capturaram-se 
$47,4 \%$. O mês de maior captura foi junho/1988 ( $n=260)$.

o maior número de Araneae ( $\mathrm{n}=527)$ foi coletado durante à estação menos chuvosa, com aproximadamente $76,7 \%$ do total capturado, enquanto que, 23,3\% foi capturado na estação chuvosa. A maior densidade de atividade foi observada em Julho/1987 ( $n=191)$. 


\section{DISCUSSĀo}

\subsection{PSEUDOSCORPIONES}

Pseudoscorpiones são pequenos aracnídeos, raramente com mais de $5 \mathrm{~mm}$ de comprimento e assemelham-se aos escorpiões verdadeiros por terem grandes pedipalpos em forma de pinça. o abdome é curto e oval e não têm ferrão. São encontrados embaixo de madeira, no solo, no folhedo, nos troncos, sob cascas de árvores etc. (BORROR \& DELONG, 1969). No que diz respeito à alimentação dos Pseudoscorpiones, EISENBEIS \& WICHARD (1987) os classificam como carnívoros que se alimentam principalmente de colêmbolos, ácaros e nematóides. Vivem predominantemente em região tropical e subtropical, embora possam ser encontrados também em regiões temperadas. Na região Amazônica mais de 60 espécies já foram identificadas por ADIS \& MAHNERT (1990a), sendo que 29 espécies vivem em florestas inundáveis.

$\mathrm{Na}$ floresta inundada por água mista, coletaram-se T. amazonicus, P. homodentatus (Chthoniidae) G. amazonicus (Garypidae) e P. irmgardae (olpiidae). A densidade de atividade de Pseudoscorpiones no folhedo da floresta inundada por água mista ( $\approx 4$ indivíduos $/ \mathrm{m}^{2} / \mathrm{mês}$ ) foi inferior a densidade de atividade encontrada por ADIS (1981), para floresta inundada por água preta $(\approx 102$ indivíduos $/ \mathrm{m}^{2} / \mathrm{mês}$ ). Nos troncos, durante a migração para cima, 0 número de Pseudoscorpiones capturados por fotoeclector, na floresta inundada por água mista ( 97 indivíduos) foi menor que 0 número encontrado por ADIS (1981), numa floresta inundada por água preta (Tarumã Mirim: $\mathrm{n}=2.811)$ e superior ao número coletado em floresta 
inundada por água branca (Ilha do Curari: $n=18$ ).

Durante a migração para baixo, o número coletado por fotoeclector na área experimental (144 individuos) foi inferior ao coletado por ADIS (1981), para floresta inundada por água preta (3.087 individuos) e superior ao número coletado para floresta inundada por água branca (61 indivíduos).

5.1.1 Tyrannochthonius amazonicus Mahnert, 1979

Na floresta inundada por água mista, $T$. amazonicus foi a espécie capturada em maior número e a maior densidade de atividade ocorreu principalmente durante 0 período chuvoso, não inundado (Figura 5). A reprodução ocorreu no solo e teve início no final do periodo seco, se estendendo até o período chuvoso (Figura 7). As primeiras protoninfas foram capturadas em outubro/1987 através do extrator Kempson $e$, nos meses subseqüentes, aumentou o número de deutoninfas e tritoninfas, indicando um ciclo de vida relativamente curto e sincronizado com o período não inundado (Figura 7, Apêndice 5). As tritoninfas foram mais abundantes, migraram para a copa (Figuras 8 e 12a), e retornaram ao solo no final da inundação (Figura 12b). A migração ocorreu principalmente em fevereiro e março/1988 (Figuras 8, 12a), durante 0 periodo chuvoso. 0 número de tritoninfas foi superior durante a migração solo-copa, que na migração copasolo (Figuras $12 \mathrm{a}$ e $12 \mathrm{~b}$ ). O número reduzido de tritoninfas, capturado na descida, foi ocasionado por uma primeira emergência dos adultos, ocorrida na região do tronco, próxima ao chão, no final do período inundado. Além disso, conforme indica o trabalho de ADIS (1981), uma grande quantidade de tritoninfas é predada durante a permanência forçada no tronco. A ausência de protoninfas e o número reduzido de 
deutoninfas no folhedo e em fotoeclectores de árvores reconfirmam os dados de ADIS \& MAHNERT (1985), que estes estágios ocorrem em maior número no chão da floresta. A maior abundância de imaturos e adultos no solo da floresta inundada por água mista (265 indivíduos $/ \mathrm{m}^{2}$; fevereiro/1988), foi inferior à encontrada por ADIS \& MAHNERT (1985) para floresta inundada por água preta (655 indivíduos $/ \mathrm{m}^{2}$; janeiro/1981).

Com relação à distribuição vertical no solo $T$. amazonicus foi mais abundante na primeira camada (Figura 6) . Entretanto, as protoninfas foram mais abundantes na camada de 3,5 a $7 \mathrm{~cm}$ de profundidade que na camada orgânica do solo. Provavelmente por não serem muito ativas e, portanto, mais suscetiveis à predação elas permanecem nas camadas inferiores do solo (Apêndice 5).

Os resultados das correlações entre a distribuição vertical de $T$. amazonicus e os fatores abióticos locais, indicaram que a densidade populacional diminuiu das camadas superiores do solo para as camadas inferiores, com 0 aumento da umidade do solo ( $p<0,01$ em março e $p<0,001$ em abril/1988), com a diminuição da temperatura do solo ( $\mathrm{p}<$ 0,01 em fevereiro e $p<0,05$ em março/1988) e com a diminuição do $\mathrm{pH}$ do solo ( $\mathrm{p}<0,01$ em março e abril/1988).

As observações sobre $T$. amazonicus obtidas neste trabalho, coincidem com aquelas apresentadas por ADIS \& MAHNERT (1985), para floresta inundada por água preta, onde T. amazonicus é considerada uma espécie endêmica. As tritoninfas são estágios migratórios que sobrevivem à inundação na região dos troncos, copas, sob cascas e retornam ao solo no final da inundação. Ao contrário da floresta inundada por água preta, onde a migração ocorreu somente 2 a 3 semanas antes da inundação, na floresta inundada por água mista, ocorreu aproximadamente 14 semanas 
antes.

Na área experimental do Lago Janauari, $T$. amazonicus é considerada uma espécie terrícola migrante, adaptada à inundação anual conforme indicaram ADIS \& MAHNERT (1985).

5.1.2 Pseudochthonius homodentatus Chamberlin, 1929

P. homodentatus foi praticamente ausente no solo e apenas alguns indivíduos, adultos na maioria, foram capturados no folhedo $(n=22)$. A captura nos troncos foi superior à captura no solo e no folhedo e foi menor em fotoeclector de árvore para cima $(B E \uparrow)(n=56)$ que em fotoeclector de árvore para baixo ( $B E \downarrow)(n=120)$, indicando, deste modo, que a espécie vive preferencialmente nas árvores (Figuras 11a e 11b). A captura ocorreu somente no período chuvoso e os primeiros adultos foram capturados em dezembro/1987 (BE $\downarrow$ ) (Figura 11B). Nenhuma protoninfa foi capturada, indicando deste modo uma total ausência de atividade neste estágio. As poucas deutoninfas e tritoninfas capturadas no folhedo, surgiram a partir de janeiro/1988 indicando, deste modo, o período de reprodução e um tempo de desenvolvimento relativamente curto (Figura 10). Nos troncos, as primeiras deutoninfas e tritoninfas surgiram a partir de fevereiro/1988 (Figuras 11a e 11b).

Na floresta inundada por água mista, $P$. homodentatus representa, segundo a classificação de ADIS (1992b), uma espécie arborícola migrante, que apresenta sua reprodução principal na área dos troncos e uma reprodução secundária no solo durante o período não inundado. Entretanto, trabalhos desenvolvidos por MAHNERT \& ADIS (1985) e por ADIS \& MAHNERT (1990b, 1993) indicam que esta espécie, em floresta primária e secundária de terra firme, habita o 
solo e o folhedo. Isto significa uma adaptação da vida terrícola na terra firme, para uma vida arboricola nas florestas inundadas por água preta e mista. Tal tipo de adaptação já foi determinada por ADIS et alii (1988), para Brazilatemnus browni Muchmore (Miratemnidae). Em florestas primária e secundária de terra firme, segundo trabalhos desenvolvidos por MORAIS (1985), RODRIGUES (1986) e ADIS et alii (1988), B. browni, foi encontrada somente no solo e apresentou uma reprodução polivoltina ao longo do ano. Entretanto, em florestas inundáveis, B. browni, apresentou uma reprodução bivoltina, sendo um período mais longo, nas árvores, durante à inundação, e um periodo mais curto, no solo, durante o período não inundado, conforme indicam ADIS et alii (1988).

\subsubsection{Pachyolpium irmgardae Mahnert, 1979}

P. irmgardae foi capturada em baixo número na floresta inundada por água mista. Alguns individuos foram capturados pelo método de extração do solo. Entretanto, a maioria foi capturada através de fotoeclectores de solo durante 0 período chuvoso. Nos troncos, o número de indivíduos coletados não foi suficiente para caracterizar uma migração vertical para a copa das árvores. Em floresta inundada por água preta, ADIS \& MAHNERT (1985) indicaram que $P$. irmgardae também foi capturada em baixo número, e nenhum indivíduo foi coletado pelo método de extração do solo. Entretanto, ela é considerada como uma espécie arborícola migrante. 
5.1.4 Geogarypus amazonicus Mahnert, 1979

Apenas alguns individuos foram coletados nos troncos da área experimental e portanto, é considerada, na área experimental, como uma espécie arborícola não migrante. Na floresta inundada por água preta, segundo ADIS \& MAHNERT (1985), G. amazonicus é também considerada como uma espécie arborícola não migrante.

\subsection{CHILOPODA}

Segundo BORROR \& DELONG (1969), os Chilopoda ou centopéias, são animais alongados, achatados, vermiformes. Geralmente ocorrem em lugares protegidos, como por exemplo, debaixo de pedras, em madeira podre etc. São predadores e alimentam-se de insetos, aranhas e outros animais pequenos. Estudos desenvolvidos por ADIS (1992a) indicaram que, em áreas alagáveis da Amazônia, alguns Chilopoda apresentam estratégias de sobrevivência à inundação, por exemplo, Lamyctes adisi Zalesskaja, 1994 (Henicopidae, Lithobiomorpha) deposita os ovos no solo, os quais sobrevivem durante toda à inundação.

\subsubsection{Geophilomorpha}

No solo da floresta inundada por água mista, foram capturadas: Pectiniunguis ascendens, Ribautia centralis, Geophilidae n.sp. e Schendylidae n.spp. (Figura $13)$.

Na área experimental, $P$. ascendens é considerada habitante do solo, vive nos primeiros $7 \mathrm{~cm}$ de 
profundidade (Figura 13) e sobrevive à inundação nas árvores. Os primeiros imaturos surgiram no solo, seis semanas após a inundação (setembro/1987), indicando deste modo o início do período reprodutivo (Figuras 14 e 15). 0 número de indivíduos capturado nos troncos não foi suficiente para caracterizar uma migração vertical para os troncos e copas. Porém, estudos ecológicos desenvolvidos em floresta de água preta, conforme indicam ADIS et $a l i i^{3}$, revelaram que adultos de $P$. ascendens começam a se deslocar para a região dos troncos/copas no início da época chuvosa (dezembro) e voltam para o solo no final da fase emersa.

R. centralis é um habitante do solo da floresta inundada por água mista, vive na camada de 0 a 10,5 $\mathrm{cm}$ de profundidade (Figura 13) e sobrevive à inundação nas árvores. Apenas adultos foram capturados durante a subida no tronco, no início do período inundado. Eles descem ao solo logo no final da inundação (julho/1987) onde se reproduzem. Estes dados reconfirmam a fenologia encontrada para esta espécie por ADIS et alii', em floresta inundada por água preta.

Schendylidae n.spp., também são habitantes do solo na área experimental e vivem na camada de 0 a 10,5 cm de profundidade (Figura 13). Os primeiros imaturos surgiram no solo em dezembro/1987, indicando, deste modo, o início do período de reprodução. Nenhum indivíduo foi coletado nos

${ }^{3}$ ADIS, J.; BARBIERI, F. MINELLI, A. (Instituto Max-Planck de Limnologia, Plön, Alemanha - Università degli studi de Padova, Padova, Italia). Comunicação pessoal, 1994.

4 ADIS, J.; BARBIERI, F. \& MINELLI, A. (Instituto MaxPlanck de Limnologia, Ploen, Alemanha - Università degli studi de Padova, Italia). Behavioural and morphological adaptations of Geophilomorpha centipedes in a periodically inundated amazonian forest. (Em elaboração). 
troncos, durante a migração vertical para cima, entretanto, apenas um indivíuo foi coletado na descida no final do período inundado, indicando assim que, provavelmente, eles utilizam os troncos para sobreviverem à inundação.

Geophilidae n.sp. foi coletado somente através do extrator de solo, nos primeiros $7 \mathrm{~cm}$ de profundidade (Figura 13) e durante a descida da copa em direção ao solo, indicando, deste modo, que a espécie habita o solo e sobrevive à inundação nas árvores.

\subsection{DIPLOPODA}

Os diplópodos desempenham um importante papel na decomposição de restos de plantas no solo. Segundo HOPKIN \& READ (1992), eles são na maioria herbívoros, principalmente trituradores de folhas caidas e outros materiais vegetais em decomposição. A forma do corpo é bem adaptada para a vida no folhedo e camadas mais profundas do solo (EISENBEIS \& WICHARD, 1987; GOLOVATCH, 1987).

$\mathrm{Na}$ área inundada por água mista, as principais familias de Diplopoda encontradas no solo e nos troncos foram: Polyxenidae, Fuhrmannodesmidae e Pyrgodesmidae. Por outro lado, trabalhos desenvolvidos por ADIS (1981) e ADIS et alii (1993), em floresta inundada por água preta, indicam que os grupos mais abundantes nos troncos foram pertencentes à ordem Polydesmida $e$ às familias siphonophoridae $e$ Polyxenidae. Em floresta inundada por água branca, os Polyxenidae foram os mais abundantes.

A maior abundância dos diplópodos, na área experimental do Lago Janauari, ocorreu no solo durante a 
período chuvoso. A atividade destes animais no solo e no folhedo foi maior no final do período não inundado $e$ ocorreu, principalmente, na camada orgânica, devido a maior disponibilidade de recursos alimentares.

$\mathrm{Na}$ migração vertical para cima, a maior atividade ocorreu duas semanas antes da inundação (maio/1988), com a subida dos Fuhrmannodesmidae para a copa das árvores. Na migração vertical para baixo, houve um aumento na densidade populacional, no início do período não inundado, com a descida dos Polyxenidae, Stemmiulidae e siphonophoridae ao solo. A maior atividade da copa para o solo ocorreu duas semanas antes da inundação (abril/1988) e se estendeu até o início do período inundado. Entretanto, o aumento no número de indivíduos, durante este período, não significa uma migração vertical para baixo e foi ocasionado pela grande atividade dos animais no tronco, durante a subida e que foram também capturados nos fotoeclectores direcionados para baixo.

\subsubsection{POLYXENIDAE}

Os Polyxenidae são animais típicos de solo que, na maioria, se alimentam de algas e vivem em humus, sob folhas ou pedras. Apresentam o corpo coberto por tricomas (EISENBEIS \& WICHARD, 1987; HOPKIN \& READ, 1992). OS Polyxenidae foram os mais abundantes no solo e no folhedo (Figura 16a). A maior atividade ocorreu durante o período chuvoso e na primeira camada do solo (Figuras 16a e 16b). $\mathrm{Na}$ área experimental, os Polyxenidae podem ser considerados, segundo a classificação de ADIS (1992b), como animais terrícolas migrantes. No final da inundação houve migração vertical da copa em direção ao solo, e durante este período, nenhum animal foi coletado no solo, ou no folhedo (Figura 
16a). Somente a partir de setembro, cinco semanas após à inundação, surgiram os primeiros polixenídeos no chão da floresta. A atividade no solo, principalmente de imaturos, aumentou a partir de dezembro/1987 indicando, assim, o início da reprodução. No início da inundação eles realizaram migração vertical para as árvores (maio/1988)(Figura 16a). Serão necessárias a identificação das espécies e a determinação dos estágios de desenvolvimento, a fim de se obterem informações mais detalhadas sobre adaptações e estratégias de sobrevivência à inundação.

Os resultados das correlações entre a distribuição vertical e os fatores abióticos indicaram que a abundância dos Polyxenidae diminuiu das camadas superiores para as camadas inferiores do solo, com o aumento da umidade do solo ( $p<0,05$ em março/1988), com a diminuição da temperatura e $\mathrm{pH}$ do solo ( $\mathrm{p}<0,05$ em março/1988).

\subsubsection{FUHRYANNODESMIDAE}

Os Fuhrmannodesmidae representam uma das famílias mais abundantes da ordem Polydesmida, e estão distribuídos por todas as partes do mundo, principalmente em áreas tropicais e subtropicais da Ásia, África e Américas. Apenas 100 espécies foram descritas, segundo GOLOVATCH (1992). Na floresta inundada por água mista, os Fuhrmannodesmidae foram mais abundantes nos troncos (Figura 17). No total foram identificadas quatro espécies: Phaneromerium distinctum Golovatch, 1994 (apenas uma fêmea foi capturada em fotoeclector de árvore $\mathrm{BE} \uparrow$, na direção solocopa); Moojenodesmus pumilus Schubart, 1943 e Moojenodesmus wellingtoni $n$. sp. Golovatch, 1994 (ambas coletadas no solo e no folhedo); Fuhrmannodesmus rhinocerus Golovatch, 1994 (capturados através de fotoeclectores BE $\downarrow$, na 
direção copa-solo e no solo).

Os resultados das correlações entre a distribuição vertical e os fatores abióticos locais indicaram que a abundância dos Fuhrmannodesmidae diminuiu das camadas superiores para as camadas inferiores do solo, com o aumento na umidade do solo ( $p<0,01$ em março/1988) e com a diminuição do $\mathrm{pH}$ do solo ( $\mathrm{p}<0,01$ em março/1988).

Não foi possível fazer a determinação entre os estágios imaturos de M. pumilus e M. wellingtoni. Portanto, as observações sobre atividade de densidade, abundância (individuos $/ \mathrm{m}^{2}$ ) e fenologia das duas espécies serão discutidas conjuntamente.

5.3.2.1 Moojenodesmus wellingtoni n. sp. Golovatch, 1994 e Moojenodesmus pumilus Schubart, 1943.

M. wellingtoni foi coletada através da extração de solo. Os adultos apresentam cerca de 7,3 a 9,5 mm de comprimento. M. pumilus é uma espécie de tamanho pequeno $e$ as fêmeas adultas medem de 2,2 a 2,5 mm de comprimento. Apresentam carenas laterais curtas e cerdas claviformes. Segundo SCHUBART (1944), os adultos apresentam 18 segmentos e 27 pares de pernas. Não existem machos na espécie indicando que a mesma é partenogenética. As duas espécies vivem nos primeiros $3,5 \mathrm{~cm}$ de profundidade do solo (Figura 18) e migraram do solo para o tronco durante à época chuvosa. A migração ocorreu 4 a 6 semanas antes da inundação (Figuras 17 e 21) e a maioria dos individuos era de 17 e 18 segmentos. Os imaturos com 15 e 12 segmentos e os adultos (machos e fêmeas) foram menos frequentes. Provavelmente, os imaturos voltaram para o solo no final do período inundado e, duas semanas depois da inundação (agosto/1987), foram extraídos do solo (Figuras 19 e 20). A reprodução ocorreu 
após atingirem o estágio adulto. Os primeiros estágios imaturos surgiram, no folhedo, em setembro/1987, cinco semanas após o início da fase emersa (Figura 21). Entretanto, no solo, o maior período de reprodução ocorreu durante à época chuvosa (fevereiro/1988), que resultou numa abundância mais alta de imaturos com 7 e 9 segmentos $e$, duas semanas antes da inundação, ocorreu o início da migração para a copa, cuja maioria dos individuos apresentaram 17 e 18 segmentos (Figuras 21, 22, 24a e 24b). Este tipo de estratégia já foi observada, por ADIS et alii (1993), para Cutervodesmus adisi Golovatch, 1992, em floresta inundada por água preta, onde estágios migratórios com 17 e 18 segmentos, sobrevivem a inundação nos troncos e retornam ao solo logo após o período inundado.

5.3.2.2 Fuhrmannodesmus rhinocerus n.sp. Golovatch, 1994

Os adultos foram capturados apenas com fotoeclector de árvore $(B E \downarrow)$, onde a espécie foi a mais abundante durante o período em estudo. Os adultos apresentam de 4,5 a 4,9 mm de comprimento (GOLOVATCH, 1994) e foram capturados somente duas semanas antes da inundação. A época de maior atividade ocorreu no final do período não inundado (maio e junho/1988)(Figura 27a). Apenas os últimos estágios imaturos foram coletados (Figura 27b) e, portanto, é provável que esta espécie seja proveniente do solo e tenha subido à copa, sendo capturada no fotoeclector de árvore BE $\downarrow$ junto com alguns imaturos de M. pumilus e M. wellingtoni, durante a inundação. A freqüência de fêmeas 7 vezes maior que a de machos garante a existência da espécie em condições extremas de inundação. A razao entre machos e fêmeas observado em diplópodos da floresta inundada por água mista, 
no lago Janauari é maior nas fêmeas que nos machos e, portanto, a captura é mais alta nas fêmeas.

\subsubsection{PYRGODESMIDAE}

5:3.3.1 Muyudesmus obliteratus Kraus, 1960

M. obliteratus é proveniente de áreas de terra firme e se adaptou às áreas inundáveis do Rio Negro, segundo KRAUS (1960) e ADIS (1986). Na região de água mista do Lago Janauari, poucos indivíduos foram coletados no solo e no folhedo. Entretanto, no tronco, M. obliteratus foi a segunda espécie de maior ocorrência. A maior atividade no tronco ocorreu na época chuvosa, principalmente durante o periodo de fevereiro a março/1988 (Figura 25a). Somente 6 imaturos (com 7 e 9 segmentos) foram coletados no solo (setembro/1987) e apenas 2 (com 7 segmentos) nos troncos (fevereiro/1988). A determinação dos imaturos através do número de segmentos do corpo foi ilustrada (Figura 25b). A presença dos imaturos, em época e local diferentes, indica uma reprodução polivoltina ou que, provavelmente, os imaturos nesta fase de desenvolvimento não são muito ativos e, portanto, difíceis de serem capturados.

Em região de igapó, $M$. obliteratus habita a camada organica do solo ou regiões mais baixas do tronco e migra para áreas não alagáveis dos troncos ou copas durante à inundação, segundo ADIS (1981). Como estratégia de sobrevivência à inundação eles apresentam uma camada incompleta de plastrão no corpo, o que possibilita permanecerem submersos durante um curto periodo de tempo, conforme mostram os trabalhos de MESSNER \& ADIS (1988), ADIS (1986). 


\subsubsection{STEMMIULIDAE}

Os Stemmiulidae foram capturados no solo e no folhedo. Apenas três indivíduos foram coletados durante a subida nos troncos. Entretanto, a abundância foi maior no final da inundação, com a captura em direção ao solo.

\subsection{SYMPHYLA}

Os sínfilos são miriápodos delgados,
esbranquiçados e que vivem no interior do solo, debaixo de
pedras, madeira em decomposição e se alimentam de raízes de
plantas jovens. Algumas vezes podem ser considerados pragas na agricultura.

Na área em estudo $R$. amazonica e $S$. adisi foram capturadas através do extrator de solo. H. arborea foi capturada através de fotoeclectores de solo e também nos troncos durante a subida e descida da água em fotoeclectores de árvores (BE $\uparrow$ e $B E \downarrow$ ). Os trabalhos de ADIS \& SCHELLER (1984); SCHELLER \& ADIS (1984) e SCHELLER (1992) fornecem dados sobre a biologia e a ecologia destas espécies em florestas inundáveis e floresta de terra firme (primária e secundária). Na floresta inundada por água mista do Lago Janauari, a abundância média de symphyla, foi de 1.060 individuos $/ \mathrm{m}^{2} / \mathrm{mês}$, um valor cinco vezes mais alto do que a média de 208 individuos $/ \mathrm{m}^{2} /$ mês encontrada por ADIS \& SCHELLER (1984), para uma floresta inundada por água preta. 
5.4.1 Ribautiella amazonica Scheller, 1984

(Scolopendrellidae)

Apresenta $2,1 \mathrm{~mm}$ de comprimento e é considerada uma espécie terrestre, não migrante e univoltina. Segundo ADIS (1992a), em floresta inundada por água preta, esta espécie sobrevive à inundação no solo, dentro de raízes de árvores, em fase de dormência. $R$. amazonica apresentou o mesmo comportamento em floresta inundada por água mista, onde, através do método de flotação, foram obtidos subadultos e os últimos estágios juvenis ( 10 pares de pernas) em amostras de solo submerso. Logo após a inundação da floresta (final de julho/1987), estes sínfilos mudam de subadultos para adultos.

Os dados obtidos de extração do solo indicam que a reprodução ocorre no início do período não inundado, quando os primeiros juvenis surgem a partir de setembro, quatro semanas após o solo da floresta ter secado (Figura 29a). R. amazonica é considerada hemiedáfica, pois $76,0 \%$ de todas as espécies extraídas das amostras de solo foram encontradas nos primeiros $7 \mathrm{~cm}$ de profundidade (Figuras $28 a$ e 29b). Estes dados não concordam com aqueles obtidos por ADIS (1992a), em florestas inundadas por água preta, onde $86 \%$ do total coletado no solo foi obtido na camada abaixo de $7 \mathrm{~cm}$ de profundidade e, portanto, a espécie seria considerada euedáfica nesta região.

A densidade populacional foi mais baixa duas semanas antes da inundação. Neste período a maioria dos sínfilos se abriga no interior das raízes, para passar a inundação em fase de dormência. A abundância foi mais alta oito semanas após o final da inundação devido a um alto número de imaturos da progênie nos primeiros $7 \mathrm{~cm}$ de profundidade do solo (Figuras 29a e 29b). 
Não foram obtidos resultados estatisticamente significativos nas correlações entre a distribuição vertical no solo, durante o período não inundado, e os fatores abióticos locais para $R$. amazonica.

\subsubsection{Symphylella adisi Scheller, 1992}

(Scolopendrellidae)

É a espécie de menor tamanho dentre aquelas coletadas na área experimental e atinge no máximo 1,5 mm de comprimento. Ela foi encontrada somente no solo, porém em todas as camadas estudadas (Figura 30A, Apêndice 27).

Não foram obtidos resultados estatisticamente significativos entre a densidade populacional de $S$. adisi e os fatores abióticos da área experimental.

Devido a sua baixa abundância, presume-se que s. adisi sobrevive à inundação em fase de dormência no solo. Entretanto, até o momento, esta espécie ainda não foi encontrada nas amostras de solo retiradas debaixo d'água e se desconhece o tipo de estratégia utilizada. Seis semanas após à inundação quando o solo da floresta já se encontrava totalmente seco, surgiram os primeiros adultos e juvenis (primeiros estágios juvenis, 8 a 9 pares de pernas) no solo $(3,5-14 \mathrm{~cm}$ de profundidade). Os subadultos surgiram a partir do final de outubro (Figuras $30 b$ e 31b). 0 aparecimento de estágios juvenis foi maior durante a estação chuvosa (fevereiro/1988) (Figuras 31a e 31b). Supõe-se que a reprodução ocorra durante este período. A abundância dos subadultos diminuiu, à medida que aumentou a dos estágios juvenis (9 e 10 pares de pernas), até que os subadultos dominaram (Figura 31a). Duas semanas antes da inundação, poucos indivíduos foram encontrados e estavam presentes somente nas camadas inferiores do solo $(10,5-14 \mathrm{~cm})$. A maior 
parte da população, neste período, não estava mais ativa pois já se encontrava em fase de dormência (Figura 31b). Com base nas características acima citadas, $s$. adisi é considerada uma espécie terrícola não migrante e univoltina, com uma fase de dormência (provavelmente os estágios subadulto e últimos estágios imaturos) submerso durante a inundação.

5.4.3 Hanseniella arborea Scheller, 1979

(Scutigerellidae)

É considerada uma espécie migrante e univoltina com aproximadamente $2,7 \mathrm{~mm}$ de comprimento. Em florestas inundadas de água preta os adultos sobrevivem à inundação nas árvores (ADIS \& SCHELLER 1984). Este mesmo comportamento foi confirmado para $H$. arborea em florestas inundáveis de água mista (Apêndice 27 e 28). H. arborea é considerada hemiedáfica, uma vez que $51 \%$ das espécies coletadas no solo foram extraídas da camada superior de 3,5 $\mathrm{cm}$ e $90 \%$ na camada de 0 a $7 \mathrm{~cm}$ de profundidade no solo (Figuras 32a e 33b). Estes dados diferem daqueles obtidos por ADIS \& SCHELLER (1984), em florestas inundáveis de água preta, onde $H$. arborea foi mais abundante de 3,5 a $7 \mathrm{~cm}$ de profundidade (47\% do total capturado) e somente $12 \%$ de todas as espécies foram obtidas na camada superior de 0 a 3,5 cm.

$\mathrm{Na}$ área experimental, o decréscimo na densidade populacional de $H$. arborea, de 3,5 para $14 \mathrm{~cm}$ de profundidade do solo, foi correlacionada com um aumento de grãos < $2 \mu \mathrm{m}$ de argila de $32 \%$ a $49 \%$ por camada de solo ( $p$ $<0,10$ por captura total, p < 0,05 por captura mensal de $10 /$ outubro e $12 /$ dezembro/1987 e 1 a $30 /$ março/1988). A análise granulométrica do tamanho do grão e a composição 
mineral do solo de floresta inundada de água mista e de água preta (IRION \& $\mathrm{ADIS}^{5}$ ) indicaram que a abundância mais baixa de $H$. arborea nas camadas do solo corresponderam à maior presença de grãos $<2 \mu \mathrm{m}$, devido a maior quantidade de argila. Estes dados concordam com aqueles apresentados por ADIS \& SCHELLER (1984), na floresta inundada por água preta, onde a abundância de $H$. arborea foi mais alta com a diminuição na quantidade de grãos $<2 \mu \mathrm{m}$ de argila (12\% de 3,5 a $7 \mathrm{~cm}$ de profundidade do solo) quando comparada às camadas inferiores $(25 \%$ a $31 \%$ de 7 a $14 \mathrm{~cm}$ de profundidade), onde a abundância foi mais baixa. Estes resultados indicam que $H$. arborea tem dificuldade em habitar camadas argilosas do solo, devido, provavelmente, a menor quantidade de oxigênio nestas camadas argilosas e ao seu tamanho relativamente grande (Figuras $32 \mathrm{a}$ e $33 \mathrm{~b}$ ).

A menor abundância desta espécie, no solo de áreas inundáveis por água mista, foi observada durante o início do período não inundado (agosto/1987; 14,4 individuos $/ \mathrm{m}^{2}$ ) (Figuras $33 a$ e $33 b$ ).

Adultos de $H$. arborea retornam ao solo, provenientes da área de tronco e copa, após a inundação e recolonizam a camada superior de $3,5 \mathrm{~cm}$ de profundidade. Estágios juvenis e subadultos da progênie foram detectados somente quatro semanas mais tarde (Figura 33a). Sua abundância foi mais alta no início da estação chuvosa (dezembro/1987 a janeiro/1988), logo após ter ocorrido a reprodução. Os adultos foram dominantes entre fevereiro e abril quando voltaram à superfície (onde eles foram capturados em fotoeclectores de solo) e iniciaram a subida

${ }^{5}$ IRION, G. \& ADIS, J. (Instituto Senckenberg, Wilhelmshaven e Instituto Max-Planck de Limnologia, Plön, Alemanha). Comunicação pessoal, 1994 . 
aos troncos de árvores, aproximadamente 12 semanas antes da inundação da floresta (Figura 33a). Durante o período de menor insolação $o$ número de adultos capturados em fotoeclector de árvore foi mais baixo $(p<0,05)$. Nenhuma correlação foi encontrada entre o número de captura e 0 aumento no nível de água do Rio Negro. Segundo ADIS \& SCHELLER (1984), em florestas de inundação de água preta, adultos de $H$. arborea ocorrem mais freqüentemente em fotoeclector de solo após forte precipitação quando comparado com o período menos chuvoso $(p<0,05)$.

Os dados sobre a fenologia de $H$. arborea em floresta inundada por água mista, obtidos neste trabalho, concordam com os de ADIS \& SCHELLER (1984) para esta espécie em áreas inundáveis por água preta.

\subsection{ARCHAEOGNATHA (Microcoryphia)}

Os Archaeognatha BÖRNER, 1904 ( = Microcoryphia VERHOEFF, 1904) são insetos noturnos, semelhantes a Thysanura e são encontrados sob folhas, cascas, pedras e madeira morta. Estudos realizados por STURM \& ADIS $(1984)^{\prime}$ indicaram que apenas representantes da família Meinertellidae estão presentes na América do Sul. Os primeiros dados sobre a história natural e ecologia dos Meinertellidae na Amazônia Central, fornecidos por ADIS \& STURM (1987a), indicaram a existência de representantes dos gêneros Neomachilellus e Meinertellus na região próxima de Manaus/AM. Na floresta inundada por água mista foram coletadas Meinertellus adisi Sturm, 1983; Neomachilellus scandens Wygodzinsky, 1978 e Neomachilellus adisi Wygodzinisky, 1978, durante o período de estudo. 
5.5.1 Neomachilellus scandens Wygodzinsky, 1978

Em florestas inundáveis no vale do Rio Negro, $N$. scandens é considerada uma espécie terrícola não migrante e univoltina. Os ovos sobrevivem à inundação durante um período de 5 a 6 meses e eclodem no início do período não inundado (ADIS \& STURM, 1987a, 1987b). Comportamento semelhante, para esta espécie, foi observado na floresta inundada por água mista, onde $N$. scandens foi coletada apenas no folhedo através de fotoeclectores de solo. A presença de imaturos pequenos, somente no início da época não inundada (agosto/1987) indica um periodo definido de reprodução (Figuras $34 \mathrm{a}$ e $34 \mathrm{~b}$ ). A eclosão dos ovos deve ter ocorrido no início deste período, pois no mês seguinte (setembro/1987) apenas adultos foram capturados, indicando, assim, que a especle apresenta um desenvolvimento pósembrionário rápido de aproximadamente 40 a 50 dias (de ovo a subadulto)(Figura 34b). Nenhum indivíduo foi coletado descendo ou subindo nos troncos indicando que todo $o$ desenvolvimento ocorre no solo. Ao contrário, em floresta primária e secundária de terra firme, $N$. scandens praticamente não foi coletada no solo (PENNY \& ARIAS, 1982; MORAIS, 1985; RODRIGUES, 1986) e portanto é considerada arborícola. Vive principalmente nas regiões mais baixas do tronco e apresenta um período de reprodução polivoltino ao longo do ano (ADIS \& STURM, 1987a). A mais alta densidade de atividade de $N$. scandens, na área experimental do Lago Janauari, ocorreu em agosto/1987 (3,5 individuos $\left./ \mathrm{m}^{2}\right)$, durante a eclosão, e foi duas vezes mais baixa que a encontrada para florestas inundáveis por água preta ( 7 indivíduos $/ \mathrm{m}^{2}$ ).

Estudos desenvolvidos com eletroforese, utilizando animais provenientes da área experimental, e comparados com áreas inundadas por água preta e regiões de 
terra firme indicam que, apesar de morfologicamente idênticas, existe uma grande diferença genética entre as populações das duas regiões. Uma parte dos indivíduos da floresta inundada por água mista apresentou características genéticas da população existente em floresta inundada por água preta, enquanto que outra parte apresentou características genéticas da população de floresta de terra firme, e segundo WOLF \& ADIS (1992) as duas espécies são consideradas simpátricas. Provavelmente a população de terra firme vizinha migrou para a floresta inundada de água mista. A mudança de um ciclo de vida polivoltino para univoltino, e portanto sazonal, representa uma adaptação ao "pulso de inundação" .

Não foram obtidos resultados estatisticamente significativos entre a densidade populacional de $N$. scandens e os fatores abióticos da área experimental.

\subsubsection{Meinertellus adisi Sturm, 1983}

A maioria dos indivíduos de M.adisi foi capturada nos troncos, e a maior parte foi representada por imaturos, os quais ocorreram durante todo o ano indicando, deste modo, uma reprodução polivoltina (Figuras 36a e 36b). Não houve aumento da atividade, para caracterizar uma migração vertical no período de estudo. Somente alguns imaturos $(n=3)$ foram coletados ocasionalmente no sentido da copa para o solo através de fotoeclector direcionado para baixo ( $B E \downarrow$ : outubro/1987 e abril/1988). Deste modo M. adisi pode ser caracterizada, na área experimental, como uma espécie arborícola não migrante, conforme indicam os trabalhos de ADIS (1992a, 1992b). A espécie foi mais ativa nos troncos durante o período não inundado, e somente alguns individuos imaturos e adultos desceram até o solo 
(Figuras 35a e 35b). Estes dados diferem dos apresentados por ADIS \& STURM (1987a) para floresta inundada por água preta, onde $M$. adisi aparentemente apresenta um período definido de reprodução (bivoltina ou univoltina) e, têm a sua ocorrência limitada à região da copa e parte superior do tronco. Somente durante o período menos chuvoso, os animais desceram temporariamente para partes mais baixas do tronco, mas não chegaram até o solo como ocorreu na floresta inundada por água mista. Segundo ADIS \& STURM (1987a), em floresta primária de terra firme, $M$. adisi apresentou uma reprodução polivoltina, e a atividade se limitou às áreas da copa e do tronco. Entretanto, em floresta secundária de terra firme, alguns subadultos e últimos estágios imaturos foram capturados no solo, durante a estação menos chuvosa. Na floresta inundada por água mista, o número de individuos capturados nos troncos $(\mathrm{n}=91)$ foi intermediário ao encontrado em florestas primária e secundária de terra firme. Aproximadamente duas vezes menos individuos foram coletados nos troncos da área em estudo que na floresta secundária ( (195). Entretanto, na floresta primária, coletaram-se duas vezes menos individuos $(n=44)$ que na área experithertal. Não foram obtidos resultados estatisticamente. significativos entre a densidade populacional de M. adisi e os fatores abióticos da área experimental. 


\subsection{COLEOPTERA}

De acordo com os resultados obtidos, Staphylinidae, Carabidae e Pselaphidae foram as famílias mais abundantes no solo (Figura 37a) e no folhedo e apresentaram uma densidade de atividade elevada nos troncos da floresta inundada por água mista. Estudos desenvolvidos por outros autores demonstram que estas familias são encontrados em todos os tipos de florestas da Amazônia, tais como: florestas inundáveis, segundo os trabalhos de IRMLER (1978, 1979), ADIS \& RIBEIRO (1989), ERWIN (1983), FRIEBE (1984); florestas primárias e secundárias de terra firme, conforme os trabalhos de SCHUBART \& BECK (1968), MORAIS (1985), RODRIGUES (1992) e PENNY \& ARIAS (1982), ou em outras regiões e ecossistemas tropicais e temperados, segundo TRIHAS \& LEGAKIS (1991) e STRÜVE-KUSENBERG (1981). Nos troncos, além de Staphylinidae e Carabidae, foram freqüentes os scolytidae, Curculionidae e Ptiliidae cujo número no folhedo é maior que nos troncos. Platypodidae ainda não foi capturado na floresta inundada por água mista, porém, de acordo com ADIS (1981), foi capturado em número elevado na floresta inundada por água preta e na floresta inundada por água branca.

5.6.1 Abundância e distribuição vertical de Coleoptera no solo

A abundância dos coleópteros adultos no solo foi maior na fase inicial do periodo não inundado (agosto/1987) e na fase final, duas semanas antes da inundação (maio/1988)(Figura 37b). O aumento na abundância durante a fase inicial deste período, provavelmente ocorreu devido ao retorno dos adultos ao solo, no final da inundação, 
enquanto que o aumento na abundância durante a fase final, ocorreu devido à emergência dos adultos no solo, antes da inundação. Isto foi observado pela diminuição no número de larvas e aumento no número de adultos, no solo e folhedo (maio/1988), indicando, deste modo, que houve emergência no solo (Figura 37b; Apêndice 38). A maior abundância das larvas de coleópteros ocorreu na primeira camada do solo e no início da época não inundada (agosto/1987) e, se estendeu até 8 semanas após o final da inundação (outubro/1987) (Figura 38). A abundância elevada de larvas, durante este período, ocorreu em conseqüência da eclosão delas a partir de ovos que, em parte, se encontravam no solo submerso e também foram depositados depois do retorno dos adultos ao solo, no final da inundação. Pois, conforme afirmaram IRMLER (1978, 1979) e ADIS (1982a, 1982b), a reprodução de muitos coleópteros em áreas alagáveis é sincronizada com o período emerso.

Com relação à distribuição vertical no solo, os coleópteros (adultos e larvas) foram mais abundantes na primeira camada (Figura 37a). Esta camada representa a camada orgânica e, portanto, existe maior disponibilidade de alimentos para artrópodos herbivoros, fungivoros (incluíndo por exemplo, Pselaphidae) e, consequentemente, para os predadores (incluíndo por exemplo, muitas espécies de Staphylinidae e Carabidae). Porém adultos de coleópteros herbivoros foram praticamente ausentes no solo.

No que diz respeito às estações sazonais, a abundância dos coleópteros adultos no solo foi maior durante o período chuvoso do que no período menos chuvoso. Porém uma maior abundância foi apresentada pelos predadores (Carabidae e Staphylinidae), seguidos pelos fungívoros (Pselaphidae), tanto na estação chuvosa como na estação menos chuvosa (Tabela 1). Estes dados diferem daqueles apresentados por 
ADIS \& RIBEIRO (1989) para floresta inundada por água branca (Ilha do Careiro), onde a maior abundância no solo, durante a estação chuvosa foi de fungívoros, entretanto, em área de plantação de milho e mandioca, na mesma região, a maior abundância foi dos predadores.

Os resultados das correlações, entre a distribuição vertical dos coleópteros adultos e os fatores abióticos locais, indicaram que a densidade populacional dos coleópteros diminuiu das camadas superiores do solo para as camadas inferiores, com o aumento da umidade do solo ( $p$ < 0,01 em março e p 0,05 em abril/1988), com a diminuição da temperatura do solo ( $p<0,01 \mathrm{em}$ fevereiro e $p<0,05 \mathrm{em}$ março/1988) e com a diminuição do $\mathrm{pH}$ do solo $(\mathrm{p}<0,01 \mathrm{em}$ março/1988).

Com relação às larvas, a abundância das camadas superiores para as camadas inferiores diminuiu, com o aumento da umidade do solo ( $p<0,05$ em setembro, outubro e novembro/1987 e março/1988), com a diminuição na temperatura ( $p<0,05$ em setembro, outubro/1987 e janeiro, fevereiro/1988 e $\mathrm{p}<0,01$ em março/1988) e diminuição do $\mathrm{pH}$ do solo ( $p<0,05$ em março/1988).

5.6.2 Densidade de atividade de Coleoptera no folhedo

A densidade de atividade dos coleópteros no folhedo foi obtida através da captura com fotoeclectores de solo. o número de famílias capturadas $(n=18)$ foi superior ao coletado com armadilhas de Kempson $(n=10)$. Porém, o número de famílias foi inferior ao encontrado por FRIEBE (1984) para floresta inundada por água preta $(n=29)$ e por água branca $(n=28)$. A maior atividade dos coleópteros, no início do período não inundado (agosto/1987), provavelmente foi devido à recolonização do solo, ocasionada pelo retorno 
dos adultos e pela eclosão de larvas e emergência de adultos. A maior atividade observada no final deste período (maio/1988) foi ocasionada pela emergência dos insetos e migração para regiões não inundáveis e ocorreu, principalmente, duas semanas antes da inundação (maio/1988). Dentre as famílias de coleópteros (adultos) capturadas no folhedo foram dominantes: Staphylinidae, Carabidae e Pselaphidae. Estas famílias também são dominantes em áreas inundáveis de água preta e água branca, conforme demonstraram os trabalhos de ADIS (1981 e 1985) e FRIEBE (1984).

No que diz respeito às estações, o grupo mais dominante na estação chuvosa foram os predadores (Carabidae e Staphylinidae), seguidos dos fungívoros (Pselaphidae e Scolytidae) e herbívoros (Chrysomelidae e Curculionidae). Na estação menos chuvosa a maior densidade de atividade foi de predadores, seguido de herbívoros, fungívoros e saprófagos (Tabela 2). Portanto, os predadores foram mais freqüentes tanto no solo como no folhedo durante as duas estações. Estes dados concordam com aqueles apresentados por FRIEBE (1984), para floresta inundada por água branca, onde os predadores foram dominantes (captura com armadilhas de solo ("pitfall traps") e fotoeclectores de solo). Ao contrário, os dados apresentados pelo mesmo autor, demonstram que os saprófagos foram mais freqüentes na floresta inundada por água preta. Supõem-se que a maior densidade de atividade de predadores no folhedo (principalmente staphylinidae e Carabidae), foi devido ao maior número de larvas e pequenos artrópodos existentes na camada orgânica do solo. A atividade de densidade dos herbivoros no folhedo (Cerambycidae, Chrysomelidae, Curculionidae, Elateridae e Scarabaeidae) foi superior quando comparada à encontrada no solo, devido à emergência dos adultos provenientes do solo, 
onde foi capturado maior número de larvas (Apêndices 33 e 38 ).

\subsubsection{Densidade de atividade e migração vertical de Coleoptera nos troncos}

Segundo IRMLER (1979) e ADIS (1992b), a migração dos artrópodos, através dos troncos, em áreas periodicamente inundáveis da Amazônia, é considerada uma das estratégias de sobrevivência à inundação. Estes animais deslocam-se em direção aos troncos e/ou copa das árvores por ocasião da subida da água.

Em fotoeclector direcionado para cima (Apêndice 39), coletaram-se 13 famílias de coleópteros, basicamente todos os grupos encontrados em fotoeclectores de solo e em armadilhas de Kempson. Com relação ao nível trófico, os coleópteros fungívoros foram capturados em maior número, devido à presença dos scolytidae no caule e/ou sob cascas no tronco. Entretanto, se se levam em consideração as diferentes estações, houve oscilação na frequência dos grupos ao longo do ano: na estação chuvosa predominaram os fungívoros (Scolytidae), seguidos pelos predadores (Carabidae e Staphylinidae) e herbívoros (Curculionidae), enquanto que na estação menos chuvosa predominaram os herbívoros, seguidos por predadores e fungívoros (Tabela 3). Estes dados referentes ao período menos chuvoso coincidem com aqueles apresentados por ERWIN \& SCOTT (1980), em trabalho desenvolvido na Zona do canal do Panamá. Eles trabalharam com insetos em árvores cuja predominância foi de herbivoros, seguida de predadores, necrófagos e fungívoros.

$\mathrm{Em}$ fotoeclector direcionado para baixo, a maior ocorrência foi dos predadores (Carabidae e staphylinidae) e a mainr densidade foi devido ao número 
elevado dos Carabidae, no final da inundação (julho e agosto/1987), os quais pouco utilizam o tronco para subirem à copa das árvores e, segundo ADIs et alii (1986), migram pelo vôo, tanto na estação chuvosa quanto na estação menos chuvosa. Na estação chuvosa os predadores (Carabidae) foram mais abundantes, seguidos de fungívoros (Scolytidae e Pselaphidae) e herbívoros (Scarabaeidae) (Tabela 4).

\subsubsection{DENSIDADE DE ATIVIDADE E FENOLOGIA DAS FAMÍLIAS} DE COLEOPTERA CLASSIFICADAS FM NÍVEIS TRÓFICOS

A discussão apresentada a seguir, foi baseada no hábito alimentar das familias, através de fontes obtidas na literatura e, portanto, é necessário um conhecimento mais amplo e a identificação das espécies para se obter melhores resultados a respeito.

\subsubsection{PREDADORES}

Os Staphylinidae foram abundantes no solo, porém, a sua presença foi superior no folhedo e ocorreu no início do período não inundado e duas semanas antes da inundação (Figura 39). Esta maior abundância no início do período não inundado (agosto/1987) foi, provavelmente, devido à recolonização do solo pelos adultos, enquanto que o segundo período (maio/1988) foi, provavelmente, devido à emergência dos adultos no solo antes da inundação. Entretanto, IRMLER (1978, 1979) afirmou que somente algumas espécies estão adaptadas a mudanças periódicas do nível da água, e que a fauna de Staphylinidae e Carabidae, em áreas inundáveis da Amazônia Central, são destruidas, aparentemente de forma catastrófica, durante o período da enchente.

Na área inundada do Lago Janauari, a densidade 
média mensal de Staphylinidae, no solo, obtida através do método de Kempson ( $\approx 150$ indivíduos $/ \mathrm{m}^{2} / \mathrm{mês}$ ) foi superior à encontrada no folhedo, através de fotoeclectores de solo ( $\approx 63$ indivíduos $/ \mathrm{m}^{2} / \mathrm{mês}$ ). o resultado de estudos desenvolvidos por IRMLER (1978), através da captura direta em quadrados de 33 x $33 \mathrm{~cm}$, estão relacionados a seguir: $\approx 249$ indivíduos $/ \mathrm{m}^{2}$ na mesma área inundada do Lago Janauari; $\approx 313$ indivíduos $/ \mathrm{m}^{2}$ na floresta inundada por água preta e $\approx 259$ indivíduos $/ \mathrm{m}^{2}$ na floresta inundada por água branca. Quando se comparam os dados da área experimental com aqueles apresentados por ADIS (1982), percebe-se que a densidade média mensal, no folhedo, foi superior na floresta inundada por água preta (953 indivíduos/mês) e inferior na floresta inundada por água branca ( 35 indivíduos/mês). Entretando, a densidade média mensal no solo, de 0 a $7 \mathrm{~cm}$ de profundidade, foi superior na floresta inundada por água mista ( $\approx 150$ indivíduos $/ \mathrm{m}^{2} / \mathrm{mês}$ ), que a densidade média mensal encontrada por MORAIS (1985) para floresta primária de terra firme ( $\approx 46$ indivíduos $/ \mathrm{m}^{2} / \mathrm{mês}$ ) e a encontrada por RODRIGUES (1992) para floresta secundária de terra firme ( $\approx 96$ indivíduos $/ \mathrm{m}^{2} / \mathrm{mês}$ ).

Nos troncos, o número médio mensal de Staphylinidae, capturados em ambos fotoeclectores de árvores ( $\mathrm{BE} \uparrow$ e $\mathrm{BE} \downarrow$ ), da floresta inundada por água mista ( 8 indivíduos/mês), quando comparado com o trabalho de ADIS (1981), foi inferior ao número capturado em floresta inundada de água preta (35 indivíduos/mês) e ao número capturado em floresta inundada por água branca (79 indivíduos/mês).

No que diz respeito às estações anuais, os staphylinidae do solo foram mais abundantes durante à estação chuvosa, enquanto que no folhedo a maior densidade ocorreu durante à época menos chuvosa. Porém, esta diferença em diferentes épocas está também relacionada com imigração dos adultos no solo após a inundação e à eclosão das larvas 
antes do início da inundação.

A atividade destes coleópteros, na primeira camada do solo (Figura 37a), é determinada pela maior disponibilidade de recurso alimentar, uma vez que a maioria dos adultos e larvas são predadores. Pois, conforme demonstra ADIS (1992b), no período em que o solo não se encontra mais inundado ocorre um aumento considerável de pequenos organismos, principalmente ácaros, colêmbolas e imaturos de pequenos artrópodos. Isto, evidentemente, justifica a presença dos staphylinidae durante este período.

os resultados, obtidos nas correlações entre a distribuição vertical e os fatores abióticos locais, indicam que a abundância dos staphylinidae das camadas superiores para as camadas inferiores do solo diminuiu com 0 aumento da umidade do solo ( $p<0,01$ em março/1988), com a diminuição da temperatura do solo ( $p<0,05$ em março/1988) e diminuição no pH do solo ( $\mathrm{p}<0,01$ em março/1988) nas diferentes camadas.

Carabidae (na maioria representantes de Carabinae) apresentou maior densidade de atividade no folhedo, e o maior número ocorreu no início e no final do período não inundado (Figura 40a). o aumento no início do período não inundado (agosto/1987), certamente ocorreu também devido à recolonização dos adultos no folhedo, enquanto que o segundo aumento, durante o final do período não inundado (maio/1988) foi provavelmente devido à emergência dos adultos no folhedo e migração para os troncos e as copas. A atividade de densidade nos troncos foi elevada logo após a inundação no sentido da copa em direção ao solo. Isto significa que, durante a subida da água, eles voaram até as árvores e, portanto, a captura em fotoeclector direcionado para cima foi inferior, quando comparada com fotoeclector direcionado para baixo. Este tipo de migração já foi 
demonstrado para Polyderis nympha e outras espécies de Carabinae, no estudo realizado por ADIS et alii (1986) e ADIS (1982b), onde o autor relacionou os diferentes tipos de colonização, por carabídeos, em florestas inundáveis da Amazônia Central. Porém, scarites sp. (Carabidae) ADIS et alii, 1990) e Pentacomia egregia (Cicindelinae) que permanece em estado de dormência gonodal durante a inundação (PAARMANN et alii, 1982), representam carabídeos que sobem aos troncos. $\mathrm{Na}$ área inundada do Lago Janauari, a densidade média mensal de Carabidae encontrada no solo, através do método de Kempson ( $\approx 133$ individuos $/ \mathrm{m}^{2} / \mathrm{mês}$ ) foi superior a densidade média mensal, no folhedo, através de fotoeclectores de solo ( $\approx 24$ indivíduos $/ \mathrm{m}^{2} / \mathrm{mês}$ ). Entretanto, trabalhos desenvolvidos por IRMLER (1978), na mesma região, através da captura direta em quadrados de 33 × $33 \mathrm{~cm}$, revelaram uma densidade de $\approx 293$ indivíduos $/ \mathrm{m}^{2}$. O número de coleópteros capturados, pelo mesmo autor na floresta inundada por água preta foi $\approx 134$ indivíduos $/ \mathrm{m}^{2}$ e $\approx 194$ indivíduos $/ \mathrm{m}^{2}$, na floresta inundada por água branca. A densidade média mensal de carabídeos no solo, de 0 a $7 \mathrm{~cm}$ de profundidade, na área experimental ( $\approx 107$ indivíduos $/ \mathrm{m}^{2} / \mathrm{mês}$ ), foi superior à encontrada por MORAIS (1985), em floresta primária de terra firme $\left(<0,1\right.$ indivíduos $\left./ \mathrm{m}^{2} / \mathrm{mês}\right)$ e a encontrada por RODRIGUES (1992) para floresta secundária de terra firme ( $\approx 16$ indivíduos $\left./ \mathrm{m}^{2} / \mathrm{mês}\right)$.

Nos troncos, o número médio mensal de Carabidae, capturados em ambos fotoeclectores de árvores (BE $\uparrow$ e $\mathrm{BE} \downarrow$ ), na floresta inundada de água mista (26 indivíduos/mês), quando comparado com os dados de ADIS (1981), foi semelhante ao número capturado na floresta inundada por água preta (28 indivíduos/mês) e inferior ao número capturado na região de água branca $(43$ indivíduos/mês). 
No tocante às estações anuais, os carabídeos do solo e do folhedo foram mais abundantes durante a época chuvosa. Entretanto, no tronco, eles foram mais freqüentes durante a época menos chuvosa e apresentaram maior atividade no sentido da copa para o solo. Esta atividade foi registrada principalmente no início do período não inundado, quando os insetos desceram para recolonizar o solo.

No que diz respeito à distribuição vertical no solo (captura com o método de Kempson), os carabídeos foram menos abundantes no subsolo mineral, e sua maior atividade ocorreu na camada orgânica do solo e no folhedo, devido a maior disponibilidade de alimento.

Os resultados obtidos nas correlações entre a distribuição dos carabídeos do solo e os fatores abióticos na área experimental, indicam que a variação na abundância das camadas superiores para as camadas inferiores diminuiu com 0 aumento da umidade do solo $(p<0,05$ em dezembro/1987, março/1988 e p < 0,01 em abril/1988), com a diminuição da temperatura do solo ( $p<0,05 \mathrm{em}$ dezembro/1987, fevereiro e março/1988) e com a diminuição no pH do solo ( $p<0,05$ em fevereiro, março e abril/1988 e $p<0,01$ em maio/1988).

Scydmaenidae são predadores especialmente de ácaros e foram pouco abundantes no solo, porém sua maior densidade ocorreu no folhedo (Figura 43). A atividade no tronco foi baixa, indicando, assim, que este grupo vive preferencialmente no solo. A densidade média mensal de Scydmaenidae no solo, de 0 a $7 \mathrm{~cm}$ de profundidade, na floresta inundada por água mista ( $\approx 6$ individuos $/ \mathrm{m}^{2} / \mathrm{mês}$ ) foi inferior à encontrada por MORAIS (1985), para floresta primária de terra firme $\left(\approx 45\right.$ individuos $\left./ \mathrm{m}^{2} / \mathrm{mês}\right)$ e à encontrada por RODRIGUES (1992) para floresta secundária de terra firme ( $\approx 117$ indivíduos $\left./ \mathrm{m}^{2} / \mathrm{mês}\right)$.

Além dos predadores, acima mencionados, foram 
coletados indivíduos pertencentes à família Phengodidae.

\subsubsection{FUNGÍVOROS}

Os Pselaphidae foram mais freqüentes na primeira camada do solo e sua presença foi maior no início e no final do período não inundado (Figura 40b). Com referência às estações sazonais, a sua densidade de atividade foi mais alta durante o período chuvoso tanto no solo como no folhedo e no tronco (captura com fotoeclector de árvore BE $\downarrow$ ). A atividade no tronco foi maior no sentido da copa para o solo, indicando, deste modo, que eles utilizam as árvores como habitat para sobreviver a inundação. O deslocamento para as árvores, provavelmente, foi realizada através do vôo.

A densidade média mensal de Pselaphidae, no solo, de 0 a $7 \mathrm{~cm}$ de profundidade, na área experimental ( $\approx 65$ indivíduos $\left./ \mathrm{m}^{2} / \mathrm{mês}\right)$, foi inferior à encontrada por MORAIS (1985) para floresta primária de terra firme ( $\approx 55$ individuos $/ \mathrm{m}^{2} / \mathrm{mês}$ ) e superior à encontrada por RODRIGUES (1992) para floresta secundária de terra firme ( 110 individuos $/ \mathrm{m}^{2} / \mathrm{mês}$ ).

Os resultados obtidos nas correlações, entre a distribuição vertical e os fatores abióticos locais, indicam que a abundância dos individuos nas camadas superiores do solo para as camadas inferiores diminuiu com o aumento da umidade do solo ( $p<0,05$ em março e abril/1988), com a diminuição da temperatura do solo ( $p<0,05$ em fevereiro e p $<0,01$ em março/1988) e com a diminuição do pH do solo ( $p<0,05$ em março/1988).

Os Scolytidae foram pouco abundantes no solo, porém apresentaram uma alta densidade de atividade no folhedo durante o período chuvoso (Figura 41b). A atividade no 
tronco também /foi alta quando comparada com a do folhedo e foi superior no sentido do tronco para a copa. Os escolitídeos são habitantes dos troncos ou folhedo, uma vez que apresentam hábito alimentar diversificado. Eles constróem galerias sob a casca do tronco das árvores, madeira morta no chão e, algumas espécies, se alimentam de fungos que se desenvolvem no interior dos orifícios. Podem ser ainda encontrados no folhedo, no interior de frutos caídos e galhos. Portanto, em virtude desta diversidade de habitats, não foi possivel determinar nenhum tipo de migração vertical.

A densidade média mensal de Scolytidae, no solo, de 0 a $7 \mathrm{~cm}$ de profundidade, na área experimental ( $\approx 4$ individuos $/ \mathrm{m}^{2} / \mathrm{mês}$ ) foi superior à encontrada por MORAIS (1985), em floresta primária de terra firme $(\approx 3$ individuos $/ \mathrm{m}^{2} / \mathrm{mês}$ ) e à encontrada por RODRIGUES (1992) em floresta secundária de terra firme ( $\approx 3$ individuos $/ \mathrm{m}^{2} / \mathrm{mês}$ ).

Os Ptiliidae se alimentam de esporos de fungos, algumas espécies são inquilinos obrigatórios de formigas. Na área experimental, eles foram mais freqüentes no folhedo, do que no solo e no tronco durante o periodo chuvoso e foram considerados como habitantes de solo e folhedo (Figura 42b).

A densidade média mensal de Ptiliidae, no solo, de 0 a $7 \mathrm{~cm}$ de profundidade, na área experimental ( $\approx 7$ individuos $/ \mathrm{m}^{2} / \mathrm{mês}$ ), foi superior à encontrada por MORAIS (1985), em floresta primária de terra firme ( $\approx 4$ individuos $\left./ \mathrm{m}^{2} / \mathrm{mês}\right)$ e inferior à encontrada por RODRIGUES (1992), em floresta secundária de terra firme ( $\approx 114$ indivíduos $/ \mathrm{m}^{2} / \mathrm{mês}$ ) .

Além das famílias de fitófagos acima mencionadas, coletou-se um individuo de Endomychidae, considerado como ocasional no solo. 
5.6.4.3 HERBÍVOROS

Os Chrysomelidae apresentaram maior atividade quase que exclusivamente no folhedo e durante o período chuvoso. Por ocasião da inundação, provavelmente, eles voam para a região alta dos troncos. Segundo ERWIN (1983), em áreas alagáveis, muitos chrysomelidae ocorrem na copa das árvores, durante a inundação. Na área em estudo, poucos indivíduos foram capturados nos troncos e nenhum indivíduo foi capturado no solo (Figura 41a).

$\mathrm{Na}$ floresta inundada por água mista, o número médio mensal de curculionidae capturado nos troncos ( 4 indivíduos/mês), quando comparado ao trabalho de ADIS (1981), foi inferior ao número encontrado em floresta inundada por água preta ( 35 indivíduos/mês) e ao número encontrado em floresta inundada de água branca (27 indivíduos/mês).

Outras famílias de coleópteros herbívoros encontrados em menor freqüência foram: Cerambycidae, Elateridae e Scarabaeidae.

\subsubsection{SAPRÓFAGOS}

A maioria de adultos e larvas de Hydrophilidae são aquáticos. As larvas são carnívoras e os adultos se alimentam de material vegetal em decomposição. 0 aparecimento dos adultos em fotoeclectores de solo foi somente no início do período não inundado (agosto/1987). Provavelmente, na ocasião em que foi colocada a armadilha no solo, ainda existiam adultos em locais com folhiço e umidade suficiente para mantê-los no local por um certo período de tempo e, portanto, foram capturados.

Os Nitidulidae apresentam hábito alimentar 
bastante diverso. Algumas espécies podem ser consideradas carnívoras, outras se alimentam de pólen, néctar e plantas, porém a maioria é considerada saprófagas. Eles foram capturados somente no folhedo, no início do período não inundado (época menos chuvosa) e desapareceram alguns meses antes da inundação.

Outras familias, com hábitos alimentares não muito bem conhecidos, capturadas na área foram Psephenidae e Brentidae. Entretanto, segundo LIMA (1956), as larvas de várias espécies de Brentidae são micetófagas.

\subsubsection{RELAÇÃO ENTRE OS FATORES ABIÓTICOS E A DENSIDADE POPULACIONAL DE COLEOPTERA}

De acordo com os dados obtidos nas correlações entre os fatores abióticos locais e a densidade populacional dos coleópteros (número de captura total e familias isoladas), percebe-se que a maior influência nas larvas e adultos ocorreu durante o mês de março/1988. Os efeitos da ação conjunta desses fatores, durante este periodo, aparentemente estimulou a emergência dos adultos no solo e, posteriormente, deu início ao processo de emigração para as árvores. Isto pode ser observado pelo aumento na captura dos adultos e diminuição no número total de captura das larvas durante este período (Figura 37b, Apêndice 33). ERWIN \& SCOTT (1980) sugeriram que coleópteros predadores também se alimentam de coleópteros herbivoros. Segundo os autores, isto talvez signifique uma tendência natural na fauna de artrópodos. Entretanto, nenhuma correlação positiva foi encontrada entre os dois grupos. Porém, a densidade populacional dos predadores aumentou juntamente com a dos herbívoros na estação chuvosa. 
5.7 DISCUSSÃO GERAL DOS GRUPOS DE ARTHROPODA CAPTURADOS NO SOLO, NO FOLHEDO E NOS TRONCOS

Os resultados obtidos na captura, em floresta inundada por água mista, indicam que os artrópodos vivem preferencialmente no folhedo e na primeira camada do solo.

Seis a oito semanas após a inundação, o solo da floresta inundada por água mista foi recolonizado por uma grande quantidade de Arthropoda adultos e imaturos. Os animais retornaram ao solo, provenientes de troncos, copas ou áreas adjacentes. o retorno desses animais ao solo, após a inundação, segundo ADIS (1981) e ADIS \& SCHUBART (1984), pode ter sido estimulado, principalmente, pela forte insolação que normalmente ocorre no mês de julho e pela queda das folhas, durante este período. Na área experimental do Lago Janauari, o aumento na densidade populacional durante este período foi representado principalmente por imaturos e/ou adultos de Araneae, Pseudoscorpiones, Chilopoda, Diplopoda, Symphyla, Coleoptera e Formicidae. A densidade populacional de imaturos aumentou também, segundo ADIS (1992a), em conseqüência de ovos anteriormente deixados no solo e que eclodiram após a inundação, como por exemplo, alguns Acari (Eremobelba foliata), Collembola (Arthropleona e Symphypleona), Chilopoda (Lamyctes sp.) e Meinertellidae (Neomachilellus scandes).

o número de Arthropoda capturado no solo e no folhedo, aumentou gradativamente, nos meses subseqüentes após a inundação, à medida que o solo foi sendo recolonizado e, conseqüentemente, iniciou-se a reprodução de alguns grupos. A densidade populacional no solo foi mais elevada no início do período chuvoso (dezembro/1987), ocasionada principalmente pelo aumento na densidade de atividade de Araneae, Pseudoscorpiones, Diplopoda e Formicidae. Ao 
contrário, no folhedo, o aumento na densidade populacional dos artrópodos ocorreu seis a oito semanas após a inundação devido a maior abundância principalmente de Diptera (especialmente Cecidomyiidae) e microhimenópteros.

Alguns grupos, cuja freqüência é relativamente alta em florestas de terra firme da Amazônia, não foram capturados na floresta inundada por água mista, tais como: Projapygidae, Campodeidae (Diplura), Palpigradi e Protura. Dermaptera, ocorre no solo em micro-habitats especiais, tais como frutos caídos ou no interior de madeira morta e foram capturados em menor número através do método de extração de Kempson. Entretanto alguns subiram aos troncos, por ocasião da inundação, e retornaram ao solo logo após.

Em fotoeclector de solo, a densidade de atividade e a abundância de emergência foram superiores em outubro/1987, período este equivalente ao mês mais quente na área durante a época em estudo. Este aumento se deu, principalmente, devido ao elevado número de cecidomyiidae e microhimenópteros capturados.

Devido a mudanças climáticas ocasionadas pelo inicio das chuvas, a migração de determinados grupos mais sensiveis, tais como Pseudoscorpiones e symphyla, iniciou-se mais cedo, em janeiro e fevereiro/1988. Outros grupos, presentes no folhedo, tais como, alguns Isopoda, algumas Araneae, Opiliones, Blattodea (ninfas e adultos), Heteroptera (principalmente Dipsocoridae e Gelastocoridae adultos), migraram somente por ocasião da chegada da água (Apêndices 46 e 47). Dois meses antes da inundação (abril/1988), iniciou-se a migração dos outros grupos de artrópodos, para a região de troncos e copas, onde se observou o aumento na densidade populacional no solo, principalmente de Diplopoda, algumas espécies de Araneae e alguns Isopoda. No mês seguinte (maio/1988), este aumento na 
densidade populacional foi observado no folhedo, pelos mesmos grupos de artrópodos, como também por outros grupos, tais como, adultos de coleópteros e formigas. Por exemplo, segundo ADIS et alii (1993), Cutervodesmus adisi Golovatch, 1992 (Fuhrmannodesmidae, Polydesmida, Diplopoda), inicia a subida nos troncos, 6 a 9 semanas antes da inundação. A migração dos artrópodos do solo para a região de troncos e copas é estimulada principalmente, segundo ADIS (1992b), por fatores abióticos, especialmente fatores climáticos, tais como: umidade do solo, aumento na umidade relativa do ar e diminuição da temperatura do solo, como também pela diferença entre os extremos de temperatura ocorridos durante o dia e a noite.

Com relação às estações anuais, a maior abundância dos artrópodos, no solo, ocorreu durante o periodo chuvoso, sendo que os grupos dominantes foram Arachnida, Myriapoda, Isopoda e Formicidae, enquanto que no folhedo, a densidade foi maior durante o periodo menos chuvoso, devido à alta densidade de atividade de Diptera (principalmente Cecidomyiidae). Arachnida, Myriapoda, Isopoda e Formicidae foram mais freqüentes durante o período chuvoso.

A subida da água no início da inundação, provocou a migração para cima nos troncos, e a saída da água no final, provocou a migração para baixo, favorecendo assim uma alta densidade de atividade de determinados grupos como Brachycera por exemplo, a qual ocorreu logo após a inundação. Excluindo-se as capturas de Brachycera (julho/1987), em fotoeclector de árvore direcionado para cima ( $B E \uparrow)$, o número de artrópodos na estação chuvosa, independente da inundação $(n=6.287)$ foi superior ao número capturado na estação menos chuvosa ( $n=3.588)$. Em menor número, ocorreram ninfas de Tettigonioidea, Grylloidea, 
Mantodea, Phasmatodea, Blattodea, Hemiptera (ninfas) e Homoptera. Os predadores, principalmente aranhas e formigas, que dominaram tanto no solo como no folhedo, também tiveram uma densidade elevada nos troncos, quando comparados com os demais grupos de artrópodos. A maioria dos Embioptera foi capturada no tronco, apenas em fotoeclector direcionado para cima, durante o período menos chuvoso. Provavelmente, devido à vida gregária arborícola.

De acordo com os dados analisados, pode-se afirmar que numerosos artrópodos sobrevivem à inundação, seja nos troncos, nas copas, em áreas vizinhas através de adaptações desenvolvidas. Entretanto, conforme demonstram os trabalhos de ADIS (1981) e ADIS \& SCHUBART (1984), o ciclo de inundação causa um impacto dramático sobre a fauna das florestas inundáveis e uma grande parte dos artrópodos perece durante a inundação. o número real de artrópodos que sobem aos troncos é, na realidade, superior ao número revelado pelos dados de captura. FUNKE (1971) indica que até $35 \%$ dos artrópodos conseguem ultrapassar a barreira do fotoeclector de árvore, em regiões temperadas e alcançam as regiões mais altas do tronco e copa. Isto foi reconfirmado por ADIS (1984) e PLATNICK \& HÖFER (1990). Alguns artrópodos podem subir e permanecer durante à inundação no interior de troncos ocos.

A abundância e a distribuição vertical dos grupos de artrópodos no solo e a ocorrência nos troncos variou, ao longo do ano, de acordo com as estações anuais (estação chuvosa e menos chuvosa), com os fatores abióticos locais e com o período de enchente e vazante. No solo, a densidade de atividade de Formicidae, por exemplo, foi maior durante a estação chuvosa e apresentou diferença estatística significativa entre as duas estações. Entretanto esta diferença não foi observada no folhedo, uma vez que, a 
densidade populacional aumentou duas semanas antes da inundação, devido à migração vertical as árvores. Nos troncos, a atividade das formigas ocorreu durante todo o ano. Houve diferença significativa entre as duas estações durante a migração do solo para a região do tronco, e a densidade de atividade aumentou também com 0 início das chuvas (dezembro/1987). No início do período não inundado, as formigas retornaram para recolonizar o solo. Entretanto, o maior número capturado na descida da copa em direção ao solo $(\mathrm{BE} \downarrow)$, ocorreu no início da inundação, indicando, deste modo, que devido à alta atividade nos troncos, as formigas são inevitavelmente capturadas ao mesmo tempo pelos dois tipos de fotoeclectores ( $\mathrm{BE} \uparrow$ e $\mathrm{BE} \downarrow$ ). Isto não caracteriza nenhuma migração e sim a falha no método de captura.

Com relação à distribuição vertical no solo, a maior abundância ocorreu na camada orgânica e diminuiu até - subsolo mineral. o resultado das correlações, por exemplo, entre Formicidae e os fatores abióticos locais indicam que a distribuição vertical diminuiu, das camadas superiores para as camadas inferiores do solo, com o aumento da umidade do solo ( $p<0,01$ em dezembro/1987 e $p<0,05$ em março/1988), com a diminuição da temperatura do solo ( $p$ < 0,05 em dezembro/1987 e $p<0,01$ em março/1988) e com o aumento e a diminuição do $\mathrm{pH}$ do solo $(\mathrm{p}<0,01 \mathrm{em}$ dezembro/1987 e $\mathrm{p}<0,05$ em março/1988, respectivamente). Os dados de captura, obtidos com o método de Kempson, revelam que a abundância média mensal de Formicidae no solo na floresta inundada por água mista ( $\approx 1.863$ indivíduos $\left./ \mathrm{m}^{2} / \mathrm{mês}\right)$, foi inferior à encontrada por RODRIGUES (1986), em floresta secundária de terra firme ( $\approx 2.766$ indivíduos $\left./ \mathrm{m}^{2} / \mathrm{mês}\right)$ e à encontrada por MORAIS (1985), em floresta primária de terra firme ( $\approx 3.679$ indivíduos $/ \mathrm{m}^{2} / \mathrm{mês}$ ). Com relação à abundância de emergência nas áreas alagáveis (captura com fotoeclector de 
solo), a abundância média mensal por fotoeclector de solo, na floresta inundada por água mista ( $\approx 59$ indivíduos $/ \mathrm{m}^{2} / \mathrm{mês}$ ), foi superior à encontrada por ADIS (1981), para floresta inundada por água preta ( $\approx 19$ indivíduos $\left./ \mathrm{m}^{2} / \mathrm{mês}\right)$ e para floresta inundada por água branca ( $\approx 11$ indivíduos $/ \mathrm{m}^{2} / \mathrm{mês}$ ).

Araneae foi um dos grupos dominante no solo. A atividade de densidade foi maior no início da estação chuvosa com o aumento da precipitação pluviométrica ( $\mathrm{p}<$ $0,05)$. Houve diferença estatística significativa, entre as duas estações anuais, nos diferentes habitats (solo, folhedo e troncos). No solo, no folhedo e durante a migração para cima, a maior densidade ocorreu durante a estação chuvosa. Duas semanas antes da inundação, iniciou-se a migração das aranhas pequenas, para a região dos troncos e copas que, conforme afirma ADIS (1984), a maioria migra, no momento em que a floresta está sendo inundada. Na área experimental, as aranhas permaneceram nos troncos e copas durante todo este período e retornaram ao solo após a descida da água. No solo, elas vivem preferencialmente na camada de 0 a $7 \mathrm{~cm}$ de profundidade, entretanto, nenhuma correlação significativa foi encontrada entre a distribuição vertical no solo com os fatores abióticos da área. De acordo com os dados de captura, através do método de Kempson, a abundância média mensal de Araneae, no solo da floresta inundada por água mista ( $\approx 670$ indivíduos $/ \mathrm{m}^{2} / \mathrm{mês}$ ), foi superior à encontrada por MORAIS (1985), em floresta primária ( $\approx 411$ indivíduos $/ \mathrm{m}^{2} / \mathrm{mês}$ ) e semelhante à encontrada por RODRIGUES (1986), em floresta secundária de terra firme ( $\approx 592$ indivíduos $\left./ \mathrm{m}^{2} / \mathrm{mês}\right)$. Com relação às áreas inundáveis, a densidade média em fotoeclectores de solo na área experimental ( $\approx 50$ indivíduos $/ \mathrm{m}^{2} / \mathrm{mês}$ ) foi inferior à encontrada por ADIS (1981) para floresta inundada por água preta ( $\approx 123$ individuos $/ \mathrm{m}^{2}$ ) e superior à encontrada para floresta inundada por água branca 
( $\approx 14$ indivíduos $/ \mathrm{m}^{2} / \mathrm{mês}$ ). Trabalhos desenvolvidos por HÖFER (1990) e PLATNICK \& HÖFER (1990), em floresta inundada por água preta (captura com fotoeclector de solo e armadilhas de solo), indicam que a densidade de atividade foi maior em fevereiro e março. o autor afirmou que muitas espécies se movem gradualmente próximo à linha da água, onde é maior o número de presas e seguem, quando possível, em direção a áreas adjacentes de terra firme ou áreas mais altas do tronco. Entretanto, PLATNICK \& HÖFER (1990) afirmaram que a migração de algumas espécies pode começar dois meses antes da inundação.

Dentre as famílias de Diplura existentes na Amazônia, capturaram-se apenas Japygidae na área experimental. Houve diferença estatística significativa no solo, entre as duas estações, e a maior abundância ocorreu durante o período menos chuvoso. Os primeiros Japygidae surgiram no solo no início do período não inundado e a densidade de atividade foi maior seis semanas após (outubro/1987), indicando, deste modo, eclosão e/ou emergência no solo. Com a subida da água a densidade populacional decresceu e o menor número capturado foi duas semanas antes da inundação (maio/1988). Durante o período inundado, os Japygidae se abrigam em casulos, construídos através de um par de glândulas secretoras, localizadas no primeiro segmento abdominal, conforme indicaram ADIS et alii (1989), onde sobrevivem durante um período de 5 a 6 meses no solo inundado. Embora a distribuição no solo da área experimental não tenha sido homogênea em todas as camadas $(66,7 \%$ foram encontrados na camada de 0 a $7 \mathrm{~cm}$ de profundidade), os Japygidae são considerados euedáficos. Os indivíduos capturados na área experimental são fitófagos 
$\left(A^{\prime} I S^{6}\right)$ e, portanto, vivem na camada mais superficial do solo. Entretanto, o decréscimo na densidade populacional de Japygidae, de 3,5 para $14 \mathrm{~cm}$ de profundidade no solo, foi correlacionada com o aumento do teor de argila de $32 \%$ a 49 $\%$ por camada de solo ( $p<0,05$ em outubro/1987 e janeiro/1988), indicando, deste modo, que os Japygidae provavelmente têm dificuldades em habitar camadas mais profundas, devido a problemas de aeração no solo, ocasionada pelo maior teor de argila e ao seu tamanho relativamente grande (até $3,5 \mathrm{~mm}$ ). Estudos desenvolvidos por SERAFINO \& MERINO (1978), em áreas cultivadas da Costa Rica, indicaram que a distribuição no solo foi homogênea em todas as camadas. Ao contrário, os resultados obtidos por PRICE \& BENHAM (1977), na Califórnia, revelaram que os Japygidae foram mais abundantes abaixo de $30,5 \mathrm{~cm}$ de profundidade no solo. Os dados de captura obtidos através do método de Kempson, indicam que a abundância média mensal de Japygidae no solo da floresta inundada por água mista (428 indivíduos $/ \mathrm{m}^{2} / \mathrm{mês}$ ), foi intermediária entre à encontrada por MORAIS (1985), na floresta primária de terra firme (263 indivíduos $/ \mathrm{m}^{2} / \mathrm{mês}$ ) e por RODRIGUES (1986), na floresta secundária ( 936 indivíduos $/ \mathrm{m}^{2} / \mathrm{mês}$ ).

Pauropoda são animais terrestres com alguns milímetros de comprimento e, segundo LAGERLÖF \& SCHELLER (1989), vivem nas camadas inferiores do solo devido ao seu pequeno tamanho. A forma delgada do corpo permite um movimento eficiente através dos poros e cavidades do solo. são, portanto, considerados euedáficos, porém na área experimental $76,0 \%$ foram capturados na camada de 0 a $7 \mathrm{~cm}$ de profundidade no solo. A preferência por esta camada é

${ }^{6}$ ADIS, J. (Instituto Max-Planck de Limnologia, Plön, Alemanha). Comunicação pessoal, 1994 . 
devido ao hábito alimentar, que segundo BELFIELD (1956), é baseado em humus, material animal e vegetal em decomposição. Entretanto, trabalhos desenvolvidos por PRICE \& BENHAM (1977), na Califórnia, indicaram que os Pauropoda podem ocorrer também abaixo de $30,5 \mathrm{~cm}$ de profundidade no solo.

$\mathrm{Na}$ área experimental, houve diferença estatística significativa durante as estações do ano, sendo que a maior abundância ocorreu durante a estação chuvosa. Entretanto, a densidade populacional diminuiu durante este período, duas semanas antes da inundação, indicando, deste modo, uma possível estratégia de sobrevivência à inundação não conhecida nos pauropodas (resistência à submersão) e que poderá ser objeto de estudo posteriormente.

Não foram obtidos resultados, estatisticamente significativos, nas correlações entre a distribuição de Pauropoda ao longo do ano e a temperatura do ar, umidade relativa do ar e precipitação pluviométrica. Entretanto, a densidade populacional no solo diminuiu, das camadas superiores para as camadas inferiores, com o aumento da umidade do solo ( $p<0,01$ em janeiro/1988 e $p<0,05$ em março/1988), com a diminuição da temperatura do solo ( $p<$ 0,01 em janeiro/1988) e com a diminuição do pH do solo ( $\mathrm{p}<$ 0,05 em março/1988). O decréscimo na densidade populacional de Pauropoda, de 3,5 para $14 \mathrm{~cm}$ de profundidade no solo, foi correlacionada com o aumento no teor de argila de $32 \%$ a $49 \%$ por camada de solo ( $p<0,05$ em janeiro, fevereiro e abril/1988). Assim, a abundância de Pauropoda em determinadas áreas diminuiu quando o teor de argila no solo foi mais alto, e conseqüentemente apresentou uma menor quantidade de oxigênio nesta camada. Por outro lado, trabalhos desenvolvidos por MERINO \& SERAFINO (1979), com fauna de solo, em áreas cultivadas da Costa Rica, demonstraram que a densidade de Pauropoda foi maior nas camadas mais profundas 
do solo (de 5 a $20 \mathrm{~cm}$ de profundidade).

Os dados de captura, obtidos com o método de extração do Kempson, revelam que a abundância média mensal de Pauropoda no solo da floresta inundada por água mista ( 2390 indivíduos $\left./ \mathrm{m}^{2} / \mathrm{mês}\right)$, foi semelhante à encontrada por MORAIS (1985), na floresta primária de terra firme ( $\approx 397$ indivíduos $\left./ \mathrm{m}^{2} / \mathrm{mês}\right)$ e inferior à encontrada por RODRIGUES (1986), em floresta secundária de terra firme ( $\approx 1.274$ indivíduos $/ \mathrm{m}^{2} / \mathrm{mês}$ ). Porém, o número de espécies nas florestas inundáveis é menor do que em florestas de terra firme (SCHELLER ${ }^{7}$ ).

Dentre os Homoptera capturados no solo e no folhedo, a maior densidade foi de Coccoidea (na maioria ninfas e adultos de Pseudococcidae). Com relação às estações anuais, houve diferença estatística significativa somente com os machos adultos, no solo, que foram mais abundantes durante - período chuvoso. As ninfas e fêmeas adultas foram capturadas no solo, durante todo o período em estudo. Entretanto, a maior densidade populacional ocorreu no início de período emerso, seis semanas após a inundação (setembro/1987), indicando, deste modo, o período de reprodução no solo. Machos adultos foram mais abundantes, no folhedo, em outubro/1987, indicando assim um ciclo de desenvolvimento pós-embrionário relativamente curto. Houve outro aumento na densidade populacional das ninfas e fêmeas adultas no solo, em dezembro/1987 e janeiro/1988, provavelmente provenientes da progênie anterior, e um novo aumento na densidade populacional dos machos adultos em janeiro e fevereiro/1988, caracterizando, deste modo, mais de um ciclo de desenvolvimento no solo. Na área experimental,

'SCHELLER, U. (Häggboholm, Häggesled. S - 53194 Järpås, Suécia). Comunicação pessoal, 1994. 
ninfas e fêmeas adultas de coccoidea são consideradas hemiedáficas uma vez que $67,4 \%$ foram extraídas na camada de 0 a $7 \mathrm{~cm}$ e $32,6 \%$ foram extraídas na camada de 7,5 a $10 \mathrm{~cm}$ de profundidade. Machos adultos vivem preferencialmente no folhedo. Eles sobrevivem a inundação, segundo ADIS \& MESSNER (1991) e ADIS (1992b), debaixo d’água, envolvidos por uma proteção de cera em todo o corpo.

\section{Nenhum resultado,}

estatisticamente significativo, foi obtido nas correlações entre a abundância de Coccoidea, ao longo do ano, e a temperatura do ar, a umidade relativa do ar e a precipitação pluviométrica. Entretanto, os resultados das correlações entre a distribuição vertical das ninfas e fêmeas adultas com os fatores abióticos locais, indicam que a densidade populacional diminuiu, das camadas superiores para as camadas inferiores, com o aumento da umidade do solo ( $p$ < 0,05 em janeiro/1988), com a diminuição na temperatura do solo ( $p<0,05 \mathrm{em}$ janeiro/1988) e com o aumento no teor de argila de $32 \%$ a $49 \%$ por camada do solo ( $p<0,05$ novembro/1987, janeiro, abril e maio/1988). Portanto, ninfas e fêmeas adultas de Coccoidea provavelmente têm dificuldades em habitar determinadas áreas, onde o teor de argila é mais elevado, dificultando assim a sua sobrevivência devido a quantidade de oxigênio mais baixa nesta camada. A densidade populacional dos machos adultos diminuiu com 0 aumento na profundidade do solo, de 3,5 para $14 \mathrm{~cm}$, com 0 aumento da umidade e pH do solo ( $\mathrm{p}<0,05$, em dezembro/1987). Ao contrário, trabalhos desenvolvidos em áreas cultivadas na Costa Rica, por MERINO \& SERAFINO (1978), não indicaram nenhuma relação com os fatores climáticos da área. Entretanto, estes autores afirmaram que a distribuição vertical de Coccoidea, no solo, foi relativamente uniforme nas diferentes camadas estudadas (4 sub-amostras de $5 \mathrm{~cm}$ de 
profundidade). Posteriormente, SERAFINO \& MERINO (1978) verificaram que o fator mais importante, que determinou a distribuição de Coccoidea no solo, foi a densidade entre plantas, em plantio de café. Os autores afirmaram que o nicho ecológico de Coccoidea está diretamente relacionado com as raízes dos arbustos de café, e sua abundância no solo aumentou na profundidade de 10 a $15 \mathrm{~cm}$. Isto justifica a maior densidade populacional de Coccoidea, na floresta inundada por água mista do Lago Janauari, de 0 a $7 \mathrm{~cm}$ de profundidade, uma vez que é nesta camada que se encontra a maior quantidade de pequenas raízes, suficientes para a sua sobrevivência.

Os dados de captura com o método de Kempson revelam que, na área experimental, a abundância média mensal de Coccoidea (adultos e ninfas; $\approx 447$ indivíduos $/ \mathrm{m}^{2} / \mathrm{mês}$ ) foi inferior à encontrada por RODRIGUES (1986), para floresta secundária de terra firme ( $\approx 1.360$ indivíduos $\left./ \mathrm{m}^{2} / \mathrm{mês}\right)$.

A maioria dos Isoptera foram coletados, na superfície do solo (método de Kempson e fotoeclectores de solo). A captura nos troncos pode ter sido influenciada, segundo ADIS (1981), pela precipitação pluviométrica, onde eles são levados para baixo juntamente com as galerias. Não houve diferença significativa, na captura, entre a estação chuvosa e a estação menos chuvosa, embora a densidade de atividade tenha sido maior durante a estação chuvosa. A abundância de Isoptera, das camadas superiores para as camadas inferiores do solo, decresceu com o aumento da umidade do solo ( $p<0,05$, em maio/1988) e com a diminuição do $\mathrm{pH}$ do solo ( $\mathrm{p}<0,05$, em maio/1988). Do total de Isoptera capturado no solo (método de Kempson), 32,0 \% foi representado por Nasutitermes sp.. Este gênero, juntamente com Anoplotermes sp., segundo MARTIUS (1989), são dominantes em área de várzea. Entretanto, de acordo com MARTIUS (1994a, 
1994b, 1994C), Nasutitermes sp. representa, sozinho, aproximadamente $25 \%$ da população de térmitas no campo (em floresta de várzea). Eles constroem ninhos em árvores que, quando abandonados, servem de abrigos para outros artrópodos durante a inundação (Arachnida, Diplopoda, Blattodea, Staphylinidae e Formicidae). Durante o período não inundado, eles usam também o chão da floresta como fonte alimentar. Os dados de captura, através do método de Kempson, indicam que a abundância média mensal de Isoptera, no solo da floresta inundada por água mista ( $\approx 223$ indivíduos $\left./ \mathrm{m}^{2} / \mathrm{mês}\right)$, foi inferior à encontrada por MORAIS (1985), em floresta primária de terra firme ( $\approx 1.560$ individuos $/ \mathrm{m}^{2} / \mathrm{mês}$ ) e inferior à encontrada por RODRIGUES (1986), em floresta secundária de terra firme $\left(\approx 3.622\right.$ individuos $\left./ \mathrm{m}^{2} / \mathrm{mês}\right)$. A estratégia de sobrevivência dos Nasutitermes spp. à inundação, conforme indica o trabalho de MARTIUS (1992), é a estocagem de alimentos nos ninhos arborícolas e que facilita a sua sobrevivência durante a inundação.

Diptera (adultos) foi o grupo de maior ocorrência na área; especialmente Cecidomyiidae (Nematocera) foi mais abundante no solo e no folhedo. Entretanto, nos troncos (captura com fotoeclector $\mathrm{BE} \downarrow$ ) a maior ocorrência foi de Brachycera adultos. No solo, a abundância das larvas de Diptera diminuiu, das camadas superiores para as camadas inferiores, com $o$ aumento da umidade do solo ( $p<0,05$, em outubro, novembro, dezembro/1987, março e maio/1988), com a diminuição da temperatura do solo ( $p<0,01$, em outubro/1987 e $\mathrm{p}<0,05$, em março/1988) e com a diminuição do $\mathrm{pH}$ do solo $(p<0,05$, em março e maio/1988).

Thysanoptera foram capturados em maior número

no solo e no folhedo, e a maior densidade de atividade ocorreu na primeira camada, uma vez que alguns são predadores e outros são fitófagos ou se alimentam de esporos de fungos. 
Houve diferença significativa entre as estações anuais, tanto no solo como no folhedo e a maior densidade de atividade ocorreu durante o período menos chuvoso. A ocorrência nos troncos foi baixa. Não existe nenhuma informação sobre migração ou estratégia de sobrevivência à inundação utilizada por Thysanoptera.

Os dados de captura, com o método de Kempson, revelam que a abundância média mensal de Thysanoptera, no solo da floresta inundada por água mista $(\approx 77$ indivíduos $\left./ \mathrm{m}^{2} / \mathrm{mês}\right)$, foi superior à encontrada por MORAIS (1985), em floresta primária de terra firme ( $\approx 52$ individuos $/ \mathrm{m}^{2} / \mathrm{mês}$ ) e inferior à encontrada por RODRIGUES (1986), para floresta secundária de terra firme ( $\approx 193$ indivíduos $/ \mathrm{m}^{2} / \mathrm{mês}$ ).

Conforme estudos desenvolvidos por BAZ (1991), a distribuição de Psocoptera é extremamente variável, provavelmente em conseqüência do seu hábito alimentar que, segundo BORROR \& DELONG (1968), preferem fungos, cereais, pólen, fragmentos de insetos mortos, etc. Poucos estudos sobre Psocoptera edáficos foram realizados, e, de acordo com SEASTEDT (1984), eles atuam na decomposição do folhedo. Na área experimental, eles foram capturados em maior número nos troncos que no solo e no folhedo. Entretanto, no solo, a maioria de Psocoptera capturados foram ninfas, e a maior abundância ocorreu na camada inferior, provavelmente como forma de evitar a predação, que é maior na camada superior. Os dados de captura com o método de Kempson revelam que a abundância média mensal de Psocoptera ( $\approx 33$ indivíduos $/ \mathrm{m}^{2} / \mathrm{mês}$ ) foi semelhante à encontrada por MORAIS (1985), para floresta primária de terra firme $(\approx 31$ indivíduos $/ \mathrm{m}^{2} / \mathrm{mês}$ ) e superior à encontrada por RODRIGUES (1986), para floresta secundária de terra firme ( $\approx 8$ indivíduos $\left./ \mathrm{m}^{2} / \mathrm{mês}\right)$. Na área experimental, houve diferença 
significativa na captura entre às estações anuais, tanto no solo como nos troncos. No solo, a maior densidade de atividade foi durante à estação menos chuvosa, enquanto que no folhedo foi durante à estação chuvosa. Nos troncos, a densidade foi maior no período chuvoso, provavelmente ocasionada pela migração de parte da população para os troncos e copas. Em fotoeclector direcionado para baixo, a maior captura ocorreu na estação menos chuvosa, devido, provavelmente, ao retorno da população ao solo após a inundação. A mudança de habitat nos Psocoptera já foi mencionada por BAZ (1991), na Espanha. O autor afirmou que em determinadas espécies (Caecilius flavidus Stephens, 1836) a primeira geração vive no folhedo e, em seguida, os adultos voam para as árvores. Entretanto, trabalhos desenvolvidos por NEW et alii (1991) em floresta primária e secundária de terra firme da Amazônia, revelaram pouca evidência no intercâmbio de Psocoptera entre o solo e árvores. Dados apresentados por PENNY \& ARIAS (1982), em floresta primária de terra firme, indicaram que, psocópteros alados foram capturados em grande número em armadilhas colocadas a $15 \mathrm{~m}$ de altura, assim como em armadilhas de vôo ("flight traps"), indicando, deste modo, uma alta mobilidade de espécies arborícolas.

De acordo com os resultados obtidos, percebese que inúmeras questões permanecem sem respostas, como por exemplo, quais as estratégias de sobrevivência utilizadas por Pauropoda, Thysanoptera etc. Portahto, é de fundamental importância a identificação futura a nível de espécie e a necessidade de um trabalho conjunto com inúmeros taxônomos. 
5.8 COMPARAÇÃO ENTRE A FAUNA DA FLORESTA INUNDADA POR ÁGUA MISTA E A FAUNA DAS FLORESTAS DE VÁRzEA E IGAPÓ.

Segundo IRMLER (1975), em média, aproximadamente $5,4 \mathrm{t} / \mathrm{ha}$ de peso seco de folhedo cobre o solo da floresta de água mista do lago Janauari. Na floresta inundada por água preta, esta quantidade é superior, chegando a aproximadamente $18 \mathrm{t} / \mathrm{ha}$ no final da inundação $e$ aproximadamente $9 \mathrm{t} / \mathrm{ha}$ no começo da inundação. Na floresta inundada por água branca, esta quantidade decresce para uma média de aproximadamente 3,6 t/ha. Naturalmente, esta grande diferença na quantidade de folhedo sobre o solo afeta diretamente a abundância e a diversidade dos animais terrícolas.

Portanto, comparando-se os dados obtidos da fauna de Arthropoda, coletada na área experimental, com a fauna já conhecida da floresta inundada por água preta (igapó) e com a floresta inundada por água branca (várzea), percebe-se que a maioria da fauna terrícola não voadora, da floresta inundada por água mista, representa a fauna do igapó, porém em número e abundância reduzido. Por outro lado, o número de indivíduos capturado na área experimental foi superior ao encontrado na floresta de várzea, porém as espécies foram diferentes daquelas já mencionadas por ADIS (1981), ADIS \& MAHNERT (1990a) e MAHNERT \& ADIS (1985). Por exemplo, dentre as quatro espécies de Pseudoscorpiones capturadas na área experimental, Tyrannochthonius amazonicus, Geogarypus amazonicus e Pachyolpium irmgardae são representantes da fauna da floresta inundada por água preta, enquanto que Pseudochthonius homodentatus habita floresta primária e secundária de terra firme, conforme indicam ADIS 
(1981) e MAHNERT \& ADIS (1985). Entretanto, estas espécies não fazem parte da fauna de solo da floresta de várzea, onde, segundo ADIS(1981) e ADIS \& MAHNERT (1990a), a maioria dos artrópodos terrestres, nesta área, vive preferencialmente na região dos troncos e copas. T. amazonicus, é considerada, segundo ADIS \& MAHNERT (1985), uma espécie endêmica noturna do igapó, que sobrevive à inundação nas árvores, copas e embaixo de cascas e recoloniza o solo da floresta no início do período não inundado. É, portanto, considerada como uma espécie terrícola migrante e apresentou estas mesmas características na floresta inundada por água mista. $P$. irmgardae é uma espécie arborícola migrante, provavelmente originada do igapó e que colonizou secundariamente florestas de terra firme. $\mathrm{E}$, apesar do baixo número capturado na floresta inundada por água mista, ela é também considerada uma espécie arborícola migrante. G. amazonicus é considerada uma espécie típica de água preta e que também habita floresta de água mista, onde foi considerada como arborícola não migrante. $P$. homodentatus habita 0 solo e o folhedo da floresta primária e secundária de terra firme (MORAIS, 1985; RODRIGUES, 1986; MAHNERT \& ADIS, 1985; ADIS \& MAHNERT, 1993), e adaptou-se a vida arborícola na floresta inundada por água mista do Lago Janauari.

Com relação aos Archaeognatha, foram capturadas três espécies na floresta inundada por água mista do Lago Janauari, as quais já foram encontradas em igapó, conforme o trabalho de ADIS \& STURM (1987a, 1987b). Entretanto, nenhum Archaeognatha foi capturado em floresta de várzea. Neomachilellus scandens, segundo WOLF \& ADIS (1992), é uma espécie provavelmente originária de terra firme, que imigrou para áreas inundadas por água mista e água preta e é considerada, em ambas as áreas, uma espécie terrícola não migrante (ovos inundáveis) e univoltina. 
Meinertellus adisi é uma espécie arborícola, não migrante, tanto em floresta inundada por água mista como no igapó. Entretanto, na floresta inundada por água mista, os animais também descem até o chão durante o periodo não inundado. Neomachilellus adisi, apesar do número reduzido capturado na área experimental, também é encontrada na floresta de igapó e ausente na floresta de várzea.

Os Symphyla, segundo ADIS (1981), também não foram capturados na floresta de várzea; entretanto, todas as espécies capturadas na floresta inundada por água mista são representantes da floresta de igapó. Ribautiella amazonica, por exemplo, é uma espécie terrestre, não migrante e univoltina e apresentou o mesmo comportamento tanto em floresta inundada por água mista quanto em floresta de igapó. symphylella adisi habita tanto áreas de floresta primária e secundária de terra firme, quanto floresta de igapó e água mista (SCHELLER, 1992). Tanto na floresta inundada por água mista do Lago Janauari, como na floresta de igapó, ela é considerada uma espécie terrícola não migrante e univoltina. Hanseniella arborea é considerada uma espécie migrante, noturna e univoltina e apresentou o mesmo comportamento, tanto em floresta inundada por água mista, como na floresta de igapó.

Na Amazônia Central, segundo SIOLI (1951), - leito dos rios maiores de água preta são relativamente estáveis e a água tem uma correnteza relativamente fraca, enquanto que, os rios de água branca sempre mudam o seu leito e tem uma correnteza relativamente forte. Assim, do ponto de vista entomológico, supõe-se, segundo $\mathrm{ADIS}^{8}$, que a fauna de artrópodos terrestres da várzea representa uma fauna

${ }^{8}$ ADIS, J. (Instituto Max-Planck de Limnologia, Plön, Alemanha). Arthropods of várzea forest. (Em elaboração). 
pioneira, e a maioria vive na região de tronco e copa, segundo ADIS (1981, 1985, 1992b).

o solo da floresta inundada por água mista, apresenta uma quantidade de folhedo maior que o da floresta inundada por água branca, mas inferior ao da floresta inundada por água preta e, também, uma quantidade intermediária de artrópodos terrícolas, cuja maioria das espécies são representantes do igapó e diferentes das espécies de várzea. Esta menor quantidade de folhedo, na área experimental, deve-se, provavelmente, à influência parcial do Rio Solimões, que devido a sua correnteza mais forte, leva parte do folhedo ou a cobre por sedimentos. Conseqüentemente, alguns grupos terrícolas tais como Ricinulei, Projapygidae, Campodeidae (Diplura), e Protura não se adaptaram a um habitat tão instável. A pouca quantidade de folhedo existente na área torna o solo inabitável para determinados grupos de artrópodos. Conseqüentemente, poucos grupos passam a inundação no chão, a fauna arborícola prevalece e utiliza o solo durante o período não inundado (ADIS, 1981).

Seria interessante verificar, em estudos posteriores, se existem na região de água mista representantes de artrópodos voadores, tanto da água preta quanto da água branca tornando, deste modo, à região de água mista num ecotone entre a várzea e o igapó, conforme foi sugerido por ERWIN (1983) e ADIS (1985, 1992b). Os primeiros estudos de ERWIN (1983) indicaram que a fauna de coleópteros na copa, da floresta inundada por água mista, é mais rica em espécies e a floresta inundada por água branca é mais rica em número de indivíduos. 


\section{CONCLUSŌES}

Na floresta inundada por água mista são encontradas 4 espécies de Pseudoscorpiones: Tyrannochthonius amazonicus, Pseudochthonius homodentatus, Geogarypus amazonicus e Pachyolpium irmgardae. As estratégias de sobrevivência à inundação utilizadas pela espécie terrícola, T. amazonicus, é o deslocamento do solo para as árvores por estágios imaturos mais avançados (na maioria tritoninfas).

As espécies de Diplopoda existentes na área experimental são: Phaneromerium distinctum n.sp., Fuhrmannodesmus rhinocerus n.sp., Moojenodesmus wellingtoni n.sp., Moojenodesmus pumilus, e Muyudesmus obliteratus. As estratégias de sobrevivência à inundação utilizadas pelas espécies terrícolas incluem a migração vertical para as árvores realizada pelos estágios imaturos com 17 e 18 segmentos.

As espécies de Symphyla que habitam a floresta inundada por água mista são: Symphylella adisi, Ribautiella amazonica e Hanseniella arborea. As estratégias de sobrevivência à inundação, utilizadas por estas espécies terrícolas incluem ou estágios migratórios adultos, que passam à inundação nas árvores ( $H$. arborea) ou uma fase de dormência representada pelos últimos estágios juvenis e subadultos que sobrevivem a inundação embaixo d'água ( $R$. amazonica).

Os Archaeognatha que vivem na floresta inundada por água mista são: Neomachilellus scandens, Meinertellus adisi e Neomachilellus adisi. As estratégias de sobrevivência à inundação utilizadas, na área experimental, incluem a mudança do ciclo de vida polivoltino para univoltino, constatada para $N$. scandens. Esta espécie tem ovos resistentes à inundação $e$, os juvenis eclodem no final 
do período emerso.

Com relação à distribuição vertical, no solo, os artrópodos são mais abundantes na camada de 0 a 3,5 $\mathrm{cm}$ de profundidade. Dentre outros, um fator limitante é o teor de argila do solo que dificulta a penetração de algumas espécies terricolas maiores, por exemplo: symphyla ( $H$. arborea), Diplura (Japygidae) e Homoptera (Coccoidea).

No que diz respeito às estações anuais, os artrópodos terrícolas apresentam uma maior atividade de densidade no solo durante a estação chuvosa, ocasionada pela migração para as árvores. Entretanto a sua densidade no folhedo durante o período não inundado é superior na estação menos chuvosa, ocasionado pela eclosão de Diptera, particularmente Cecidomyiidae.

Além do pulso de inundação, que é considerado o eco-fator primário para a migração de artrópodos terrícolas os fatores abióticos secundários, principalmente a temperatura do solo e a umidade do solo são mais importantes para a migração, por exemplo em Isopoda, Opiliones e Araneae. Deste modo, o início da migração para as árvores em muitos grupos e espécies (por exemplo, Pseudoscorpiones, Symphyla e Diplopoda) começa várias semanas, antes da inundação, na área experimental.

A fauna terrícola não voadora, da floresta inundada por água mista apresenta um número de indivíduos inferior a fauna, já conhecida, da floresta inundada por água preta (igapó), porém as espécies são semelhantes. Entretanto, o número de indivíduos na área experimental é superior ao número de indivíduos da floresta inundada por água branca, mas as espécies são diferentes. Isto deve-se à quantidade de folhedo que é inferior a existente na floresta de igapó e superior a existente em floresta de várzea, em conseqüência da influência parcial do Rio Solimões e do Rio Negro. 
Entretanto, estudos futuros mostrarão se a fauna de Arthropoda (terrícola e arborícola) é constituída por representantes provenientes do igapó e da várzea e, neste caso, a floresta inundada por água mista é considerada um ecotone. 


\section{REFERÊNCIAS BIBLIOGRÁFICAS}

ADIS, J. Bodenfallenfaenge in einem Buchenwald und ihr Aussagewert. Göttingen, 1974. 49p. (Diplomarbeit an der Naturwissenschaftlichen Fakultaet der Universitaet Göttingen ).

ADIS, J. Programa mínimo para análises de ecossistemas: Artrópodos terrestres em florestas inundáveis da Amazônia Central. Acta Amazonica, Manaus, 7(2): 223-9, 1977.

ADIS, J. Siebeinsatz zum Ein- und Umfüllen flüssigkeitskonservierter Arthropoda in Sammelgläser. Emtomologia Generalis, Stuttgart, 5 (2): 177-9, 1979 b.

ADIS, J. Comparative ecological studies of the terrestrial arthropod fauna in Central Amazonian inundationforests, Amazoniana, Kiel, 7(2): 87-173, 1981.

ADIS, J. Eco-entomological observations from the Amazon:II. Carabids are adapted to inundationforests! The Coleopterists Bulletin, Washington, 36(2) : 439-40, 1982a.

ADIS, J. Zur Besiedlung zentralamazonischer Überschwemmungswälder (Várzea-Gebiet) durch Carabiden (Coleoptera). Archiv für Hydrobiologie, Stuttgart, 95(1/4): 3-15, Okt.1982b. 
ADIS, J. "Seasonal igapó"-forests of Central Amazonian blackwater-rivers and their terrestrial arthropod fauna. In. SIOLI, H., ed. The Amazon. Limnology and landscape ecology of a mighty tropical river and its basin. Dordrecht, Junk Publ., 1984. p.245-68.

ADIS, J. Adaptations of arthropods to Amazonian inundation-forests. In: SILVER JUBILEE SYMPOSIUM OF INT. SOC. TROP. ECOLOGY, Varanasi, 1981. Ecology and resource management in tropics; Proceedings. Varanasi, Bhargava book Depot Chawk, 1985, v.1, p. 29-40.

ADIS, J. An "aquatic" millipede from a Central Amazonian inundation forest. Oecologia, Berlin, 68: 347-9, 1986.

ADIS, J. Extraction of arthropods from neotropical soils with a modified Kempson apparatus. Journal of Tropical Ecology, Cambridge, 3: 131-8, 1987.

ADIS, J. On the abundance and density of terrestrial arthropods in Central Amazonian dryland forests. Journal of Tropical Ecology, Cambridge, 4: 19-24, 1988.

ADIS, J. How to survive six months in a flooded soil: Strategies in Chilopoda and Symphyla from Central Amazonian floodplains. In: SYMPOSIUM ON LIFE-HISTORY TRAITS IN TROPICAL INVERTEBRATES, Yokohama, 1990. Studies on Neotropical Fauna and Environment. Amsterdam, 27(2/3), 117-29, 1992a. 
ADIS, J. Überlebensstrategien terrestrischer Invertebraten in Überschwemmungswäldern Zentralamazoniens. Verhandlungen des Naturwissenschaftlichen Vereins, Hamburg, 33: 21-114, $1992 b$.

ADIS, J. \& ARNETT Jr., R.H. Eco-entomological observations from the Amazon: VI. Notes on the natural history and flood resistance of Sisenopiras gounellei Pic (Coleoptera: Oedemeridae). Coleopterists Bulletin, Washington, 41(2): 171-2, 1987 .

ADIS, J. \& BOGEN, V. Reaction of Glossoscolecidae (Annelida, Oligochaeta) to flooding in a central Amazonian inundation forest. Acta Amazônica, Manaus, $12(4): 741-3,1982$

ADIS, J. \& MAHNERT, V. On the natural history and ecology of Pseudoscorpiones (Arachnida) from an Amazonian blackwater inundation forests. Amazoniana, Kiel, 9(3): 297-314, 1985.

ADIS, J. \& MAHNERT, $V$. On the species composition of pseudoscorpiones (Arachnida) from Amazonian dryland and inundation forest in Brazil. Revue Suisse de Zoologie, Genève, 97(1): 49-53, Dec. 1990a.

ADIS, J. \& MAHNERT, V. Vertical distribution and abundance of Pseudoscorpion species (Arachnida) in the soil of a Neotropical secondary forest during the dry ad the rainy season. Acta Zoologica Fennica, Helsinki, 190: 11-6, 1990b. 
ADIS, J. \& MAHNERT, V. Vertical distribution and abundance of Pseudoscorpions (Arachnida) in the soil of two different neotropical primary forests during the dry and rainy seasons. Memoirs of the Queensland Museum, Brisbane, 32(2): 432-9, 1993.

ADIS, J. \& MESSNER, B. Langzeit-Überflutungsresistenz als Überlebensstrategie bei terrestrischen Arthropoden. Beispiele aus zentralamazonische Überschwemmungsgebieten. Deutsche Entomologische Zeitschrift, Berlin, 38(1/3): 211-23, 1991.

ADIS, J. \& RIBEIRO, M.O.A. Impacto de desmatamento em invertebrados de solo de florestas inundáveis da Amazônia central e suas estratégias de sobrevivência às inundações de longo prazo. Boletin do Museu Paraense Emílio Goeldi, Belém, 5(1): 101-25, 1989.

ADIS, J. \& RIGHI, G. Mass migration and life cycle adaptation - a survival strategy of terrestrial earthworms in Central Amazonian inundation forests. Amazoniana, Manaus, 11(1): 23-30, 1989.

ADIS, J. \& SCHUBART, H.O.R. Ecological research on arthropods in Central Amazonian forest ecosystems with recommendations for study procedures. In: COOLEY, J.H. \& GOOLEY, F.B. ed. Trends in ecological research for the 1980s. Nato Conference Series, Series I: Ecology. New York, Plenum Press, v.7, 1984, p.11-114. 
ADIS, J. \& SCHELLER, U. On the natural history and ecology of Hanseniella arborea Scheller, 1979 (Myriapoda, Symphyla, Scutigerellidae), a migrating symphylan from an Amazonian black-water inundation forest. Pedobiologia, New York, 27(1): 35-41, 1984.

ADIS, J. \& STURM, H. On the natural history and ecology of Meinertellidae (Archaeognatha, Insecta) from dryland and inundation forests of Central Amazonia. Amazoniana, Kiel, 10: 197-218, 1987a.

ADIS, J \& STURM, H. Flood resistance of eggs and life-cycle adaptation, a survival strategy of Neomachilellus scandens (Meinertellidae, Archaeognatha) in Central Amazonian inundation forests. Insect Science and its Apllication, New York, 8: 523-8, $1987 \mathrm{~b}$.

ADIS, J.; GOLOVATCH, S.; HAMANN, S. Survival strategy of the terricolous millipede Cutervodesmus adisi Golovatch (Fuhrmannodesmidae, Polydesmida) in a blackwater inundation forest of Central Amazonia (Brazil) in response to the flood pulse. In: INTERNATIONAL CONGRESS OF MYRIAPODOLOGY, (26.-31.7.1993, Paris): in press.

ADIS, J.; MESSNER, B.; GROTH, I. Zur Überflutungsresistenz und zum Spinnvermögen von Japygiden (Diplura). Zoologische Jahrbücher. Abteilung für Anatomie und Antogenie des Tiere, Jena, 119 (3/4): $371-82,1989$. 
ADIS, J.; MORAIS, J.W. de; MESQUITA, H.G. Vertical distribution and abundance of arthropods in the soil of a Neotropical Secondary forest during the rainy season. Studies on Neotropical Fauna and Environment, Amsterdam, 22(4): 189-97, 1987a.

ADIS, J.; MORAIS, J. W. de; RIBEIRO, E. F.

Vertical distribution and abundance of arthropods in the soil of a neotropical secondary forest during the dry season. Tropical Ecology, Allahabad, 28: 174-81, 1987b.

ADIS, J.; PAARMANN, W.; ERWIN, T.L. On the natural history and ecology of small terrestrial groundbeetles (Col.: Bembidiini: Tachyina: Polyderis) from an Amazonian black-water inundation forest. In: DEN BOER, J.P.; LUFF, M.L.; MOSSAKOWSKI, D.; WEBER, F., ed. Carabid beetles, their adaptations and dynamics). Stuttgart, G.Fischer, 1986. p. 413-27.

ADIS, J.; PAARMANN, W.; HÖFER, H. On phenology and life cycle of scarites sp. (Scaritini, Carabidae from Central Amazonian floodplains. In: Stork, N.E., ed. The role of ground beetles in ecological and environmental studies. Andover, Intercept, 1990. 269-75.

ADIS, J.; MAHNERT, V.; MORAIS, J.W. de; RODRIGUES, J.M.G. Adaptation of an Amazonian pseudoscorpion (Arachnida) from dryland forests to inundation forest. Ecology, Tempe, 69: 287-91, 1988 . 
ADIS, J.; MORAIS, J.W.; RIBEIRO, E.F.; RIBEIRO, J.C. Vertical distribution and abundance of arthropods from white sand soil of a neotropical Campinarana forest during the rainy season. Studies on Neotropical Fauna and Environment, Amsterdam, 24(4): 193-200, 1989a.

ADIS, J.; RIBEIRO, E.F.; MORAIS, J.W.; CAVALCANTE, E.T.S. Vertical distribution and abundance of Arthropods from white sand soil of a neotropical Campinarana forest during the dry season. Studies on Neotropical Fauna and Environment, Amsterdam, 24(4): 201-11, 1989b.

AL-ASSIUTY, A.I.M.; BAYOUMI, B.M.; KHALIL, M.A.; VAN STRAALEN, N.M. The influence of vegetational type on seasonal abundance and species composition of soil fauna at different localities in Egypt. Pedobiologia, New York, 37: 210-22, 1993.

BAZ, A. Observations on the biology and ecology of Psocoptera found in different kinds of leaf litter in East-Central Spain. Pedobiologia, New York, 35: 89$100,1991$.

BECK, L. Zum jahreszeitlichen Massenwechsel zweier Oribatidenarten (Acari) im neotropischen Überschwemmungswald. Verhandlungen der Deutschen Zoologischen Gessellschaft. Leipzig, 535-40, 1969.

BECK, L. Der Einfluß der jahresperiodischen Überflutungen auf den Massenwechsel der Bodenarthropoden im zentralamazonischen Regenwaldgebiet. Pedobiologia, New York, 12: 133-48, 1972. 
BELFIELD, $W$. The Arthropoda of the soil in a west African pasture. Journal of Animal Ecology, London, 25: 275$87,1956$.

BORROR, D.J. \& DELONG, D.M., ed. Introdução ao estudo dos insetos. São Paulo, Edgard Blücher, 1969. 653p.

BORROR, D.J.; DELONG, D.M.; TRIPLEHORN, C.A., ed. An introdution to the study of insects. New York, Saunders College, 1976. 852p.

BRAGA, P.I.S. Subdivisão fitogeográfica, tipos de vegetação, conservação e inventário florístico da floresta amazônica. Acta Amazonica, Manaus, 9(4): $53-80,1979$.

BRESCOVIT, A.D. \& HÖFER, H. Amazoromus, a new genus of the spider family Gnaphosidae (Araneae) from central Amazonia, Brazil. Andrias, Karlsruhe, 13: 65-70, $1994 a$.

BRESCOVIT, A.D. \& HÖFER, H. Heidrunea, a new genus of the spider subfamily Rhoicininae (Araneae, Trechaleidae) from central Amazonia, Brazil. Andrias, Karlsruhe, 13: 71-80, 1994b.

CEPEDA-PIZARRO, J.G.; ROJAS, M.A.G.; MALDONADO, M.R.C.; VILCHES, J.L.; PEREIRA, N.M.P. Effect of season, substrate quality, litter quality, and soil conditions on edaphic microarthropods in a coastal desert site of north-central chile. Revista chilena de Historia Natural, Santiago, 65: 65-73, 1992 . 
CHARDART, R. Nouvelles stations de symphyles, distinction et rapport numérique des sexes. Bulletin du Musee d'Histoire Naturelle de Paris, Paris, 2(19): 177-84, 1947 .

EDWARDS, C.A. Macroarthropods. In: DICKINSON, C.H.; RIGH, G.J.F., ed. Biology of plant litter decomposition. London, Academic Press, 1974. v.2, p.775.

EISENBEIS, G. \& WICHARD,W. Atlas on the biology of soil arthropods. London, Springer-Verlag, 1987. 437p.

ERWIN, T.L. Beetles and other insects of tropical forest canopies at Manaus, Brazil, sampled by insecticidal fogging. In: SUTTON, S.L.; WHITOME, T.C.; CHADWICK, A.C., ed. Tropical rain forest; ecology and management) . Oxford, Blackwell Scientific, 1983. p.498.

ERWIN, T.L. \& SCOTT, J.C. Seasonal and size patterns, trophic structure, and richness of Coleoptera in the tropical arboreal ecosystem the fauna of the tree Luehea seemannii Triana and Planch in the canal zone of Panama. The Coleopterists Bulletin, Washington, $34(3): 305-22,1980$.

FRIEBE, B. Vergleichende Betrachtungen zur Käferbesiedlung von Weißwasser-und Schwarzwasserüberschwemmungswäldern (Várzea, Igapó) Zentral-Amazoniens. Biogeographica, Saarbrücken, 19: 101-9, 1984. 
FRIEBE, B. \& ADIS, J. Entwicklungszyklen von opiliones (Arachnida) im Schwarzwasser-Überschwemmungswald (Igapó) des Rio Tarumã Mirím (Zentralamazonien, Brasilien). Amazoniana, Kiel, 8(1): 101-10, 1983.

FUNKE, W. Food and energy turnover of leaf-eating insects and their influence on primary production. Ecological studies, Berlin, 2: 81-93, 1971.

FUNKE, W. Wälder, Objekte der ökosystemforschung. Die Stammregion - Lebensraum und Durchgangszone von Arthropoden. Jahresbericht des Naturwissenschaftlichen Vereins, Wuppertal, 32: 45 $-50,1979$.

GILL, R.W. Soil microarthropod abundance following oldfield litter manipulation. Ecology, Tempe, 50(5): 805 $-16,1969$.

GOLOVATCH, S.I. Soil fauna and soil fertility . In: INTERNATIONAL COLLOQUIUM ON SOIL ZOOLOGY, MOSCOW, 1985. Proceedings. Moscow, 1987. p.210-3.

GOLOVATCH, S.I. Review of the neotropical fauna of the millipede family Fuhrmannodesmidae, with the description of four new species from near Manaus, Central Amazonia, Brazil (Diplopoda, Polydesmida). Amazoniana, Kiel, 7(2): 207-26, Dec. 199 
GOLOVATCH, S.I. Further new Fuhrmannodesmidae from the environs of Manaus, Central Amazonia, Brazil, with a revision of Cryptogonodesmus Silvestri, 1898 (Diplopoda, Polydesmida). Amazoniana, Kiel, 13(112), 1994. (no prelo)

GRIMM, R.; FUNKE, W.; SCHAUERMANN, J. Minimalprogramm zur Ökosystemanalyse: Untersuchungen an Tierpopulationen in Wald-ökosystemen. Verhandlungen der Gesellschaft für ökologie, Erlangen, 3: 77-87, 1974 .

GUPTA, G.P. \& MUKHARJI, S.P. Qualitative composition of the fauna of cultivated and uncultivated soil. Indian Journal of Entomology, New Delhi, 38(4): 313-24, 1976.

HANLON, R.D.G. \& ANDERSON, J.M. The effects of Collembola grazing on microbial activity in decomposing leaf litter. Oecologia, Berlin, 38: 93-9, 1979.

HARADA, A.Y. \& BANDEIRA, A.G. Estratificação e densidade de invertebrados em solo arenoso sob floresta primária e plantios arbóreos na Amazônia Central durante a estação seca. Acta Amazônica, Manaus, 1994.(no prelo).

HEATH, G.; ARNOLD, M.; EDWARDS, C. Studies in leaflitter breakdown I. Breakdown rates of leaves of different species. Pedobiologia, New York, 6: 1-12, 1966 .

HÖFER, H. The spider community (Araneae) of a Central Amazonian blackwater inundation forest (Igapó). Acta Zoologica Fenica, Helsinki, 190: 137-9, Dec.1990. 
HÖFER, H.; BRESCOVIT, H.D.; GASNIER, T. The wandering spiders of genus Ctenus (Ctenidae, Araneae) of Reserva Ducke, a rainforest reserve in central Amazonia. Andrias, Karlsruhe, 13: 81-98, 1994.

HOPKIN, S.P. \& READ, H.J. The biology of Millipedes. New York, Oxford Universty Press, 1992. 232p.

IRION, G. \& ADIS,J. Evolução das florestas amozônicas inundadas, de igapó - um exemplo do rio Tarumã-Mirim, Acta Amazonica, Manaus, 9(2): 299-303, 1979.

IRMLER, U. Ecological studies of the aquatic soil invertebrates in three inundation forests of central Amazonia. Amazoniana, Kiel, 5(3): 337-409, 1975.

IRMLER, U. Inundation-forest types in the vicinity of Manaus. Biogeographica, Saarbrücken, 8: 17-29; 1977.

IRMLER, U. Die Struktur der Carabiden und Staphylinidengesellschaften in zentralamazonischen Überschwemmungswäldern. Amazoniana, Kiel, 6 (3): 301326,1978 .

IRMLER, U. Abundance fluctuations and habitat changes of soil beetles in Central Amazonian inundation forests. Studies on Neotropical Fauna and Environment, Amsterdam, 14: 1-16, Ago.1979.

IRMLER, U. Überlebensstrategien von Tieren im saisonal überfluteten amazonischen Überschwemmungswald. Zoologischer Anzeiger, Leipzig, 206(1/2): 26-38, 1981 . 
JUNK, W.J.; BAYLEY, P.B., SPARKS, R.E. The flood pulse concept in river-floodplain systems. Canadian Special Publication of Fisheries and Aguatic Sciences, Ottawa, 106: 110-27, 1989 .

JUNK, W.J. Flood tolerance and tree distribution in central Amazonian floodplains. In: HOLM-NIELSEN, L.B.; NIELSEN, I.C.; BALSTEV, H. eds. Tropical forest, botanical dynamics, speciation and diversit. London, Academic Press, 1989. p.47-64.

JAMBU, P.; JUCHAULT, P.; MOCQUARD, J.P. Étude expérimentale de la contribution du crustacé isopode Oniscus asellus à la transformation des litières forestières sous chêne sessile. Pedobiologia, New York, 32: 147-56, 1988.

KEMPSON, D.; LLOYD, M.; GHELARDI, R. A new extractor for woodland "litter". Pedobiologia, New York, 3(1): 1-21, 1963 .

KLINGE, H.; ADIS, J.; FURCH, K.; JUNK, W.J. Algunos elementos básicos del ecossistema amazónico. Tübịnger Geographische Studien, Tübingen, 95, 31-43, 1987.

KRAUS, O. Myriapoden aus Peru. Senckenbergiana biologica, Frankfurt am Main, 41(3/4): 241-64, 1960.

KURCHEVA; G. Influence des invertébrés du sol sur l'intensité de dégradation de la litière dans une forêt de chênes de la région de Koursk. Pedobiologia, New York, 7(2/3): 228-38, 1967. 
LAGERLÖF, J. \& SCHELLER, U. Abundance and activity of Pauropoda and Symphyla (Myriapoda) in four cropping systems. Pedobiologia, New York, 33, 315-21, 1989.

LEVINGS, S.C. \& WINDSOR, D.M. Litter arthropod populations in a tropical deciduous forest: relationships between years and arthropod groups. Journal of Animal Ecology, London, 54: 61-9, 1985.

LIMA, A.C. Insetos do Brasil. Rio de Janeiro, Escola Nacional de Agronomia, 1956. v.8: Coleópteros, 323p. (Didática, 10).

LOPES, B. U. Aspectos físicos, químicos e ecológicos das misturas naturais de águas físico-químicamente diferentes, na Amazônia. Manaus, "s.d." 49p. (Doutorado - Instituto Nacional de Pesquisas da Amazônia/Fundação Universidade do Amazonas).

MAHNERT, V. \& ADIS, J. On the occurrence and habitat of pseudoscorpiones (Arachnida) from Amazonian forests of Brazil. Studies on Neotropical Fauna and Environment, Amsterdam, 20(49): 211-5, 1985.

MARTIUS, C. Untersuchung zur Ökologie des Holzabbaus durch Termiten (Isoptera) in zentralamazonischen Überschwemmungswäldern (Várzea). Göttingen, 1989. 285p. (Doktorarbeit an der Naturwissenschaftlichen Fakultät der Universität Göttingen). 
MARTIUS, C. Food provision storing by xylophagous termites in Amazonia (Isoptera: Nasutitermitidae). Entomologia Generalis, stuttgart, 17(4): 269-76, Dec. 1992 .

MARTIUS, C. Diversity and ecology of termites in Amazonian forests. Pedobiologia, New York, 38: 407-28, $1994 a$.

MARTIUS, C. Terrestrial arthropods colonizing an abandoned termite nest in a floodplain forest of the Amazon River during the flood. Andrias, Karlsruhe, 13: 17-22, Aug. 1994b.

MARTIUS, C. Termite nests as structural elements of the Amazon floodplain forest. Andrias, Karlsruhe, 13: 137-50, Aug. 1994c.

MERINO. J. F. \& SERAFINO, A. Variaciones mensuales en la densidad de microartrópodos edáficos en un cafetal de Costa Rica. Revista de Biologia Tropical, San Jose, 26 (2): 291-301, 1978.

MESSNER, B. \& ADIS, J. Die Plastronstrukturen der bisher einzigen submers lebenden Diplopodenart Gonographis adisi Hoffman 1985 (Pyrgodesmidae, Diplopoda).

Zoologische Jahrbücher. Abteilung für Anatomie und Ontogenie der Tiere, Jena, 117: 277-90, 1988. 
MESSNER, B.; ADIS, J. \& RIBEIRO, E.F. Eine vergleichende Untersuchung über die Plastronstrukturen bei Milben (Acari). Deutsche entomologische Zeitschrift. Berlin, 39:(1/3), 159-76, 1992 .

MIKHAIL, W.Z.A. Effect of soil structure on soil fauna in a desert wadi in Southern Egypt. Journal of Arid Environments, London, 24: 321-31, 1993.

MORAIS, J.W. DE, Abundância e distribuição vertical de Arthropoda do solo numa floresta primária não inundada. Manaus, 1985. 92p. (Mestrado - Instituto Nacional de Pesquisas da Amazônia/Fundação Universidade do Amazonas).

NEW, T.R.; ADIS, J.; MORAIS, J.W. DE; RODRIGUES, J.M.G. Notes on phenology and abundance of Psocoptera from primary and secondary dryland forest in Central Amazonia, Brazil. Studies on Neotropical Fauna and Environment, Amsterdam, 26(4): 243-7, 1991.

OLIVEIRA, E. P. \& FRANKLIN. E. Efeito do fogo sobre a mesofauna do solo: recolonização em áreas queimadas. Pesquisa agropecuária brasileira, Brasília, 28(3): 357 $-69,1993$.

PAARMANN, W.; IRMLER, U.; ADIS, J. Pentacomia egregia Chaud. (Carabidae, Cicindelinae), an univoltine species in the Amazonian inundation forest. Coleopterists Bulletin, New York, 36(2): 183-8, 1982 . 
PENNY, N.D. \& ARIAS, J.R. Insects of an Amazon forest. New York, Columbia University Press, 1982. 269p.

PETERSEN, H. \& LUXTON, M. A comparative analysis of soil fauna populations and their role in decomposition processes. Oikos, Copenhagen, 39(3): 288-399, 1982.

PLATNICK, N.I. \& HÖFER, H. Systematics and ECology of Ground Spiders (Araneae, Gnaphosidae) from Central Amazonian Inundation Forests. American Museum Novitates, New York, 2971, 18p., Apr. 1990

PRANCE, G.T. Notes on the vegetation of Amazonia III. The terminology of Amazonian forest types subject to inundation. Brittonia, New York, 31(1): 26-38, 1979.

PRANCE, G.T. A terminologia dos tipos de florestas amazônicas sujeitas a inundação. Acta Amazônica, Manaus, 10(3): 495-504, 1980 .

PRICE, D.W. \& BENHAM, G. S. Vertical distribution of soil-inhabiting microarthropods in an agricultural habitat in California. Environmental Entomology, College Park, 6(4): 575-80, 1977.

RIBEIRO, M.N.G \& ADIS, J. Local rainfall variability - a potential bias for bioecological studies in the Central Amazon. Acta Amazônica, Manaus, 14(1/2): 159-74, 1984 . 
RODRIGUES, J.M.G. Abundância e distribuição vertical de Arthropoda do solo em capoeira de terra firme, Manaus, 1986. 80p. (Mestrado - Instituto Nacional de Pesquisas da Amazônia/Fundação Universidade do Amazonas).

RODRIGUES, J.M.G. Abundância e distribuição vertical de coleópteros do solo em capoeira de terra firme na região de Manaus/AM, Brasil. Acta Amazônica, Manaus, $22(3): 323-33,1992$.

SCHAEFER, M. \& TISCHLER, W. Wörterbücher der Biologie: Ökologie. Stuttgart, G. Fischer, 1983. 354p.

SCHELLER, U. Hanseniella arborea n. sp., a migrating symphylan from an Amazonian blackwater inundation forest (Myriapoda, Symphyla, Scutigerellidae). Acta Amazônica, Manaus, 9(3): 603-7, 1979.

SCHELLER, U. A study of neotropical symphyla (Myriapoda): list of species, keys to genera and description of two new Amazonian species. Amazoniana, Kiel, 12(2): 16980 , Dec. 1992 .

SCHELLER, U. \& ADIS, J. A new species of Ribautiella (Myriapoda, Symphyla, scolopendrellidae) from an Amazonian black-water inundation forest and notes on its natural history and ecology. Amazoniana, Kiel, 8(3): 299-310, 1984 .

SCHUBART, O. Os Diplópodos de Pirassununga. Acta Zoologica Lilloana, Tucuman, 2: 321-440, 1944. 
SCHUBART, H.O. \& BECK,L. Zur Coleopterenfauna amazonischer Böden. Amazoniana, Kiel, 1(4): 311-22, 1968 .

SEASTEDT, T.R. The role of microarthropods in decomposition and mineralization processes. Annual Review of Entomology, Stanford, 29: 25-46, 1984 .

SERAFINO, A. \& MERINO, J.F. Poblaciones de microartrópodos en diferentes suelos de Costa Rica. Revista de Biologia Tropical, San Jose, 26(1): 139-51, 1978 .

SGARDELIS, S.P. \& MARGARIS, N.S. Effects of fire on soil microarthropods of a phryganic ecosystem. Pedobiologia, New York, 37: 83-94, 1993.

SIOLI, H. Zum Alterungsprozeß von Flüssen und Flußtypen im Amazonasgebiet. Archiv für Hydrobiologie, Stuttgart, 43: 267-83, 1951 .

SIOLI, H. Über Natur und Mensch im brasilianischen Amazonasgebiet. Erdkunde, 10(2): 89-109, 1956.

STORK, N.E. \& EGGLETON, P. Invertebrates as determinants and indicators of soil quality. American Journal of Alternative Agriculture, Greenbelt, 7(1/2): 23-31, 1992 .

STURM, H. \& ADIS, J. Zur Entwicklung und zum Paarungsverhalten zentralamazonischer Meinertelliden (Machiloidea, Archaeognatha, Insecta). Amazoniana, Kiel, 8(4): 447-73, Okt. 1984 . 
STRÜVE-KUSENBERG, R. Sukzession und trophische Struktur der Bodenfauna von Brachlandflächen. Pedobiologia, New York, 21: 132-41, 1981.

THIEDE, U. Untersuchungen über die Arthropodenfauna in Fichtenforsten (Populationsökologie, Energieumsatz). Zoologische Jahrbücher. Abteilung für Systematik, Okologie und Geographie der Tiere. Jena, 104: 137-202, 1977.

TISCHLER, W. Einführung in die ökologie. Stuttgart, G. Fischer, 1984. 437p.

TRIHAS, A. \& LEGAKIS, A. Phenology and patterns of activity of ground Coleoptera in an insular Mediterranean ecosystem (Cyclades, Greece). Pedobiologia, New York, 35: 327-35, 1991.

WOLDA, H. \& WRIGHT, S.J. Artificial dry season rain and its effects on tropical insect abundance and seasonality. Proceedings of the Koninklijke Nederlandse Akademie van Wetenschappen, Amsterdam, 94(4): 535-48, Dec. 1992.

WOLF, H.G. \& ADIS,J. Genetic differentiation between populations of Neomachilellus scandens (Meinertellidae, Archaeognatha, Insecta) inhabiting neighbouring forest in Central Amazonia, Verhandlungen des naturwissenschaftlichen Vereins, Hamburg, 33: 5-13, 1992 . 
191

A P E N D I C E 
Apêndice 01 - Precipitação pluvionétrica (m), temperatura do ar $\left({ }^{\circ} \mathrm{C}\right)$ e unidade relativa do ar $(\%)$ da floresta inundada por água nista, no período de julho/1987 a junho/1988. Precip. = precipitação pluvionétrica; T. = temperatura (próxina ao solo);

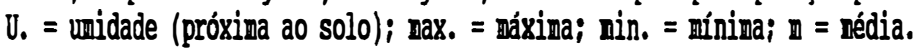

\begin{tabular}{lccccccc} 
PeríodolParâmetros & Precip. & T.max. & T.min. & T.m & U.max. & U.min. & U.m. \\
\hline Julho/1987 & 81,5 & 28,5 & 22,5 & 25,6 & 100,0 & 80,0 & 94,0 \\
Agosto & 92,6 & 27,5 & 21,5 & 24,9 & 100,0 & 82,0 & 95,1 \\
Setembro & 71,8 & 29,0 & 22,0 & 25,4 & 100,0 & 74,0 & 94,5 \\
Outubro & 56,7 & 29,8 & 22,0 & 25,7 & 100,0 & 74,0 & 92,6 \\
Novembro & 220,1 & 28,5 & 22,3 & 24,6 & 100,0 & 73,0 & 96,7 \\
Dezembro & 236,9 & 28,5 & 22,0 & 24,9 & 100,0 & 85,0 & 95,3 \\
Janeiro/1988 & 198,7 & 26,5 & 22,0 & 23,7 & 100,0 & 88,0 & 98,9 \\
Fevereiro & 241,0 & 27,0 & 22,0 & 24,0 & 100,0 & 87,0 & 98,0 \\
Marco & 157,7 & 27,5 & 22,0 & 24,6 & 100,0 & 78,0 & 97,4 \\
Abril & 227,0 & 28,0 & 22,5 & 24,4 & 100,0 & 82,0 & 97,4 \\
Maio & 138,6 & 28,0 & 22,5 & 25,0 & 100,0 & 82,0 & 97,2 \\
Junho & 291,3 & 28,0 & 22,0 & 24,8 & 100,0 & 82,0 & 95,8 \\
\hline
\end{tabular}


Apêndice 02 - Unidade $(\xi)$, temperatura $\left({ }^{\circ} \mathrm{C}\right)$, pH do solo e teor de argila $(\%)$ e silte $(\%)$ na floresta inundada por água nista, no periodo de agosto/1987 a naio/1988 .

\begin{tabular}{|c|c|c|c|c|}
\hline PeríodolCamadas & $0-3,5 \mathrm{~cm}$ & $3,5-7 \mathrm{~cm}$ & $7-10,5 c$ & $10,5-14 \mathrm{~cm}$ \\
\hline \multicolumn{5}{|l|}{ 1- Umidade do solo } \\
\hline Agosto/1987 & 23,3 & 22,7 & 15.7 & 18,8 \\
\hline Setembro & 10,8 & 14,6 & 18,1 & 17,0 \\
\hline Outubro & 13,2 & 17,9 & 19,9 & 19,1 \\
\hline Novembro & 11,8 & 16,9 & 17,6 & 18,5 \\
\hline Dezembro & 12,1 & 15,9 & 19,2 & 19,4 \\
\hline Janeiro/1988 & 14,5 & 17,4 & 19,2 & 19,7 \\
\hline Fevereiro & 21,1 & 24,2 & 23,9 & 21,1 \\
\hline Marco & 19,6 & 22,5 & 23,8 & 24,0 \\
\hline Abril & 21,1 & 22,7 & 23,6 & 22,9 \\
\hline Maio & 19,3 & 22,1 & 21,8 & 21,3 \\
\hline \multicolumn{5}{|c|}{ 2- Temperatura do solo } \\
\hline Agosto/1987 & 24,7 & 25,2 & 25,6 & 25,9 \\
\hline Setembro & 25,7 & 25,6 & 25,5 & 25,5 \\
\hline Outubro & 25,7 & 25,5 & 25,5 & 25,5 \\
\hline Novembro & 24,9 & 25,3 & 25,6 & 25,9 \\
\hline Dezembro & 27,0 & 26,6 & 26,4 & 26,4 \\
\hline Janeiro/1988 & 26,5 & 26,3 & 26,2 & 26,2 \\
\hline Fevereiro & 26,5 & 26,3 & 26,2 & 26,2 \\
\hline Marco & 26,0 & 25,9 & 25,9 & 25,9 \\
\hline Abril & 26,0 & 25,9 & 25,9 & 26,0 \\
\hline Maio & - & - & - & - \\
\hline \multicolumn{5}{|l|}{ 3- $\mathrm{pH}$ do solo } \\
\hline Agosto/1987 & 4,5 & 4,5 & 4,3 & 4,2 \\
\hline Setembro & 5,5 & 5,5 & 5,0 & 4,9 \\
\hline Outubro & 4,2 & 4,3 & 4,3 & 4,3 \\
\hline Novembro & 4,1 & 4,1 & 4,1 & 4,1 \\
\hline Dezembro & 4,1 & 4,2 & 4,3 & 4,3 \\
\hline Janeiro/1988 & 4,3 & 4,3 & 4,3 & 4,3 \\
\hline Fevereiro & 4,5 & 4,4 & 4,1 & 4,2 \\
\hline Marco & 5,2 & 4,8 & 4,6 & 4,6 \\
\hline Abril & 4,7 & 4,6 & 4,5 & 4,6 \\
\hline Maio & 5,3 & 4,6 & 4,6 & 4,4 \\
\hline 4- Análise do solo & $\%$ & $\%$ & $\%$ & $\%$ \\
\hline 1- Teor de argila & 33,2 & 41,1 & 44,7 & 49,0 \\
\hline 2- Silte & 61,6 & 49,6 & 54,1 & 50,3 \\
\hline
\end{tabular}


Apêndice 03 - Resultados das correlaçōes entre a distribuição vertical dos grupos de Arthropoda e os fatores abióticos locais (temperatura, pH e umidade do solo, temperatura do ar e teor de argila do solo), da floresta inundada por água mista (julho/1987 ajunho/1988).

\begin{tabular}{|c|c|c|c|c|c|}
\hline \multirow[b]{2}{*}{$1-$} & \multicolumn{5}{|l|}{ Grupos $\times$ Fatores abióticos } \\
\hline & Formicidae: & & & & \\
\hline & Temperatura do solo & $\begin{array}{l}p<0,05 \\
p<0,01\end{array}$ & $\begin{array}{l}r>+0,9549 \\
r>+0,9916\end{array}$ & $\begin{array}{l}n=4 \\
n=4\end{array}$ & $\begin{array}{l}\text { (dez./87) } \\
\text { (mar./88) }\end{array}$ \\
\hline & Umidade do solo & $\begin{array}{l}p<0,01 \\
p<0,01\end{array}$ & $\begin{array}{l}r>-0,9910 \\
r>-0,9791\end{array}$ & $\begin{array}{l}n=4 \\
n=4\end{array}$ & $\begin{array}{l}\text { (dez./87) } \\
\text { (mar./88) }\end{array}$ \\
\hline & pH do solo & $\begin{array}{l}p<0,01 \\
p<0,01\end{array}$ & $\begin{array}{l}r>-0,9920 \\
r>+0,9774\end{array}$ & $\begin{array}{l}n=4 \\
n=4\end{array}$ & $\begin{array}{l}\text { (dez./87) } \\
\text { (mar./88) }\end{array}$ \\
\hline $2-$ & Araneae: & & & & \\
\hline & Precipitacao pluviométrica & $p<0,05$ & $r>+0,7144$ & $n=8$ & \\
\hline 3 & Japygidae: & & & & \\
\hline & rgila & $\begin{array}{l}p<0,05 \\
p<0,05 \\
p<0,05\end{array}$ & $\begin{array}{l}r>+0,9878 \\
r>-0,9885 \\
r>-0,9636\end{array}$ & $\begin{array}{l}n=4 \\
n=4 \\
n=4\end{array}$ & $\begin{array}{l}\text { (ago./87) } \\
\text { (out./87) } \\
\text { (jan./88) }\end{array}$ \\
\hline $4-$ & Pauropoda: & & & & \\
\hline & Temperatura do solo & $p<0,01$ & $r>+0,9954$ & $n=4$ & (jan./88) \\
\hline & Umidade do solo & $\begin{array}{l}p<0,01 \\
p<0,05\end{array}$ & $\begin{array}{l}r>-0,9995 \\
r>-0,9581\end{array}$ & $\begin{array}{l}n=4 \\
n=4\end{array}$ & $\begin{array}{l}\text { (jan./88) } \\
\text { (mar./88) }\end{array}$ \\
\hline & $\mathrm{pH}$ do & $p<0,05$ & $r>+0,9660$ & $n=4$ & (mar./88) \\
\hline & Teor de argila & $p<0,05$ & $r>-0,9821$ & $n=4$ & (jan./88) \\
\hline & & $p<0,05$ & r > -0,9785; & $n=4$ & (fev./88) \\
\hline & & $p<0,05$ & $r>-0,9502 ;$ & $n=4$ & (mar./88) \\
\hline 5. & Coccoidea & & & & \\
\hline & $\begin{array}{l}\text { Umidade do solo } \\
\text { Temperatura do solo }\end{array}$ & $\begin{array}{l}p<0,05 \\
p<0,05\end{array}$ & $\begin{array}{l}r>-0,9888 \\
r>+0,9785\end{array}$ & $\begin{array}{l}n=4 \\
n=4\end{array}$ & $\begin{array}{l}\text { (jan./88) } \\
\text { (jan./88) }\end{array}$ \\
\hline & Teor de argila & $p<0,05$ & $r>-0,9739$ & $n=4$ & (nov./87) \\
\hline & & $p<0,05$ & $r>-0,9587$ & $n=4$ & (jan./88) \\
\hline & & $p<0,05$ & $r>-0,9597$ & $n=4$ & (abr./88) \\
\hline & & $p<0,05$ & $r>-0,9758$ & $n=4$ & (mai./88) \\
\hline $6-$ & C & & & & \\
\hline & Umidade do solo & $p<0,05$ & $r>-0,9723$ & $n=4$ & (dez./87) \\
\hline & $\mathrm{pH}$ do solo & $p<0,05$ & $r>-0,9716$ & $n=4$ & (dez./87) \\
\hline & Te & $p<0,05$ & $r>-0$, & $n=4$ & (dez./87) \\
\hline 7. & & & & & \\
\hline & $\begin{array}{l}\text { Umidade do solo } \\
\text { pH do solo }\end{array}$ & $\begin{array}{l}p<0,05 \\
p<0,05\end{array}$ & $\begin{array}{l}r>-0,9516 \\
r>+0,9829\end{array}$ & $\begin{array}{l}n=4 ; \\
n=4 ;\end{array}$ & $\begin{array}{l}\text { (mar./88) } \\
\text { (mar./88) }\end{array}$ \\
\hline 8 - & Dipte & & & & \\
\hline & Umidade do solo & $p<0,05$ & $r>-0,9546$ & $n=4$ & (out./87) \\
\hline & & $p<0,05$ & $r>-0,9842$ & $n=4$ & (nov./87) \\
\hline & & $p<0,05$ & $r>-0,9765$ & $n=4$ & (dez./87) \\
\hline & & $p<0,05$ & $r>-0,9762$ & $n=4$ & (mar./88) \\
\hline & & $p<0,05$ & $r>-0,9548$ & $n=4$ & (mai./88) \\
\hline & Temperatura do solo & $\begin{array}{l}\mathrm{p}<0,01 \\
\mathrm{p}<0,05\end{array}$ & $r>+0,9996$ & $n=4$ & (out./87) \\
\hline & & & $>$ & & (mar./8 \\
\hline & & $p<0,05$ & $r>+0,9710$ & $n=4$ & (mar./88) \\
\hline & & $p<0,05$ & $r>+0,9755$ & $n=4$ & (mai./88) \\
\hline $9-$ & Coleoptera (total-adultos): & & & & \\
\hline & Temperatura do solo & $\begin{array}{l}p<0,01 ; \\
p<0,05\end{array}$ & $\begin{array}{l}r>+0,9913 \\
r>+0,9786\end{array}$ & $\begin{array}{l}n=4 \\
n=4\end{array}$ & $\begin{array}{l}\text { (fev./88) } \\
\text { (mar./88) }\end{array}$ \\
\hline & Umic & $\begin{array}{l}p<0,01 ; \\
p<0,05\end{array}$ & $\begin{array}{l}r>-0,9910 \\
r>-0,9672\end{array}$ & $\begin{array}{l}n=4 \\
n=4\end{array}$ & $\begin{array}{l}\text { (mar./88) } \\
\text { (abr./88) }\end{array}$ \\
\hline & pH do solo & $p<0,01$ & $r>+0,9912$ & $n=4$ & (mar./88) \\
\hline
\end{tabular}


continuação. Apêndice 03.

\begin{tabular}{lllll}
\hline 10. & Carabidae & & & \\
& Temperatura do solo & & & \\
& $p<0,05 ;$ & $r>+0,9837 ;$ & $n=4 ;$ & (dez./87) \\
& $p<0,05 ;$ & $r>+0,9756 ;$ & $n=4 ;$ & (fev./88) \\
& $p<0,05 ;$ & $r>-0,9554 ;$ & $n=4 ;$ & (dez./87) \\
Umidade do solo & $p<0,05 ;$ & $r>-0,9622 ;$ & $n=4 ;$ & (mar./88) \\
& $p<0,01 ;$ & $r>-0,9921 ;$ & $n=4 ;$ & (abr./88) \\
& $p<0,05 ;$ & $r>+0,9618 ;$ & $n=4 ;$ & (fev./88) \\
pH do solo & $p<0,05 ;$ & $r>+0,9672 ;$ & $n=4 ;$ & (mar./88) \\
& $p<0,05 ;$ & $r>+0,9534 ;$ & $n=4 ;$ & (abr./88) \\
& $p<0,01 ;$ & $r>+0,9941 ;$ & $n=4 ;$ & (mai./88)
\end{tabular}

\begin{tabular}{l}
\hline 11- Staphylinidae: \\
\hline Temperatura do solo \\
Umidade do solo \\
pH do solo
\end{tabular}

$p<0,05 ; \quad r>+0,9645$;

$p<0,01 ; \quad r>-0,9972 ;$

$n=4$

$n=4$;

(mar./88)

$p<0,01 ; \quad r>+0,9968$;

n $=4$;

(mar./88)

(mar./88)

\begin{tabular}{c}
\hline 12- Pselaphidae: \\
\hline Temperatura \\
Umidade do solo \\
pH do solo
\end{tabular}

$p<0,05 ; \quad r>+0,9750$;

$n=4 ;$

(fev./88)

$p<0,01 ; \quad r>+0,9943$;

$n=4$;

(mar./88)

$p<0,05 ; \quad r>-0,9683$;

$n=4 ;$

(mar./88)

$p<0,05 ; \quad r>-0,9608$;

$n=4 ;$

(abr./88)

$p<0,05 ; \quad r>-0,9643$;

$n=4$;

(mar./88)

13 Coleoptera (total-lanvas):

Temperatura do solo

$p<0,05 ; \quad r>+0,9540 ;$

n $=4$;

(set./87)

$p<0,05 ; \quad r>+0,9802$;

$n=4 ;$

(out./87)

$p<0,05 ; \quad r>+0,9751$;

$n=4 ;$

(jan./88)

$p<0,05 ; \quad r>+0,9609$;

$n=4 ;$

(fev./88)

Umidade do solo

$p<0,01 ; \quad r>+0,9973$;

$n=4 ;$

(mar./88)

$p<0,05 ; \quad r>-0,9643$;

$n=4$;

(set./87)

$p<0,05 ; \quad r>-0,9662 ;$

$n=4 ;$

$p<0,05 ; \quad r>-0,9807$;

$n=4$;

$p<0,05 ; \quad r>-0,9645$;

$n=4 ;$

(out./87)

pH do solo

$p<0,05 ; \quad r>+0,9616$;

$\mathrm{n}=4$

(nov./87)

(mar./88)

(mar./88)

$\frac{\frac{14 \text { Pseudoscorpiones }}{\text { T. amazonicus }}}{\text { Temperatura do solo }}$

Umidade do solo

0,$01 ; \quad r>+0,9980$

$n=4$

(fev./88)

$p<0,05 ; \quad r>+0,9802$;

$n=4 ;$

(mar./88)

$p<0,01 ; \quad r>-0,9905$;

$n=4 ;$

(mar./88)

pH do solo

$p<0,001 ; r>-0,9999$;

$n=4$

(abr./88)

$p<0,01 ; \quad r>+0,9901$;

$\mathrm{n}=4$

(mar./88)

$p<0,01 ; \quad r>+0,9897$;

$n=4$

(abr./88)

\begin{tabular}{|c|c|c|c|c|c|}
\hline $15-$ & Diplopoda & \multirow{6}{*}{$\begin{array}{l}p<0,05 \\
p<0,05 \\
p<0,05\end{array}$} & \multirow{5}{*}{$\begin{array}{l}r>+0,9838 \\
r>-0.9880 \\
r>+0,9872\end{array}$} & \multirow{5}{*}{$\begin{array}{l}n=4 \\
n=4 \\
n=4\end{array}$} & \multirow{5}{*}{$\begin{array}{l}\text { (mar./88) } \\
\text { (mar./88) } \\
\text { (mar./88) }\end{array}$} \\
\hline & Polyxenidae & & & & \\
\hline & Temperatura do solo & & & & \\
\hline & Umidade do solo & & & & \\
\hline & pH do solo: & & & & \\
\hline \multicolumn{2}{|r|}{ Fuhrmannodesmidae } & & & & \\
\hline & $\begin{array}{l}\text { Umidade do solo } \\
\mathrm{pH} \text { do solo }\end{array}$ & $\begin{array}{l}p<0,01 \\
p<0,01\end{array}$ & $\begin{array}{l}r>-0,9931 \\
r>+0,9967\end{array}$ & $\begin{array}{l}n=4 \\
n=4\end{array}$ & $\begin{array}{l}\text { (mar./88) } \\
\text { (mar./88) }\end{array}$ \\
\hline
\end{tabular}


Apêndice 04 - Captura de Pseudoscorpiones (espécies), através do método de Rempson, nas diferentes canadas do solo, no período de

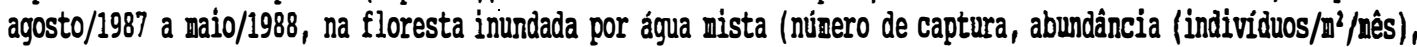
percentagen $(\%)$, média e desvio padräo (S)).

\begin{tabular}{|c|c|c|c|c|c|c|c|c|c|c|c|c|c|c|c|}
\hline Espécies/Mêses & Ago. $/ 87$ & Set. & Out. & Nov. & Dez. & Jan./88 & Fev. & Mar. & Abr. & Mai. & Total & Ind./mines & $\%$ & Média & $\mathbf{s}$ \\
\hline \multicolumn{16}{|l|}{$(0,0-3,5 \mathrm{~cm})$} \\
\hline \multicolumn{16}{|l|}{ 1- Tyrannochthonius } \\
\hline amazonicus & 0 & 2 & 4 & 7 & 16 & 21 & 42 & 10 & 8 & 3 & 113 & 54,4 & 91,1 & 11,3 & 12,6 \\
\hline \multicolumn{16}{|l|}{ 2- Psoudochthonius } \\
\hline homodertatus & 0 & 0 & 0 & 0 & 0 & 2 & 1 & 0 & 1 & 1 & 5 & 2,4 & 4.0 & 0,5 & 0,7 \\
\hline \multicolumn{16}{|l|}{ 3- Pachyolpium } \\
\hline irmgardae & 0 & 0 & 1 & 1 & 0 & 0 & 0 & 1 & 0 & 3 & 6 & 2,9 & 4,8 & 0,6 & 1,0 \\
\hline Subtotal & 0 & 2 & 5 & 8 & 16 & 23 & 43 & 11 & 9 & 7 & 124 & 59,7 & 100,0 & 12,4 & \\
\hline Ind. $/ \mathrm{m}^{2}$ & 0,0 & 9,6 & 24,1 & 38,5 & 7,0 & 110,7 & 206,9 & 52,9 & 43,3 & 33,7 & 596,7 & & & & \\
\hline$\%$ & 0,0 & 1,6 & 4,0 & 6,5 & 13,0 & 18,5 & 34,7 & 8,9 & 7,3 & 5,6 & 100,0 & & & & \\
\hline
\end{tabular}

\section{$(3,5-7,0 \mathrm{~cm})$}

1- Tyrannochthonius amazonicus Subtotal Ind. $/ \mathrm{m}^{2}$

\begin{tabular}{|c|c|c|c|c|c|c|c|c|c|c|c|c|c|c|}
\hline 0 & 0 & 1 & 5 & 23 & 17 & 12 & 2 & 3 & 1 & 64 & 30,8 & 100,0 & 6,4 & 8,1 \\
\hline 0 & 0 & 1 & 5 & 23 & 17 & 12 & 2 & 3 & 1 & 64 & 30,0 & 100,0 & 6,4 & \\
\hline 0,0 & 0,0 & 4,8 & 24,1 & 110,7 & 81,8 & 57,7 & 9,6 & 14,4 & 4,8 & 308,0 & & & & \\
\hline 0,0 & 0,0 & 1,6 & 7,8 & 36,0 & 13,8 & 18,8 & 3,1 & 4,7 & 1,7 & 100,0 & & & & \\
\hline
\end{tabular}
$\%$

(7,5-10,0 cm)

1- Tyrannochthonius

\begin{tabular}{|c|c|c|c|c|c|c|c|c|c|c|c|c|c|c|c|}
\hline amazonicus & 0 & 1 & 0 & 3 & 3 & 8 & 1 & 0 & 0 & 6 & 22 & 10,6 & 100,0 & 2,2 & 2,8 \\
\hline Subtotal & 0 & 1 & 0 & 3 & 3 & 8 & 1 & 0 & 0 & 6 & 22 & 10,6 & 100,0 & 2,2 & \\
\hline Ind./m & 0,0 & 4,8 & 0,0 & 14,4 & 14,4 & 38,5 & 4,8 & 0,0 & 0,0 & 28,9 & 105,9 & & & & \\
\hline$\%$ & 0,0 & 4,5 & 0,0 & 13,6 & 13,6 & 36,4 & 4,5 & 0,0 & 0,0 & 27,3 & 100,0 & & & & \\
\hline
\end{tabular}

$(10,5-14,0 \mathrm{~cm})$

1- Tyrannoctichonius amazonicus Subtotal

0

0

\begin{tabular}{ll}
0 & 15 \\
\hline 0 & 15
\end{tabular}

2

2

0
0

0
0

0

2

21

10,1 $100,0 \quad 2,1 \quad 4,6$ Ind./m $\mathrm{m}^{2}$ $\begin{array}{lllllllllll}0,0 & 0,0 & 0,0 & 71,4 & 9,5 & 9,5 & 0,0 & 0,0 & 0,0 & 9,5 & 100,0\end{array}$

\begin{tabular}{lcccccccccccc}
\hline Tolal $(0,0-14 \mathrm{~cm})$ & 0 & 3 & 6 & 31 & 44 & 50 & 56 & 13 & 12 & 16 & 231 & 111,1 \\
\hline Ind. $/ \mathrm{m}^{2}$ & 0,0 & 14,4 & 28,9 & 149,2 & 211,7 & 240,6 & 269,5 & 62,6 & 57,7 & 0,0 & 0,0 & 23,1 \\
\hline$\%$ & 0,0 & 1,3 & 2,6 & 13,4 & 19,2 & 21,6 & 24,2 & 5,6 & 5,2 & 6,9 & 100,0 & \\
\hline
\end{tabular}

1- Tyrannoatithonius amazonicus (Total)

\begin{tabular}{ccccccccccc}
0 & 3 & 5 & 30 & 44 & 48 & 55 & 12 & 11 & 12 & 220 \\
\hline 0,0 & 14,4 & 24,1 & 144,4 & 211,7 & 231,0 & 264,7 & 57,7 & 52,9 & 0,0 & 1058,6 \\
\hline 0,0 & 1,3 & 2,7 & 13,6 & 20,0 & 21,8 & 25,0 & 5,5 & 5,0 & 5,5 & 100,0
\end{tabular}

$\begin{array}{lllll}0,0 & 1,3 & 2,7 & 13,6 & 20,0\end{array}$


Apêndice 05 - Captura de gyrannochthonius arazonicus Mahnert, 1979 (Chthoniidae, Pseudoscorpiones) e estágios de desenvolvinento, nas diferentes camadas do s010, na floresta inundada por água nista, no periodo de agosto/1987 a naio/1988. Método de

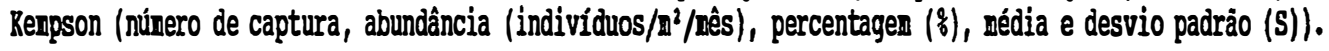

\begin{tabular}{|c|c|c|c|c|c|c|c|c|c|c|c|c|c|c|c|}
\hline Camadas/Datas & Ago. 187 & Set. & Out. & Nov. & Dez. & $\operatorname{Jan} . / 88$ & Fev. & Mar. & Abr. & Mai. & Total & Ind./mimes & $\%$ & Média & $\mathbf{s}$ \\
\hline $\begin{array}{l}\text { Tyrannochthonius } \\
\text { amazonicus }\end{array}$ & & & & & & & & & & 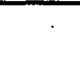 & & & & & \\
\hline \multicolumn{16}{|l|}{ 1- $(0,0-3,5 \mathrm{~cm})$} \\
\hline Protoninfa & 0 & $\mathbf{0}$ & 2 & $\mathbf{0}$ & 1 & 3 & 2 & $\mathbf{0}$ & 1 & $\mathbf{0}$ & 9 & 4,3 & 8,0 & 0,9 & 1,1 \\
\hline Deutoninfa & 0 & 2 & 1 & 0 & 4 & 4 & 15 & 1 & $\mathbf{0}$ & 2 & 29 & 13,9 & 25,7 & 2,9 & 4,5 \\
\hline Tritoninfa & 0 & $\mathbf{0}$ & 0 & 2 & 6 & 6 & 13 & 6 & 4 & 1 & 38 & 18,3 & 33,6 & 3,8 & 4,1 \\
\hline Machos & 0 & 0 & 0 & 4 & 3 & 5 & 8 & 3 & 1 & 0 & 24 & 11,5 & 21,2 & 2,4 & 2,7 \\
\hline Fémeas & 0 & 0 & 1 & 1 & 2 & 3 & 4 & 0 & 2 & 0 & 13 & 6,3 & 11,5 & 1,3 & 1,4 \\
\hline Subtotal & 0 & 2 & 4 & 7 & 16 & 21 & 42 & 10 & 8 & 3 & 113 & 54,4 & 100,0 & 11,3 & 12,6 \\
\hline Ind. $/ \mathrm{m}^{2}$ & 0,0 & 9,6 & 19,2 & 33,7 & 77,0 & 101,1 & 202,1 & 48,1 & 38,5 & 14,4 & 543,8 & & & & \\
\hline$\%$ & 0,0 & 1,8 & 3,5 & 6,2 & 14,2 & 18,6 & 37,2 & 8,9 & 7,1 & 2,7 & & & & & \\
\hline \multicolumn{16}{|l|}{ 2. $(3,5-7,0 \mathrm{~cm})$} \\
\hline Protoninfa & 0 & 0 & 0 & 0 & 7 & 4 & 8 & $\mathbf{0}$ & 1 & 0 & 20 & 9,6 & 31.3 & 2,0 & 3,2 \\
\hline Deutoninfa & 0 & 0 & 0 & 3 & 8 & 6 & 1 & $\mathbf{0}$ & 0 & 0 & 18 & 8,7 & 28,1 & 1,8 & 2,9 \\
\hline Tritoninfa & 0 & 0 & 1 & 0 & 6 & 3 & 2 & 1 & 0 & 0 & 13 & 6,3 & 20,3 & 1,3 & 1,9 \\
\hline Machos & 0 & 0 & 0 & 1 & 0 & 1 & 0 & 0 & 2 & 0 & 4 & 1,9 & 6,3 & 0,4 & 0,7 \\
\hline Fêmeas & 0 & 0 & 0 & 1 & 2 & 3 & 1 & 1 & 0 & 1 & 9 & 4,3 & 14,1 & 0,9 & 1,0 \\
\hline Subtotal & 0 & 0 & 1 & 5 & 23 & 17 & 12 & 2 & 3 & 1 & 64 & 30,8 & 100,0 & 6,4 & 8,1 \\
\hline Ind./m2 & 0,0 & 0,0 & 4,8 & 24,1 & 110,7 & 81,8 & 57,7 & 9,6 & 14,4 & 4,8 & 308,0 & & & & \\
\hline$\%$ & 0,0 & 0,0 & 1,6 & 7,8 & 35,9 & 26,6 & 18,8 & 3,1 & 4,7 & 1,6 & & & & & \\
\hline \multicolumn{16}{|l|}{ 3- $(7,5-10,0 \mathrm{~cm})$} \\
\hline Protoninfa & $\mathbf{0}$ & 0 & 0 & 2 & 0 & 0 & $\mathbf{0}$ & 0 & $\mathbf{0}$ & 5 & 7 & 3,4 & 31,8 & 0,7 & 1,6 \\
\hline Deutoninfa & $\mathbf{0}$ & 1 & $\mathbf{0}$ & 1 & 0 & 1 & 0 & 0 & 0 & 0 & 3 & 1,4 & 13,6 & 0,3 & 0,5 \\
\hline Tritoninfa & 0 & 0 & $\mathbf{0}$ & $\mathbf{0}$ & 3 & 4 & $\mathbf{0}$ & 0 & $\mathbf{0}$ & 1 & 8 & 3,9 & 36,4 & 0,8 & 1,5 \\
\hline Machos & 0 & 0 & 0 & 0 & 0 & 1 & 0 & 0 & $\mathbf{0}$ & $\mathbf{0}$ & 1 & 0,5 & 4,5 & 0,1 & 0,3 \\
\hline Fêmeas & 0 & 0 & 0 & 0 & 0 & 2 & 1 & 0 & 0 & 0 & 3 & 1,4 & 13,6 & 0,3 & 0,7 \\
\hline Subiotal & 0 & 1 & 0 & 3 & 3 & 8 & 1 & 0 & 0 & 6 & 22 & 10,6 & 100,0 & 2,2 & 2,8 \\
\hline ind./m $\mathrm{m}^{2}$ & 0,0 & 4,8 & 0,0 & 14,4 & 14,4 & 38,5 & 4,8 & 0,0 & 0,0 & 28,9 & 105,9 & & & & \\
\hline$\%$ & 0,0 & 4,5 & 0,0 & 13,6 & 13,6 & 36,4 & 4,5 & 0,0 & 0,0 & 27,3 & 0 & & & & \\
\hline \multicolumn{16}{|l|}{ 4- $(10,5-14,0 \mathrm{~cm})$} \\
\hline Protoninfa & 0 & 0 & $\mathbf{0}$ & 8 & 0 & $\mathbf{0}$ & $\mathbf{0}$ & 0 & 0 & 2 & 10 & 4,8 & 47,6 & 1,0 & 2,5 \\
\hline Deutoninfa & $\mathbf{0}$ & $\mathbf{0}$ & $\mathbf{0}$ & 0 & 1 & $\mathbf{0}$ & $\mathbf{0}$ & 0 & 0 & 0 & 1 & 0,5 & 4,8 & 0,1 & 0,3 \\
\hline Tritoninfa & 0 & 0 & 0 & 5 & 0 & 2 & $\mathbf{0}$ & 0 & 0 & 0 & 7 & 3,4 & 33,3 & 0,7 & 1,6 \\
\hline Machos & 0 & $\mathbf{0}$ & 0 & 0 & 1 & 0 & 0 & 0 & 0 & 0 & 1 & 0,5 & 4,8 & 0,1 & 0,3 \\
\hline Fêmeas & 0 & 0 & 0 & 2 & 0 & 0 & 0 & 0 & 0 & 0 & 2 & 1,0 & 9,5 & 0,2 & 0,6 \\
\hline Sublotal & 0 & 0 & 0 & 15 & 2 & 2 & 0 & 0 & 0 & 2 & 21 & 10,1 & 100,0 & 2,1 & 4,6 \\
\hline $\operatorname{lnd} . / \mathrm{m}^{2}$ & 0,0 & 0,0 & 0,0 & 72,2 & 9,6 & 9,6 & 0,0 & 0,0 & 0,0 & 9,6 & 81,804 & 39,4 & 389,5 & 8,2 & 22,7 \\
\hline$\%$ & 0,0 & 0,0 & 0,0 & 71,4 & 9,5 & 9,5 & 0,0 & 0,0 & 0,0 & 9,5 & & & & & \\
\hline \multicolumn{16}{|l|}{$5-(0,0-14,0 \mathrm{~cm})$} \\
\hline Protoninfa & $\mathbf{0}$ & 0 & 2 & 10 & 8 & 7 & 10 & 0 & 2 & 7 & 46 & 22,1 & 20,9 & 4,6 & 4,2 \\
\hline Deutoninfa & 0 & 3 & 1 & 4 & 13 & 11 & 16 & 1 & 0 & 2 & 51 & 24,5 & 23,2 & 5,1 & 5,9 \\
\hline Tritoninfa & 0 & 0 & 1 & 7 & 15 & 15 & 15 & 7 & 4 & 2 & 66 & 31,8 & $\mathbf{3 0 , 0}$ & 6,6 & 6,3 \\
\hline Machos & 0 & 0 & 0 & 5 & 4 & 7 & 8 & 3 & 3 & 0 & 30 & 14,4 & 13,6 & 3,0 & 3,0 \\
\hline Fêmeas & 0 & 0 & 1 & 4 & 4 & 8 & 6 & 1 & 2 & 1 & 27 & 13,0 & 12,3 & 2,7 & 2,7 \\
\hline Total & 0 & 3 & 5 & 30 & 44 & 48 & 55 & 12 & 11 & 12 & 220 & 105,9 & 100,0 & 22,0 & 20,5 \\
\hline Ind./m $/ \mathrm{m}^{2}$ & 0,0 & 14,4 & 24,1 & 144,4 & 211,7 & 231,0 & 264,7 & 57.7 & 52,9 & 57,7 & 1058,6 & & & & \\
\hline$\%$ & 0,0 & 1,4 & 2,3 & 13,6 & 20,0 & 21,8 & 25,4 & 5,5 & 5,0 & 5,5 & & & & & \\
\hline
\end{tabular}


Apêndice 06 - Captura de Pseudoscorpiones (espécies) no folhedo através de 4 fotoeclectores de solo, no periodo de agosto/1987 a maio/1988, na floresta inundada por água mista (número de captura, densidade de atividade (indivíduos $/ \mathbb{m}^{2} / \mathrm{mês}^{\text {) }}$, percentagen $(\xi)$, média e desvio padräo $(S))$.

\begin{tabular}{|c|c|c|c|c|c|c|c|c|c|c|c|c|c|c|c|}
\hline Espécies/Moses & Ago. $/ 87$ & Set. & Out. & Nov. & Dez. & $\operatorname{Jan} . / 88$ & Fev. & Mar. & Abr. & Mai. & Total & Ind./mímês & $\%$ & Módia & $s$ \\
\hline $\begin{array}{l}\text { 1- Tyrannochthonius } \\
\text { amazonicus }\end{array}$ & 0 & 0 & 0 & 0 & 0 & 51 & 24 & 68 & 0 & 0 & 143 & 3,6 & 80,3 & 14,3 & 25,3 \\
\hline & 0 & 0 & 0 & 0 & 0 & 13 & 7 & 2 & 0 & 0 & 22 & 0,5 & 12,4 & 2,2 & 4,4 \\
\hline $\begin{array}{l}\text { 3- Pachyolpium } \\
\text { irmgardae }\end{array}$ & 0 & 0 & 0 & 0 & 2 & 4 & 3 & 1 & 2 & 1 & 13 & 0,3 & 7,3 & 1,3 & 1,4 \\
\hline Total & 0 & 0 & 0 & 0 & 2 & 68 & 34 & 71 & 2 & 1 & 178 & 4,4 & 100,0 & 17,8 & \\
\hline Ind. $/ \mathrm{m}^{2}$ & 0,0 & 0,0 & 0,0 & 0,0 & 0,5 & 17,0 & 8 & 17,8 & 0,5 & 0,3 & 44,5 & & & & \\
\hline & 0 & 0 & 0 & 0 & 1,1 & 38,2 & 19,1 & 39,7 & 1,1 & 1,0 & 100,0 & & & & \\
\hline
\end{tabular}

Apêndice 07 - Captura de fyrannochthonins anazonicus Vahnert 1979 (Chthoniidae, Pseudoscorpiones), por estágios de desenvolvinento, no folhedo, na floresta inundada por água nista, no periodo de agosto/1987 a naio/1988. Coleta en 4 fotoeclectores de

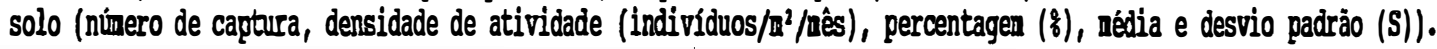

\begin{tabular}{|c|c|c|c|c|c|c|c|c|c|c|c|c|c|c|c|}
\hline Estágios/Mêses & Ago./87 & Set. & Out. & Nov. & Dez. & Jan./88 & Fev. & Mar. & Abr. & Maj. & Total & Ind. $/ \mathrm{m}^{2} / \mathrm{mês}$ & $\%$ & Média & $\mathrm{s}$ \\
\hline \multicolumn{16}{|l|}{$\begin{array}{l}\text { Tyrannochthonius } \\
\text { amazonicus }\end{array}$} \\
\hline Protoninfa & 0 & 0 & 0 & 0 & 0 & 0 & 0 & 0 & 0 & 0 & 0 & 0,0 & 0,0 & 0,0 & 0,0 \\
\hline Deutoninfa & 0 & 0 & 0 & 0 & 0 & 1 & 0 & 0 & 0 & 0 & 1 & 0,0 & 0,7 & 0,1 & 0,4 \\
\hline Tritoninfa & 0 & 0 & 0 & 0 & 0 & 46 & 24 & 67 & 0 & 0 & 137 & 3,4 & 95,8 & 13,7 & 43,7 \\
\hline Machos & 0 & 0 & 0 & 0 & 0 & 0 & 0 & 1 & 0 & 0 & 1 & 0,0 & 0,7 & 0,1 & 0,4 \\
\hline Fêmeas & 0 & 0 & 0 & 0 & 0 & 4 & 0 & 0 & 0 & 0 & 4 & 0,1 & 2,8 & 0,4 & 1,6 \\
\hline Total & 0 & 0 & 0 & 0 & 0 & 51 & 24 & 68 & 0 & 0 & 143 & 3,6 & 100,0 & 14,3 & 43,1 \\
\hline Ind. $/ \mathrm{m}^{2}$ & 0,0 & 0,0 & 0,0 & 0,0 & 0,0 & 12,8 & 6,0 & 17,0 & 0,0 & 0,0 & 35,8 & & & & \\
\hline$\%$ & 0,0 & 0,0 & 0,0 & 0,0 & 0,0 & 35,7 & 16,8 & 47,6 & 0,0 & 0,0 & 100,0 & & & & \\
\hline
\end{tabular}


Apêndice 08 - Captura de Psendochthonius howodentatus Chanberlin, 1929 (Chthoniidae, Pseudoscorpiones), e estágios de desenvolvinento, no folhedo, na floresta inundada por água nista, no período de agosto/1987 a naio/1988. Coleta en 4 fotoeclectores de solo (nuirero de captura, densidade de atividade (indivíduos/ $\mathbb{n}^{2} /$ nês), percentagen (₹), nédia e desvio padrão (s)).

\begin{tabular}{|c|c|c|c|c|c|c|c|c|c|c|c|c|c|c|c|}
\hline \multirow{2}{*}{$\begin{array}{l}\text { Estágios/Meses } \\
\text { Pseudochthoniu } \\
\text { homodentatus }\end{array}$} & Ago./87 & Set. & Out. & Nov. & Dez. & Jan./88 & Fev. & Mar. & Abr. & Mai. & Total & Ind./mimês & $\%$ & Média & $S$ \\
\hline & & & & & & & & & & & & & & & \\
\hline Protoninfa & 0 & 0 & 0 & 0 & 0 & 0 & 0 & 0 & 0 & 0 & 0 & 0,0 & 0,0 & 0 & 0,0 \\
\hline Deutoninfa & 0 & 0 & 0 & 0 & 0 & 2 & 2 & 1 & 0 & 0 & 5 & 0,1 & 22,7 & 0,5 & 0,8 \\
\hline Tritoninfa & 0 & 0 & 0 & 0 & 0 & 2 & 0 & 0 & 0 & 0 & 2 & 0,0 & 9,1 & 0,2 & 0,6 \\
\hline Macho & 0 & 0 & 0 & 0 & 0 & 9 & 4 & 1 & 0 & 0 & 14 & 0,3 & 63,6 & 1,4 & 3,0 \\
\hline Fêmeas & 0 & 0 & 0 & 0 & 0 & 0 & 1 & 0 & 0 & 0 & 1 & 0,0 & 4,5 & 0,1 & 0,3 \\
\hline Total & 0 & 0 & 0 & 0 & 0 & 13 & 7 & 2 & 0 & 0 & 22 & 0,5 & 100,0 & 2,2 & 4,4 \\
\hline $\operatorname{lnd} . / m^{2}$ & 0,0 & 0,0 & 0,0 & 0,0 & 0,0 & 3,3 & 1,8 & 0,5 & 0,0 & 0,0 & 5,5 & & & & \\
\hline$\%$ & 0,0 & 0,0 & 0,0 & 0,0 & 0,0 & 59,1 & 31,8 & 9,1 & 0,0 & 0,0 & 100,0 & & & & \\
\hline
\end{tabular}

Apêndice 09 - Captura de Pseudoscorpiones (espécies) coletados en fotoeclector de árvore direcionado para cina (BBT), no periodo de julho/1987 a junho/1988, na floresta inundada por água nista (múnero de captura, percentagen $(\xi)$, nédia e desvio padrão (S)).

\begin{tabular}{|c|c|c|c|c|c|c|c|c|c|c|c|c|c|c|c|c|}
\hline Espécies/Mêses & Jul./87 & Ago. & Set. & Out. & Nov. & Dez. & Jan./88 & Fev. & Mar. & Abr. & Mai. & Jun. & Total & $\%$ & Média & $\mathbf{S}$ \\
\hline $\begin{array}{l}\text { 1- Tyrannochthonius } \\
\text { amazonicus } \\
\text { 2. Geogaripus }\end{array}$ & 0 & 0 & 0 & 0 & 0 & 0 & 4 & 19 & 7 & 2 & 1 & 0 & 33 & 34,0 & 2,8 & 5,6 \\
\hline $\begin{array}{l}\text { amazonicus } \\
\text { 3- Pseudochthonius }\end{array}$ & 0 & 1 & 0 & 0 & 0 & 0 & 0 & 0 & 0 & 0 & 0 & 1 & 2 & 2,1 & 0,2 & 0,4 \\
\hline $\begin{array}{l}\text { homodentatus } \\
4 \text { Pachyolpium }\end{array}$ & 0 & 0 & 0 & 0 & 0 & 0 & 2 & 4 & 6 & 11 & 21 & 12 & 56 & 57,7 & 4,7 & 6,7 \\
\hline irmgardae & 0 & 0 & 0 & 0 & 1 & 0 & 2 & 2 & 0 & 1 & 0 & 0 & 6 & 6,2 & 0,5 & 0,8 \\
\hline Total & 0 & 1 & 0 & 0 & 1 & 0 & 8 & 25 & 13 & 14 & 22 & 13 & 97 & 100,0 & 8,1 & \\
\hline$\%$ & 0,0 & 1,0 & 0,0 & 0,0 & 1,0 & 0,0 & 8,2 & 26,8 & 13,4 & 14,4 & 22,7 & 13,4 & & & & \\
\hline
\end{tabular}


Apêndice 10 - Captura de Psendochthonius houodentatus Chamberlin, 1929 (Chthoniidae, Pseudoscorpiones), e estágios de desenvolvinento, en fotoeclector de árvore direcionado para cina (BEt) e para baixo (BBt), no período de julho/1987 a junho/1988, na floresta inundada por água nista (número de captura, percentagen por eclector (₹), nédia e desvio padrảo (S)).

\begin{tabular}{|c|c|c|c|c|c|c|c|c|c|c|c|c|c|c|c|c|}
\hline Estágios /Meses & Jul./87 & Ago. & Set. & Out. & Nov. & Dez. & Jan./88 & Fev. & Mar. & Abr. & Mai. & Jun. & Total & $\%$ & Média & $s$ \\
\hline \multicolumn{17}{|l|}{$\begin{array}{l}\text { Pseudochthonius } \\
\text { homodentatus }\end{array}$} \\
\hline \multirow[t]{2}{*}{ Protoninfa } & $\uparrow 0$ & 0 & 0 & 0 & 0 & 0 & 0 & 0 & 0 & 0 & 0 & 0 & 0 & 0,0 & 0,0 & 0,0 \\
\hline & +0 & 0 & 0 & 0 & 0 & 0 & 0 & 0 & 0 & 0 & 0 & 0 & 0 & 0,0 & 0,0 & 0,0 \\
\hline \multirow[t]{2}{*}{ Deutoninfa } & $\uparrow 0$ & 0 & 0 & 0 & 0 & 0 & 0 & 0 & 0 & 5 & 9 & 4 & 18 & 32,2 & 1,5 & 2,9 \\
\hline & $\downarrow 0$ & 0 & 0 & 0 & 0 & 0 & 0 & 1 & 2 & 1 & 2 & 2 & 8 & 6,7 & 0,7 & 0,9 \\
\hline \multirow[t]{2}{*}{ Tritoninfa } & $\uparrow 0$ & 0 & 0 & 0 & 0 & 0 & 0 & 2 & 0 & 1 & 4 & 4 & 11 & 19,6 & 0,9 & 1,6 \\
\hline & $\downarrow 1$ & 0 & 0 & 0 & 0 & 0 & 0 & 3 & 4 & 1 & 2 & 1 & 12 & 10,0 & 1,0 & 1,3 \\
\hline \multirow[t]{2}{*}{ Machos } & $\uparrow^{*} 0$ & 0 & 0 & 0 & 0 & 0 & 1 & 1 & 3 & 1 & 3 & 2 & 11 & 19,6 & 0,9 & 1,2 \\
\hline & $\downarrow 0$ & 0 & 0 & 0 & 0 & 1 & 3 & 7 & 11 & 5 & 1 & 6 & 34 & 28,3 & 2,8 & 3,6 \\
\hline \multirow[t]{2}{*}{ Fêmeas } & $\uparrow 0$ & 0 & 0 & 0 & 0 & 0 & 1 & 1 & 3 & 4 & 5 & 2 & 16 & 28,6 & 1,3 & 1,8 \\
\hline & $\downarrow 0$ & 0 & 0 & 0 & 0 & 2 & 8 & 13 & 18 & 10 & 8 & 7 & 66 & 55,0 & 5,5 & 6,1 \\
\hline Total & 1 & 0 & 0 & 0 & 0 & 3 & 13 & 28 & 41 & 28 & 34 & 28 & 176 & 100,0 & 14,7 & 15,9 \\
\hline$\%$ & 1,0 & 0,0 & 0,0 & 0,0 & 0,0 & 1,7 & 7,4 & 16,0 & 23,3 & 16,0 & 19,5 & 16,0 & 100,0 & & & \\
\hline
\end{tabular}

Apêndice 11 - Captura de PYramnochthonius arazonicus Mahnert, 1979 (Chthoniidae, Pseudoscorpiones), e estágios de desenvolvinento en fotoeclector de árvore direcionado para cima (BET) e para baixo (BEI), no periodo de julho/1987 a junho/1988, na floresta inundada por água mista (núnero de captura, percentagen por eclector $(\xi)$, nédia e desvio padrão (S)).

\begin{tabular}{|c|c|c|c|c|c|c|c|c|c|c|c|c|c|c|c|c|}
\hline Espécie/Meses & Jul./87 & Ago. & Set. & Out. & Nov. & Dez. & Jan./88 & Fev. & Mar. & Abr. & Mai. & Jun. & Total & $\%$ & Média & $s$ \\
\hline \multicolumn{17}{|c|}{$\begin{array}{l}\text { Tyrannochthonius } \\
\text { amazonicus } \\
\end{array}$} \\
\hline \multirow[t]{2}{*}{ Protoninfa } & 0 & 0 & 0 & 0 & 0 & 0 & 0 & 0 & 0 & 1 & 0 & 0 & 1 & 3,0 & 0,1 & 0,3 \\
\hline & & 0 & 0 & 0 & 0 & 0 & 0 & 0 & 0 & 0 & 0 & 0 & 0 & 0,0 & 0,0 & 0,0 \\
\hline \multirow[t]{2}{*}{ Deutoninfa } & 0 & 0 & 0 & 0 & 0 & 0 & 0 & 0 & 0 & 0 & 0 & 0 & 0 & 0,0 & 0,0 & 0,0 \\
\hline & & 0 & 0 & 0 & 0 & 0 & 0 & 0 & 0 & 0 & 0 & 0 & 1 & 4,5 & 0,1 & 0,3 \\
\hline \multirow[t]{2}{*}{ Tritoninfa } & 0 & 0 & 0 & 0 & 0 & 0 & 4 & 19 & 7 & 1 & 1 & 0 & 32 & 97,0 & 2,7 & 5,6 \\
\hline & $\downarrow 2$ & 5 & 0 & 0 & 0 & 0 & 0 & 2 & 1 & 0 & 0 & 0 & 10 & 45,5 & 0,8 & 1,5 \\
\hline \multirow[t]{2}{*}{ Machos } & 0 & 0 & 0 & 0 & 0 & 0 & 0 & 0 & 0 & 0 & 0 & 0 & 0 & 0,0 & 0,0 & 0,0 \\
\hline & & 1 & 1 & 0 & 0 & 0 & 0 & 0 & 0 & 0 & 0 & 0 & 7 & 31,8 & 0,6 & 1,4 \\
\hline \multirow[t]{2}{*}{ Fêmeas } & 0 & 0 & 0 & 0 & 0 & 0 & 0 & 0 & 0 & 0 & 0 & 0 & 0 & 0,0 & 0,0 & 0,0 \\
\hline & $\downarrow 2$ & 2 & 0 & 0 & 0 & 0 & 0 & 0 & 0 & 0 & 0 & 0 & 4 & 18,2 & 0,3 & 0,8 \\
\hline Total & 10 & 8 & 1 & 0 & 0 & 0 & 4 & 21 & 8 & 2 & 1 & 0 & 55 & 100,0 & 4,6 & \\
\hline$\%$ & 18,2 & 14,5 & 1,8 & 0,0 & 0,0 & 0,0 & 7,3 & 38,2 & 14,5 & 3,6 & 1,8 & 0,0 & 100,0 & & & \\
\hline
\end{tabular}


Apêndice 12 - Captura de Pseudoscorpiones (espécies), coletados en fotoeclector de árvore direcionado para baixo (BEL), no periodo de julho/1987 a junho/1988, na floresta inundada por água nista (núnero de captura, percentagen $(\%)$, rédia e desvio padräo (S)).

\begin{tabular}{|c|c|c|c|c|c|c|c|c|c|c|c|c|c|c|c|c|}
\hline Espécies/Meses & Jul./87 & Ago. & Set. & Out. & Nov. & Dez. & $\operatorname{Jan} . / 88$ & Fev. & Mar. & Abr. & Maj. & Jun. & Total & $\%$ & Média & S \\
\hline $\begin{array}{l}\text { 1- Tyrannochthonius } \\
\text { amazonicus } \\
\text { 2- Geogaripus }\end{array}$ & 10 & 8 & 1 & 0 & 0 & 0 & 0 & 2 & 1 & 0 & 0 & 0 & 22 & 15,3 & 1,8 & 3,4 \\
\hline $\begin{array}{l}\text { amazonicus } \\
\text { 3- Pseudochthonius }\end{array}$ & 1 & 1 & 0 & 0 & 0 & 0 & 0 & 0 & 0 & 0 & 0 & 0 & 2 & 1,4 & $\begin{array}{l}0,2 \\
0,0\end{array}$ & 0,4 \\
\hline homodentatus & 1 & 0 & 0 & 0 & 0 & 3 & 11 & 24 & 35 & 17 & 13 & 16 & 120 & 83,3 & 10,0 & 11,5 \\
\hline Total & 12 & 9 & 1 & 0 & 0 & 3 & 11 & 26 & 36 & 17 & 13 & 16 & 144 & 100,0 & & \\
\hline$\%$ & 8,3 & 6,2 & 0,7 & 0,0 & 0,0 & 2,0 & 7,6 & 18,1 & 25.0 & 11.8 & 9,0 & 11,1 & 100,0 & & & \\
\hline
\end{tabular}


Apêndice 13 - Captura de Geophilomorpha (espécies) através do método de Rempson, nas diferentes camadas do solo, no periodo de agosto/1987 a maio/1988, na floresta inundada por água mista (múmero de captura, abundância (individuos/m²/mês), percentagen $(\%)$, média e desvio padrảo (S)).

Meses Ago./87 Set. Out. Nov. Dez. Jan./88 Fev. Mar. Abr. Mai. Total Ind./ḿ/mês

$\% \quad$ Média S Camadas

I- $0-3,5 \mathrm{~cm}$

1- Pectiniunguis ascendens

2- Ribautia centralis

4. Schendylidae n.spo Subtotal 0

\begin{tabular}{|c|c|c|c|c|c|c|c|c|c|c|c|c|c|c|c|}
\hline Meses & Ago./87 & Set. & Out. & Nov. & Dez. & $\operatorname{Jan} . / 88$ & Fev. & Mar. & Abr. & Mai. & Total & Ind./mêes & $\%$ & Média & $\mathrm{s}$ \\
\hline Camadas & & & & & & & & & & & & & & & \\
\hline $1-0-3,5 \mathrm{~cm}$ & & & & & & & & & & & & & & & \\
\hline $\begin{array}{l}\text { 1- Pectiniunguis } \\
\text { ascendens }\end{array}$ & 0 & 1 & 0 & 1 & 1 & 1 & 0 & 2 & 1 & 1 & 8 & 3,8 & 40,0 & 0,8 & 0,6 \\
\hline $\begin{array}{l}\text { 2- Ribautia } \\
\text { centralis }\end{array}$ & 0 & 0 & 2 & 0 & 1 & 0 & 2 & 0 & 0 & 0 & 5 & 2,4 & 25,0 & 0,5 & 0,8 \\
\hline 3- Geophilidae n.sp. & 0 & 0 & 0 & 1 & 0 & 0 & 0 & 0 & 0 & 0 & 1 & 0,5 & 5,0 & 0,1 & 0,3 \\
\hline 4. Schendylidae n.spp. & 0 & 1 & 0 & 1 & 0 & 2 & 1 & 0 & 1 & 0 & 6 & 2,9 & 30,0 & 0,6 & 0,7 \\
\hline Subtotal & 0 & 2 & 2 & 3 & 2 & 3 & 3 & 2 & 2 & 1 & 20 & 9,6 & 100,0 & 2 & 0,9 \\
\hline Ind. $/ \mathrm{m}^{2}$ & 0,0 & 9,6 & 9,6 & 14,4 & 9,6 & 14,4 & 14,4 & 9,6 & 9,6 & 4,8 & & & & & \\
\hline$\%$ & 0,0 & 10,0 & 10,0 & 15,0 & 10,0 & 15,0 & 15,0 & 10,0 & 10,0 & 5,0 & & & & & \\
\hline $11-3,5-7 \mathrm{~cm}$ & & & & & & & & & & & & & & & \\
\hline $\begin{array}{l}\text { 1- Pectiniunguis } \\
\text { ascendens }\end{array}$ & 0 & 10 & 0 & 0 & 0 & 0 & 0 & 0 & 0 & 0 & 10 & 4,8 & 66,7 & 1,0 & 3,2 \\
\hline $\begin{array}{l}\text { 2- Ribautia } \\
\text { centralis }\end{array}$ & 0 & 0 & 0 & 0 & 0 & 0 & 1 & 0 & 0 & 0 & 1 & 0,5 & 6,6 & 0,1 & 0,3 \\
\hline 3- Geophilidae n.sp. & 0 & 0 & 0 & 0 & 0 & 2 & 1 & 0 & 0 & 1 & 4 & 1,9 & 26,7 & 0,4 & 0,7 \\
\hline Subtotal & 0 & 10 & 0 & 0 & 0 & 2 & 2 & 0 & 0 & 1 & 15 & 7,2 & 100,0 & 1,5 & 3,1 \\
\hline Ind./m ${ }^{2}$ & 0,0 & 48,1 & 0,0 & 0,0 & 0,0 & 9,6 & 9,6 & 0,0 & 0,0 & 4,8 & & & & & \\
\hline$\%$ & 0,0 & 66,7 & 0,0 & 0,0 & 0,0 & 13,3 & 13,3 & 0,0 & 0,0 & 6,7 & & & & & \\
\hline III- $7-10,5 \mathrm{~cm}$ & & & & & & & & & & & & & & & \\
\hline 1- Ribautia centralis & 0 & 1 & 0 & 0 & 0 & 1 & 0 & 0 & 0 & 0 & 2 & 1,0 & 18,2 & 0,2 & 0,4 \\
\hline 2- Schendylidae n.spp. & 0 & 1 & 0 & 0 & 7 & 1 & 0 & 0 & 0 & 0 & 9 & 4,3 & 81,8 & 0,9 & 2,2 \\
\hline Subtotal & 0 & 2 & 0 & 0 & 7 & 2 & 0 & 0 & 0 & 0 & 11 & 5,3 & 100,0 & 1,1 & 2,2 \\
\hline Ind./mi & 0,0 & 9,6 & 0,0 & 0,0 & 33,7 & 9,6 & 0,0 & 0,0 & 0,0 & 0,0 & & & & & \\
\hline$\%$ & 0,0 & 18,2 & 0,0 & 0,0 & 63,6 & 18,2 & 0,0 & 0,0 & 0,0 & 0,0 & & & & & \\
\hline
\end{tabular}

IV- $0.14 \mathrm{~cm}$

\section{1- Pectiniunguis} ascendens

2- Ribauti a centralis

3- Geophilidaen sp

4- Schendylidae n.spp.

\begin{tabular}{|c|c|c|c|c|c|c|c|c|c|c|c|c|c|c|c|}
\hline Meses & Ago./87 & Set. & Out. & Nov. & Dez. & $\operatorname{Jan} . / 88$ & Fev. & Mar. & Abr. & Mai. & Total & Ind./mímês & $\%$ & Média & $\mathrm{S}$ \\
\hline Camadas & & & & & & & & & & & & & & & \\
\hline $0-3,5 \mathrm{~cm}$ & & & & & & & & & & & & & & & \\
\hline $\begin{array}{l}\text { 1- Pectiniunguis } \\
\text { ascendens }\end{array}$ & 0 & 1 & 0 & 1 & 1 & 1 & 0 & 2 & 1 & 1 & 8 & 3,8 & 40,0 & 0,8 & 0,6 \\
\hline $\begin{array}{l}\text { 2- Ribautia } \\
\text { centralis }\end{array}$ & 0 & 0 & 2 & 0 & 1 & 0 & 2 & 0 & 0 & 0 & 5 & 2,4 & 25,0 & 0,5 & 0,8 \\
\hline 3- Geophilidae n.sp. & 0 & 0 & 0 & 1 & 0 & 0 & 0 & 0 & 0 & 0 & 1 & 0,5 & 5,0 & 0,1 & 0,3 \\
\hline 4- Schendylidae n.spp. & 0 & 1 & 0 & 1 & 0 & 2 & 1 & 0 & 1 & 0 & 6 & 2,9 & 30,0 & 0,6 & 0,7 \\
\hline Subtotal & 0 & 2 & 2 & 3 & 2 & 3 & 3 & 2 & 2 & 1 & 20 & 9,6 & 100,0 & 2 & 0,9 \\
\hline Ind. $/ \mathrm{m}^{2}$ & 0,0 & 9,6 & 9,6 & 14,4 & 9,6 & 14,4 & 14,4 & 9,6 & 9,6 & 4,8 & & & & & \\
\hline$\%$ & 0,0 & 10,0 & 10,0 & 15,0 & 10,0 & 15,0 & 15,0 & 10,0 & 10,0 & 5,0 & & & & & \\
\hline $11-3,5-7 \mathrm{~cm}$ & & & & & & & & & & & & & & & \\
\hline $\begin{array}{l}\text { 1- Pectiniunguis } \\
\text { ascendens }\end{array}$ & 0 & 10 & 0 & 0 & 0 & 0 & 0 & 0 & 0 & 0 & 10 & 4,8 & 66,7 & 1,0 & 3,2 \\
\hline $\begin{array}{l}\text { 2- Ribautia } \\
\text { centralis }\end{array}$ & 0 & 0 & 0 & 0 & 0 & 0 & 1 & 0 & 0 & 0 & 1 & 0,5 & 6,6 & 0,1 & 0,3 \\
\hline 3- Geophilidae n.sp. & 0 & 0 & 0 & 0 & 0 & 2 & 1 & 0 & 0 & 1 & 4 & 1,9 & 26,7 & 0,4 & 0,7 \\
\hline Subtotal & 0 & 10 & 0 & 0 & 0 & 2 & 2 & 0 & 0 & 1 & 15 & 7,2 & 100,0 & 1,5 & 3,1 \\
\hline Ind. $/ \mathrm{m}^{2}$ & 0,0 & 48,1 & 0,0 & 0,0 & 0,0 & 9,6 & 9,6 & 0,0 & 0,0 & 4,8 & & & & & \\
\hline$\%$ & 0,0 & 66,7 & 0,0 & 0,0 & 0,0 & 13,3 & 13,3 & 0,0 & 0,0 & 6,7 & & & & & \\
\hline $111-7-10,5 \mathrm{~cm}$ & & & & & & & & & & & & & & & \\
\hline 1- Ribautia centralis & 0 & 1 & 0 & 0 & 0 & 1 & 0 & 0 & 0 & 0 & 2 & 1,0 & 18,2 & 0,2 & 0,4 \\
\hline 2- Schendylidaen.spp. & 0 & 1 & 0 & 0 & 7 & 1 & 0 & 0 & 0 & 0 & 9 & 4,3 & 81,8 & 0,9 & 2,2 \\
\hline Subtotal & 0 & 2 & 0 & 0 & 7 & 2 & 0 & 0 & 0 & 0 & 11 & 5,3 & 100,0 & 1,1 & 2,2 \\
\hline Ind. $/ \mathrm{m}^{2}$ & 0,0 & 9,6 & 0,0 & 0,0 & 33,7 & 9,6 & 0,0 & 0,0 & 0,0 & 0,0 & & & & & \\
\hline$\%$ & 0,0 & 18,2 & 0,0 & 0,0 & 63,6 & 18,2 & 0,0 & 0,0 & 0,0 & 0,0 & & & & & \\
\hline
\end{tabular}

02

\begin{tabular}{|c|c|c|c|c|c|c|c|c|c|c|c|c|c|c|c|}
\hline Meses & Ago./87 & Set. & Out. & Nov. & Dez. & $\operatorname{Jan} . / 88$ & Fev. & Mar. & Abr. & Mai. & Total & Ind./mímês & $\%$ & Média & $\mathrm{S}$ \\
\hline Camadas & & & & & & & & & & & & & & & \\
\hline $0-3,5 \mathrm{~cm}$ & & & & & & & & & & & & & & & \\
\hline $\begin{array}{l}\text { 1- Pectiniunguis } \\
\text { ascendens }\end{array}$ & 0 & 1 & 0 & 1 & 1 & 1 & 0 & 2 & 1 & 1 & 8 & 3,8 & 40,0 & 0,8 & 0,6 \\
\hline $\begin{array}{l}\text { 2- Ribautia } \\
\text { centralis }\end{array}$ & 0 & 0 & 2 & 0 & 1 & 0 & 2 & 0 & 0 & 0 & 5 & 2,4 & 25,0 & 0,5 & 0,8 \\
\hline 3- Geophilidae n.sp. & 0 & 0 & 0 & 1 & 0 & 0 & 0 & 0 & 0 & 0 & 1 & 0,5 & 5,0 & 0,1 & 0,3 \\
\hline 4- Schendylidae n.spp. & 0 & 1 & 0 & 1 & 0 & 2 & 1 & 0 & 1 & 0 & 6 & 2,9 & 30,0 & 0,6 & 0,7 \\
\hline Subtotal & 0 & 2 & 2 & 3 & 2 & 3 & 3 & 2 & 2 & 1 & 20 & 9,6 & 100,0 & 2 & 0,9 \\
\hline Ind. $/ \mathrm{m}^{2}$ & 0,0 & 9,6 & 9,6 & 14,4 & 9,6 & 14,4 & 14,4 & 9,6 & 9,6 & 4,8 & & & & & \\
\hline$\%$ & 0,0 & 10,0 & 10,0 & 15,0 & 10,0 & 15,0 & 15,0 & 10,0 & 10,0 & 5,0 & & & & & \\
\hline $11-3,5-7 \mathrm{~cm}$ & & & & & & & & & & & & & & & \\
\hline $\begin{array}{l}\text { 1- Pectiniunguis } \\
\text { ascendens }\end{array}$ & 0 & 10 & 0 & 0 & 0 & 0 & 0 & 0 & 0 & 0 & 10 & 4,8 & 66,7 & 1,0 & 3,2 \\
\hline $\begin{array}{l}\text { 2- Ribautia } \\
\text { centralis }\end{array}$ & 0 & 0 & 0 & 0 & 0 & 0 & 1 & 0 & 0 & 0 & 1 & 0,5 & 6,6 & 0,1 & 0,3 \\
\hline 3- Geophilidae n.sp. & 0 & 0 & 0 & 0 & 0 & 2 & 1 & 0 & 0 & 1 & 4 & 1,9 & 26,7 & 0,4 & 0,7 \\
\hline Subtotal & 0 & 10 & 0 & 0 & 0 & 2 & 2 & 0 & 0 & 1 & 15 & 7,2 & 100,0 & 1,5 & 3,1 \\
\hline Ind. $/ \mathrm{m}^{2}$ & 0,0 & 48,1 & 0,0 & 0,0 & 0,0 & 9,6 & 9,6 & 0,0 & 0,0 & 4,8 & & & & & \\
\hline$\%$ & 0,0 & 66,7 & 0,0 & 0,0 & 0,0 & 13,3 & 13,3 & 0,0 & 0,0 & 6,7 & & & & & \\
\hline $111-7-10,5 \mathrm{~cm}$ & & & & & & & & & & & & & & & \\
\hline 1- Ribautia centralis & 0 & 1 & 0 & 0 & 0 & 1 & 0 & 0 & 0 & 0 & 2 & 1,0 & 18,2 & 0,2 & 0,4 \\
\hline 2- Schendylidaen.spp. & 0 & 1 & 0 & 0 & 7 & 1 & 0 & 0 & 0 & 0 & 9 & 4,3 & 81,8 & 0,9 & 2,2 \\
\hline Subtotal & 0 & 2 & 0 & 0 & 7 & 2 & 0 & 0 & 0 & 0 & 11 & 5,3 & 100,0 & 1,1 & 2,2 \\
\hline Ind. $/ \mathrm{m}^{2}$ & 0,0 & 9,6 & 0,0 & 0,0 & 33,7 & 9,6 & 0,0 & 0,0 & 0,0 & 0,0 & & & & & \\
\hline$\%$ & 0,0 & 18,2 & 0,0 & 0,0 & 63,6 & 18,2 & 0,0 & 0,0 & 0,0 & 0,0 & & & & & \\
\hline
\end{tabular}

\begin{tabular}{|c|c|c|c|c|c|c|c|c|c|c|c|c|c|c|c|}
\hline Meses & Ago./87 & Set. & Out. & Nov. & Dez. & $\operatorname{Jan} . / 88$ & Fev. & Mar. & Abr. & Mai. & Total & Ind./mímês & $\%$ & Média & $\mathrm{S}$ \\
\hline Camadas & & & & & & & & & & & & & & & \\
\hline $0-3,5 \mathrm{~cm}$ & & & & & & & & & & & & & & & \\
\hline $\begin{array}{l}\text { 1- Pectiniunguis } \\
\text { ascendens }\end{array}$ & 0 & 1 & 0 & 1 & 1 & 1 & 0 & 2 & 1 & 1 & 8 & 3,8 & 40,0 & 0,8 & 0,6 \\
\hline $\begin{array}{l}\text { 2- Ribautia } \\
\text { centralis }\end{array}$ & 0 & 0 & 2 & 0 & 1 & 0 & 2 & 0 & 0 & 0 & 5 & 2,4 & 25,0 & 0,5 & 0,8 \\
\hline 3- Geophilidae n.sp. & 0 & 0 & 0 & 1 & 0 & 0 & 0 & 0 & 0 & 0 & 1 & 0,5 & 5,0 & 0,1 & 0,3 \\
\hline 4- Schendylidae n.spp. & 0 & 1 & 0 & 1 & 0 & 2 & 1 & 0 & 1 & 0 & 6 & 2,9 & 30,0 & 0,6 & 0,7 \\
\hline Subtotal & 0 & 2 & 2 & 3 & 2 & 3 & 3 & 2 & 2 & 1 & 20 & 9,6 & 100,0 & 2 & 0,9 \\
\hline Ind. $/ \mathrm{m}^{2}$ & 0,0 & 9,6 & 9,6 & 14,4 & 9,6 & 14,4 & 14,4 & 9,6 & 9,6 & 4,8 & & & & & \\
\hline$\%$ & 0,0 & 10,0 & 10,0 & 15,0 & 10,0 & 15,0 & 15,0 & 10,0 & 10,0 & 5,0 & & & & & \\
\hline $11-3,5-7 \mathrm{~cm}$ & & & & & & & & & & & & & & & \\
\hline $\begin{array}{l}\text { 1- Pectiniunguis } \\
\text { ascendens }\end{array}$ & 0 & 10 & 0 & 0 & 0 & 0 & 0 & 0 & 0 & 0 & 10 & 4,8 & 66,7 & 1,0 & 3,2 \\
\hline $\begin{array}{l}\text { 2- Ribautia } \\
\text { centralis }\end{array}$ & 0 & 0 & 0 & 0 & 0 & 0 & 1 & 0 & 0 & 0 & 1 & 0,5 & 6,6 & 0,1 & 0,3 \\
\hline 3- Geophilidae n.sp. & 0 & 0 & 0 & 0 & 0 & 2 & 1 & 0 & 0 & 1 & 4 & 1,9 & 26,7 & 0,4 & 0,7 \\
\hline Subtotal & 0 & 10 & 0 & 0 & 0 & 2 & 2 & 0 & 0 & 1 & 15 & 7,2 & 100,0 & 1,5 & 3,1 \\
\hline Ind. $/ \mathrm{m}^{2}$ & 0,0 & 48,1 & 0,0 & 0,0 & 0,0 & 9,6 & 9,6 & 0,0 & 0,0 & 4,8 & & & & & \\
\hline$\%$ & 0,0 & 66,7 & 0,0 & 0,0 & 0,0 & 13,3 & 13,3 & 0,0 & 0,0 & 6,7 & & & & & \\
\hline $111-7-10,5 \mathrm{~cm}$ & & & & & & & & & & & & & & & \\
\hline 1- Ribautia centralis & 0 & 1 & 0 & 0 & 0 & 1 & 0 & 0 & 0 & 0 & 2 & 1,0 & 18,2 & 0,2 & 0,4 \\
\hline 2- Schendylidaen.spp. & 0 & 1 & 0 & 0 & 7 & 1 & 0 & 0 & 0 & 0 & 9 & 4,3 & 81,8 & 0,9 & 2,2 \\
\hline Subtotal & 0 & 2 & 0 & 0 & 7 & 2 & 0 & 0 & 0 & 0 & 11 & 5,3 & 100,0 & 1,1 & 2,2 \\
\hline Ind. $/ \mathrm{m}^{2}$ & 0,0 & 9,6 & 0,0 & 0,0 & 33,7 & 9,6 & 0,0 & 0,0 & 0,0 & 0,0 & & & & & \\
\hline$\%$ & 0,0 & 18,2 & 0,0 & 0,0 & 63,6 & 18,2 & 0,0 & 0,0 & 0,0 & 0,0 & & & & & \\
\hline
\end{tabular}

Total 0-14 cm Ind. $/ \mathrm{m}^{2}$

$\begin{array}{lll}0 & 11 & 0\end{array}$

0

1

1

0

\begin{tabular}{ccccccccccccccc}
0 & 0 & 0 & 1 & 0 & 2 & 1 & 0 & 0 & 1 & 5 & 2,4 & 10,9 & 0,5 & 0,7 \\
0 & 2 & 0 & 1 & 7 & 3 & 1 & 0 & 1 & 0 & 15 & 1,5 & 32,6 & 1,5 & 2,2 \\
\hline 0 & 14 & 2 & 3 & 9 & 7 & 5 & 2 & 2 & 2 & 46 & 22,1 & 100,0 & 4,6 & 4,3 \\
\hline
\end{tabular}
$\%$

$\begin{array}{llllllllll}0,0 & 67,4 & 9,6 & 14,4 & 43,3 & 33,7 & 24,1 & 9,6 & 9,6 & 9,6\end{array}$

\begin{tabular}{rrrrrrrrrr}
0,0 & 67,4 & 9,6 & 14,4 & 43,3 & 33,7 & 24,1 & 9,6 & 9,6 & 9,6 \\
0,0 & 30,5 & 4,3 & 6,6 & 19,6 & 15,2 & 10,9 & 4,3 & 4,3 & 4,3 \\
\hline
\end{tabular}


Apêndice 14 - Captura de Geophiloworpha (espécies) e estágios de desenvolvimento nas diferentes camadas do solo, através do rétodo de Reapson, no periodo de agosto/1987 a maio/1988, na floresta inundada por água nista (número de captura, abundância (indivíduos/副/nês), percentagen (\%), média e desvio padrão (S)).

\begin{tabular}{|c|c|c|c|c|c|c|c|c|c|c|c|c|c|c|c|}
\hline Espécies/Moses & Ago./87 & Set. & Out. & Nov. & Dez & $\operatorname{Jan} .188$ & Fev. & Mar. & Abr. & Mai. & Total & Ind./mt/mês & $\%$ & Módia & $\mathbf{s}$ \\
\hline \multicolumn{16}{|c|}{$\begin{array}{l}\text { 1- Pectiring guis acenders } \\
0,3,5 \mathrm{~cm}\end{array}$} \\
\hline Imaturos & 0 & 0 & 0 & 1 & 1 & 0 & 0 & 0 & 1 & 0 & 3 & 1,4 & 16,7 & 0,3 & 0,5 \\
\hline Subadultos & 0 & 0 & 0 & 0 & 0 & 0 & 0 & 0 & 0 & 0 & 0 & 0,0 & 0,0 & 0 & 0,0 \\
\hline Machos & 0 & 0 & 0 & 0 & 0 & 0 & 0 & 0 & 0 & 1 & 1 & 0,5 & 5,5 & 0,1 & 0,3 \\
\hline Fêmeas & 0 & 1 & 0 & 0 & 0 & 1 & 0 & 0 & 0 & 0 & 2 & 1,0 & 11,1 & 0,2 & 0,4 \\
\hline Indeterminados & 0 & 0 & 0 & 0 & 0 & 0 & 0 & 2 & 0 & 0 & 2 & 1,0 & 11,1 & 0,2 & 0,8 \\
\hline Subtotal & 0 & 1 & 0 & 1 & $t$ & 1 & 0 & 2 & 1 & 1 & 8 & 3,8 & 44,4 & 0,8 & 0,6 \\
\hline \multicolumn{16}{|l|}{$3,5-7 \mathrm{~cm}$} \\
\hline Imaturos & 0 & $\boldsymbol{\theta}$ & 0 & 0 & 0 & 0 & 0 & 0 & 0 & 0 & 9 & 4,3 & 50,0 & 0,8 & 2,8 \\
\hline Subadultos & 0 & 1 & 0 & 0 & 0 & 0 & 0 & 0 & 0 & 0 & 1 & 0,5 & 5,6 & 0,1 & 0,3 \\
\hline Subtotal & 0 & 10 & 0 & 0 & 0 & 0 & 0 & 0 & 0 & 0 & 10 & 4,8 & 55,6 & 1 & 3,2 \\
\hline Total $0.7 \mathrm{~cm})$ & 0 & 11 & 0 & 1 & 1 & 1 & 0 & 2 & 1 & 1 & 18 & 8,7 & 100,0 & 1,8 & 3,3 \\
\hline $\operatorname{lnd} . / \mathrm{m}^{2}$ & 0,0 & 52,9 & 0,0 & 48 & 4,8 & 4,8 & 0,0 & 9,6 & 48 & 4,8 & & & & & \\
\hline$\%$ & 0,0 & 61,0 & 0,0 & 5,6 & 5,6 & 5,6 & 0,0 & 11,0 & 5,6 & $5, \overline{6}$ & & & & & \\
\hline \multicolumn{16}{|l|}{$\begin{array}{l}\text { 2- Ribarsis consolis } \\
0-3,5 \mathrm{~cm}\end{array}$} \\
\hline Imaturos & 0 & 0 & 1 & 0 & 0 & 0 & 1 & 0 & 0 & 0 & 2 & 1,0 & 25,0 & 0,2 & 0,4 \\
\hline Fémeas & 0 & 0 & 1 & 0 & 1 & 0 & 1 & 0 & 0 & 0 & 3 & 1,4 & 37,5 & 0,3 & 0,5 \\
\hline Subtotal & 0 & 0 & 2 & 0 & 1 & 0 & 2 & 0 & 0 & 0 & 5 & 2,4 & 62,5 & 0,5 & 0,8 \\
\hline \multicolumn{16}{|l|}{$3,5-7 \mathrm{~cm}$} \\
\hline Imaturos & 0 & 0 & 0 & 0 & 0 & 0 & 1 & 0 & 0 & 0 & 1 & 0,5 & 12,5 & 0,1 & 0,3 \\
\hline Subtotal & 0 & 0 & 0 & 0 & 0 & 0 & 1 & 0 & 0 & 0 & 1 & 0,5 & 12,5 & 0,1 & 0,3 \\
\hline \multicolumn{16}{|l|}{$7-10,5 \mathrm{~cm}$} \\
\hline Fómeas & 0 & 1 & 0 & 0 & 0 & 0 & 0 & 0 & 0 & 0 & 1 & 0,5 & 12,5 & 0,1 & 0,3 \\
\hline Indeterminados & 0 & 0 & 0 & 0 & 0 & 1 & 0 & 0 & 0 & 0 & 1 & 0,5 & 12,5 & 0,1 & 0,3 \\
\hline Subpotal & 0 & 1 & 0 & 0 & 0 & 1 & 0 & 0 & 0 & 0 & 2 & 1,0 & 25,0 & 0,2 & 0,4 \\
\hline Total $(0-10 \mathrm{~cm})$ & 0 & 1 & 2 & 0 & 1 & 1 & 3 & 0 & 0 & 0 & 8 & 3,8 & 100,0 & 0,8 & 1,0 \\
\hline $\ln d . / \mathrm{m}^{2}$ & 0,0 & 4,8 & 9,8 & 0,0 & 4,8 & 4,8 & 14,4 & 0,0 & 0,0 & 0,0 & & & & & \\
\hline$\%$ & 0,0 & 12,5 & 25,0 & 0,0 & 12,5 & 12,5 & 37,5 & 0,0 & 0,0 & 0,0 & & & & & \\
\hline \multicolumn{16}{|l|}{$\begin{array}{l}\text { 3- Geophilidae n.sp. } \\
0,3,5 \mathrm{~cm}\end{array}$} \\
\hline Fomed & 0 & 0 & 0 & 1 & 0 & 0 & 0 & 0 & 0 & 0 & 1 & 0,5 & 20,0 & 0,1 & 0,3 \\
\hline Subtotal & 0 & 0 & 0 & 1 & 0 & 0 & 0 & 0 & 0 & 0 & 1 & 0,5 & 20,0 & 0,1 & 0,3 \\
\hline \multicolumn{16}{|l|}{$3,5-7 \mathrm{~cm}$} \\
\hline Subadultos & 0 & 0 & 0 & 0 & 0 & 1 & 0 & 0 & 0 & 0 & 1 & 0,5 & 20,0 & 0,1 & 0,3 \\
\hline Fémens & 0 & 0 & 0 & 0 & 0 & 0 & 0 & 0 & 0 & 1 & 1 & 0,5 & 20,0 & 0,1 & 0,3 \\
\hline Indeterminados & 0 & 0 & 0 & 0 & 0 & 1 & 1 & 0 & 0 & 0 & 2 & 1,0 & 40,0 & 0,2 & 0,4 \\
\hline Subtotal & 0 & 0 & 0 & 0 & 0 & 2 & 1 & 0 & 0 & 1 & 4 & 1,8 & 80,0 & 0,4 & 0,7 \\
\hline Total $(0.7 \mathrm{~cm})$ & 0 & 0 & 0 & 1 & 0 & 2 & 7 & 0 & 0 & 7 & 5 & 2,4 & 100,0 & 0,5 & 0,7 \\
\hline $\ln d . / m^{2}$ & 0,0 & 0,0 & 0,0 & 4,8 & 0,0 & 9,6 & 4,8 & 0,0 & 0,0 & 4,8 & & & & & \\
\hline$\%$ & 0,0 & 0,0 & 0,0 & 20,0 & 0,0 & 40,0 & 20,0 & 0,0 & 0,0 & 20,0 & & & & & \\
\hline \multicolumn{16}{|c|}{$\begin{array}{l}\text { 4. Schendylidae n.spp. } \\
0,3,5 \mathrm{~cm}\end{array}$} \\
\hline Imaturos & 0 & 0 & 0 & 0 & 0 & 0 & 1 & 0 & 0 & 0 & 1 & 0,5 & 6,7 & 0,1 & 0,3 \\
\hline Mechos & 0 & 0 & 0 & 0 & 0 & 2 & 0 & 0 & 0 & 0 & 2 & 1,0 & 13,3 & 0,2 & 0,6 \\
\hline Fômans & 0 & 0 & 0 & 1 & 0 & 0 & 0 & 0 & 1 & 0 & 2 & 1,0 & 13,3 & 0,2 & 0,4 \\
\hline Indeterminados & 0 & 1 & 0 & 0 & 0 & 0 & 0 & 0 & 0 & 0 & 1 & 0,5 & 6,7 & 0,1 & 0,3 \\
\hline Subtotal & 0 & 1 & 0 & 1 & 0 & 2 & 1 & 0 & 1 & 0 & 6 & 2,8 & 40,0 & 0,6 & 0,7 \\
\hline \multicolumn{16}{|l|}{$7-10,5 \mathrm{~cm}$} \\
\hline imathuros & 0 & 0 & 0 & 0 & 3 & 1 & 0 & 0 & 0 & 0 & 4 & 1,8 & 28,6 & 0,4 & 1,0 \\
\hline Subadultos & 0 & 0 & 0 & 0 & 1 & 0 & 0 & 0 & 0 & 0 & 1 & 0,5 & 6,7 & 0,1 & 0,3 \\
\hline Machos & 0 & 0 & 0 & 0 & 2 & 0 & 0 & 0 & 0 & 0 & 2 & 1,0 & 13,3 & 0,2 & 0,6 \\
\hline Fómose & 0 & 0 & 0 & 0 & 1 & 0 & 0 & 0 & 0 & 0 & 1 & 0,5 & 6,7 & 0,1 & 0,3 \\
\hline Indeterminado & 0 & 1 & 0 & 0 & 0 & 0 & 0 & 0 & 0 & 0 & 1 & 0,5 & 6,7 & 0,1 & 0,3 \\
\hline Subtotal & 0 & 1 & 0 & 0 & 7 & 1 & 0 & 0 & 0 & 0 & 9 & 4,3 & 60,0 & 0,8 & 2,2 \\
\hline Total $(0-10,5 \mathrm{~cm})$ & 0 & 2 & 0 & 1 & 7 & 3 & 1 & 0 & 1 & 0 & 15 & 72 & 100,0 & 1,5 & 2,2 \\
\hline Ind. $/ \mathrm{m}^{2}$ & 0,0 & 9,6 & 0,0 & 4,8 & 33,7 & 14,4 & 4,8 & 0,0 & 4,8 & 0,0 & & & & & \\
\hline$\%$ & 0,0 & 13,3 & 0,0 & 6,7 & 46,6 & 20,0 & 6,7 & 0,0 & 6,7 & 0,0 & & & & & \\
\hline 5. Total $(0-14 \mathrm{~cm})$ & . & & & & & & & & & & & & & & \\
\hline Imaturos & 0 & 9 & 1 & 1 & 4 & 1 & 3 & 0 & 1 & 0 & 20 & 9,6 & 43,5 & 2,0 & 2,8 \\
\hline Subadultos & 0 & 1 & 0 & 0 & 2 & 1 & 0 & 0 & 0 & 0 & 4 & 1,8 & 8,7 & 0,4 & 0,7 \\
\hline Machos & 0 & 0 & 0 & 1 & 2 & 0 & 0 & 1 & 0 & 0 & 4 & 1,8 & 8,7 & 0,4 & 0,7 \\
\hline Fêmeas & 0 & 2 & 1 & 1 & 2 & 3 & 1 & 0 & 0 & 1 & 11 & 5,3 & 23,9 & 1,1 & 1,0 \\
\hline Indeterninados & 0 & 2 & 0 & 0 & 0 & 2 & 1 & 2 & 0 & 0 & 7 & 3,4 & 15,2 & 0,7 & 09 \\
\hline Total & 0 & 14 & 2 & 3 & 10 & 7 & 5 & 3 & 1 & 1 & 48 & 22,1 & 100,0 & 4,6 & $\frac{1}{4,5}$ \\
\hline ind./m2 & 0,0 & 67,4 & 9,6 & 14,4 & 48,1 & 33,7 & 24,1 & 14,4 & 4,8 & 4,8 & 221,4 & & & & \\
\hline 70 & 0,0 & 30,4 & 44,3 & 8.5 & 21,7 & 15,2 & $11, \overline{0}$ & 85 & 2,2 & $2, \overline{2}$ & & & & & \\
\hline
\end{tabular}


Apêndice 15 - Captura de Geophilomorpha (espécies) en fotoeclector de árvore direcionado para baixo (BE!), no periodo de julho/1987 a junho/1988, na floresta inundada por água nista (número de captura, percentagen (\%), rédia e desvio padráo (S)).

\begin{tabular}{|c|c|c|c|c|c|c|c|c|c|c|c|c|c|c|c|c|}
\hline Espécies/Meses & JUI./87 & Ago. & Set. & Out. & Nov. & Dez & Jan./88 & Fev. & Mar. & Abr. & Mai. & Jun. & Total & $\%$ & Média & $\underline{s}$ \\
\hline \multicolumn{17}{|l|}{ 1- Ribautia centralis } \\
\hline Imaturos & 0 & 0 & 0 & 0 & 0 & 0 & 0 & 0 & 0 & 0 & 0 & 0 & 0 & 0,0 & 0,0 & 0,0 \\
\hline Subadultos & 0 & 1 & 0 & 0 & 0 & 0 & 0 & 0 & 0 & 0 & 0 & 0 & 1 & 2,8 & 0,1 & 0,3 \\
\hline Machos & 3 & 11 & 0 & 0 & 0 & 0 & 0 & 0 & 0 & 0 & 0 & 0 & 14 & 38,9 & 1,2 & 3,2 \\
\hline Fêmeas & 2 & 17 & 0 & 0 & 0 & 0 & 0 & 0 & 0 & 0 & 0 & 1 & 20 & 55,5 & 1,7 & 4,9 \\
\hline Indeterminados & 0 & 1 & 0 & 0 & 0 & 0 & 0 & 0 & 0 & 0 & 0 & 0 & 1 & 2,8 & 0,1 & 0,3 \\
\hline Subtotal & 5 & 30 & 0 & 0 & 0 & 0 & 0 & 0 & 0 & 0 & 0 & 1 & 36 & 100,0 & 3,0 & 8,6 \\
\hline$\%$ & 13,9 & 83,8 & 0,0 & 0,0 & 0,0 & 0,0 & 0,0 & 0,0 & 0,0 & 0,0 & 0,0 & 2,8 & & & & \\
\hline \multicolumn{17}{|l|}{ 2- Geophilidae n.sp. } \\
\hline Machos & 2 & 1 & 0 & 0 & 0 & 0 & 0 & 0 & 0 & 0 & 0 & 0 & 3 & 30,0 & 0,3 & 0,6 \\
\hline Fême & 1 & 2 & 0 & 0 & 0 & 0 & 0 & 0 & 0 & 0 & 0 & 0 & 3 & 30,0 & 0,3 & 0,6 \\
\hline Indeterminados & 2 & 2 & 0 & 0 & 0 & 0 & 0 & 0 & 0 & 0 & 0 & 0 & 4 & 40,0 & 0,3 & 0,8 \\
\hline Subtotal & 5 & 5 & 0 & 0 & 0 & 0 & 0 & 0 & 0 & 0 & 0 & 0 & 10 & 100,0 & 0,8 & 1,9 \\
\hline$\%$ & 50,0 & 50,0 & 0,0 & 0,0 & 0,0 & 0,0 & 0,0 & 0,0 & 0,0 & 0,0 & 0,0 & 0,0 & & & & \\
\hline \multicolumn{17}{|l|}{ 3- Schendylidae n.spp. } \\
\hline Machos & 1 & 0 & 0 & 0 & 0 & 0 & 0 & 0 & 0 & 0 & 0 & 0 & 1 & 100,0 & 0,1 & 0,3 \\
\hline Subtotal & 1 & 0 & 0 & 0 & 0 & 0 & 0 & $\overline{0}$ & 0 & $\overline{0}$ & 0 & 0 & 1 & 100,0 & 0,1 & 0,3 \\
\hline$\%$ & 100,0 & 0,0 & 0,0 & 0,0 & 0,0 & 0,0 & 0,0 & 0,0 & 0,0 & 0,0 & 0,0 & 0,0 & & & & \\
\hline \multicolumn{17}{|c|}{ 4- Pectiniunquis ascendens } \\
\hline Machos & 0 & 1 & 0 & 0 & 0 & 0 & 0 & 0 & 0 & 0 & 0 & 0 & 1 & 100,0 & 0,1 & 0,3 \\
\hline Subtotal & 0 & 1 & 0 & 0 & 0 & 0 & 0 & 0 & 0 & 0 & 0 & 0 & 1 & 100,0 & 0,1 & 0,3 \\
\hline$\%$ & 0,0 & 100, & 0,0 & 0,0 & 0,0 & 0,0 & 0,0 & 0,0 & 0,0 & 0,0 & 0,0 & 0,0 & & & & \\
\hline 5- Total $(1)+(2)+(3)+(4)$ & 11 & 36 & 0 & 0 & 0 & $\overline{0}$ & 0 & 0 & $\overline{0}$ & $\overline{0}$ & 0 & 1 & 48 & & 4,0 & \\
\hline$\%$ & 22,9 & 75,0 & 0,0 & 0,0 & 0,0 & $\overline{0,0}$ & $\overline{0,0}$ & 0,0 & 0,0 & 0,0 & 0,0 & $\overline{2,1}$ & & & & \\
\hline
\end{tabular}


Apêndice 16 - Captura de Diplopoda no solo, através do método de Reapson, de 0 a 14 cn de profundidade, no periodo de agosto/1987 a naio/1988, na floresta inundada por água nista (núrero de captura, percentagen $(\%)$, abundância (individuos/m²/mês), nédia e desvio padräo (S)).

\begin{tabular}{|c|c|c|c|c|c|c|c|c|c|c|c|c|c|c|c|}
\hline Grupos/Muses & Ago./87 & Set. & Out. & Nov. & Dez. & $\operatorname{Jan} . / 88$ & Fev. & Mar. & Abr. & Mai. & Total & $\%$ & Ind./minenês & Módia & $\mathbf{s}$ \\
\hline 1- Potyxenidae & 0 & 15 & 14 & 27 & 190 & 355 & 242 & 300 & 333 & 229 & 1705 & 77,9 & 820,4 & 170,5 & 143,2 \\
\hline 2- Fuhrmannondesmldae & 17 & 30 & 1 & 8 & 15 & 12 & 67 & 17 & 33 & 233 & 433 & 18,8 & 208,4 & 43,3 & 69,1 \\
\hline 3. Pyrgodesmidae & 0 & 7 & 0 & 0 & 0 & 0 & 1 & 2 & 0 & 3 & 13 & 0,6 & 6,3 & 1,3 & 2,3 \\
\hline 4- Paradoxomatidae & 0 & 12 & 0 & 0 & 0 & 0 & 0 & 0 & 0 & 0 & 12 & 0,5 & 5,8 & 1,2 & 3,8 \\
\hline 5. Siphonophoridas & 0 & 3 & 3 & 1 & 0 & 0 & 3 & 1 & 0 & 1 & 12 & 0,5 & 5,8 & 1,2 & 1,3 \\
\hline 6- Stemmlulidae & 0 & 1 & 3 & 0 & 0 & 2 & 1 & 2 & 1 & 0 & 10 & 0,5 & 4,8 & 1,0 & 1,1 \\
\hline 7- Spirostreptida & 0 & 0 & 0 & 0 & 2 & 1 & 0 & 0 & 0 & 0 & 3 & $-0,1$ & $-1,4$ & $-0,3$ & $-0,7$ \\
\hline Total & 17 & 88 & 21 & 36 & 207 & 370 & 314 & 322 & 367 & 466 & 2188 & 100,0 & 1052,8 & 218.8 & 170.6 \\
\hline$\%$ & 0,8 & 3,1 & 1,0 & 1,6 & 9,5 & 16,8 & 14,3 & 14,7 & 16,8 & 21,3 & & & & & \\
\hline Tnd. $/ m^{2}$ & 81,8 & 327,2 & 101,1 & 773,2 & 996,1 & 1780,4 & 1511,0 & 1549,5 & 1786,0 & 2242,4 & & & & & \\
\hline
\end{tabular}

Apêndice 17 - Captura de Diplopoda através do nétodo de Keapson nas diferentes canadas do solo, no período de agosto/1987 a naio/1988, na floresta inundada por água nista (núnero de captura, percentagen (६), abundância (indivíduos/n²/nês), nédia e desvio padrão (S)).

\begin{tabular}{|c|c|c|c|c|c|c|c|c|c|c|c|c|c|c|c|}
\hline Fomflias/Meses & Ago./87 & Set. & Out. & Nov. & Dez & Jan./88 & Fev. & Mar. & Abr. & Mal. & Total & $\%$ & Ind./minmês & Médlia & s \\
\hline \multicolumn{16}{|l|}{$\begin{array}{l}\text { T- Phinilia Celikara } \\
0-3,5 \mathrm{~cm}\end{array}$} \\
\hline 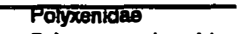 & 0 & 4 & 6 & 7 & 83 & 182 & 157 & 211 & 282 & 147 & 1000 & 74,8 & 514,4 & 108,8 & 99,4 \\
\hline Fuhrmarnondesmida & 7 & 27 & 1 & 4 & 10 & 8 & 58 & 12 & 28 & 170 & 321 & 22,5 & 154,5 & 32,1 & 51,1 \\
\hline Outras & 0 & 21 & 5 & 0 & 2 & 2 & 2 & 2 & 1 & 3 & 38 & 2.7 & 18.3 & 3.8 & 62 \\
\hline Subtotal & 7 & 52 & 12 & 11 & 85 & 202 & 215 & 225 & 289 & 320 & 1428 & 100,0 & 687,2 & 1428 & 1210 \\
\hline$\frac{\%}{\pi\left[1 / m^{2}-\right.}$ & $\begin{array}{r}0,5 \\
38,7\end{array}$ & 23,6 & 0,8 & $\begin{array}{r}0,8 \\
52, \overline{9} \\
\end{array}$ & $\begin{array}{c}6,7 \\
457,1 \\
\end{array}$ & $\frac{14,1}{972,0}$ & $\frac{15,1}{1034,6}$ & $\begin{array}{r}15,8 \\
1082,7\end{array}$ & 20,2 & $\frac{22,4}{1539}, 8$ & & & & & \\
\hline \multicolumn{16}{|l|}{$\begin{array}{l}\text { 2- Segunda Camada } \\
3,5-7 \mathrm{~cm}\end{array}$} \\
\hline Polyxenloter & 0 & 8 & 5 & 5 & 70 & 47 & 47 & 53 & 56 & 65 & 358 & 80,5 & 171,3 & 35,6 & 27,7 \\
\hline Fuhrmannondesmida & 1 & 3 & 0 & 2 & 1 & 3 & 7 & 4 & 4 & 55 & 80 & 18,1 & 38,5 & 8,0 & 16,6 \\
\hline Outros & 0 & 2 & 0 & 0 & 0 & 1 & 1 & 2 & 0 & 0 & 6 & $-1,4$ & 2,8 & 0 & م, \\
\hline Subtotal & 1 & 13 & 5 & 7 & 71 & 51 & 55 & 59 & 60 & 120 & 442 & 100.0 & 2127 & 442 & 37,8 \\
\hline & 0,2 & 2,8 & 1,1 & 1,6 & 16,1 & 11,5 & 12,4 & 13,4 & 13,6 & 27,2 & & & & & \\
\hline Tna. $/ \mathrm{m}^{2-}$ & 48 & 62,6 & 24,9 & 33,7 & 341,7 & 245,4 & 2647 & 283,9 & 288,7 & 574 & & & & & \\
\hline \multicolumn{16}{|l|}{$\begin{array}{l}\text { 3. Tercelra Camada } \\
7-10,5 \mathrm{~cm}\end{array}$} \\
\hline Polyxentace & 0 & 1 & 2 & 12 & 16 & 74 & 33 & 18 & 13 & 10 & 180 & 87,8 & 88,6 & 18,0 & 22,0 \\
\hline Fuhmannondeemida & 3 & 0 & 0 & 1 & 4 & 0 & 3 & 0 & 3 & 7 & 21 & 10,2 & 10,1 & 2,1 & 2,3 \\
\hline Outros & 0 & 0 & 0 & 1 & 0 & 0 & 1 & 1 & 0 & 1 & 4 & 2.0 & 19 & 0.4 & 0,5 \\
\hline Subtotal & 3 & 1 & 2 & 14 & 20 & 74 & 37 & 20 & 16 & 18 & 205 & 100,0 & 98.7 & 20.5 & 217 \\
\hline$\%$ & 1,5 & 0,5 & 1,0 & 6,8 & 9,6 & 36,1 & 18,0 & 9,8 & 7,8 & 8,9 & & & & & \\
\hline Tnd. $/ \mathrm{m}^{2}$ & 74,4 & 4,8 & $8, \overline{8}$ & 67,4 & 86,2 & 356,1 & 178,0 & 86,2 & 7,0 & 68,6 & & & & & \\
\hline \multicolumn{16}{|l|}{$\begin{array}{c}\text { 4- Quarta Camads } \\
10,5-14 \mathrm{~cm}\end{array}$} \\
\hline 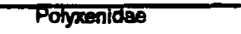 & 0 & 2 & 1 & 3 & 21 & 42 & 5 & 17 & 2 & 7 & 100 & 88,5 & 48,1 & 10,0 & 13,3 \\
\hline Fuhrmannondesmida & 6 & 0 & 0 & 1 & 0 & 1 & 1 & 1 & 0 & 1 & 11 & 9,7 & 5,3 & 1,1 & 1,8 \\
\hline Outros & 0 & 0 & 1 & 0 & 0 & 0 & 1 & 0 & 0 & 0 & 2 & 1,8 & 1,0 & 0,2 & 0,4 \\
\hline Subtotal & 6 & 2 & 2 & 4 & 21 & 43 & 7 & 18 & 2 & 8 & 113 & 100,0 & 54,4 & 11,3 & 13,0 \\
\hline$\%$ & 5,3 & 18 & 1,8 & 3,5 & 18,5 & 38,0 & 6,2 & 15,8 & 18 & 7,2 & & & & & \\
\hline Ind. $/ \mathrm{m}^{2}$ & 28,9 & 9,6 & 9,6 & 19,2 & 101,1 & 200,8 & 33,7 & 88,6 & 9,6 & 38,5 & & & & & \\
\hline Total & 17 & 68 & 21 & 36 & 207 & 370 & 314 & 322 & 367 & 466 & 2188 & & 1052,9 & 218,8 & $>150$ \\
\hline$\%$ & 0,8 & 3,1 & 1,0 & 1,6 & 1,5 & 16,8 & 14,3 & 14,7 & 16,8 & 21,3 & & & & & \\
\hline Ind./m ${ }^{2}$ & 81,8 & 327,2 & 101,1 & $173 \underline{2}$ & 996,1 & 1780,4 & 1511,0 & 1549,5 & 1766,0 & 22424 & & & & & \\
\hline
\end{tabular}


Apêndice 18 - Captura nensal e estágios de desenvolvinento de Moojenodessus vellingtoni n.sp. Golovatsch, 1994 e Moojenodesmus parilns Schubart, 1944 (Rehrmannodesnidae, Diplopoda), no solo da floresta inundada por água nista, de 0 a 14 ca de profundidade no período de agosto/1987 a maio/1988. Método de Rempson (minero de captura, percentagen (६), abundância

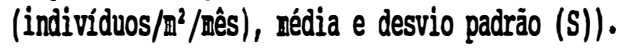

\begin{tabular}{|c|c|c|c|c|c|c|c|c|c|c|c|c|c|c|c|}
\hline Estágios/Meses & Ago./87 & Set. & Out. & Nov. & Dez. & Jan./88 & Fev. & Mar. & Abr. & Mai & Total & $\%$ & Média & Ind. $/ \mathrm{m}^{2} / \mathrm{mês}$ & $\mathbf{S}$ \\
\hline \multicolumn{16}{|l|}{ Fuhrmannondesmidae } \\
\hline Segmento 7 & 0 & 18 & 0 & 0 & 0 & 0 & 13 & 0 & 0 & 18 & 49 & 11,3 & 4,9 & 23,6 & 8,0 \\
\hline Segmento 9 & 0 & 11 & 0 & 0 & 0 & 0 & 22 & 1 & 4 & 28 & 66 & 15,2 & 6,6 & 31,8 & 10,4 \\
\hline Segmento 12 & 0 & 0 & 0 & 0 & 2 & 1 & 4 & 0 & 5 & 17 & 29 & 6,7 & 2,9 & 13,9 & 5,3 \\
\hline Segmento 15 & 0 & 0 & 0 & 0 & 1 & 0 & 6 & 0 & 5 & 35 & 47 & 10,9 & 4,7 & 22,6 & 10,9 \\
\hline Segmento 17 & 4 & 0 & 0 & 1 & 0 & 0 & 1 & 5 & 4 & 24 & 39 & 9,1 & 3,9 & 18,8 & 7,3 \\
\hline Segmento 18 & 5 & 0 & 0 & 1 & 1 & 2 & 1 & 4 & 2 & 8 & 24 & 5,5 & 2,4 & 11,5 & 2,5 \\
\hline Segmento 19 & 4 & 0 & 1 & 0 & 0 & 4 & 1 & 4 & 4 & 8 & 26 & 6,0 & 2,6 & 12,5 & 2,6 \\
\hline Indeterminados & 4 & 0 & 0 & 1 & 11 & 5 & 17 & 3 & 4 & 92 & 137 & 31,6 & 13,7 & 65,9 & 28,0 \\
\hline Machos (M) & 0 & 0 & 0 & 1 & 0 & 0 & 0 & 0 & 2 & 0 & 3 & 0,7 & 0,3 & 1,4 & 0,7 \\
\hline Fêmeas (F) & 0 & 1 & 0 & 5 & 0 & 0 & 1 & 0 & 3 & 3 & 13 & 3,0 & 1,3 & 6,3 & 1,8 \\
\hline Subtotal Imaturos & 17 & 29 & 1 & 3 & 15 & 12 & 65 & 17 & 28 & 230 & 417 & 96,3 & 41,7 & 200,7 & $\overline{68,6}$ \\
\hline Subtotal Adultos & 0 & 1 & 0 & 6 & 0 & 0 & 1 & 0 & 5 & 3 & 16 & 3,7 & 1,6 & 7,7 & 2,3 \\
\hline Total & 17 & 30 & 1 & 9 & 15 & 12 & 66 & 17 & 33 & 233 & 433 & 100,0 & 43,3 & 208,4 & 69,1 \\
\hline$\%$ & 3,9 & 6,9 & 0,2 & 2,1 & 3,5 & 2,8 & 15,3 & 3,9 & 7,6 & 53,8 & 100,0 & & & & \\
\hline Ind. $/ \mathrm{m}^{2}$ & 81,8 & 144,4 & 4,8 & 43,3 & 72,2 & 57,7 & 317,6 & 81,8 & 158,8 & 1121,2 & & & & & \\
\hline
\end{tabular}

Apêndice 19 - Captura de Diplopoda no folhedo con fotoeclectores de solo, no periodo de agosto/1987 a naio/1988, na floresta inundada por água nista (nímero de captura, densidade de atividade (indivíduos $/ \mathbf{n}^{2} / \mathbf{r e ̂ s}^{\text {) }}$, percentagen $(\%)$, aédia e desvio padrão (S)).

\begin{tabular}{|c|c|c|c|c|c|c|c|c|c|c|c|c|c|c|c|}
\hline Grupos/Meses & Ago./87 & Set. & Out. & Nov. & Dez. & Jan./88 & Fev. & Mar. & Abr. & Mai. & Total & Ind. $/ \mathrm{m}^{2} / \mathrm{mês}$ & $\%$ & Média & $\mathbf{S}$ \\
\hline blyxenidae & 0 & 15 & 1 & 0 & 0 & 38 & 36 & 24 & 6 & 8 & 128 & 3,2 & 73,1 & 12,8 & 14,9 \\
\hline dhmannodesmidae & 0 & 5 & 0 & 0 & 0 & 0 & 0 & 0 & 0 & 32 & 37 & 1,0 & 21,1 & 3,7 & 10,1 \\
\hline godesmidae & 0 & 0 & 0 & 0 & 0 & 0 & 1 & 0 & 2 & 1 & 4 & 0,1 & 2,3 & 0,4 & 0,7 \\
\hline nmiulidae & 0 & 0 & 0 & 1 & 0 & 0 & 2 & 0 & 0 & 2 & 5 & 0,1 & 2,9 & 0,5 & 0,8 \\
\hline robolida & 0 & 0 & 0 & 0 & 0 & 0 & 1 & 0 & 0 & 0 & 1 & 0,0 & 0,6 & 0,1 & 0,3 \\
\hline 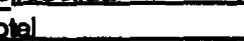 & 0 & 20 & 1 & 1 & 0 & 38 & 40 & 24 & 8 & 43 & 175 & 4,4 & 100,0 & 17,5 & \\
\hline$/ \mathrm{m}^{2}$ & 0.0 & 5,0 & 0,3 & 0,3 & 0,0 & 9,5 & 10,0 & 6,0 & 2,0 & 10,8 & 43,8 & & & & \\
\hline & 0,0 & 11,4 & 0,6 & 0,6 & 0,0 & 21,7 & 22,9 & 13,7 & 4,6 & 24,6 & 100,0 & & & & \\
\hline
\end{tabular}


Apêndice 20 - Captura mensal e estágios de desenvolvimento de Moojenodesws vellingtoni n. sp. Golovatsch, 1994 e Moojenodesuns puriilus Schubart, 1944 (Fuhrnannodesnidae, Diplopoda), no folhedo, na floresta inundada por água mista, no periodo de agosto/1987 a naio/1988. Coleta con fotoeclectores de solo (núnero de captura, densidade de atividade

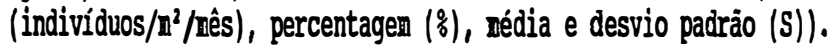

\begin{tabular}{|c|c|c|c|c|c|c|c|c|c|c|c|c|c|c|c|}
\hline Espécie/Meses & Ago./87 & Set. & Out. & Nov. & Dez. & Jan./88 & Fev. & Mar. & Abr. & Mai. & Total & $\%$ & Média & Ind./min/mês & $\mathbf{s}$ \\
\hline \multicolumn{16}{|c|}{ Fuhrmannodesmidae } \\
\hline \multicolumn{16}{|l|}{ No. segmentos } \\
\hline Segmento 7 & 0 & 0 & 0 & 0 & 0 & 0 & 0 & 0 & 0 & 0 & 0 & 0,0 & 0,0 & 0,0 & 0,0 \\
\hline Segmento 9 & 0 & 0 & 0 & 0 & 0 & 0 & 0 & 0 & 0 & 0 & 0 & 0,0 & 0,0 & 0,0 & 0,0 \\
\hline Segmento 12 & 0 & 0 & 0 & 0 & 0 & 0 & 0 & 0 & 0 & 6 & 6 & 16,2 & 0,6 & 0,1 & 2,0 \\
\hline Segmento 15 & 0 & 1 & 0 & 0 & 0 & 0 & 0 & 0 & 0 & 0 & 1 & 2,7 & 0,1 & 0,0 & 0,3 \\
\hline Segmento 17 & 0 & 0 & 0 & 0 & 0 & 0 & 0 & 0 & 0 & 10 & 10 & 27,1 & 1,0 & 0,2 & 3,3 \\
\hline Segmento 18 & 0 & 0 & 0 & 0 & 0 & 0 & 0 & 0 & 0 & 8 & 8 & 21,6 & 0,8 & 0,2 & 2,7 \\
\hline Segmento 19 & 0 & 0 & 0 & 0 & 0 & 0 & 0 & 0 & 0 & 0 & 0 & 0,0 & 0,0 & 0,0 & 0,0 \\
\hline Indeterminados & 0 & 3 & 0 & 0 & 0 & 0 & 0 & 0 & 0 & 8 & 11 & 29,7 & 1,1 & 0,3 & 2,7 \\
\hline Machos (M) & 0 & 0 & 0 & 0 & 0 & 0 & 0 & 0 & 0 & 0 & 0 & 0,0 & 0,0 & 0,0 & 0,0 \\
\hline Fômeas (F) & 0 & 1 & 0 & 0 & 0 & 0 & 0 & 0 & 0 & 0 & 1 & 2,7 & 0,1 & 0,0 & 0,3 \\
\hline Subtotal imaturos & 0 & 4 & 0 & 0 & 0 & 0 & 0 & 0 & 0 & 32 & 36 & 97,3 & 3,6 & 0,9 & 10,6 \\
\hline Subtotal Adullos & 0 & 1 & 0 & 0 & 0 & 0 & 0 & 0 & 0 & 0 & 1 & 2,7 & 0,1 & 0,0 & 0,3 \\
\hline Total & 0 & 5 & 0 & 0 & 0 & 0 & 0 & 0 & 0 & 32 & 37 & 100,0 & 3,7 & 1,0 & 10,6 \\
\hline
\end{tabular}

Apêndice 21 - Captura de Diplopoda en fotoeclector de árvore direcionado para cima (BET), no periodo de julho/1987 a junho/1988, na floresta inundada por água nista (número de captura, percentagen (\%), nédia e desvio padrão (S)).

\begin{tabular}{|c|c|c|c|c|c|c|c|c|c|c|c|c|c|c|c|c|}
\hline Grupo/Meses & Jul./87 & Ago. & Set. & Out. & Nov. & Dez. & $\operatorname{Jan} . / 88$ & Fev. & Mar. & Abr. & Mai. & Jun. & Total & $\%$ & Média & $\mathbf{s}$ \\
\hline 1- Fuhrmannodesmidae & $\overline{0}$ & 0 & 1 & $\overline{0}$ & 0 & 0 & 1 & 9 & 12 & 104 & 270 & $\mathbf{0}$ & 397 & 78,9 & 33,08 & 80,2 \\
\hline 2- Pyrgodesmidae & 0 & 0 & 0 & 0 & 6 & 3 & 9 & 24 & 2 & 10 & 6 & 2 & 62 & 12,3 & 5,167 & 6,9 \\
\hline 3- Polyxenidae & 0 & 0 & 1 & 0 & 0 & 0 & 0 & 2 & 1 & 1 & 20 & 0 & 25 & 5,0 & 2,083 & 5,7 \\
\hline 4 Spirostreptida & 0 & 0 & 0 & 0 & 1 & 3 & 7 & 1 & 0 & 2 & 0 & 0 & 14 & 2,8 & 1,167 & 2,1 \\
\hline 5- Stermmiulidae & 0 & 0 & 1 & 0 & 0 & 0 & 0 & 1 & 0 & 0 & 1 & 0 & 3 & 0,6 & 0,25 & 0,5 \\
\hline 6- Siphonophoridae & 0 & 0 & 0 & 0 & 0 & 0 & 0 & 0 & 0 & 0 & 2 & 0 & 2 & 0,4 & 0,167 & 0,6 \\
\hline Total & 0 & 0 & 3 & 0 & 7 & 6 & 17 & 37 & 15 & 117 & 299 & 2 & 503 & 100,0 & 41,92 & \\
\hline$\%$ & 0,0 & 0,0 & $\overline{0,6}$ & 0,0 & 1,4 & 1,2 & 3,4 & 7,4 & 3,2 & 23,3 & 59,4 & $\overline{0,4}$ & 100,0 & & & \\
\hline
\end{tabular}


Apêndice 22 - Captura mensal e estágios de desenvolvimento de Moojenodesnus purilus Schubart, 1944 (Fuhrmannodesnidae, Diplopoda), en fotoeclector direcionado para cima (BEf), na floresta inundada por água nista, no periodo de julho/1987 a junho/1988 (núnero de captura, percentagen $(\%)$, nédia e desvio padrão (S)).

\begin{tabular}{|c|c|c|c|c|c|c|c|c|c|c|c|c|c|c|c|c|}
\hline $\begin{array}{l}\text { Espécie/Meses } \\
\text { M.pumilus }\end{array}$ & Jul./87 & Ago. & Set. & Out. & Nov. & Dez. & Jan./88 & Fev. & Mar. & Abr. & Mai. & Jun. & Total & $\%$ & Média & s \\
\hline \multicolumn{17}{|l|}{ M.pumulus } \\
\hline Segmento 7 & 0 & 0 & 0 & 0 & 0 & 0 & 0 & 0 & 0 & 0 & 0 & 0 & 0 & 0,0 & 0,0 & 0,0 \\
\hline Segmento 9 & 0 & 0 & 0 & 0 & 0 & 0 & 0 & 0 & 0 & 0 & 0 & 0 & 0 & 0,0 & 0,0 & 0,0 \\
\hline Segmento 12 & 0 & 0 & 0 & 0 & 0 & 0 & 0 & 0 & 0 & 5 & 1 & 0 & 6 & 1,5 & 0,5 & 1,4 \\
\hline Segmento 15 & 0 & 0 & 0 & 0 & 0 & 0 & 0 & 1 & 1 & 6 & 19 & 0 & 27 & 6,8 & 2,3 & 5,5 \\
\hline Segmento 17 & 0 & 0 & 0 & 0 & 0 & 0 & 0 & 4 & 7 & 55 & 47 & 0 & 113 & 28,5 & 9,4 & 19,6 \\
\hline Segmento 18 & 0 & 0 & 0 & 0 & 0 & 0 & 1 & 1 & 0 & 18 & 23 & 0 & 43 & 10,8 & 3,6 & 8,0 \\
\hline Segmento 19 & 0 & 0 & 0 & 0 & 0 & 0 & 0 & 0 & 0 & 0 & 0 & 0 & 0 & 0,0 & 0,0 & 0,0 \\
\hline Indeterminados & 0 & 0 & 0 & 0 & 0 & 0 & 0 & 3 & 3 & 3 & 149 & 0 & 158 & 39,8 & 13,2 & 42,8 \\
\hline Machos (M) & 0 & 0 & 1 & 0 & 0 & 0 & 0 & 0 & 1 & 4 & 0 & 0 & 6 & 1,5 & 0,5 & 1,2 \\
\hline Fêmeas $(\mathbf{F})$ & 0 & 0 & 0 & 0 & 0 & 0 & 0 & 0 & 0 & 13 & 31 & 0 & 44 & 11,1 & 3,7 & 9,4 \\
\hline Subtotal Imaturos & 0 & 0 & 0 & 0 & 0 & 0 & 1 & 9 & 11 & 87 & 239 & 0 & 347 & 87,4 & 28,9 & 70,6 \\
\hline Subtotal Adultos & 0 & 0 & 1 & 0 & 0 & 0 & 0 & 0 & 1 & 17 & 31 & 0 & 50 & 12,6 & 4,2 & 9,7 \\
\hline Total & 0 & 0 & 1 & 0 & 0 & 0 & 1 & 9 & 12 & 104 & 270 & 0 & 397 & 100,0 & 33,1 & \\
\hline$\%$ & 0,0 & 0,0 & 0,3 & 0,0 & 0,0 & 0,0 & 0,25 & 2,3 & 3,0 & 26,2 & 68.0 & 0,0 & 100,0 & & & \\
\hline
\end{tabular}

Apêndice 23 - Captura nensal e estágios de desenvolvinento de lturyodeszons obliteratus Schubart, 1943 (Pyrgodesnidae, Diplopoda), en fotoeclector direcionado para cima (BEt), na floresta imundada por água nista, no período de julho/1987 a junho/1988 (nínero de captura, percentagea (\%), rédia e desvio padrão (s)).

$\begin{array}{llllllllllllll}\text { Espécie/Meses Jul.87 Ago. } & \text { Set. } & \text { Out. Nov. Dez. Jan./8 } & \text { Fev. } & \text { Mar. Abr. } & \text { Mai } & \text { Jun. Total } & \% & \text { Média } & S\end{array}$ M. obliteratus

No. segmentos

\begin{tabular}{|c|c|c|c|c|c|c|c|c|c|c|c|c|c|c|c|c|}
\hline Segmento 7 & 0 & 0 & 0 & 0 & 0 & 0 & 0 & 0 & 0 & 0 & 0 & 0 & 0 & 0,0 & 0,0 & 0,0 \\
\hline Segmento 9 & 0 & 0 & 0 & 0 & 0 & 0 & 0 & 0 & 0 & 0 & 0 & 0 & 0 & 0,0 & 0,0 & 0,0 \\
\hline Segmento 12 & 0 & 0 & 0 & 0 & 0 & 0 & 0 & 0 & 0 & 1 & 0 & 0 & 1 & 1,6 & 0,1 & 0,3 \\
\hline Segmento 15 & 0 & 0 & 0 & 0 & 0 & 0 & 0 & 4 & 0 & 0 & 0 & 0 & 4 & 6,5 & 0,3 & 1,2 \\
\hline Segmento 17 & 0 & 0 & 0 & 0 & 0 & 1 & 1 & 2 & 0 & 0 & 1 & 1 & 6 & 9,7 & 0,5 & 0,7 \\
\hline Segmento 18 & 0 & 0 & 0 & 0 & 1 & 1 & 1 & 0 & 0 & 3 & 0 & 0 & 6 & 9,7 & 0,5 & 0,9 \\
\hline Segmento 19 & 0 & 0 & 0 & 0 & 2 & 0 & 1 & 2 & 0 & 5 & 4 & 0 & 14 & 22,6 & 1,2 & 1,7 \\
\hline Indeterminados & 0 & 0 & 0 & 0 & 0 & 1 & 0 & 0 & 0 & 0 & 1 & 1 & 3 & 4,8 & 0,3 & 0,5 \\
\hline Machos (M) & 0 & 0 & 0 & 0 & 2 & 0 & 3 & 10 & 2 & 1 & 0 & 0 & 18 & 29,0 & 1,5 & 2,9 \\
\hline Fêmeas (F) & 0 & 0 & 0 & 0 & 1 & 0 & 3 & 6 & 0 & 0 & 0 & 0 & 10 & 16,1 & 0,8 & 1,9 \\
\hline Subtotal Imaturo & 0 & 0 & 0 & 0 & 3 & 3 & 3 & 8 & 0 & 9 & 6 & 2 & 34 & 54,8 & 2,8 & 3,2 \\
\hline Subtotal MeF & 0 & 0 & 0 & 0 & 3 & 0 & 6 & 16 & 2 & 1 & 0 & 0 & 28 & 45,2 & 2,3 & 4,7 \\
\hline Total & 0 & 0 & 0 & 0 & 6 & 3 & 9 & 24 & 2 & 10 & 6 & 2 & 62 & 100,0 & 5,2 & \\
\hline$\%$ & 0,0 & 0,0 & 0,0 & 0,0 & 9,7 & 4,8 & 14,5 & 38,7 & 3,2 & 16,1 & 9,7 & 3,2 & 100,0 & & & \\
\hline
\end{tabular}


Apêndice 24 - Captura de Diplopoda en fotoeclector de árvore direcionado para baixo (BE†), no periodo de julho/1987 a junho/1988, na floresta inundada por água nista (número de captura, percentagen $(\xi)$, nédia e desvio padrão (S)).

\begin{tabular}{lccccccccccccccccc}
\hline \multicolumn{1}{c}{ Familias/Meses } & Jul./87 & Ago. & Set. & Out. & Nov. & Dez. & Jan./8 & Fev. & Mar. & Abr. & Maj. & Jun. & Total & $\%$ & Média & $S$ \\
\hline 1- Fuhmmannodesmidae & 0 & 0 & 0 & 0 & 0 & 0 & 0 & 0 & 3 & 3 & 303 & 276 & 585 & 78,9 & 48,8 & 112,6 \\
2- Pyrgodesmidae & 0 & 0 & 0 & 0 & 1 & 1 & 4 & 20 & 21 & 11 & 1 & 15 & 74 & 10,0 & 6,2 & 8,3 \\
3- Polyxenidae & 18 & 16 & 1 & 0 & 0 & 0 & 0 & 0 & 0 & 0 & 0 & 0 & 35 & 4,7 & 2,9 & 6,6 \\
4- Stemmiulidae & 23 & 4 & 1 & 0 & 0 & 0 & 0 & 0 & 0 & 0 & 0 & 0 & 28 & 3,8 & 2,3 & 6,6 \\
5- Siphonophoridae & 11 & 0 & 0 & 0 & 0 & 0 & 0 & 0 & 0 & 2 & 0 & 3 & 16 & 2,2 & 1,3 & 3,2 \\
6- Spirostreptida & 0 & 1 & 0 & 1 & 0 & 0 & 0 & 0 & 0 & 0 & 1 & 0 & 3 & 0,4 & 0,3 & 0,5 \\
\hline$\quad$ Total & 52 & 21 & 2 & 1 & 1 & 1 & 4 & 20 & 24 & 16 & 305 & 294 & 741 & 100,0 & 61,8 & 112,0 \\
\hline$\%$ & 7,0 & 2,8 & 0,3 & 0,1 & 0,1 & 0,1 & 0,5 & 2,7 & 3,2 & 2,1 & 41.2 & 39,7 & 100,0 & \\
\hline
\end{tabular}

Apêndice 25 - Captura rensal e estágios de desenvolvinento de Pulronnnodestus rhinocerus n.5p. Golovatch, 1994 (Fuhroannodesnidae, Diplopoda), en fotoeclector de árvore direcionado para baixo (BEl), na floresta inundada por áqua nista, no periodo de julho/1987 a junho/1988 (núnero de captora, percentagen (ई), nédila e desvio padrào (S)).

\begin{tabular}{|c|c|c|c|c|c|c|c|c|c|c|c|c|c|c|c|c|}
\hline Espécie/Meses & Jul./87 & Ago. & Set. & Out. & Nov. & Dez. & $\operatorname{Jan} . / 88$ & Fev. & Mar. & Abr. & Mai & Jun. & Total & $\%$ & Média & $\mathbf{s}$ \\
\hline \multicolumn{17}{|l|}{ F.rhinocerus n. sp. } \\
\hline \multicolumn{17}{|l|}{ No. segmentos } \\
\hline Segmento 7 & 0 & 0 & 0 & 0 & 0 & 0 & 0 & 0 & 0 & 0 & 0 & 0 & 0 & 0,0 & 0,0 & 0,0 \\
\hline Segmento 9 & 0 & 0 & 0 & 0 & 0 & 0 & 0 & 0 & 0 & 0 & 0 & 0 & 0 & 0,0 & 0,0 & 0,0 \\
\hline Segmento 12 & 0 & 0 & 0 & 0 & 0 & 0 & 0 & 0 & 0 & 0 & 0 & 1 & 1 & 0,2 & 0,1 & 0,3 \\
\hline Segmento 15 & 0 & 0 & 0 & 0 & 0 & 0 & 0 & 0 & 0 & 0 & 1 & 1 & 2 & 0,3 & 0,2 & 0,4 \\
\hline Segmento 17 & 0 & 0 & 0 & 0 & 0 & 0 & 0 & 0 & 0 & 0 & 14 & 51 & 65 & 11,1 & 5,4 & 14,9 \\
\hline Segmento 18 & 0 & 0 & 0 & 0 & 0 & 0 & 0 & 0 & 0 & 0 & 47 & 43 & 90 & 15,4 & 7,5 & 17,5 \\
\hline Segmento 19 & 0 & 0 & 0 & 0 & 0 & 0 & 0 & 0 & 2 & 2 & 168 & 132 & 304 & 52,0 & 25,3 & 58,7 \\
\hline Indeterminados & 0 & 0 & 0 & 0 & 0 & 0 & 0 & 0 & 1 & 0 & 66 & 48 & 115 & 19,7 & 9,6 & 22,5 \\
\hline Machos (M) & 0 & 0 & 0 & 0 & 0 & 0 & 0 & 0 & 0 & 0 & 5 & 0 & 5 & 0,8 & 0,4 & 1,4 \\
\hline Fêmeas (F) & 0 & 0 & 0 & 0 & 0 & 0 & 0 & 0 & 0 & 1 & 2 & 0 & 3 & 0,5 & 0,3 & 0,6 \\
\hline Subtotal Imaturos & 0 & 0 & 0 & 0 & 0 & 0 & 0 & 0 & 3 & 2 & 296 & 276 & 577 & 98,6 & 48,1 & 111,2 \\
\hline Subtotal Adulios & 0 & 0 & 0 & 0 & 0 & 0 & 0 & 0 & 0 & 1 & 7 & 0 & 8 & 1,4 & 0,7 & 2,0 \\
\hline Total & 0 & 0 & 0 & 0 & 0 & 0 & 0 & 0 & 3 & 3 & 303 & 276 & 585 & 100,0 & 48,8 & \\
\hline$\overline{\%}$ & 0,0 & 0,0 & 0,0 & 0,0 & 0,0 & 0,0 & 0,0 & 0,0 & 0,5 & 0,5 & 51,8 & 47,2 & 100,0 & & & \\
\hline
\end{tabular}


Apêndice 26 - Captura mensal e estágios de desenvolvinento de Muyudesins obliteratus Schubart, 1943 (Pyrgodesnidae, Diplopoda), ell fotoeclector de árvore direcionado para baixo (BE!), na floresta inundada por água uista, no período de julho/1987 a junho/1988 (número de captura, percentagen (\&)), rédia e desvio padrão(S)).

\begin{tabular}{|c|c|c|c|c|c|c|c|c|c|c|c|c|c|c|c|c|}
\hline Espécie/Meses & Jul./87 & Ago & Set. & Out. & Nov. & Dez. & Jan./88 & Fev. & Mar. & Abr. & Mai. & Jun. & Total & $\%$ & Média & $\mathbf{s}$ \\
\hline \multicolumn{17}{|c|}{ M.obliteratus } \\
\hline \multicolumn{17}{|l|}{ No segmentos } \\
\hline Segmento 7 & 0 & 0 & 0 & 0 & 0 & 0 & 0 & 2 & 0 & 0 & 0 & 0 & 2 & 2,7 & 0,2 & 0,6 \\
\hline Segmento 9 & 0 & 0 & 0 & 0 & 0 & 0 & 0 & 0 & 0 & 0 & 0 & 0 & 0 & 0,0 & 0,0 & 0,0 \\
\hline Segmento 12 & 0 & 0 & 0 & 0 & 0 & 0 & 0 & 5 & 0 & 0 & 0 & 0 & 5 & 6,8 & 0,4 & 1,4 \\
\hline Segmento 15 & 0 & 0 & 0 & 0 & 0 & 0 & 0 & 4 & 2 & 0 & 0 & 0 & 6 & 8,1 & 0,5 & 1,2 \\
\hline Segmento 17 & 0 & 0 & 0 & 0 & 0 & 0 & 0 & 1 & 0 & 1 & 0 & 2 & 4 & 5,4 & 0,3 & 0,7 \\
\hline Segmento 18 & 0 & 0 & 0 & 0 & 1 & 0 & 0 & 0 & 3 & 5 & 1 & 10 & 20 & 27,0 & 1,7 & 3,1 \\
\hline Segmento 19 & 0 & 0 & 0 & 0 & 0 & 1 & 1 & 2 & 6 & 4 & 0 & 3 & 17 & 23,0 & 1,4 & 2,0 \\
\hline Indeterminados & 0 & 0 & 0 & 0 & 0 & 0 & 0 & 4 & 1 & 1 & 0 & 0 & 6 & 8,1 & 0,5 & 1,2 \\
\hline Machos (M) & 0 & 0 & 0 & 0 & 0 & 2 & 3 & 2 & 5 & 0 & 0 & 0 & 12 & 16,2 & 1,0 & 1,7 \\
\hline Fêmeas $(F)$ & 0 & 0 & 0 & 0 & 0 & 1 & 0 & 0 & 1 & 0 & 0 & 0 & 2 & 2,7 & 0,2 & 0,4 \\
\hline Subtotal Imaturo & $\overline{0}$ & $\overline{0}$ & $\overline{0}$ & 0 & 1 & 1 & 1 & 18 & 12 & 11 & 1 & 15 & 60 & 81,1 & 5,0 & 6,9 \\
\hline Subtotal $M$ eF & 0 & 0 & 0 & $\underline{0}$ & 0 & 3 & 3 & 2 & 6 & 0 & 0 & 0 & 14 & 18,9 & 1,2 & 1,9 \\
\hline Total & 0 & $\overline{0}$ & 0 & 0 & 1 & 4 & $\overline{4}$ & 20 & 18 & 11 & 1 & 15 & 74 & 100,0 & 6,2 & \\
\hline$\%$ & 0,0 & 0,0 & 0,0 & 0,0 & 1,4 & 5,4 & 5,4 & 27,0 & 24,3 & 14,8 & 1,4 & 20,3 & 100,0 & & & \\
\hline
\end{tabular}


Apêndice 27 - Captura de Ribautiella arazonica Scheller, 1984, Synphylella adisi Scheller, 1989 e Hanseniella arborea Scheller, 1979 (Scolopendrellidae, Syaphyla), através do método de Reapson, nas diferentes camadas do solo, no período de agosto/1987 a maio/1988, na floresta inundada por água nista (nứrero de captura, percentagen ( $\%)$, abundância (indivíduos/ $/ \mathbf{n}^{2} /$ nês), média e desvio padrão (S)).

\begin{tabular}{|c|c|c|c|c|c|c|c|c|c|c|c|c|c|c|c|}
\hline Espécies/Meses & Ago./87 & Set & Out. & Nov. & Dez. & Jan./88 & Fev. & Mar. & Abr. & Mai & Total & $\%$ & Ind./mintmês & Média & $\mathbf{s}$ \\
\hline \multicolumn{16}{|c|}{ 1- Ribautiella amazonica } \\
\hline $0-3,5 \mathrm{~cm}$ & 17 & 42 & 88 & 11 & 84 & 79 & 55 & 38 & 28 & 4 & 446 & 38,8 & 214,6 & 44,6 & 30,9 \\
\hline $3,5-7 \mathrm{~cm}$ & 14 & 56 & 139 & 13 & 16 & 62 & 91 & 15 & 9 & 15 & 430 & 37,4 & 206,9 & 43,0 & 43,8 \\
\hline $7-10,5 \mathrm{~cm}$ & 10 & 46 & 55 & 3 & 5 & 21 & 12 & 22 & 16 & 2 & 192 & 16,7 & 92,4 & 19,2 & 18,0 \\
\hline $10,5-14 \mathrm{~cm}$ & 10 & 13 & 31 & 4 & 4 & 11 & 5 & 3 & 1 & 0 & 82 & 7,1 & 39,5 & 8,2 & 9,1 \\
\hline Subtotal & 51 & 157 & 313 & 31 & 109 & 173 & 163 & 78 & 54 & 21 & 1150 & 100,0 & 553,4 & 115,0 & 89,3 \\
\hline$\%$ & 4,4 & 13,7 & 27,2 & 2,7 & 9,5 & 15,0 & 14,2 & 6,8 & 4,7 & 1,8 & & & & & \\
\hline Ind. $/ \mathrm{m}^{2}$ & 245,4 & 755,5 & 1506,2 & 149,2 & 524,5 & 832,5 & 784,4 & 375,3 & 259,8 & 101,1 & & & & & \\
\hline \multicolumn{16}{|l|}{ 2- Symphylella adisi } \\
\hline $0-3,5 \mathrm{~cm}$ & 0 & $\mathbf{0}$ & 7 & 0 & 1 & 4 & 22 & 2 & 0 & 0 & 36 & 20,5 & 17,3 & 3,6 & 6,9 \\
\hline $3,5-7 \mathrm{~cm}$ & 0 & 2 & 2 & 0 & 5 & 3 & 25 & 9 & $\mathbf{0}$ & 0 & 46 & 26,1 & 22,1 & 4,6 & 7,7 \\
\hline $7-10,5 \mathrm{~cm}$ & 0 & 2 & 8 & 3 & 3 & 5 & 11 & 7 & $\mathbf{0}$ & $\mathbf{0}$ & 39 & 22,2 & 18,8 & 3,9 & 3,8 \\
\hline $10,5-14 \mathrm{~cm}$ & 0 & 11 & 4 & 6 & 7 & 4 & 11 & 9 & 2 & 1 & 55 & 31,3 & 26,5 & 5,5 & 4,0 \\
\hline Subtotal & 0 & 15 & 21 & 9 & 16 & 16 & 69 & 27 & 2 & 1 & 176 & 100,0 & 84,7 & 17,6 & 20,2 \\
\hline$\%$ & 0,0 & 8.5 & 11,9 & 5,1 & 9,1 & 9,1 & 39,2 & 15,4 & 1,1 & 0,6 & & & & & \\
\hline Ind./m ${ }^{2}$ & 0,0 & 72,2 & 101,1 & 43,3 & 77,0 & $\pi, 0$ & 332,0 & 129,9 & 9,6 & 4,8 & & & & & \\
\hline \multicolumn{16}{|c|}{ 3- Hanseniella arborea } \\
\hline $0,3,5 \mathrm{~cm}$ & 3 & 18 & 26 & 12 & 28 & 85 & 41 & 82 & 116 & 33 & 444 & 50,7 & 213,7 & 44,4 & 37,1 \\
\hline $3,5-7 \mathrm{~cm}$ & 0 & 21 & 30 & 8 & 25 & 29 & 59 & 61 & 75 & 38 & 346 & 39,5 & 166,5 & 34,6 & 24,0 \\
\hline $7-10,5 \mathrm{~cm}$ & $\mathbf{0}$ & 1 & 1 & 5 & 11 & 9 & 2 & 17 & 17 & 4 & 67 & 7,6 & 32,2 & 6,7 & 6,5 \\
\hline $10,5-14 \mathrm{~cm}$ & 0 & 1 & 1 & 4 & 3 & 1 & 0 & 1 & 3 & 5 & 19 & 2,2 & 9,1 & 1,9 & 1,7 \\
\hline Subrotal & 3 & 41 & 58 & 29 & 67 & 124 & 102 & 161 & 211 & 80 & 876 & 100,0 & 421,5 & 87,6 & 63,5 \\
\hline$\%$ & 0,3 & 4,7 & 6,6 & 3,3 & 7,7 & 14,2 & 11,6 & 18,4 & 24,1 & 9,1 & & & & & \\
\hline Ind./m ${ }^{2}$ & 14,4 & 197,3 & 279,1 & 139,5 & 322,4 & 596,7 & 490,8 & 774,7 & 1015,3 & 385,0 & & & & & \\
\hline Total & 53 & 213 & 392 & 69 & 192 & 313 & 334 & 266 & 267 & 102 & 2202 & & 10596,0 & & \\
\hline$\%$ & 2,4 & 9,7 & 17,8 & 3,1 & 8,9 & 14,2 & 15,2 & 12,1 & 12,1 & 4,7 & & & & & \\
\hline $\operatorname{lnd} . / \mathrm{m}^{2}$ & 255,0 & 1025,0 & 1886,3 & 332,0 & 923,9 & 1506,2 & 1607,2 & 1280,0 & 1284,8 & 490,8 & & & & & \\
\hline
\end{tabular}


Apêndice 28 - Captura mensal e estágios de desenvolvimento de Ribautiella arazonica Scheller, 1984, STrphrylella adisi Scheller 1984 e Hanseniella arborea Scheller 1979 (Scolopendrellidae, Syyphyla), através do nétodo de Renpson, nas diferentes canadas do solo, no periodo de agosto/1987 a naio/1988, na floresta inundada por água nista (núinero de captura, percentagen

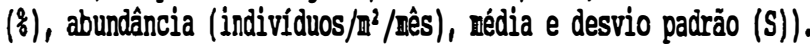

\begin{tabular}{|c|c|c|c|c|c|c|c|c|c|c|c|c|c|c|c|}
\hline Espécies/Meses & Ago./87 & Set. & Out. & Nov. & Dez. & $\operatorname{Jan} . / 88$ & Fev. & Mar. & Abr. & Mai & Total & $\%$ & Ind./minênês & Média & $\mathbf{s}$ \\
\hline \multicolumn{16}{|c|}{ 1- Ribautiella amazonica } \\
\hline Juvenil 8 & 0 & 75 & 8 & 5 & 15 & 28 & 15 & 8 & 2 & 8 & 164 & 14,3 & 78,9 & 16,4 & 22,1 \\
\hline Juvenil 9 & 1 & 26 & 79 & 1 & 3 & 28 & 54 & 24 & 20 & 4 & 240 & 20,9 & 115,5 & 24,0 & 25,5 \\
\hline Juvenil 10 & 3 & 0 & 170 & 12 & 19 & 26 & 43 & 23 & 18 & 7 & 321 & 27,9 & 154,5 & 32,1 & 50,0 \\
\hline Sub-adulto 11 & 18 & 4 & 15 & 11 & 35 & 22 & 14 & 7 & 4 & 3 & 133 & 11,5 & 64,0 & 13,3 & 10,0 \\
\hline Machos & 13 & 23 & 19 & 2 & 20 & 22 & 12 & 6 & 5 & 0 & 122 & 10,6 & 58,7 & 12,2 & 8,6 \\
\hline Fêmeas & 16 & 26 & 16 & 0 & 15 & 40 & 20 & 10 & 3 & 0 & 146 & 12,7 & 70,3 & 14,6 & 12,4 \\
\hline Indeterminados & 0 & 3 & 6 & 0 & 2 & 7 & 5 & 0 & 1 & 0 & 24 & 2,1 & 11,5 & 2,4 & 2,7 \\
\hline Subtotal & 51 & 157 & 313 & 31 & 109 & 173 & 163 & 78 & 53 & 22 & 1150 & 100,0 & 553,4 & 115,0 & 89,2 \\
\hline$\%$ & 4,4 & 13,7 & 27,2 & 2,7 & 9,5 & 15,0 & 14,2 & 6,8 & 4,6 & 1,9 & & & & & \\
\hline Ind. $/ \mathrm{m}^{2}$ & 245,4 & 755,5 & 1506,2 & 149,2 & 524,5 & 832,5 & 784,4 & 375,3 & 255,0 & 105,9 & & & & & \\
\hline \multicolumn{16}{|l|}{ 2- Symphylella adisi } \\
\hline Juvenil 8 & 0 & 5 & 5 & 2 & 2 & 2 & 14 & 3 & $\mathbf{0}$ & 0 & 33 & 18,7 & 15,9 & 3,3 & 4,2 \\
\hline Juvenil 9 & 0 & 1 & 5 & 1 & 2 & 6 & 13 & 7 & 0 & 0 & 35 & 19,9 & 16,8 & 3,5 & 4,2 \\
\hline Juvenil 10 & 0 & 0 & 6 & 1 & 4 & 4 & 21 & 9 & 2 & 0 & 47 & 26,7 & 22,6 & 4,7 & 6,4 \\
\hline Sub-adulto 11 & 0 & $\mathbf{0}$ & 2 & 4 & 2 & 0 & 7 & 5 & $\mathbf{0}$ & 0 & 20 & 11,4 & 9,6 & 2,0 & 2,5 \\
\hline Machos & 0 & 6 & 1 & 0 & 3 & 0 & 6 & 1 & $\mathbf{0}$ & 0 & 17 & 9,7 & 8,2 & 1.7 & 2,5 \\
\hline Fêmeas & 0 & 3 & 1 & 1 & 0 & 4 & 7 & 1 & 0 & 1 & 18 & 10,2 & 8,7 & 1,8 & 2,3 \\
\hline Indeterminados & 0 & 0 & 1 & 0 & 3 & 0 & 1 & 1 & 0 & 0 & 6 & 3,4 & 2,9 & 0,6 & 1,0 \\
\hline Subtotal & 0 & 15 & 21 & 9 & 16 & 16 & 69 & 27 & 2 & 1 & 176 & 100,0 & 84,7 & 17,6 & 20,2 \\
\hline$\%$ & 0,0 & 8,5 & 11,9 & 5,1 & 9,1 & 9,1 & 39,2 & 15,3 & 1,2 & 0,6 & & & & & \\
\hline Ind. $/ \mathrm{m}^{2}$ & 0,0 & 72,2 & 101,1 & 43,3 & 7,0 & 77,0 & 332,0 & 129,9 & 9,6 & 4,8 & & & & & \\
\hline \multicolumn{16}{|c|}{ 3- Hanseniella arborea } \\
\hline Juvenil 8 & $\mathbf{0}$ & 0 & 1 & 1 & 2 & 3 & 2 & 0 & 1 & 0 & 10 & 1,1 & 4,8 & 1,0 & 1.1 \\
\hline Juvenil 9 & $\mathbf{0}$ & 1 & 26 & 10 & 14 & 7 & 20 & 20 & 34 & 0 & 132 & 15,1 & 63,5 & 13,2 & 11,7 \\
\hline Juvenil 10 & 0 & 1 & 4 & 4 & 18 & 24 & 24 & 10 & 29 & 9 & 123 & 14,0 & 59,2 & 12,3 & 10,6 \\
\hline Sub-adulto 11 & $\mathbf{0}$ & 21 & 3 & 3 & 6 & 27 & 15 & 41 & 16 & 17 & 149 & 17,0 & 71,7 & 14,9 & 12,7 \\
\hline Machos & 2 & 7 & 7 & 4 & 11 & 18 & 11 & 32 & 60 & 18 & 170 & 19,4 & 81,8 & 17,0 & 17,5 \\
\hline Fêmeas & 1 & 10 & 17 & 6 & 11 & 39 & 19 & 53 & 67 & 36 & 259 & 29,6 & 124,6 & 25,9 & 21,9 \\
\hline Indeterminados & 0 & 1 & 0 & 1 & 5 & 6 & 11 & 5 & 4 & 0 & 33 & 3,8 & 15,9 & 3,3 & 3,6 \\
\hline Subtotal & 3 & 41 & 58 & 29 & 67 & 124 & 102 & 161 & 211 & 80 & 876 & 100,0 & 421,5 & 87,6 & 63,5 \\
\hline$\%$ & 0,3 & 4.7 & 6,6 & 3,3 & 7,7 & 14,2 & 11,6 & 18,4 & 24,1 & 9,1 & & & & & \\
\hline Ind. $/ \mathrm{m}^{2}$ & 14,4 & 197,3 & 279,1 & 139,5 & 322,4 & 596,7 & 490,8 & 774,7 & 1015,3 & 385,0 & & & & & \\
\hline Total & 54 & 213 & 392 & 69 & 192 & 313 & 334 & 266 & 266 & 103 & 202 & & & & \\
\hline$\%$ & 2,4 & 9,7 & 17,8 & 3,1 & 8,9 & 14,2 & 15,2 & 12,1 & 12,1 & 4,7 & & & 10596,0 & & \\
\hline Ind./ $\mathrm{m}^{2}$ & 259,8 & 1025,0 & 1886,3 & 332,0 & 923,9 & 1506,2 & 1607,2 & 1280,0 & 1280,0 & 495,6 & & & & & \\
\hline
\end{tabular}


Apêndice 29 - Captura mensal e estágios de desenvolvinento de Hanseniella arborea Scheller, 1979 (Scolopendrellidae, Syuphylla), no folhedo, através de 4 fotoeclectores de solo, no período de agosto/1987 a maio/1988, na floresta inundada por água nista

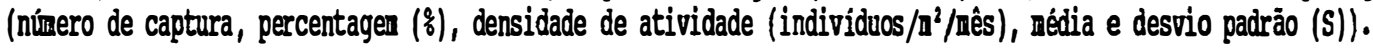

\begin{tabular}{|c|c|c|c|c|c|c|c|c|c|c|c|c|c|c|c|}
\hline Espécle/Moses & Ago./87 & Set. & Out & Nov & Dez & Jan./87 & Fev. & Mar. & Abr. & Mai. & Total & $\%$ & Ind./min/mês & Média & $\mathbf{s}$ \\
\hline \multicolumn{16}{|c|}{ 1- Hansentella arborae } \\
\hline Machos & 0 & 0 & 0 & 0 & 0 & 0 & 13 & 40 & 15 & 12 & 60 & 47,1 & 2,0 & 8,0 & 12,8 \\
\hline Fómeas & 0 & 0 & 0 & 0 & 0 & 0 & 18 & 35 & 22 & 15 & 80 & 52,8 & 2,3 & 9,0 & 12,7 \\
\hline Total & 0 & 0 & 0 & 0 & $\overline{0}$ & 0 & 31 & 75 & 37 & 27 & 170 & 1000 & 4,2 & 17,0 & 25,4 \\
\hline$\%$ & 0,0 & 0,0 & 0,0 & 0,0 & 0,0 & 0,0 & 18,2 & 44,1 & 21,8 & 15,8 & & 100,0 & & & \\
\hline Ind. $/ \mathrm{m}^{2}$ & 0,0 & 0,0 & 0,0 & 0,0 & 0,0 & 0,0 & 7,8 & 18,8 & 9,3 & 6,8 & 42,5 & & & & \\
\hline
\end{tabular}

Apêndice 30 - Captura nensal e estágios de desenvolvinento de Banseniella arbarea Scheller, 1979 (Scolopendrellidae, Syaphylla) en fotoeclector de árrore direcionado para cina (BE1) e para baixo (BEI), no período de julho/1987 a junho/1988, na floresta inundada por água nista (núnero de captura, percentagen (६)), nédia e desvio padrảo (S)).

\begin{tabular}{|c|c|c|c|c|c|c|c|c|c|c|c|c|c|c|c|c|}
\hline Espécie/Meses & Jul./87 & Ago. & Set. & Out. & Nov. & Dez. & $\operatorname{Jan} / 88$ & Fev. & Mar. & Abr. & Mai. & Jun. & Total & $\%$ & Média & $\mathbf{S}$ \\
\hline \multicolumn{17}{|c|}{ Hanseniella arborea } \\
\hline \multicolumn{17}{|c|}{ 1- BEF. } \\
\hline Machos & 0 & 0 & 0 & 0 & 0 & 0 & 0 & 6 & 11 & 1 & 1 & 0 & 19 & 26,4 & 1,6 & 3,4 \\
\hline Fêmeas & 0 & 0 & 0 & 0 & 0 & 0 & 0 & 15 & 32 & 4 & 2 & 0 & 53 & 73,6 & 4,4 & 9,7 \\
\hline Total & 0 & 0 & 0 & 0 & 0 & 0 & 0 & 21 & 43 & 5 & 3 & 0 & 72 & 100,0 & 6,0 & 13,1 \\
\hline$\%$ & 0,0 & 0,0 & 0,0 & 0,0 & 0,0 & 0,0 & 0,0 & 29,2 & 59,7 & 6,9 & 4,2 & 0,0 & & 100,0 & & \\
\hline \multicolumn{17}{|l|}{ 2- BEi } \\
\hline Machos & 23 & 0 & 0 & 0 & 0 & 0 & 0 & 0 & 0 & 0 & 0 & 0 & 23 & 46,0 & 1,9 & 6,6 \\
\hline Fêmeas & 26 & 1 & 0 & 0 & 0 & 0 & 0 & 0 & 0 & 0 & 0 & 0 & 27 & 54,0 & 2,3 & 7,5 \\
\hline Total & 49 & 1 & 0 & 0 & 0 & 0 & 0 & 0 & 0 & 0 & 0 & 0 & 50 & 100,0 & 4,2 & 14,1 \\
\hline$\%$ & 98,0 & 2,0 & 0,0 & 0,0 & 0,0 & 0,0 & 0,0 & 0,0 & 0,0 & 0,0 & 0,0 & 0,0 & & 100,0 & & \\
\hline
\end{tabular}


Apêndice 31 - Captura nensal e estágios de desenvolvinento de Neomachilellus scandens Wygodzinsky, 1979 e Yeinertellus adisi Wigodzinsk, 1989 (Meinertellidae, Archaeognatha), no folhedo, através de 4 fotoeclectores de solo , no periodo de agosto/1987 a naio/1988, na floresta inundada por água nista (número de captura, densidade de atividade (individuo/m²/rês), percentagen (\&), nédia e desvio padrảo (S)).

\begin{tabular}{|c|c|c|c|c|c|c|c|c|c|c|c|c|c|c|c|}
\hline Espécies|Mêses & Ago./87 & Set. & Out. & Nov. & Dez. & $\operatorname{Jan} . / 88$ & Fev. & Mar. & Abr. & Maj. & Total & $\%$ & Média & Ind./mt/mês & $\mathrm{s}$ \\
\hline $\begin{array}{c}\text { 1- Neomachilellu } \\
\text { scandens }\end{array}$ & & & & & & & & & & & & & & & \\
\hline Juvenis & 14 & 0 & 0 & 0 & 0 & 0 & 0 & 0 & 0 & 0 & 14 & 45,2 & 1,4 & 0,3 & 4,4 \\
\hline Machos & 0 & 2 & 1 & 2 & 1 & 0 & 1 & 0 & 0 & 0 & 7 & 22,6 & 0,7 & 0,2 & 0,8 \\
\hline Fêmeas & 0 & 6 & 0 & 2 & 1 & 0 & 0 & 1 & 0 & 0 & 10 & 32,2 & 1,0 & 0,2 & 1,9 \\
\hline Total & 14 & 8 & 1 & 4 & 2 & 0 & 1 & $\overline{1}$ & 0 & 0 & 31 & 100,0 & 3,1 & 0,8 & \\
\hline Ind. $/ \mathrm{m}^{2}$ & 3,5 & 2,0 & 0,3 & 1,0 & 0,5 & 0,0 & 0,3 & 0,3 & 0,0 & 0,0 & 7,8 & & & & \\
\hline$\%$ & 45,2 & 25,8 & 3,2 & 13,0 & 6,5 & 0,0 & 3,2 & 3,2 & 0,0 & 0,0 & 100,0 & & & & \\
\hline
\end{tabular}

\begin{tabular}{|c|c|c|c|c|c|c|c|c|c|c|c|c|c|c|c|}
\hline 2-Meinertellus adisi & & & & & & & & & & & & & & & \\
\hline Juvenis & 2 & 1 & 13 & 0 & 0 & 0 & 3 & 1 & 0 & 0 & 20 & 87,0 & 2,0 & 0,5 & 4,0 \\
\hline Machos & 0 & 0 & 0 & 0 & 0 & 1 & 0 & 1 & 0 & 0 & 2 & 8,7 & 0,2 & 0,0 & 0,4 \\
\hline Fêmeas & 0 & 0 & 0 & 0 & 0 & 1 & 0 & 0 & 0 & 0 & 1 & 4,3 & 0,1 & 0,0 & 0,3 \\
\hline Total & 2 & 1 & 13 & 0 & 0 & 2 & 3 & 2 & 0 & 0 & 23 & 100,0 & 2,3 & 0,6 & \\
\hline Ind./m & 0,5 & 0,3 & 3,3 & 0,0 & 0,0 & 0,5 & 0,8 & 0,5 & 0,0 & 0,0 & 5,8 & & & & \\
\hline$\%$ & 8,7 & 4,4 & 56,5 & 0,0 & 0,0 & 8,7 & 13,0 & 8,7 & 0,0 & 0,0 & 100,0 & & & & \\
\hline
\end{tabular}

\begin{tabular}{lcccccccccccccc}
\hline Total (1) $+(2)$ & 16 & 9 & 14 & 4 & 2 & 2 & 4 & 3 & 0 & 0 & 54 & 100,0 & 5,4 & 1,3 \\
\hline Ind./m & 4,0 & 2,2 & 3,5 & 1,0 & 0,5 & 0,5 & 1,0 & 1,8 & 0,0 & 0,0 & 13,5 & & & \\
\hline$\%$ & 29,6 & 16,7 & 25,9 & 7,4 & 3,7 & 3,7 & 7,4 & 5,6 & 0,0 & 0,0 & 100,0 & & \\
\hline
\end{tabular}

Apêndice 32 - Captura nensal e estágios de desenvolvinento de Meinertellus adisi hygodzinsky, 1987 (Meinertellidae, Archaeognatha), en fotoeclector de arvore direcionado para cina (BET) e para baixo (BE1), no periodo julbo/1987 a junho/1988, na floresta inundada por água nista (nímero de captura, percentagen (₹), nédia e desvio padrảo (\$)).

\begin{tabular}{|c|c|c|c|c|c|c|c|c|c|c|c|c|c|c|c|c|}
\hline $\begin{array}{c}\text { Meses } \\
\text { Estágios }\end{array}$ & Jul./87 & Ago. & Set. & Out. & Nov. & Dez. & Jan./88 & Fev. & Mar. & Abr. & Mai. & Jun. & Total & $\%$ & Média & $S$ \\
\hline \multirow[t]{2}{*}{ Juvenis } & $\uparrow 0$ & 2 & 1 & 7 & 7 & 5 & 6 & 13 & 7 & 6 & 1 & 0 & 55 & 60,4 & 4,583 & 3,9 \\
\hline & $\downarrow 0$ & 0 & 0 & 2 & 0 & 0 & 0 & 0 & 0 & 1 & 0 & 0 & 3 & 3,3 & 0,25 & 0,6 \\
\hline Machos & $\uparrow 0$ & 3 & 0 & 3 & 2 & 1 & 2 & 3 & 1 & 0 & 0 & 0 & 15 & 16,5 & 1,25 & 1,3 \\
\hline Fêmeas & $\uparrow 0$ & 0 & 0 & 4 & 5 & 3 & 1 & 3 & 2 & 0 & 0 & 0 & 18 & 19,8 & 1,5 & 1,8 \\
\hline Total & 0 & 5 & 1 & 16 & 14 & 9 & 9 & 19 & 10 & 7 & 1 & 0 & 91 & 100,0 & 7,583 & \\
\hline$\%$ & 0,0 & 5,5 & 1,2 & 17,6 & 15,4 & 9,9 & 9,9 & 20,9 & 11,0 & 7,7 & 1,1 & 0,0 & 100,0 & & & \\
\hline
\end{tabular}


Apêndice 33 - Captura de Coleoptera (famílias) no solo, através do método de Kempson, de 0 a 14 cn de profundidade, no periodo de

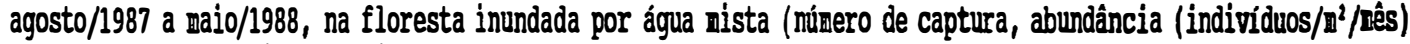

percentagem $(\%)$, média e desvio padrão (S)).

\begin{tabular}{|c|c|c|c|c|c|c|c|c|c|c|c|c|c|c|c|c|}
\hline & Meses & Ago./87 & Set. & Out. & Nov. & Dez. & Jan./88 & Fev. & Mar. & Abr. & Mai. & Total & Ind.nf $m^{2} / m e ̂ s$ & $\%$ & Média & $\mathrm{s}$ \\
\hline \multicolumn{17}{|c|}{ Familias } \\
\hline $1-$ & Staphylinidae & 66 & 15 & 5 & 5 & 7 & 15 & 17 & 38 & 47 & 96 & 311 & 149,6 & 36,0 & 31,1 & 30,5 \\
\hline 2 & Carabidae & 15 & 6 & 16 & 20 & 19 & 27 & 21 & 38 & 50 & 64 & 276 & 132,8 & 31,9 & 27.6 & 17,9 \\
\hline $3-$ & Pselaphidae & 4 & 10 & 4 & 2 & 17 & 7 & 15 & 34 & 29 & 29 & 151 & 72,7 & 17,5 & 15,1 & 11,8 \\
\hline 4- & Ptilidae & 2 & 1 & 0 & 0 & 0 & 0 & 4 & 1 & 5 & 3 & 16 & 7,7 & 1,8 & 1,6 & 1,8 \\
\hline $5-$ & Scydmaenidae & 3 & 0 & 0 & 0 & 1 & 3 & 3 & 2 & 2 & 0 & 14 & 6,7 & 1,6 & 1,4 & 1,3 \\
\hline $6-$ & Scolytidae & 0 & 0 & 2 & 0 & 6 & 2 & 0 & 0 & 0 & 1 & 11 & 5,3 & 1,3 & 1,1 & 1,9 \\
\hline $7-$ & Scarabaeidae & 1 & 0 & 0 & 0 & 0 & 0 & 0 & 2 & 3 & 0 & 6 & 2,9 & 0,7 & 0,6 & 1,1 \\
\hline $8-$ & Curculionidae & 0 & 0 & 0 & 1 & 0 & 0 & 0 & 0 & 0 & 0 & 1 & 0,5 & 0.1 & 0,1 & 0,3 \\
\hline 9 & Outros & 9 & 2 & 3 & 9 & 6 & 17 & 4 & 3 & 14 & 12 & 79 & 38,0 & 9,1 & 7,9 & 5,2 \\
\hline & Total & 100 & 34 & 30 & 37 & 56 & 71 & 64 & 118 & 150 & 205 & 865 & 416,2 & 100,0 & 86,5 & 57.1 \\
\hline & Ind./m ${ }^{2}$ & 481,2 & 163,6 & 144,4 & 178,0 & 269,5 & 341,7 & 308,0 & 567.8 & 721,8 & 986,5 & & & & & \\
\hline & $\%$ & 11,7 & 4,0 & 3,5 & 4,3 & 6,5 & 8,2 & 7,4 & 13,4 & 17,3 & 23,7 & & & 100,0 & & \\
\hline & Lavas & 94 & 68 & 62 & 31 & 52 & 44 & 48 & 42 & 69 & 30 & 540 & 259,8 & & 54,0 & 19,6 \\
\hline & $\%$ & 17,4 & 12,6 & 11,5 & 5,7 & 9,6 & 8,2 & 8,9 & 7.8 & 12,8 & 5,5 & & & 100,0 & & \\
\hline & Ind. $/ \mathrm{m}^{2}$ & 452,3 & 327,2 & 298,3 & 149,2 & 250.2 & 211.7 & 298,3 & 202,1 & 332,0 & 144,4 & & & & & \\
\hline
\end{tabular}

Apêndice 34 - Captura de Coleoptera (fanílias) no solo, através do nétodo de Reupson, de 0 a 3,5 cn de profundidade, no periodo de agosto/1987 a naio/1988, na floresta inundada por água nista (nínero de captura, abundância (indivíduos/ñª̂s), percentagen (₹), rédia e desvio padrão (S)).

\begin{tabular}{|c|c|c|c|c|c|c|c|c|c|c|c|c|c|c|c|}
\hline Meses & Ago./87 & Set. & Out. & Nov. & Dez. & Jan./88 & Fev. & Mar. & Abr. & Mai. & Total & Ind./mitmês & $\%$ & Média & $\mathrm{S}$ \\
\hline \multicolumn{16}{|l|}{ Familias } \\
\hline 1- Staphylinidae & 60 & 8 & 4 & 5 & 1 & 12 & 9 & 29 & 42 & 76 & 246 & 118,4 & 40,5 & 26,4 & 26,4 \\
\hline 2- Carabidae & 11 & 2 & 2 & 13 & 10 & 13 & 12 & 26 & 29 & 44 & 162 & 77,9 & 26,6 & 16,2 & 13,1 \\
\hline 3- Pselaphidae & 3 & 9 & 2 & 0 & 7 & 6 & 12 & 26 & 20 & 17 & 102 & 49,1 & 16,8 & 10,2 & 8,5 \\
\hline 4- Ptlidae & 2 & 0 & 0 & 0 & 0 & 0 & 4 & 0 & 5 & 2 & 13 & 6,3 & 2,1 & 1,3 & 1,9 \\
\hline 5- Scydmaenidae & 3 & 0 & 0 & 0 & 0 & 3 & 2 & 2 & 2 & 0 & 12 & 5,8 & 2,0 & 1,2 & 1,3 \\
\hline 6- Scolytidae & 0 & 0 & 1 & 0 & 6 & 1 & 0 & 0 & 0 & 1 & 9 & 4,3 & 1,5 & 0,9 & 1,9 \\
\hline 7- Scarabaeidae & 1 & 0 & 0 & 0 & 0 & 0 & 0 & 1 & 2 & 0 & 4 & 1,9 & 0,7 & 0,4 & 0,7 \\
\hline 8- Outros & 8 & 2 & 3 & 8 & 3 & 12 & 3 & 1 & 12 & 8 & 60 & 28,8 & 9,9 & 6,0 & 4,1 \\
\hline Total & 88 & 21 & 12 & 26 & 27 & 47 & 42 & 85 & 112 & 148 & 608 & 292,6 & 100,0 & 60,8 & 45,2 \\
\hline Ind./m $/ m^{2}$ & 423,5 & 101,1 & 57,7 & 125,1 & 129,9 & 226,2 & 202,1 & 409,0 & 538,9 & $712, \underline{2}$ & & & & & \\
\hline$\%$ & 14,5 & 3,5 & 2,0 & 4,3 & 4,4 & 7,7 & 6,9 & 14,0 & 18,4 & 24,3 & & & 100,0 & & \\
\hline Lanas & 73 & 55 & 34 & 24 & 19 & 38 & 38 & 27 & 57 & 19 & 384 & 184,8 & & 38,4 & 18,0 \\
\hline Ind./m & 351,3 & 264,7 & 163,6 & 115,5 & 91,4 & 182,9 & 182,9 & 129,9 & 274,3 & 91,4 & & & & & \\
\hline$\%$ & 19,0 & 14,3 & 8,9 & 6,3 & 4,9 & 9,9 & 9,9 & 7,0 & 14,9 & 4,9 & & & 100,0 & & \\
\hline
\end{tabular}


Apêndice 35 - Captura de Coleoptera (fanilias) no solo, através do método de Rempson, de 3,5 a 7 cn de profundidade, no periodo de agosto/1987 a maio/1988, na floresta inundada por água nista (número de captura, abundância (indivíduos/ $/ \mathrm{n}^{2} / \mathrm{res}^{\mathrm{s}}$ ), percentagen $(\xi)$, nédia e desvio padrảo (\$)).

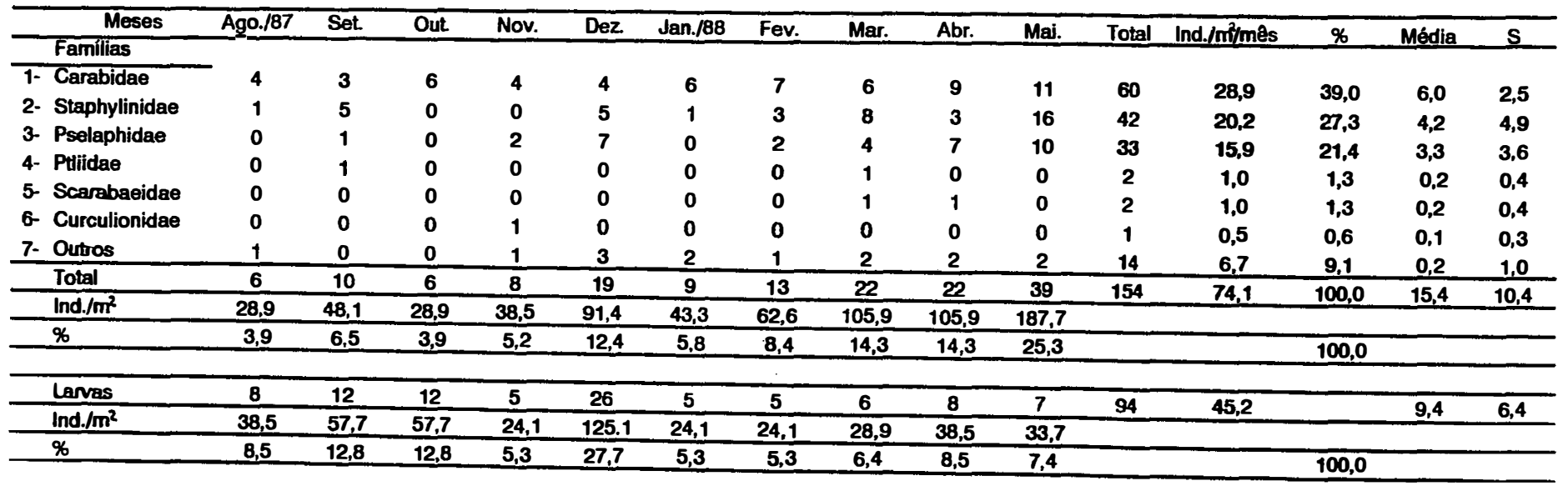

Apêndice 36 - Captura de Coleoptera (fanilias) no solo, através do nétodo de Reapson, de 7 a 10,5 cu de profundidade, no período de agosto/1987 a naio/1988, na floresta inundada por água uista (núnero de captura, abundância (indivíduos/ $\left.\mathbf{n}^{2} / \mathbf{M e ̂ s}\right)$, percentagen (₹), nédia e desvio padräo (S)).

\begin{tabular}{|c|c|c|c|c|c|c|c|c|c|c|c|c|c|c|c|}
\hline Meses & Ago./87 & Set. & Out & Nov. & Dez. & $\operatorname{Jan} . / 88$ & Fev. & Mar. & Abr. & Mai. & Total & ind./mt/mês & $\%$ & Média & S \\
\hline Famillias & & & & & & & & & & & & & & & \\
\hline 1- Carabidae & 0 & 1 & 0 & 0 & 3 & 6 & 1 & 1 & 2 & 7 & 21 & 10,1 & 40,4 & 2,1 & 2,5 \\
\hline 2- Staphylinidae & 4 & 2 & 0 & 0 & 0 & 2 & 1 & 1 & 2 & 2 & 14 & 6,7 & 26,9 & 1,4 & 1,3 \\
\hline 3- Pselaphidae & 1 & 0 & 2 & 0 & 3 & 0 & 1 & 3 & 1 & 1 & 12 & 5,8 & 23,1 & 1,2 & 1,1 \\
\hline 4- Ptliidae & 0 & 0 & 0 & 0 & 0 & 0 & 0 & 0 & 0 & 1 & 1 & 0,5 & 1,9 & 0,1 & 0,3 \\
\hline 5- Scolytidae & 0 & 0 & 0 & 0 & 0 & 1 & 0 & 0 & 0 & 0 & 1 & 0,5 & 1,9 & 0,1 & 0,3 \\
\hline 6- Outros & 0 & 0 & 0 & 0 & 0 & 3 & 0 & 0 & 0 & 0 & 3 & 1,4 & 5,8 & 0,3 & 0,9 \\
\hline Total & 5 & 3 & 2 & 0 & 6 & 12 & 3 & 5 & 5 & 11 & 52 & 25,0 & 100,0 & 5,2 & 3,8 \\
\hline Ind./m $m^{2}$ & 24,1 & 14,4 & 9,6 & 0,0 & 28,9 & 57,7 & $\overline{14,4}$ & 24,1 & 24,1 & 52,9 & & & & & \\
\hline$\%$ & 9,6 & 5,8 & 3,8 & 0,0 & 11,5 & 23,1 & 5,8 & 9,6 & 9,6 & 21.2 & & & 100,0 & & \\
\hline Lanvas & 10 & 0 & 10 & 0 & 5 & 0 & 1 & 5 & 3 & 0 & 34 & 16,4 & & 3,4 & 4,0 \\
\hline Ind./m² & 48,1 & 0,0 & 48,1 & 0,0 & 24,1 & 0,0 & 4,8 & 24,1 & 14,4 & 0,0 & & & & & \\
\hline$\%$ & 29,4 & 0,0 & 29,4 & 0,0 & 14,8 & 0,0 & 2,9 & 14,7 & 8,8 & 0,0 & & & 100,0 & & \\
\hline
\end{tabular}


Apêndice 37 - Captura de Coleoptera (famílias) no solo, através do nétodo de Reapson, de 10,5 a $14 \mathrm{~cm}$ de profundidade, no período de agosto/1987 a maio/1988, na floresta inundada por água nista (núnero de captura, abundância (individuos/裙/rês), percentagen, média e desvio padräo).

\begin{tabular}{|c|c|c|c|c|c|c|c|c|c|c|c|c|c|c|c|}
\hline Meses & Ago./87 & Set. & Out. & Nov. & Dez & Jan./88 & Fev. & Mar. & Abr. & Mai. & Total & Ind./mit/mes & $\%$ & Média & S \\
\hline \multicolumn{16}{|l|}{ Famílias } \\
\hline 1- Carabidae & 0 & 0 & 8 & 3 & 2 & 2 & 1 & 5 & 10 & 2 & 33 & 15,9 & 64,7 & 3,3 & 3,4 \\
\hline 2- Staphylinidae & 1 & 0 & 1 & $\mathbf{0}$ & 1 & $\mathbf{0}$ & 4 & $\mathbf{0}$ & 0 & 2 & 9 & 4,3 & 17,7 & 0,9 & 1,3 \\
\hline 3- Pselaphidae & 0 & 0 & 0 & 0 & 0 & 1 & $\mathbf{0}$ & 1 & 1 & 1 & 4 & 1,9 & 7,8 & 0,4 & 0,5 \\
\hline 4- Scydmaenidae & 0 & 0 & 0 & 0 & 1 & 0 & 1 & $\mathbf{0}$ & 0 & 0 & 2 & 1,0 & 3,9 & 0,2 & 0,4 \\
\hline 5- Scolytidae & $\mathbf{0}$ & 0 & 1 & 0 & 0 & $\mathbf{0}$ & $\mathbf{0}$ & $\mathbf{0}$ & $\mathbf{0}$ & 0 & 1 & 0,5 & 2,0 & 0,1 & 0,3 \\
\hline 6- Outros & 0 & 0 & 0 & 0 & 0 & 0 & 0 & 0 & 0 & 2 & 2 & 1,0 & 3,9 & 0,2 & 0,6 \\
\hline Total & 1 & 0 & 10 & 3 & 4 & 3 & 6 & 6 & 11 & 7 & 51 & 24,5 & 100,0 & 5,1 & 3,6 \\
\hline$\%$ & 2,0 & 0,0 & 19,6 & 5,9 & 7,8 & 5,9 & 11,8 & 11,8 & 21,5 & 13,7 & & & 100,0 & & \\
\hline Lavas & 3 & 1 & 6 & 2 & 2 & 1 & 4 & 4 & 1 & 4 & 28 & 13,5 & & 2,8 & 1,7 \\
\hline Ind. $/ \mathrm{m}^{2}$ & 14.4 & 4,8 & 28,9 & 9,6 & 9,6 & 4,8 & 19,2 & 19,2 & 4,8 & 19,2 & & & & & \\
\hline$\%$ & 10,7 & 3,6 & 21.4 & 7,1 & 7,1 & 3,6 & 14,3 & 14.3 & 3.6 & 14,3 & & & 100,0 & & \\
\hline
\end{tabular}

Apêndice 38 - Captura de Coleoptera (fanilias) no folhedo, através de 4 fotoeclectores de solo, no periodo de agosto/1987 a maio/1988, na floresta inundada por áqua nista, (ńmero de captura, densidade de atividade (individuos/n²/nês), percentagen (६), rédia e desvio padräo (S)).

\begin{tabular}{|c|c|c|c|c|c|c|c|c|c|c|c|c|c|c|c|c|}
\hline & Famílias/Meses & Ago. 187 & Set & Out. & Nov. & Dez. & Jan./88 & Fev. & Mar. & Abr. & Mai. & Total & $\%$ & Ind./mimes & Média & $\mathrm{s}$ \\
\hline $1-$ & Staphylinidae & 1313 & 110 & 115 & 49 & 89 & 159 & 60 & 96 & 42 & 485 & 2518 & 41,2 & 62,9 & 251,8 & $>150$ \\
\hline $2-$ & Carabidae & 123 & 60 & 14 & 16 & 22 & 20 & 22 & 43 & 30 & 611 & 961 & 15,7 & 24,0 & 96,1 & $>150$ \\
\hline $3-$ & Pselaphidae & 97 & 70 & 36 & 19 & 29 & 68 & 40 & 30 & 13 & 106 & 508 & 8,3 & 12,7 & 50,8 & 32,5 \\
\hline 4- & Chrysomelidae & 3 & 156 & 12 & 6 & 15 & 135 & 52 & 20 & 42 & 1 & 442 & 7,2 & 11,0 & 44,2 & 56,1 \\
\hline $5-$ & Curculionidae & 43 & 103 & 24 & 61 & 17 & 6 & 2 & 3 & 22 & 1 & 282 & 4,6 & 7,0 & 28,2 & 32,7 \\
\hline $6-$ & Scolytidae & 1 & 11 & 20 & 63 & 15 & 48 & 74 & 5 & 27 & 7 & 271 & 4,4 & 6,8 & 27,1 & 25.7 \\
\hline 7- & Hydrophilidae & 146 & 0 & 0 & 0 & 0 & 0 & 0 & 0 & 0 & 0 & 146 & 2,4 & 3,6 & 14,6 & 46,2 \\
\hline 8 & Scydmaenidae & 10 & 13 & 9 & 15 & 5 & 28 & 17 & 7 & 6 & 4 & 114 & 1,9 & 2,8 & 11,4 & 7,3 \\
\hline 9 & Ptilidae & 2 & 0 & 1 & 17 & 8 & 17 & 18 & 7 & 9 & 15 & 94 & 1,5 & 2,3 & 9,4 & 7,0 \\
\hline 10 & Nitidulidae & 2 & 33 & 4 & 1 & 3 & 0 & $\mathbf{0}$ & 0 & 0 & 0 & 43 & 0,7 & 1,1 & 4,3 & 10,2 \\
\hline 11- & Elateridae & 13 & 4 & 1 & 3 & 3 & 2 & 1 & 1 & 0 & 0 & 28 & 0,5 & 0,7 & 2,8 & 3,8 \\
\hline 12 & Scarabaridae & 4 & 2 & 6 & 4 & 0 & 1 & 3 & 1 & 0 & 3 & 24 & 0,4 & 0,6 & 2,4 & 2,0 \\
\hline 13- & Psephenidae & 0 & $\mathbf{0}$ & 0 & 0 & $\mathbf{0}$ & 0 & 0 & 0 & 0 & 15 & 15 & 0,2 & 0,4 & 1,5 & 4,7 \\
\hline 14- & Corambycidae & 0 & 0 & 0 & 2 & 1 & 0 & $\mathbf{0}$ & 0 & 1 & 0 & 4 & 0,1 & 0,1 & 0,4 & 0,7 \\
\hline 15 - & Brentidae & 1 & 1 & 0 & 0 & 0 & 0 & 0 & 0 & 0 & 0 & 2 & $<0,1$ & 0,0 & 0,2 & 0,4 \\
\hline $16-$ & Phengodidae & 0 & 0 & 0 & 0 & 1 & 0 & 1 & 0 & 0 & 0 & 2 & $<0,1$ & 0,0 & 0,2 & 0,4 \\
\hline 17- & Endomychidae & 1 & 0 & 0 & 0 & 0 & 0 & 0 & 0 & 0 & 0 & 1 & $<0,1$ & 0,0 & 0.1 & 0,3 \\
\hline $18-$ & Cicindelidae & 1 & 0 & 0 & 0 & 0 & 0 & 0 & 0 & 0 & 0 & 1 & $<0,1$ & 0,0 & 0,1 & 0,3 \\
\hline & Outros & 14 & 69 & 47 & 38 & 41 & 95 & 107 & 42 & 35 & 161 & 649 & 10,6 & 16,2 & 64,9 & 44,2 \\
\hline & Total & 1774 & 632 & 289 & 294 & 249 & 579 & 397 & 255 & 227 & 1409 & 6105 & 100,0 & 152,6 & 610,5 & $>150$ \\
\hline & $\%$ & 29,1 & 10,4 & 4,7 & 4,8 & 4,1 & 9,4 & 6,5 & 4,2 & 3,7 & 23,1 & & 100,0 & & & \\
\hline & Ind./m? & 443,5 & 158,0 & 72,3 & 73,5 & 62,3 & 144,8 & 99,3 & 63,8 & 56,8 & 352,3 & & & & & \\
\hline
\end{tabular}


Apêndice 39 - Captura de Coleoptera (familias), en fotoeclector de árvore direcionado para cima (BEt), no periodo de julho/1987 a junho/1988, na floresta inundada por água mista (número de captura, percentagen (₹), nédia e desvio padräo (S)).

\begin{tabular}{|c|c|c|c|c|c|c|c|c|c|c|c|c|c|c|c|c|c|}
\hline & Famílias/Meses & Jul./87 & Ago. & Set. & Out. & Nov. & Dez. & Jan./88 & Fev. & Mar. & Abr. & Mai & Jun. & Total & $\%$ & Média & $s$ \\
\hline $1-$ & Scolytidae & 0 & 0 & 0 & 1 & 1 & 3 & 2 & 6 & 98 & 19 & 2 & 0 & 132 & 43,6 & 11,0 & 27,9 \\
\hline $2-$ & Curculionidae & 3 & 10 & 10 & 7 & 6 & 5 & 3 & 1 & 3 & 2 & 1 & 0 & 51 & 16,8 & 4,3 & 3,4 \\
\hline $3-$ & Staphylinidae & 0 & 0 & 1 & 0 & 0 & 1 & 4 & 3 & 1 & 0 & 8 & 2 & 20 & 6,6 & 1,7 & 2,4 \\
\hline 4- & Carabidae & 1 & 0 & 0 & 0 & 0 & 0 & 0 & 0 & 1 & 0 & 13 & 3 & 18 & 6,0 & 1,5 & $\mathbf{3 , 7}$ \\
\hline 5 & Chrysomelidae & 2 & 0 & 1 & 0 & 4 & 0 & 1 & 3 & 3 & 0 & 0 & 0 & 14 & 4,6 & 1,2 & 1,5 \\
\hline $6-$ & Scydmaenidae & 0 & 0 & 0 & 0 & 1 & 0 & 2 & 2 & 2 & 0 & 3 & 1 & 11 & 3,6 & 0,9 & 1,1 \\
\hline 7- & Pttidae & 0 & 0 & 0 & 0 & 0 & 1 & 2 & 2 & 0 & 0 & 1 & 0 & 6 & 2,0 & 0,5 & 0,8 \\
\hline $8-$ & Pselaphidae & 0 & 0 & 0 & 0 & 0 & 0 & 0 & 0 & 0 & 1 & 5 & 0 & 6 & 2,0 & 0,5 & 1,4 \\
\hline 9 & Cerambycidae & 0 & 0 & 0 & 0 & 1 & 1 & 0 & 0 & 0 & 1 & 1 & 0 & 4 & 1,3 & 0,3 & 0,5 \\
\hline $10-$ & Elateridae & 0 & 1 & 0 & 0 & 2 & 0 & 0 & 0 & 0 & 0 & 0 & 0 & 3 & 1,0 & 0,3 & 0,6 \\
\hline 11- & Brentidae & 0 & 0 & 1 & 0 & 0 & 0 & 0 & 0 & 0 & 0 & 0 & 0 & 1 & 0,3 & $<0,1$ & 0,3 \\
\hline $12-$ & Scarabaeidae & 0 & 0 & 0 & 1 & 0 & 0 & 0 & 0 & 0 & 0 & 0 & 0 & 1 & 0,3 & $<0,1$ & 0,3 \\
\hline 13- & Lampyridae & 0 & 0 & 0 & 0 & 0 & 1 & 0 & 0 & 0 & 0 & 0 & 0 & 1 & 0,3 & $<0,1$ & 0,3 \\
\hline & Outros & 0 & 1 & 3 & 4 & 2 & 6 & 5 & 7 & 2 & 1 & 3 & 1 & 35 & 11,6 & 2,9 & 2,2 \\
\hline & Total & 6 & 12 & 16 & 13 & 17 & 18 & 19 & 24 & 110 & 24 & 37 & 7 & 303 & 100,0 & 25,5 & 28,0 \\
\hline & $\%$ & 2,0 & 4,0 & 5,3 & 4,3 & 5,6 & 6,0 & 6,2 & 7,9 & 36,3 & 7,9 & 12,2 & 2,3 & & 100,0 & & \\
\hline
\end{tabular}

Apêndice 40 - Captura de Coleoptera (fanílias), en fotoeclector direcionado para baixo (BBL), no periodo de julho/1987 a junho/1988, na floresta inundada por água nista (mínero de captura, percentagen $(\xi)$, zédia e desvio paưráo (S)).

\begin{tabular}{|c|c|c|c|c|c|c|c|c|c|c|c|c|c|c|c|c|c|}
\hline & Família/Meses & Jul./87 & Ago. & Set. & Out. & Nov. & Dez. & Jan./88 & Fev. & Mar. & Abr. & Mai. & Jun. & Total & $\%$ & Média & $\mathbf{S}$ \\
\hline $1-$ & Carabidae & 181 & 22 & 2 & 3 & 15 & 39 & 2 & 5 & 4 & 9 & 11 & 6 & 299 & 46,6 & 24,9 & 50,3 \\
\hline $2-$ & Staphylinidae & 13 & 9 & 5 & 7 & 2 & 2 & 2 & 4 & 13 & 6 & 3 & 16 & 82 & 12,8 & 6,8 & 4,9 \\
\hline 3- & Ptliidae & 1 & 3 & 1 & 2 & 0 & 2 & 3 & 1 & 2 & 3 & 1 & 17 & 36 & 5,6 & 3,0 & 4,5 \\
\hline 4 & Pselaphidae & 2 & 1 & 1 & 4 & 3 & 3 & 2 & 4 & 1 & 5 & 5 & 4 & 35 & 5,5 & 2,9 & 1,5 \\
\hline $5-$ & Scolytidae & 1 & 1 & 6 & 2 & 1 & 5 & 2 & 2 & 5 & 6 & 4 & 0 & 35 & 5,5 & 2,9 & 2,2 \\
\hline 6 & Scarabaeidae & 2 & 9 & 1 & 0 & 0 & 3 & 0 & 7 & 0 & 0 & 1 & 0 & 23 & 3,6 & 1,9 & 3,0 \\
\hline $7-$ & Curculionidae & 3 & 3 & 3 & 2 & 3 & 2 & 0 & 1 & 0 & 1 & 0 & 0 & 18 & 2,8 & 1,5 & 1,3 \\
\hline 8- & Scydmaenidae & 2 & 0 & 0 & 0 & 3 & 1 & 0 & 1 & 1 & 2 & 0 & 0 & 10 & 1,5 & 0,8 & 1,0 \\
\hline 9 & Brentidae & 0 & 1 & 1 & 0 & 0 & 0 & 0 & 0 & 0 & 0 & 0 & 0 & 2 & 0,3 & 0,2 & 0,4 \\
\hline 10 & Cerambycidae & 0 & 0 & 0 & 0 & 1 & 0 & 0 & 0 & 0 & 0 & 0 & 0 & 1 & 0,2 & $<0,1$ & 0,3 \\
\hline & Outros & 6 & 27 & 14 & 19 & 5 & 5 & 9 & 3 & 3 & 4 & 2 & 3 & 100 & 15,6 & 8,3 & 7,8 \\
\hline & Total & 211 & 76 & 34 & 39 & 33 & 62 & 20 & 28 & 29 & 36 & 27 & 46 & 641 & 100,0 & 53,4 & 52,1 \\
\hline & $\%$ & 32,9 & 11,8 & 5,3 & 6,1 & 5,2 & 9,7 & 3,1 & 4,4 & 4,5 & 5,6 & 4,2 & 7,2 & & 100,0 & & \\
\hline
\end{tabular}


Apêndice 41 - Captura dos grupos de Arthropoda extraídos do solo através do método de Rempson de 0 a 14 cn de profundidade, no período de agosto/1987 a maio/1988, na floresta inundada por água mista (nimero de captura, abundância (indivíduos/䩕/mês), percentagen $(\xi)$, nédia e desvio padräo (S)).

\begin{tabular}{|c|c|c|c|c|c|c|c|c|c|c|c|c|c|c|c|c|c|}
\hline & Meses & Ago./87 & Set. & Out. & Nov. & Dez & $\operatorname{Jan} .188$ & Fev. & Mar. & Abr. & Mai. & Total & $\operatorname{lnd} / \mathrm{m}^{2} / \mathrm{mê} \mathrm{s}$ & $\%$ & Média & $\mathrm{s}$ & $\overline{x^{2}}$ \\
\hline \multicolumn{18}{|c|}{ Grupos } \\
\hline \multirow[t]{2}{*}{$1-$} & Uropygi & & & & & & & & & & & & & & & & \\
\hline & Schizomida & 0 & 0 & 1 & 1 & 0 & 2 & 0 & 16 & 3 & 5 & 28 & 13,5 & 0,2 & 2,8 & 4,9 & $S^{* * * *}$ \\
\hline 2- & Araneae & 21 & 25 & 54 & 93 & 272 & 229 & 155 & 196 & 165 & 182 & 1392 & 669,8 & 8,6 & 139,2 & 87,0 & $S^{* * * *}$ \\
\hline 3- & Pseudoscorpiones & 0 & 3 & 6 & 31 & 44 & 50 & 56 & 13 & 12 & 16 & 231 & 111,1 & 1,4 & 23,1 & 20,6 & $\mathrm{~S}^{* * *}$ \\
\hline 4- & Isopoda & 5 & 1 & 0 & 3 & 4 & 12 & 8 & 5 & 78 & 34 & 150 & 72,2 & 0,9 & 15 & 24,2 & $\mathbf{S}^{* * *}$ \\
\hline \multirow[t]{4}{*}{ 5. } & Chilopoda & & & & & & & & & & & & & & & & \\
\hline & Geophilomorpha & 0 & 14 & 2 & 3 & 9 & 7 & 5 & 2 & 2 & 2 & 46 & 22,1 & 0,3 & 4,6 & 4,3 & NS \\
\hline & Scolopendromorpha & 0 & 1 & 1 & 1 & 3 & 3 & 4 & 1 & 0 & 1 & 15 & 7,2 & 0,1 & 1,5 & 1,4 & NS \\
\hline & Lthobiomorpha & 32 & 17 & 21 & 7 & 2 & 2 & 0 & 1 & 1 & 0 & 83 & 39,9 & 0,5 & 8,3 & 11,2 & $S^{* * *}$ \\
\hline 6- & Diplopoda & 17 & 68 & 21 & 36 & 207 & 370 & 314 & 322 & 367 & 486 & 2188 & 1052,9 & 13,5 & 218,8 & $>150,0$ & NS \\
\hline 7. & Pauropoda & 18 & 54 & 96 & 95 & 102 & 75 & 69 & 103 & 138 & 60 & 810 & 389,8 & 5,0 & 81 & 33,2 & $S^{*+*}$ \\
\hline 8- & Symphyla & 55 & 223 & 362 & 128 & 238 & 350 & 336 & 242 & 262 & 115 & 2311 & 1112,0 & 14,3 & 231,1 & 104,7 & $S^{*+* *}$ \\
\hline \multicolumn{18}{|c|}{ 9- Thysanura } \\
\hline & Nicoletildae & 0 & 0 & 1 & 1 & 1 & 0 & 0 & 0 & 0 & 0 & 3 & 1,4 & $<0,1$ & 0,3 & 0.5 & NS \\
\hline & Ateluridae & 0 & 0 & 2 & 0 & 1 & 0 & 0 & 0 & 0 & 0 & 3 & 1,4 & $<0,1$ & 0,3 & 0,7 & NS \\
\hline \multicolumn{18}{|c|}{ 10. Diplura } \\
\hline & Japygidae & 27 & 104 & 215 & 144 & 108 & 75 & 104 & 44 & 46 & 23 & 890 & 428,3 & 5,5 & 89 & 59,6 & Soen \\
\hline \multicolumn{18}{|c|}{$\begin{array}{l}\text { 11- Orthoptera } \\
\text { Grilloldea }\end{array}$} \\
\hline & Ninfas & 0 & 1 & 0 & 0 & 0 & 0 & 0 & 0 & 0 & 0 & 1 & 0,5 & $<0,1$ & 0,1 & 0,3 & NS \\
\hline & Blattodea & & & & & & & & & & & & & & & & \\
\hline & Ninfas & 0 & 0 & 4 & 3 & 0 & 3 & 5 & 2 & 4 & 9 & 30 & 14,4 & 0,2 & 3 & 2,8 & NS \\
\hline & Adultos & 0 & 0 & 0 & 0 & 0 & 0 & 0 & 0 & 3 & 7 & 10 & 4,8 & 0,1 & 1 & 2,3 & $\mathbf{S}^{*}$ \\
\hline & - Isoptera & 100 & 2 & 40 & 19 & 2 & 110 & 21 & 0 & 73 & 97 & 464 & 223,3 & 2,9 & 46,4 & 44,4 & NS \\
\hline & - Dermaptera & 1 & 1 & 0 & 0 & 0 & 27 & 1 & 3 & 6 & 5 & 44 & 21,2 & 0,3 & 4,4 & 8,2 & S***t \\
\hline 15- & - Embloptora & 0 & 0 & 0 & 0 & 1 & 0 & 0 & 0 & 0 & 1 & 2 & 1,0 & $<0,1$ & 0,2 & 0,4 & NS \\
\hline & - Psocoptera & 1 & 3 & 0 & 37 & 14 & 5 & 3 & 2 & 4 & 0 & 69 & 39,2 & 0,4 & 6,9 & 11,3 & $\mathbf{S}^{* * *}$ \\
\hline & - Thysanoptera & 21 & 18 & 15 & 28 & 28 & 31 & 17 & 2 & 1 & 2 & 161 & 77,5 & 1,0 & 16,1 & 11,1 & $\mathbf{S}^{*}$ \\
\hline & $\begin{array}{l}\text { Heteroptera } \\
\text { Dipsocoridee }\end{array}$ & & & & & & & & & & & & & & & & \\
\hline & $\begin{array}{l}\text { Dipsocoridee } \\
\text { Ninfas }\end{array}$ & & & & & & & & & & & & & & & & \\
\hline & Ninfas & 1 & 2 & 4 & 0 & 5 & 2 & 0 & 1 & 0 & 0 & 15 & 7,2 & 0,1 & 1,5 & 1,8 & NS \\
\hline & Adultos & 0 & 2 & 0 & 0 & 0 & 1 & 0 & 3 & 0 & 0 & 6 & 2,9 & $<0,1$ & 0,6 & 1,1 & NS \\
\hline & Schizopteridao & & & & & & & & & & & & & & & & \\
\hline & Adultos & 4 & 0 & 0 & 0 & 0 & 0 & 0 & 0 & 0 & 0 & 4 & 1,9 & $<0,1$ & 0,4 & 1,3 & NS \\
\hline & Gelastocoridae & & & & & & & & & & & & & & & & \\
\hline & $\begin{array}{l}\text { Ninfas } \\
\text { Outros Heteroptera }\end{array}$ & 0 & 2 & 2 & 0 & 0 & 2 & 0 & 0 & 0 & 0 & 6 & 2,9 & $<0,1$ & 0,6 & 1,0 & NS \\
\hline & Ninfas & 1 & 3 & 6 & 5 & 14 & 1 & 1 & 0 & 0 & 0 & 31 & 14,9 & 0,2 & 3,1 & 4,4 & NS \\
\hline & Adultos & 0 & 0 & 3 & 3 & 4 & 0 & 1 & 2 & 3 & 1 & 17 & 8,2 & 0,1 & 1,7 & 1,5 & NS \\
\hline & Homoptera & & & & & & & & & & & & & & & & \\
\hline & Coccoldea & & & & & & & & & & & & & & & & \\
\hline & Ninfas & 26 & 239 & 20 & 25 & 138 & 208 & 20 & 22 & 45 & 61 & 804 & 388,9 & 5,0 & 80,4 & 83,7 & NS \\
\hline & Adultos & 4 & 4 & 1 & 5 & 25 & 48 & 5 & 13 & 19 & 2 & 128 & 60,6 & 0,8 & 12,6 & 14,8 & $S^{* * * *}$ \\
\hline & Outros Homoptera & & & & & & & & & & & & & & & & \\
\hline & Ninfas & 0 & 10 & 10 & 3 & 2 & 2 & 8 & 2 & 5 & 8 & 50 & 24,1 & 0,3 & 5 & 3,7 & NS \\
\hline & Adultos & 0 & 0 & 1 & 1 & 1 & 0 & 1 & 1 & 0 & 0 & 5 & 2,4 & $<0,1$ & 0,5 & 0,5 & NS \\
\hline & - Neuroptera & & & & & & & & & & & & & & & & \\
\hline & Lavas & 2 & 1 & 1 & 0 & 0 & 1 & 0 & 1 & 0 & 0 & 6 & 2,9 & $<0,1$ & 0,6 & 0,7 & NS \\
\hline & - Colooptera & & & & & & & & & & & & & & & & \\
\hline & Lavas & 94 & 68 & 62 & 31 & 52 & 44 & 48 & 42 & 69 & 30 & 540 & 259,9 & 3,3 & 54 & 19,6 & $s^{* * * *}$ \\
\hline & Adultos & 100 & 34 & 30 & 37 & 56 & 71 & 64 & 118 & 150 & 205 & 885 & 416,2 & 5,3 & 86,5 & 57,1 & $\mathbf{S}^{* * * a}$ \\
\hline & - Mecoptera & & & & & & & & & & & & & & & & \\
\hline & Lavas & 1 & 1 & 3 & 0 & 0 & 0 & 0 & 1 & 0 & 1 & 7 & 3,4 & $<0,1$ & 0,7 & 0,9 & NS \\
\hline & - Lepidoptera & & & & & & & & & & & & & & & & \\
\hline & Lavas & 6 & 0 & 9 & 5 & 10 & 14 & 3 & 2 & 1 & 4 & 54 & 26,0 & 0,3 & 5,4 & 4,4 & NS \\
\hline & Adultos & 4 & 0 & 1 & 1 & 0 & 2 & 0 & 0 & 0 & 0 & 8 & 3,8 & 0,0 & 0,8 & 1,3 & NS \\
\hline & Diptera & & & & & & & & & & & & & & & & \\
\hline & $\begin{array}{l}\text { Laves } \\
\text { Nematocera }\end{array}$ & 24 & 45 & 38 & 43 & 36 & 23 & 14 & 22 & 72 & 44 & 361 & 173,7 & 2,2 & 36,1 & 16,6 & NS \\
\hline & Cocidomyildae & 30 & 85 & 35 & 5 & 41 & 41 & 19 & 5 & 0 & 1 & 242 & 116,4 & 1,5 & 24,2 & 21,8 & $S^{* * *}$ \\
\hline & Sciaridae & 1 & 0 & 0 & 1 & 5 & 3 & 1 & 0 & 7 & 1 & 19 & 9,1 & 0,1 & 1,9 & 2,4 & $\mathbf{S}^{*}$ \\
\hline & Outros Nematocera & 8 & 0 & 2 & 1 & 3 & 7 & 9 & 29 & 25 & 22 & 108 & 51,0 & 0,7 & 10,6 & 10,7 & $S^{* * * *}$ \\
\hline & Brachycera & 12 & 4 & 0 & 0 & 2 & 2 & 0 & 7 & 8 & 6 & 41 & 19,7 & 0,3 & 4,1 & 4,1 & NS \\
\hline & - Hymenoptera & & & & & & & & & & & & & & & & \\
\hline & Formicldae & 128 & 191 & 143 & 55 & 703 & 223 & 529 & 538 & 393 & 968 & 3871 & 1862,7 & 23,9 & 397,1 & $>150,0$ & $S^{* t * t}$ \\
\hline & Outros Hymenogtera & 1 & 5 & 19 & 16 & 8 & 3 & 5 & 7 & 5 & 5 & 74 & 35,6 & 0,5 & 7,4 & 5,7 & $\mathrm{~S}^{*}$ \\
\hline & Total & 745 & 1211 & 1231 & 867 & 2139 & 2049 & 1826 & 1770 & 1967 & 2384 & 18189 & 7790,1 & 100,0 & 1618,9 & & \\
\hline & $\operatorname{Ind} . / \mathrm{m}^{2}$ & 3584,9 & 5827,3 & 5923,6 & 4172,0 & 10292,9 & 9859,8 & 8786,7 & 8517,2 & 9465,2 & 11471,8 & 77801,5 & 37486,2 & & & & \\
\hline & $\%$ & 4,6 & 7,5 & 7,6 & 5,4 & 13,2 & 12,7 & 11,3 & 10,9 & 12,1 & 14,7 & 100,0 & & & & & \\
\hline
\end{tabular}


Apêndice 42 - Captura dos grupos de Arthropoda extraídos do solo através do método de Kenpson de 0 a 3,5 col de profundidade, no período de agosto/1987 a naio/1988, na floresta inundada por água nista (núnero de captura, abundância (indivíduos/ $\mathrm{n}^{2} /$ nês), percentagen (气)), rédia e desvio padrão (S)).

\begin{tabular}{|c|c|c|c|c|c|c|c|c|c|c|c|c|c|c|c|c|}
\hline & Meses & Ago./87 & Set. & Out. & Nov. & Dez. & $\operatorname{Jan} . / 88$ & Fev. & Mar. & Abr. & Mai. & Total & Ind./nimimês & $\%$ & Média & s \\
\hline & \multicolumn{16}{|l|}{ Grupos } \\
\hline \multirow[t]{2}{*}{$1-$} & Uropygi & & & & & & & & & & & & & & & \\
\hline & Schizomida & 0 & 0 & 0 & 0 & 0 & 0 & 0 & 10 & 2 & 2 & 14 & 6,7 & 0,1 & 1,4 & 3,1 \\
\hline 2. & Araneae & 11 & 11 & 19 & 44 & 32 & 79 & 88 & 92 & 87 & 97 & 560 & 269,5 & 5,7 & 56 & 35,9 \\
\hline 3. & Pseudoscorpiones & 0 & 2 & 5 & 8 & 16 & 23 & 43 & 11 & $\theta$ & 7 & 124 & 59,7 & 1,3 & 12,4 & 12,7 \\
\hline 4 & Isopoda & 5 & 0 & 0 & 2 & 3 & $\theta$ & 6 & 5 & 58 & 30 & 118 & 56,8 & 1,2 & 11,8 & 18,4 \\
\hline \multirow[t]{4}{*}{ 5- } & Chilopoda & & & & & & & & & & & & & & & \\
\hline & Geophilomorpha & 0 & 2 & 2 & 3 & 2 & 3 & 3 & 2 & 2 & 1 & 20 & 8,6 & 0,2 & 2 & 0,9 \\
\hline & Scolopendromorpha & 0 & 1 & 0 & 1 & 2 & 1 & 0 & 0 & 0 & 0 & 5 & 2,4 & 0,1 & 0,5 & 0,7 \\
\hline & Lithobiomorpha & 6 & 9 & 9 & 2 & 1 & 2 & 0 & 1 & 0 & 0 & 30 & 14,4 & 0,3 & 3 & 3,6 \\
\hline $6 \cdot$ & Diplopoda & 7 & 52 & 12 & 11 & 95 & 202 & 215 & 225 & 289 & 320 & 1428 & 687,2 & 14,6 & 142,8 & 121,0 \\
\hline 7. & Pauropoda & 7 & 24 & 34 & 35 & 24 & 40 & 33 & 53 & 82 & 11 & 353 & 169,9 & 3,6 & 35,3 & 24,0 \\
\hline 8. & Symphyla & 20 & 73 & 90 & 52 & 124 & 191 & 123 & 108 & 155 & 47 & 983 & 473,0 & 10,1 & 88,3 & 52,5 \\
\hline \multirow[t]{2}{*}{ g. } & Diplura & & & & & & & & & & & & & & & \\
\hline & Japygidae & 0 & 26 & 119 & 55 & 42 & 34 & 24 & 6 & 5 & 0 & 311 & 149,6 & 3,2 & 31,1 & 36,1 \\
\hline \multirow[t]{3}{*}{10.} & Orthoptera & & & & & & & & & & & & & & & \\
\hline & Grilloidea & & & & & & & & & & & & & & & \\
\hline & Ninfas & 0 & 1 & 0 & 0 & 0 & 0 & 0 & 0 & 0 & 0 & 1 & 0,5 & $<0,1$ & 0,1 & 0,3 \\
\hline \multirow[t]{3}{*}{ 11- E } & Blattodea & & & & & & & & & & & & & & & \\
\hline & Ninfas & 0 & 0 & 4 & 2 & 0 & 3 & 2 & 2 & 3 & 7 & 23 & 11,1 & 0,2 & 2,3 & 2,2 \\
\hline & Adultos & 0 & 0 & 0 & 0 & 0 & 0 & 0 & 0 & 3 & 7 & 10 & 4,8 & 0,1 & 1 & 2,3 \\
\hline 12. & Isoptera & 100 & 1 & 30 & 0 & 2 & 80 & 21 & 0 & 18 & 86 & 348 & 167,5 & 3,6 & 34,8 & 40,9 \\
\hline 13 & Dermaptera & 1 & 1 & 0 & 0 & 0 & 27 & 1 & 3 & 5 & 4 & 42 & 20,2 & 0,4 & 4,2 & 8,2 \\
\hline 14 & Embloptera & 0 & 0 & 0 & 0 & 1 & 0 & 0 & 0 & 0 & 0 & 1 & 0,5 & $<0,1$ & 0,1 & 0,3 \\
\hline $15-$ & Psocoptera & 0 & 3 & 0 & 5 & 4 & 3 & 0 & 0 & 0 & 0 & 15 & 7,2 & 0,2 & 1,5 & 2,0 \\
\hline $16-$ & Thysanoptera & 20 & 17 & 10 & 20 & 17 & 27 & 14 & 0 & 1 & 2 & 128 & 81,6 & 1,3 & 12,8 & 8,2 \\
\hline \multirow[t]{11}{*}{$17-$} & Heteroptera & & & & & & & & & & & & & & & \\
\hline & Dipsocoridas & & & & & & & & & & & & & & & \\
\hline & Ninfas & 1 & 0 & 4 & 0 & 3 & 1 & 0 & 0 & 0 & 0 & 9 & 4,3 & 0,1 & 0,9 & 1,4 \\
\hline & Adultos & 0 & 2 & 0 & 0 & 0 & $t$ & 0 & 2 & 0 & 0 & 5 & 2,4 & 0,1 & 0,5 & 0,8 \\
\hline & Schlzopteridae & & & & & & & & & & & & & & & \\
\hline & Adultos & 3 & 0 & 0 & 0 & 0 & 0 & 0 & 0 & 0 & 0 & 3 & 1,4 & $<0,1$ & 0,3 & 0,8 \\
\hline & Gelastocoridas & & & & & & & & & & & & & & & \\
\hline & Ninfes & 0 & 1 & 2 & 0 & 0 & 2 & 0 & 0 & 0 & 0 & 5 & 2,4 & 0,1 & 0,5 & 0,8 \\
\hline & Outros Heteroptera & & & & & & & & & & & & & & & \\
\hline & Ninfas & 1 & 3 & 5 & 1 & 9 & 0 & 1 & 0 & 0 & 0 & 20 & 8,6 & 0,2 & 2 & 2,9 \\
\hline & Adultos & 0 & 0 & 2 & 2 & 2 & 0 & 0 & 2 & 3 & 1 & 12 & 5,8 & 0,1 & 1,2 & 1,1 \\
\hline $18-$ & Homoptera & & & & & & & & & & & & & & & \\
\hline & Coccoidea & & & & & & & & & & & & & & & \\
\hline & Ninfas & 13 & 19 & 6 & 10 & 33 & 81 & 4 & 10 & 30 & 39 & 245 & 117,9 & 2,5 & 24,5 & 23,2 \\
\hline & Adultos & 1 & 2 & 0 & 4 & 11 & 16 & 3 & 13 & 19 & 2 & 71 & 34,2 & 0,7 & 7,1 & 7,0 \\
\hline & Outros Homoptera & & & & & & & & & & & & & & & \\
\hline & Ninfas & 0 & 5 & 6 & 0 & 0 & 1 & 6 & 1 & 5 & 4 & 28 & 13,5 & 0,3 & 2,8 & 2,6 \\
\hline & Adultos & 0 & 0 & 0 & 0 & 0 & 0 & 0 & 1 & 0 & 0 & 1 & 0,5 & $<0,1$ & 0,1 & 0,3 \\
\hline 10 & - Neuroptera & & & & & & & & & & & & & & & \\
\hline & Lavas & 0 & 1 & 1 & 0 & 0 & 1 & 0 & 0 & 0 & 0 & 3 & 1,4 & $<0,1$ & 0,3 & 0,5 \\
\hline $20-$ & - Coleoptera & & & & & & & & & & & & & & & \\
\hline & Lavas & 73 & 55 & 34 & 24 & 19 & 38 & 38 & 27 & 57 & 19 & 384 & 184,8 & 3,9 & 38,4 & 18,0 \\
\hline & Adultos & 88 & 21 & 12 & 26 & 27 & 47 & 42 & 85 & 112 & 148 & 608 & 292,6 & 6,2 & 60,8 & 45,2 \\
\hline & - Mecoptera & & & & & & & & & & & & & & & \\
\hline & Lanas & 0 & 0 & 0 & 0 & 0 & 0 & 0 & 1 & 0 & 0 & 1 & 0,5 & $<0,1$ & 0,1 & 0,3 \\
\hline $22-$ & - Lepidoptera & & & & & & & & & & & & & & & \\
\hline & Lavas & 4 & 0 & 5 & 2 & 8 & 11 & 3 & 2 & 1 & 4 & 40 & 19,2 & 0,4 & 4 & 3,3 \\
\hline & Adultos & 1 & 0 & 1 & 0 & 0 & 0 & 0 & 0 & 0 & 0 & 2 & 1,0 & $<0,1$ & 0,2 & 0,4 \\
\hline 23 & - Diptera & & & & & & & & & & & & & & & \\
\hline & Lavas & 16 & 42 & 36 & 40 & 18 & 22 & 13 & 17 & 66 & 42 & 312 & 150,1 & 3,2 & 31,2 & 16,9 \\
\hline & Nematocera & & & & & & & & & & & & & & & \\
\hline & Cecidomyiidae & 25 & 49 & 34 & 3 & 21 & 39 & 17 & 5 & 0 & 1 & 194 & 93,3 & 2,0 & 19,4 & 17,3 \\
\hline & Sciaridae & 1 & 0 & 0 & 1 & 2 & 3 & 1 & 0 & 7 & $t$ & 16 & 7,7 & 0,2 & 1,6 & 2,1 \\
\hline & Outros Nematocera & 7 & 0 & 2 & 0 & 0 & 6 & 6 & 27 & 22 & 18 & 88 & 42,4 & 0,9 & 8,8 & 8,9 \\
\hline & Brachycera & 5 & 2 & 0 & 0 & 1 & 1 & 0 & 2 & 2 & 6 & 19 & 9,1 & 0,2 & 1,9 & 2,1 \\
\hline 24 & Hymenoptera & & & & & & & & & & & & & & & \\
\hline & Formicidae & 58 & 185 & 100 & 52 & 430 & 203 & 498 & 462 & 308 & 828 & 3122 & 1502,3 & 32,0 & 312,2 & $>150,0$ \\
\hline & Outros Hymenoptera & 0 & 3 & 16 & 8 & 4 & 3 & 4 & 6 & 4 & 2 & 50 & 24,1 & 0,5 & 5 & 4,4 \\
\hline & Total & 474 & 613 & 600 & 413 & 953 & 1210 & 1207 & 1181 & 1365 & 1736 & 9752 & $4692_{1} 7$ & 100,0 & 975,2 & \\
\hline & Ind. $/ \mathrm{m}^{2}$ & 2280,9 & 2949,8 & 2887,2 & 1987,4 & 4585,8 & 5822,5 & $5808_{1} 1$ & 5683,0 & 6568,4 & 8353,6 & 46926,6 & 22581,1 & 481,2 & & \\
\hline & $\%$ & 4,9 & 6,3 & 6,1 & 4,2 & 9,8 & 12,4 & 12,4 & 12,1 & 14,0 & 17,8 & 100,0 & & & & \\
\hline
\end{tabular}


Apêndice 43 - Captura dos grupos de Arthropoda extraídos do solo, através do método de Keapson de 3,5 a 7 con de profundidade, no período de agosto/1987 a naio/1988, na floresta inundada por água mista (número de captura, abundância (indivíduos/1²/nês), percentagen ( $\%$ ), védia e desvio padrão (S)).

\begin{tabular}{|c|c|c|c|c|c|c|c|c|c|c|c|c|c|c|c|c|}
\hline & Meses & $\mathrm{Ag} 0 . / 87$ & Set. & Out. & Nov. & Dez. & $\operatorname{Jan} . / 88$ & Fev. & Mar. & Abr. & Mai. & Total I & Ind./minếs & $\%$ & Média & S \\
\hline & \multicolumn{16}{|l|}{ Grupos } \\
\hline \multirow{2}{*}{$1-$} & Uropygi & & & & & & & & & & & & & & & \\
\hline & Schizomida & 0 & 0 & 1 & 0 & 0 & 1 & 0 & 6 & 1 & 3 & 12 & 5,8 & 0,3 & 1,2 & 1,9 \\
\hline $2-$ & Araneae & 3 & 4 & 12 & 18 & 145 & 58 & 51 & 77 & 67 & 56 & 491 & 236,3 & 12,9 & 49,1 & $\mathbf{4 3 , 4}$ \\
\hline $3-$ & Pseudoscorpiones & 0 & 0 & 1 & 5 & 23 & 17 & 12 & 2 & 3 & 1 & 64 & 30,8 & 1,7 & 6,4 & 8,1 \\
\hline 4- & Isopoda & 0 & $\mathbf{0}$ & 0 & 1 & 1 & 0 & 2 & 0 & 20 & 4 & 28 & 13,5 & 0,7 & 2,8 & 6,2 \\
\hline \multirow[t]{4}{*}{5} & Chilopoda & & & & & & & & & & & & & & & \\
\hline & Geophilomorpha & 0 & 10 & 0 & 0 & 0 & 2 & 2 & 0 & 0 & 1 & 15 & 7,2 & 0,4 & 1,5 & 3,1 \\
\hline & Scolopendromorpha & 0 & 0 & 1 & 0 & 0 & $\mathbf{0}$ & 2 & 0 & 0 & 0 & 3 & 1,4 & 0,1 & 0,3 & 0,7 \\
\hline & Lithobiomorpha & 17 & 6 & 7 & 2 & 1 & 0 & 0 & 0 & 1 & 0 & 34 & 16,4 & 0,9 & 3,4 & 5,4 \\
\hline $6-$ & Diplopoda & 1 & 13 & 5 & 7 & 71 & 51 & 55 & 59 & 60 & 120 & 442 & 212,7 & 11,6 & 44,2 & 37,8 \\
\hline 7- & Pauropoda & 2 & 21 & 45 & 41 & 46 & 20 & 17 & 33 & 25 & 12 & 262 & 126,1 & 6,9 & 26,2 & 14,7 \\
\hline 8 & Symphyla & 12 & 80 & 186 & 50 & 73 & 99 & 153 & 113 & 90 & 54 & 910 & 437,9 & 24,0 & 91 & 50,7 \\
\hline \multirow[t]{2}{*}{9} & Thysanura & & & & & & & & & & & & & & & \\
\hline & Nicoletiidae & 0 & 0 & 0 & 1 & 0 & 0 & 0 & 0 & 0 & 0 & 1 & 0,5 & $<0,1$ & 0,1 & 0,3 \\
\hline \multicolumn{16}{|c|}{ 10- Diplura } & 21,6 \\
\hline \multicolumn{17}{|c|}{ 11- Blattodea } \\
\hline & Ninfas & 0 & 0 & 0 & 0 & 0 & 0 & 0 & 0 & 1 & 1 & 2 & 1,0 & 0,1 & 0,2 & 0,4 \\
\hline $12-$ & Isoptera & 0 & 0 & 0 & 0 & 0 & 1 & 0 & 0 & 9 & 3 & 13 & 6,3 & 0,3 & 1,3 & 2,9 \\
\hline 13 & Dermaptera & 0 & 0 & $\mathbf{0}$ & 0 & 0 & 0 & 0 & 0 & 1 & 1 & 2 & 1,0 & 0,1 & 0,2 & 0,4 \\
\hline 14- & Embioptera & 0 & 0 & 0 & 0 & 0 & 0 & 0 & 0 & 0 & 1 & 1 & 0,5 & $<0,1$ & 0,1 & 0,3 \\
\hline 15 & Psocoptera & 0 & 0 & 0 & 1 & 5 & 0 & 0 & 2 & 0 & 0 & 8 & 3,8 & 0,2 & 0,8 & 1,6 \\
\hline 16- & Thysanoptera & 1 & 0 & 5 & 7 & 8 & 3 & 0 & 0 & 0 & 0 & 24 & 11,5 & 0,6 & 2,4 & 3,2 \\
\hline \multicolumn{17}{|c|}{$\begin{array}{l}\text { 17- Heteroptera } \\
\text { Dipsocoridae }\end{array}$} \\
\hline \multicolumn{17}{|c|}{$\begin{array}{l}\text { Ninfas } \\
\text { Schizopteridae }\end{array}$} \\
\hline \multicolumn{17}{|c|}{$\begin{array}{l}\text { Adultos } \\
\text { Gelastocoridee }\end{array}$} \\
\hline & Ninfas & 0 & 1 & 0 & 0 & 0 & 0 & 0 & 0 & 0 & 0 & 1 & 0,5 & $<0,1$ & 0,1 & 0,3 \\
\hline \multicolumn{17}{|c|}{ Outros Heteroptera } \\
\hline & Ninfas & 0 & 0 & 1 & 2 & 4 & 1 & $\mathbf{0}$ & 0 & 0 & 0 & 8 & 3,8 & 0,2 & 0,8 & 1,3 \\
\hline & Adultos & 0 & 0 & 0 & 1 & 1 & 0 & 0 & 0 & 0 & 0 & 2 & 1,0 & 0,1 & 0,2 & 0,4 \\
\hline \multicolumn{17}{|c|}{$\begin{array}{r}\text { 18- Homoptera } \\
\text { Coccoidea }\end{array}$} \\
\hline & Ninfas & 5 & 84 & 12 & 6 & 92 & 59 & 6 & 10 & 11 & 12 & 297 & 142,9 & 7,8 & 29,7 & 34,6 \\
\hline & Adultos & 0 & 1 & 0 & 1 & 8 & 4 & 1 & 0 & 0 & 0 & 15 & 7,2 & 0,4 & 1,5 & 2,6 \\
\hline \multicolumn{17}{|c|}{ Outros Homoptera } \\
\hline & Ninfas & $\mathbf{0}$ & 1 & 4 & 1 & 2 & 0 & 2 & 1 & 0 & 2 & 13 & 6,3 & 0,3 & 1,3 & 1,3 \\
\hline & Adultos & 0 & 0 & 1 & 1 & 0 & 0 & 0 & 0 & 0 & 0 & 2 & 1,0 & 0,1 & 0,2 & 0,4 \\
\hline & Neuroptera & & & & & & & & & & & & & & & \\
\hline & $\begin{array}{l}\text { Lavas } \\
\text { Coleoptera }\end{array}$ & 1 & 0 & 0 & 0 & 0 & 0 & 0 & 0 & 0 & 0 & 1 & 0,5 & $<0,1$ & 0,1 & 0,3 \\
\hline & Lavas & 8 & 12 & 12 & 5 & 26 & 5 & 5 & 6 & 8 & 7 & 94 & 45,2 & 2,5 & 9,4 & 6,4 \\
\hline & Adultos & 6 & 10 & 6 & 8 & 19 & 9 & 13 & 22 & 22 & 39 & 154 & 74,1 & 4,1 & 15,4 & 10,4 \\
\hline 21- & Mecoptera & & & & & & & & & & & & & & & \\
\hline & $\begin{array}{l}\text { Lavas } \\
\text { Lepidoptera }\end{array}$ & 1 & 0 & 1 & 0 & 0 & 0 & 0 & 0 & 0 & 1 & 3 & 1,4 & 0,1 & 0,3 & 0,5 \\
\hline- & Lavas & 2 & 0 & 3 & 1 & 1 & 2 & 0 & 0 & 0 & 0 & 9 & 4,3 & 0,2 & 0,9 & 1,1 \\
\hline & Adultos & 3 & 0 & 0 & 1 & 0 & 0 & 0 & 0 & 0 & 0 & 4 & 1,9 & 0,1 & 0,4 & 1,0 \\
\hline & Diptera & & & & & & & & & & & & & & & \\
\hline & $\begin{array}{l}\text { Lavas } \\
\text { Nematocera }\end{array}$ & 8 & 0 & 0 & 2 & 13 & 0 & 0 & 3 & 5 & 2 & 33 & 15,9 & 0,9 & 3,3 & 4,3 \\
\hline & Cecidomyildae & 4 & 9 & 0 & 0 & 9 & 2 & 2 & 0 & 0 & 0 & 26 & 12,5 & 0,7 & 2,6 & 3,6 \\
\hline & Sciaridae & $\mathbf{0}$ & 0 & 0 & 0 & 3 & 0 & 0 & 0 & 0 & 0 & 3 & 1,4 & 0,1 & 0,3 & 0,9 \\
\hline & Outros Nematocera & 1 & 0 & 0 & 1 & 2 & 0 & 2 & 0 & 2 & 3 & 11 & 5,3 & 0,3 & 1,1 & 1,1 \\
\hline & Brachycera & 0 & 1 & 0 & 0 & 0 & 0 & 0 & 4 & 6 & 0 & 11 & 5,3 & 0,3 & 1,1 & 2,1 \\
\hline & - Hymenoptera & & & & & & & & & & & & & & & \\
\hline & Formicidae & 3 & 0 & 40 & 1 & 270 & 15 & 19 & 65 & 19 & 64 & 496 & 238,7 & 13,1 & 49,6 & 81,1 \\
\hline & Outros Hymenoptera & 0 & 1 & 2 & 5 & 3 & 0 & 0 & 1 & 0 & 2 & 14 & 6,7 & 0,4 & 14 & 16 \\
\hline & Total - & 86 & 299 & 396 & 228 & 874 & 365 & 383 & 413 & 361 & 391 & 3796 & 1826,6 & 100 & 379,6 & \\
\hline & Ind. $/ \mathrm{m}^{2}$ & 413,8 & 1438,8 & 1905,6 & 1097,1 & 4205,7 & 1756,4 & 1843,0 & 1987,4 & 1737,1 & 1881.5 & 18266,4 & & & & \\
\hline & $\mathscr{x}$ & 23 & 79 & 104 & 6,0 & 23,0 & 9,6 & 10,1 & 10,9 & 9,5 & 10,3 & 100.0 & & & & \\
\hline
\end{tabular}


Apêndice 44 - Captura dos grupos de Arthropoda extraídos do solo através do método de Keapson de 7 a 10,5 ca de profundidade, no periodo de

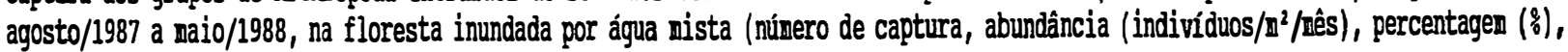
rédia e desvio padrão (S)).

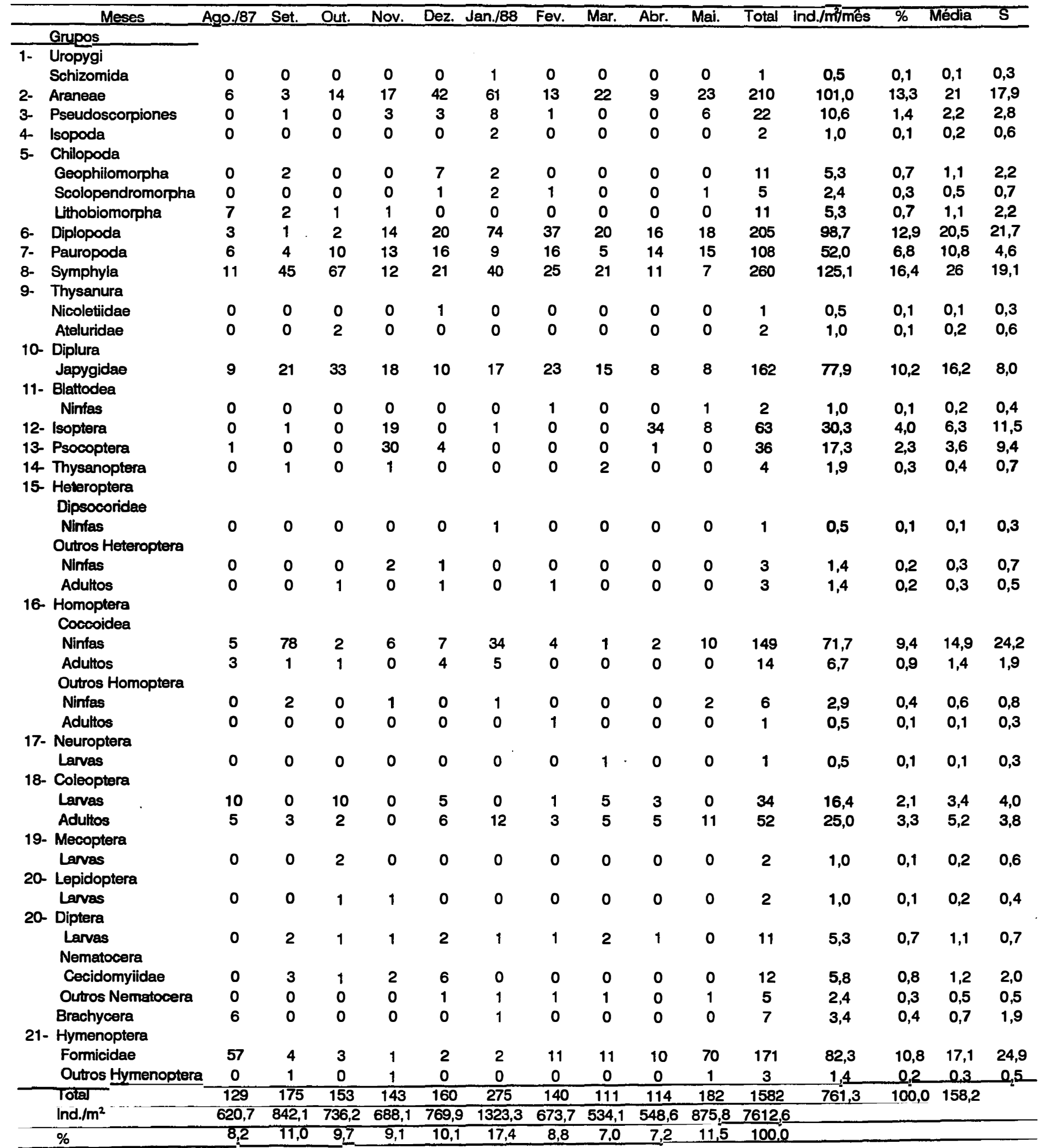


Apêndice 45 - Captura dos grupos de Arthropoda extraídos do solo, através do método de Kempson de 10,5 a $14 \mathrm{~cm}$ de profundidade, no período de agosto/1987 a maio/1988, na floresta inundada por água mista (número de captura, abundância (indivíduos $\mathbb{\boxplus}^{2}$ ), percentagen (\%), média e desvio padrão (S)).

1- Uropygi

Schizomida

2- Araneae

3. Pseudosconpiones

4. Isopoda

5- Chilopoda

Geophilomorpha Scolopendromorpha Lithobiomorpha

6- Diplopoda

7- Pauropoda

8- Symphyla

9- Thysanura Nicoletiidae Ateluridae

10- Diplura Japygidae

11- Blattodea Ninfas

12- Isoptera

13. Psocoptera

14 Thysanoptera

15- Heteroptera

Dipsocoridae

Ninfas

Adultos

16- Homoptera

Coccoidea

Ninfas

Adultos

Outros Homoptera

Ninfas

Adultos

17- Neuroptera

Lanvas

18- Coleoptera

Lanvas

Adultos

19. Mecoptera

Larvas

20- Lepidoptera

Larvas

Adultos

21- Diptera

Larvas

Nematocera

Cecidomyiidae

Outros Nematocera

Brachycera

22- Hymenoptera

Formicidae

Outros Hymenoptera

$$
\begin{aligned}
& 0 \\
& 1 \\
& 0 \\
& 0 \\
& 0 \\
& 0 \\
& 6 \\
& 3 \\
& 12 \\
& 0 \\
& 0 \\
& 11 \\
& 0 \\
& 0 \\
& 0 \\
& 0
\end{aligned}
$$

0
1
0

0$$
\begin{gathered}
3 \\
12
\end{gathered}
$$

0
0
2
6
3
12

0
7
0
1

0

$\begin{array}{ccccc}0 & 0 & 0 & 0 & 0 \\ 0 & 0 & 0 & 0 & 0 \\ 0 & 4 & 2 & 0 & 0 \\ 2 & 2 & 4 & 21 & 43 \\ 5 & 7 & 6 & 16 & 6 \\ 25 & 19 & 14 & 20 & 20\end{array}$

$$
0
$$

$\begin{array}{cccccc}1 & 0 & 0 & 0 & 0 & 0 \\ 14 & 53 & 31 & 3 & 5 & 2 \\ 15 & 2 & 2 & 0 & 0 & 0 \\ 0 & 0 & 1 & 0 & 0 & 0\end{array}$

$\begin{array}{cc}0 & 1 \\ 6 & 131 \\ 2 & 21\end{array}$

0,5

63,0

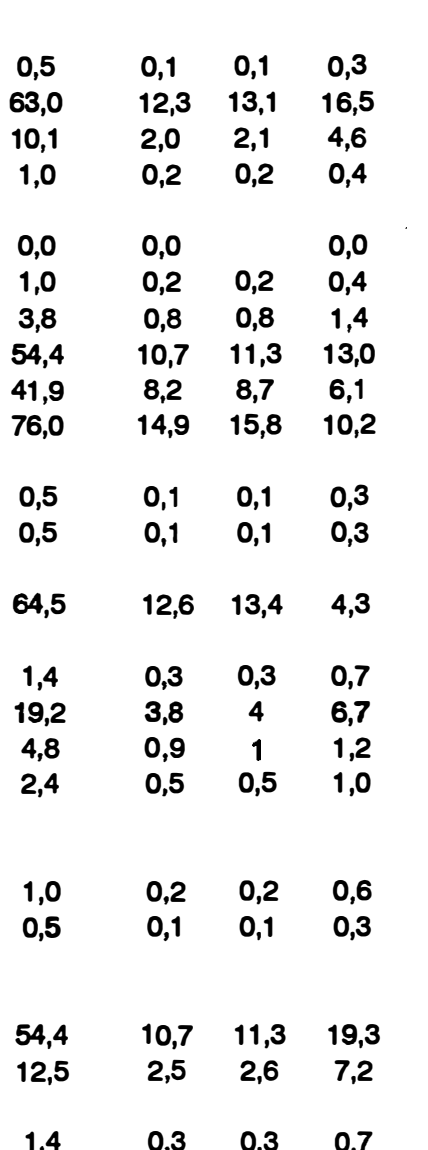

1,0

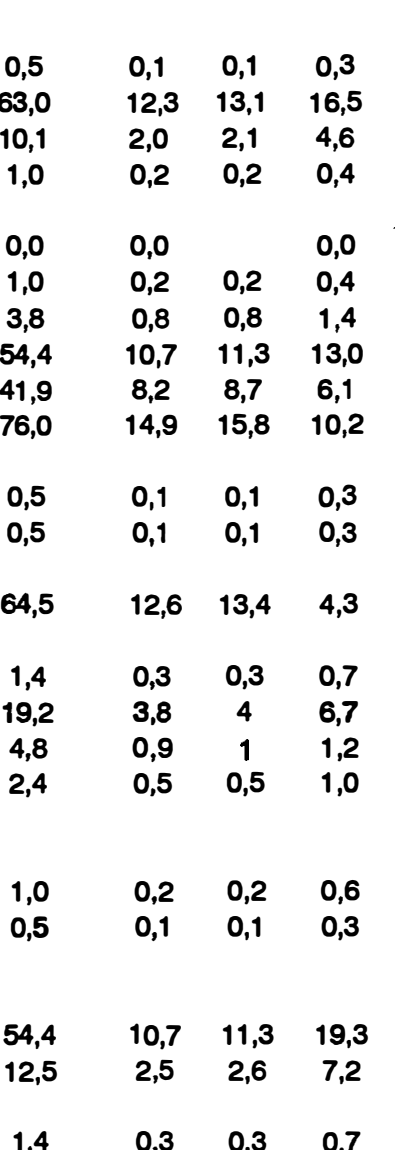

$\begin{array}{llllll}0 & 0 & 0 & 0 & 0 & 0\end{array}$

0,0

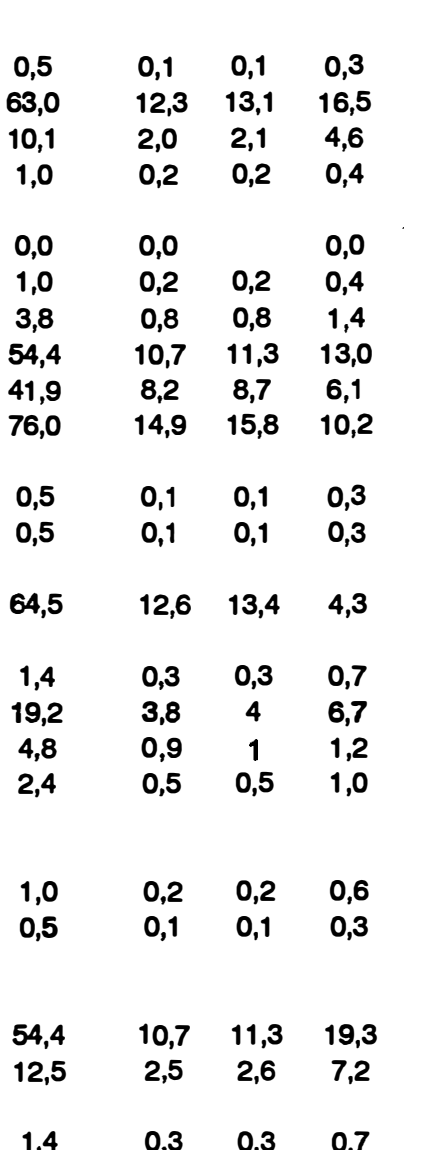

3,8

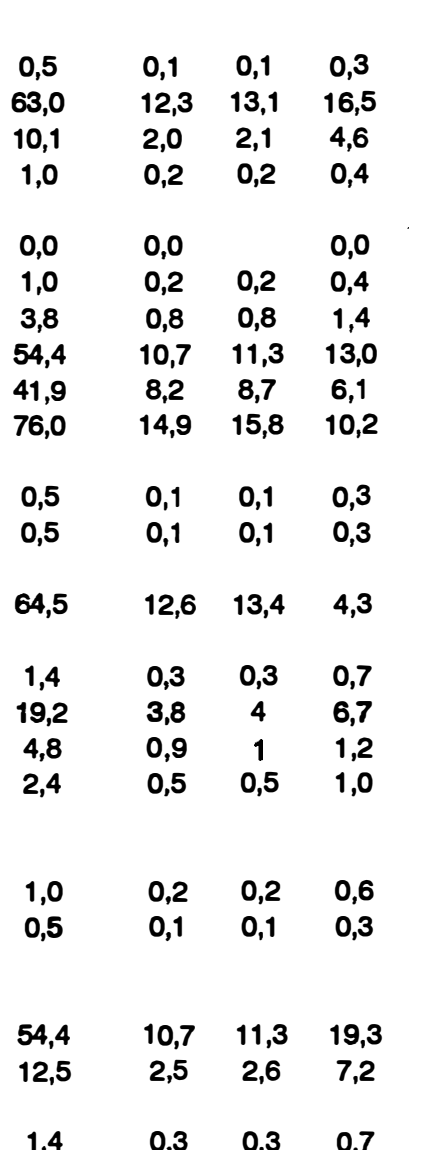

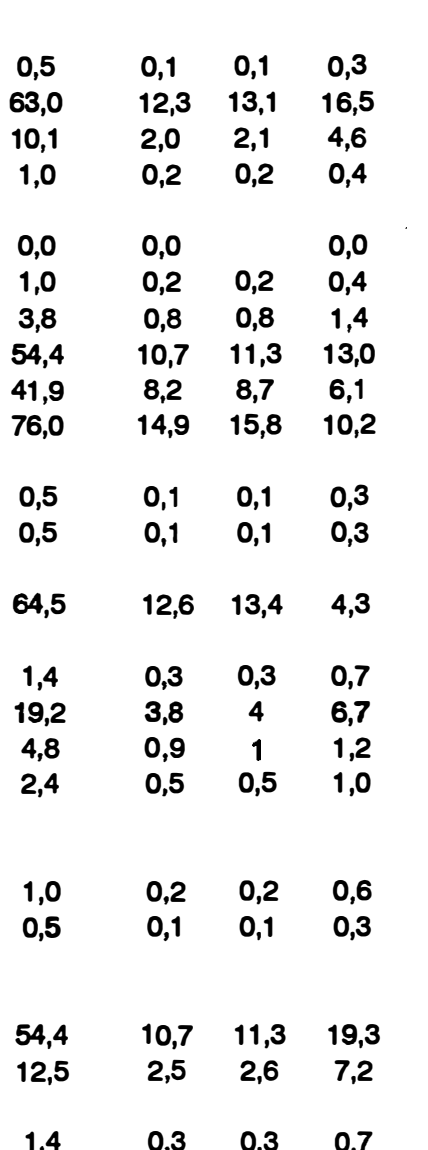

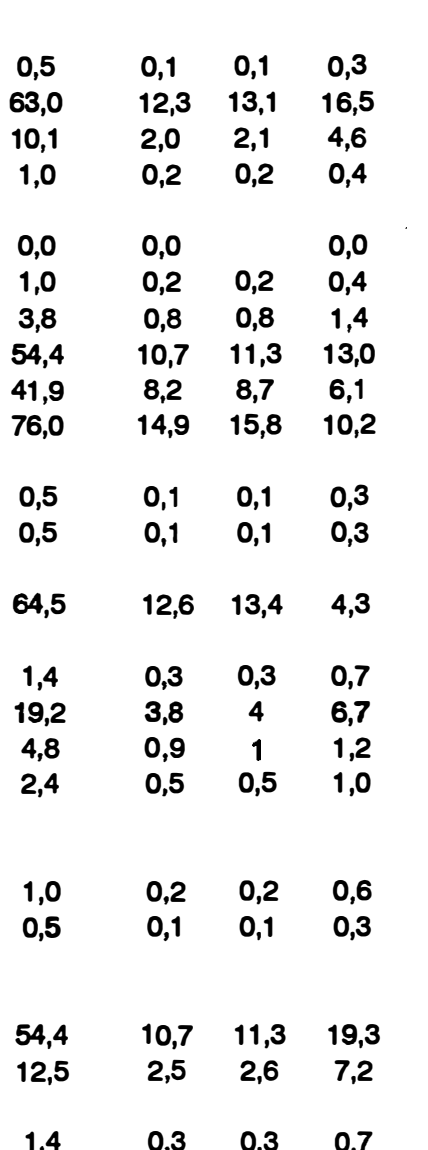

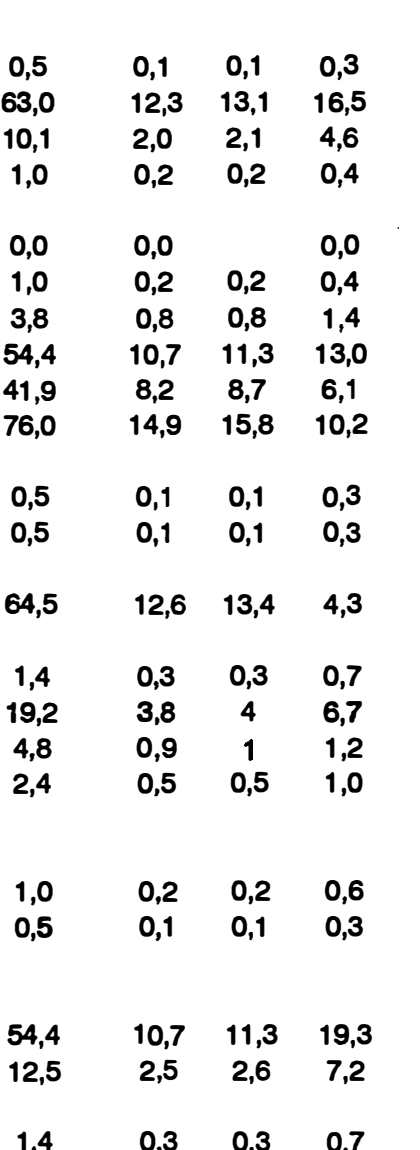

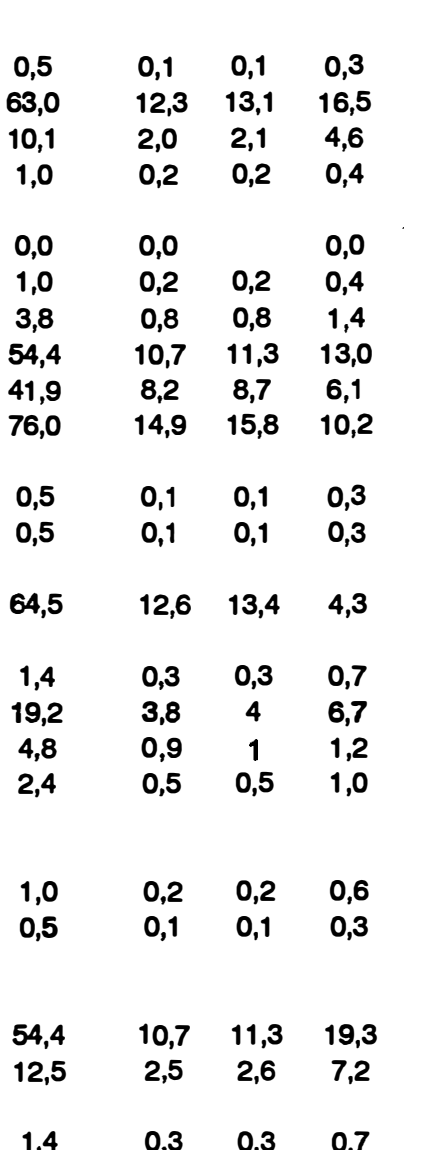

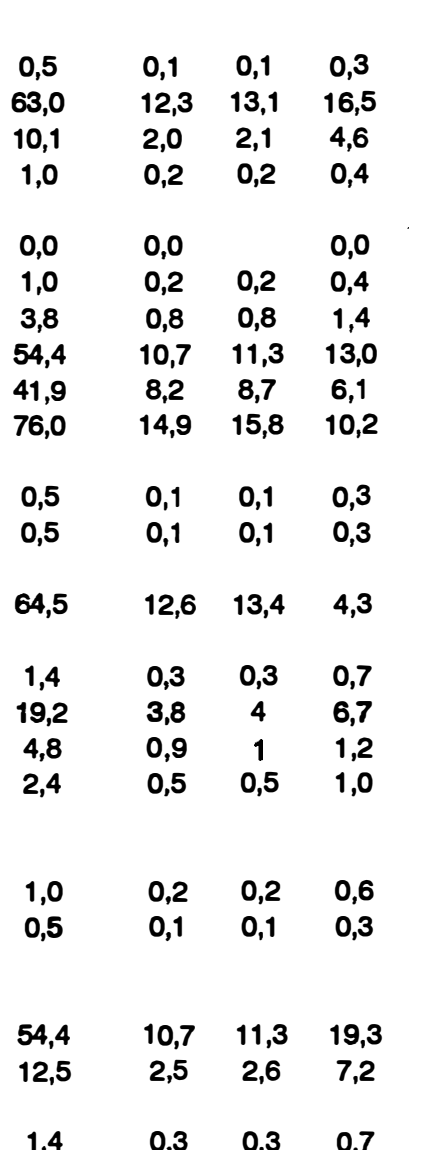

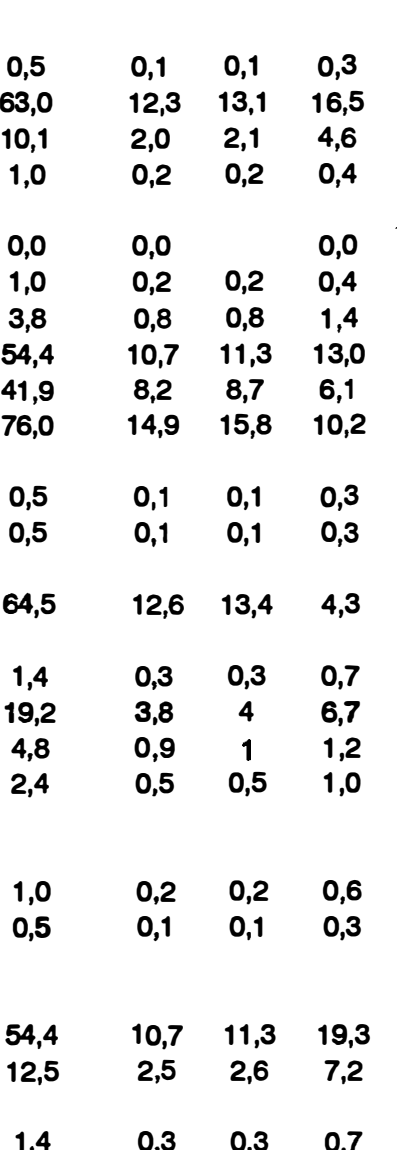

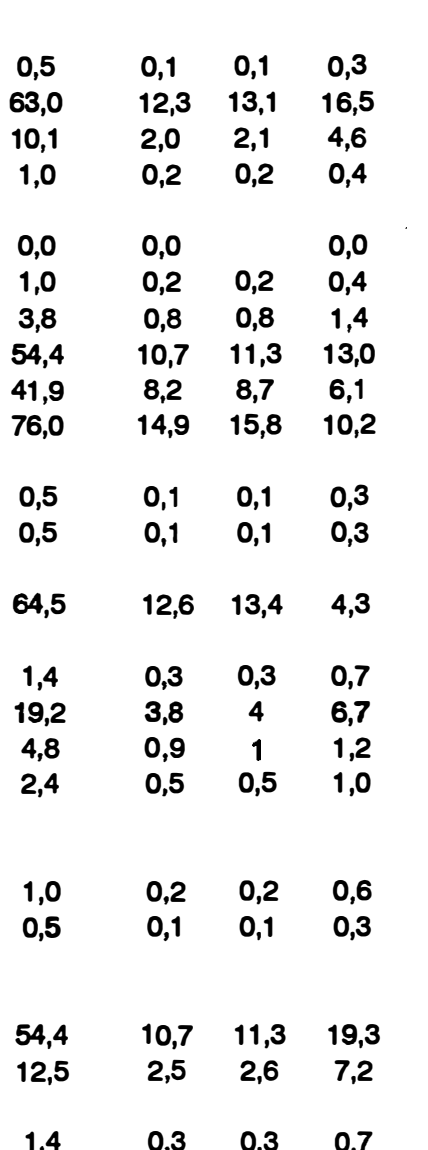

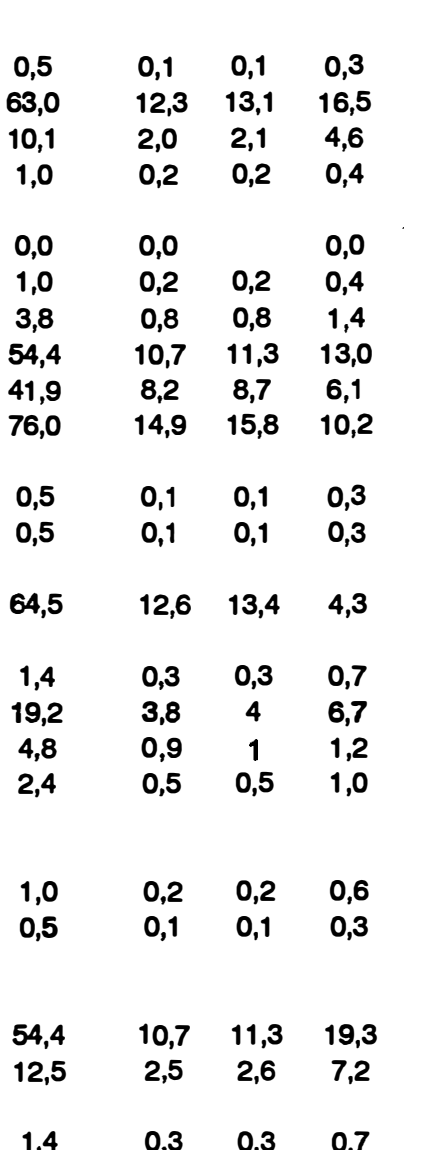

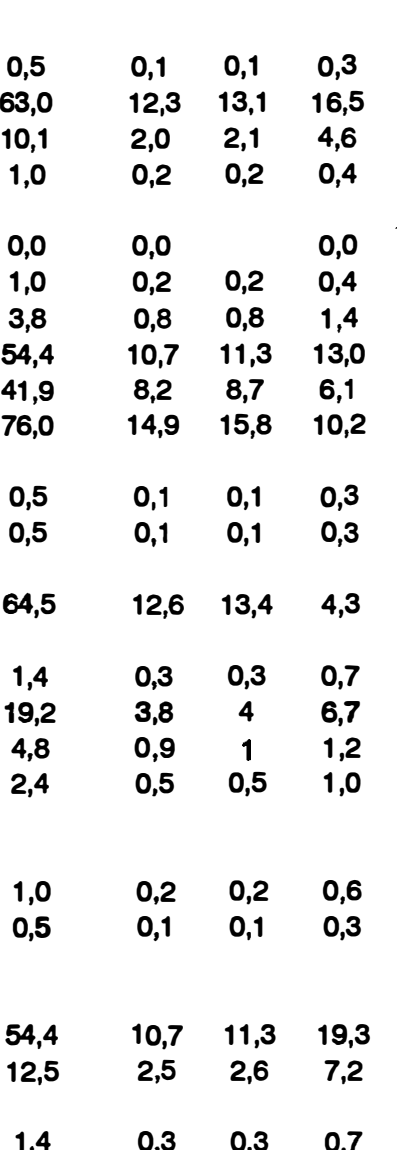

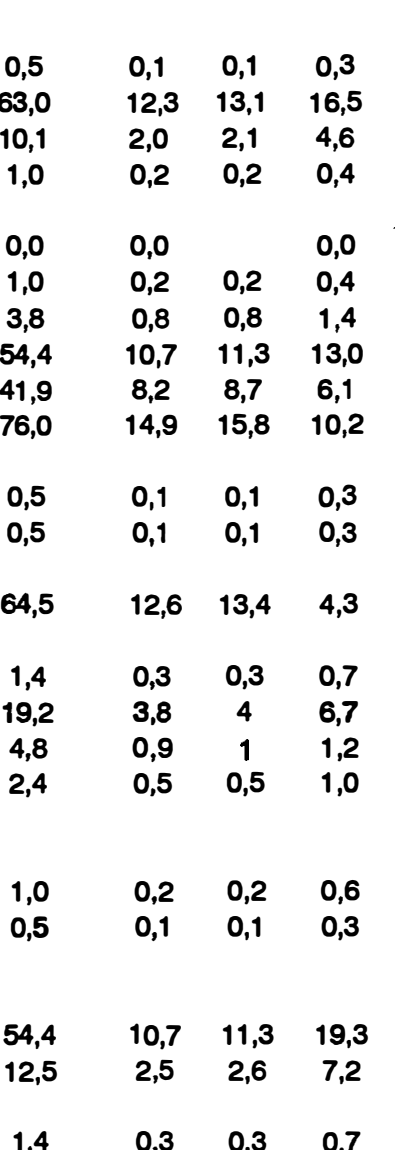

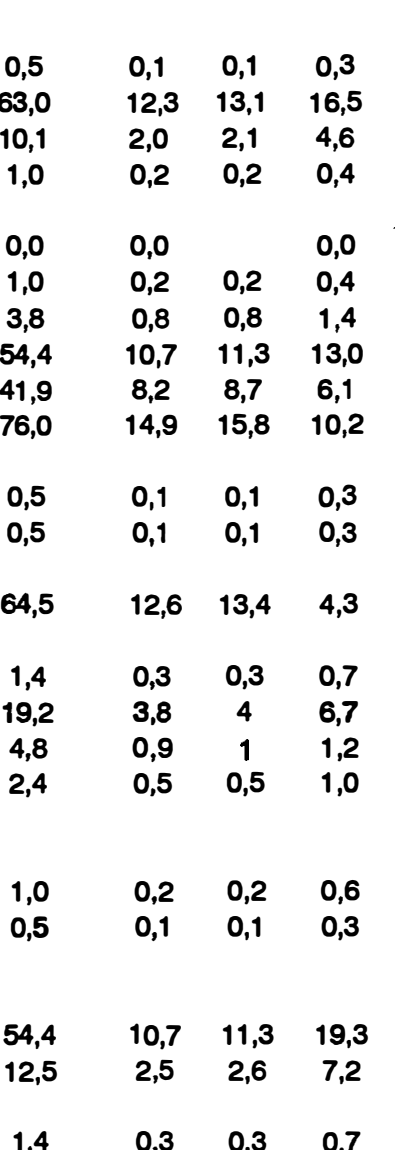

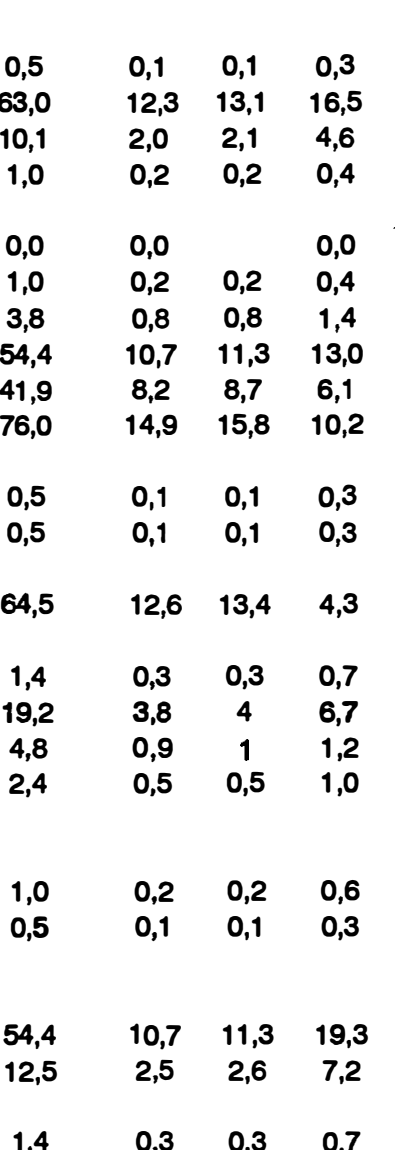

$\begin{array}{ll}0 & 2 \\ 0 & 0\end{array}$

$\begin{array}{ccccccccccc}3 & 58 & 0 & 3 & 6 & 34 & 6 & 1 & 2 & 0 & 113 \\ 0 & 0 & 0 & 0 & 2 & 23 & 1 & 0 & 0 & 0 & 26\end{array}$

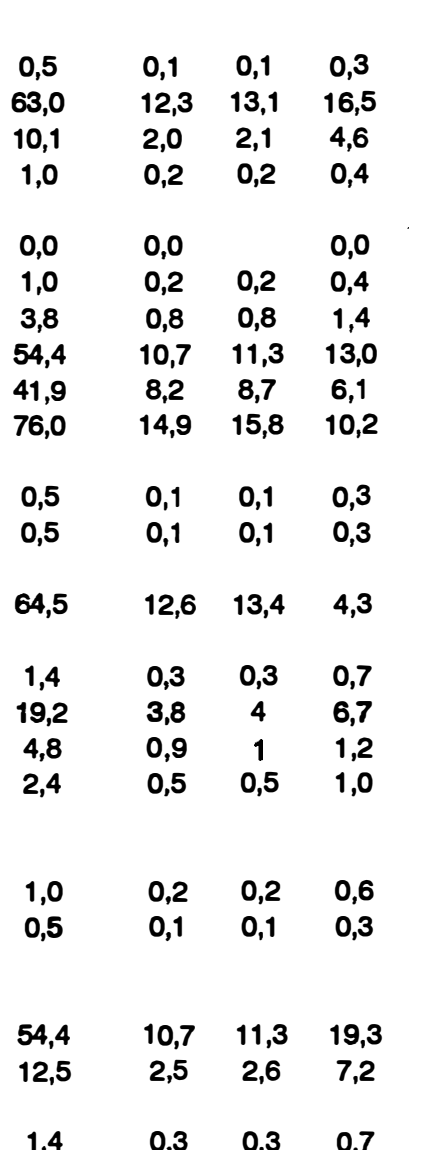

\begin{tabular}{|c|c|c|c|}
\hline$/ \mathrm{m}^{3} / \mathrm{mes}^{2}$ & $\%$ & Média & 5 \\
\hline 0,5 & 0,1 & 0,1 & 0,3 \\
\hline 63,0 & 12,3 & 13,1 & 16,5 \\
\hline 10,1 & 2,0 & 2,1 & 4,6 \\
\hline 1,0 & 0,2 & 0,2 & 0,4 \\
\hline 0,0 & 0,0 & & 0,0 \\
\hline 1,0 & 0,2 & 0,2 & 0,4 \\
\hline 3,8 & 0,8 & 0,8 & 1,4 \\
\hline 54,4 & 10,7 & 11,3 & 13,0 \\
\hline 41,9 & 8,2 & 8,7 & 6,1 \\
\hline 76,0 & 14,9 & 15,8 & 10,2 \\
\hline 0,5 & 0,1 & 0,1 & 0,3 \\
\hline 0,5 & 0,1 & 0,1 & 0,3 \\
\hline 64,5 & 12,6 & 13,4 & 4,3 \\
\hline 1,4 & 0,3 & 0,3 & 0,7 \\
\hline 19,2 & 3,8 & 4 & 6,7 \\
\hline 4,8 & 0,9 & 1 & 1,2 \\
\hline 2,4 & 0,5 & 0,5 & 1,0 \\
\hline 1,0 & 0,2 & 0,2 & 0,6 \\
\hline 0,5 & 0,1 & 0,1 & 0,3 \\
\hline 54,4 & 10,7 & 11,3 & 19,3 \\
\hline 12,5 & 2,5 & 2,6 & 7,2 \\
\hline
\end{tabular}

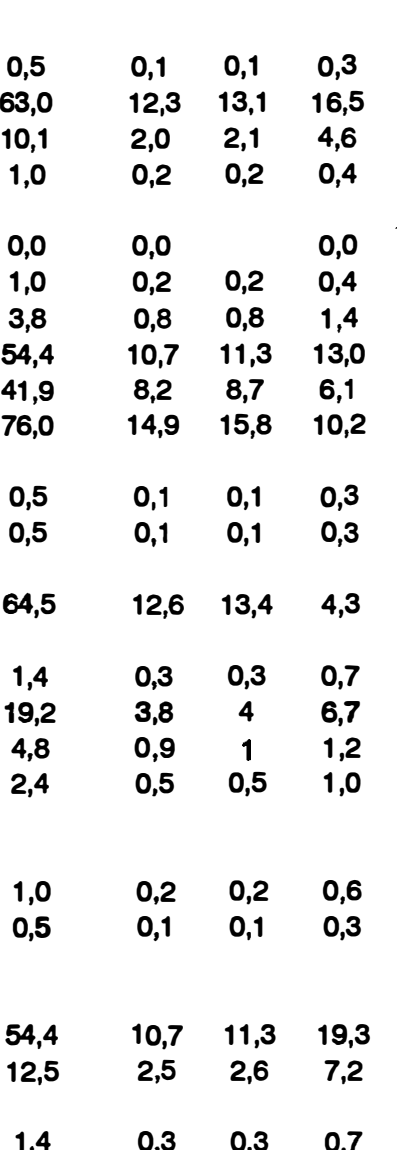

$\begin{array}{lllllllllll}0 & 2 & 0 & 1 & 0 & 0 & 0 & 0 & 0 & 0 & 3\end{array}$

$\begin{array}{lllllllllll}0 & 2 & 0 & 1 & 0 & 0 & 0 & 0 & 0 & 0 & 3 \\ 0 & 0 & 0 & 0 & 1 & 0 & 0 & 0 & 0 & 0 & 1\end{array}$

$\begin{array}{llll}1,4 & 0,3 & 0,3 & 0,7\end{array}$

$0,5 \quad 0,1 \quad 0,1 \quad 0,3$

$\begin{array}{lllllllllll}1 & 0 & 0 & 0 & 0 & 0 & 0 & 0 & 0 & 0 & 1\end{array}$

0,5

$\begin{array}{llc}3 & 1 & 6 \\ 1 & 0 & 10\end{array}$

$\begin{array}{lll}2 & 2 & 1 \\ 3 & 4 & 3\end{array}$

$\begin{array}{ccccc}4 & 4 & 1 & 4 & 28 \\ 6 & 6 & 11 & 7 & 51\end{array}$

$\begin{array}{llll}13,5 & 2,6 & 2,8 & 1,7\end{array}$ $24,5 \quad 4,8 \quad 5,1 \quad 3,6$

$0,5 \quad 0,1 \quad 0,1 \quad 0,3$

$\begin{array}{llll}1,4 & 0,3 & 0,3 & 0,5\end{array}$ $\begin{array}{llll}1,0 & 0,2 & 0,2 & 0,6\end{array}$

\begin{tabular}{|c|c|c|c|c|}
\hline 2 & 0 & 0 & 0 & 0 \\
\hline 0 & 0 & 0 & 0 & 0 \\
\hline
\end{tabular}

$\begin{array}{llll}0 & 0 & 0 \\ 1 & 1 & 1 & 0 \\ 0 & 0 & 2 & 0\end{array}$

\section{$\begin{array}{lllll}0 & 1 & 1 & 0 & 3\end{array}$}



Apêndice 46 - Captura dos grupos de Arthropoda no folhedo, coletados através de fotoeclectores de solo, no periodo de agosto /1987 a maio/1988,
na floresta inundada por água mista (núnero de captura, densidade de atividade (individuos $\mathbf{\boxplus}^{2}$ ), percentagen $(\%)$, média e desvio padräo(S)).

\begin{tabular}{|c|c|c|c|c|c|c|c|c|c|c|c|c|c|c|c|c|}
\hline Meses & Ago. 187 & Set. & Out. & Nov. & Dez. & $\operatorname{Jan} .88$ & Fev. & Mar. & Abr. & Mai. & Total & Ind./mi mês & $\%$ & Média & S & $x^{i-}$ \\
\hline Grupos & & & & & & & & & & & & & & & & \\
\hline 1- Scorpiones & 0 & 0 & 0 & 0 & 0 & 0 & 0 & 0 & 1 & 0 & 1 & 0,0 & $<0,1$ & 0,1 & 0,3 & NS \\
\hline 2- Araneae & 23 & 290 & 228 & 213 & 378 & 165 & 156 & 231 & 84 & 2018 & 3786 & 94,6 & 5,3 & 378,6 & $>150,0$ & $S^{*+*}$ \\
\hline $25 \mathrm{~mm}$ & 1 & 0 & 1 & 9 & 6 & 9 & 2 & 0 & 6 & 5 & 39 & 1,0 & 0,1 & 3,9 & 3,5 & NS \\
\hline $\begin{array}{l}\text { 3. Pseudoscorpiones } \\
4 \text { Opiliones }\end{array}$ & 0 & 0 & 0 & 0 & 2 & 68 & 34 & 71 & 2 & 1 & 178 & 4,4 & 0,2 & 17,8 & 29,2 & $\mathbf{S}^{*}$ \\
\hline Laniatores & 0 & 0 & 0 & 0 & 1 & 0 & 0 & 0 & 0 & 7 & 8 & 0,2 & $<0,1$ & 0,8 & 2,2 & NS \\
\hline $\begin{array}{l}\text { 5- Isopoda } \\
\text { 6- Chilopoda }\end{array}$ & 0 & 4 & 0 & 0 & 1 & 3 & 14 & 1 & 1 & 185 & 209 & 5,2 & 0,3 & 20,9 & 57,8 & $\mathbf{s}^{*}$ \\
\hline Geophilomorpha & 0 & 0 & 0 & 0 & 0 & 0 & 0 & 0 & 0 & 2 & 2 & 0,0 & $<0,1$ & 0,2 & 0,6 & NS \\
\hline Scolopendromorpha & 0 & 0 & 0 & 2 & 0 & 4 & 0 & 1 & 0 & 0 & 7 & 0,2 & $<0,1$ & 0,7 & 1,3 & NS \\
\hline Lithoblomorpha & 0 & 4 & 0 & 1 & 0 & 0 & 0 & 0 & 0 & 0 & 5 & 0,1 & $<, 01$ & 0,5 & 1,3 & NS \\
\hline 7- Diplopoda & 0 & 20 & 1 & 1 & 0 & 38 & 40 & 24 & 8 & 43 & 175 & 4,4 & 0,2 . & 17,5 & 17,9 & NS \\
\hline 8- Symphyla & 0 & 0 & 0 & 0 & 0 & 0 & 33 & 84 & 49 & 32 & 208 & 5,2 & 0,3 & 20,8 & 31,7 & $\mathbf{S}^{*}$ \\
\hline $\begin{array}{l}\text { 9- Diplura } \\
\text { Japygidae }\end{array}$ & 0 & 2 & 0 & 0 & 0 & 0 & 0 & 0 & 0 & 0 & 2 & 0,0 & $<0,1$ & 0,2 & 0,6 & NS \\
\hline 10- Archaeognatha & & & & & & & & & & & & & & & & \\
\hline Meinertellidae & 16 & 9 & 14 & 4 & 2 & 2 & 4 & 3 & 0 & 0 & 54 & 1,3 & 0,1 & 5,4 & 5,7 & NS \\
\hline $\begin{array}{l}\text { 11- Odonata } \\
\text { 12- Orthoptera } \\
\text { Tettigonloidea }\end{array}$ & 0 & 0 & 0 & 0 & 0 & 0 & 1 & 0 & 0 & 0 & 1 & 0,0 & $<0,1$ & 0,1 & 0,3 & NS \\
\hline Ninfas & 0 & 3 & 3 & 0 & 1 & 6 & 1 & 6 & 0 & 1 & 21 & 0,5 & $<0,1$ & 2,1 & 2,3 & NS \\
\hline $\begin{array}{l}\text { Adultos } \\
\text { Grilloidea }\end{array}$ & 0 & 0 & 0 & 0 & 0 & 5 & 1 & 11 & 1 & 5 & 23 & 0,6 & $<0,1$ & 2,3 & 3,7 & NS \\
\hline Nintas & 0 & 4 & 2 & 3 & 2 & 3 & 6 & 0 & 2 & 1 & 23 & 0,6 & $<0,1$ & 2,3 & 1,8 & NS \\
\hline Adultos & 1 & 1 & 3 & 0 & 0 & 1 & 0 & 0 & 6 & 1 & 13 & 0,3 & $<0,1$ & 1,3 & 1,9 & NS \\
\hline 13- Phasmatodea & & & & & & & & & & & & & & & & \\
\hline Ninfas & 0 & 1 & 0 & 0 & 0 & 0 & 0 & 0 & 0 & 0 & 1 & 0,0 & $<0,1$ & 0,1 & 0,3 & NS \\
\hline 14. Blattodea & & & & & & & & & & & & & & & & \\
\hline Ninfas & 1 & 15 & 31 & 19 & 5 & 16 & 5 & 3 & 5 & 34 & 134 & 3,3 & 0,2 & 13,4 & 11,8 & NS \\
\hline Adultos & 7 & 10 & 8 & 24 & 16 & 62 & 14 & 12 & $14^{\prime}$ & 30 & 197 & 4,9 & 0,3 & 19,7 & 18,5 & NS \\
\hline 15- isoptera & 0 & 2 & 0 & 0 & 0 & 0 & 0 & 0 & 0 & 0 & 2 & 0,0 & $<0,1$ & 0,2 & 0,6 & NS \\
\hline 16- Dermapters & 0 & 0 & 0 & 0 & 0 & 0 & 0 & 0 & 1 & 1 & 2 & 0,0 & $<0,1$ & 0,2 & 0,4 & NS \\
\hline 17- Psocoptera & 14 & 3 & 24 & 15 & 43 & 19 & 7 & 15 & 3 & 0 & 143 & 3,6 & 0,2 & 14,3 & 12,7 & NS \\
\hline 18- Thysanoptera & 141 & 191 & 944 & 158 & 107 & 156 & 14 & 13 & 19 & 23 & 1766 & 44,1 & 2,5 & 176,6 & $>150,0$ & $S^{\sin }$ \\
\hline $\begin{array}{l}\text { 19- Heteroptera } \\
\text { Dipsocoridae }\end{array}$ & & & & & & & & & & & & & & & & \\
\hline Ninftas & 0 & 0 & 4 & 0 & 0 & 0 & 1 & 0 & 0 & 0 & 5 & 0,1 & $<0,1$ & 0,5 & 1,3 & NS \\
\hline Adultos & 1 & 0 & 2 & 3 & 8 & 1 & 2 & 1 & 0 & 10 & 28 & 0,7 & $<0,1$ & 2,8 & 3,4 & NS \\
\hline Schizopteridae & & & & & & & & & & & & & & & & \\
\hline Ninfas & 0 & 0 & 2 & 4 & 1 & 0 & 0 & 1 & 0 & 0 & 8 & 0,2 & $<0,1$ & 0,8 & 1,3 & NS \\
\hline Adultos & 0 & 0 & 3 & 7 & 1 & 8 & 2 & 2 & 5 & 1 & 29 & 0,7 & $<0,1$ & 2,9 & 2,8 & NS \\
\hline Gelastocoridae & & & & & & & & & & & & & & & & \\
\hline Ninfas & 0 & 3 & 2 & 6 & 8 & 3 & 8 & 0 & 0 & 0 & 30 & 0,7 & $<0,1$ & 3 & 3,3 & NS \\
\hline $\begin{array}{l}\text { Adultos } \\
\text { Outros Heteropter }\end{array}$ & 1 & 0 & 0 & 0 & 0 & 18 & 3 & 7 & 0 & 27 & 58 & 1,4 & 0,1 & 5,6 & 9,4 & NS \\
\hline Ninfas & 3 & 4 & 5 & 12 & 1 & 1 & 0 & 0 & 1 & 1 & 28 & 0,7 & $<0,1$ & 2,8 & 3,6 & NS \\
\hline Adultos & 11 & 18 & 2 & 6 & 11 & 7 & 0 & 3 & 4 & 8 & 70 & 1,7 & 0,1 & 7 & 5,3 & NS \\
\hline 20. Homoptera & & & & & & & & & & & & & & & & \\
\hline Coccoldea & & & & & & & & & & & & & & & & \\
\hline Ninfas & 1 & 16 & 6 & 1 & 0 & 0 & 0 & 0 & 0 & 0 & 24 & 0,6 & $<0,1$ & 2,4 & 5,1 & NS \\
\hline $\begin{array}{l}\text { Adultos } \\
\text { Outros Homoptera }\end{array}$ & 9 & 6 & 105 & 9 & 36 & 170 & 28 & 2 & 3 & 0 & 368 & 9,2 & 0,5 & 38,8 & 56,4 & NS \\
\hline Ninfas & 3 & 68 & 14 & 3 & 3 & 5 & 9 & 12 & 16 & 4 & 137 & 3,4 & 0,2 & 13,7 & 19,7 & NS \\
\hline $\begin{array}{c}\text { Adultos } \\
\text { 21- Neuroptera }\end{array}$ & 6 & 28 & 181 & 206 & 222 & 25 & 14 & 26 & 19 & 6 & 733 & 18,3 & 1,0 & 73,3 & $\mathbf{8 0 , 3}$ & NS \\
\hline Lavas & 0 & 0 & 0 & 0 & 0 & 0 & 0 & 0 & 0 & 2 & 2 & 0,0 & $<0,1$ & 0,2 & 0,6 & NS \\
\hline $\begin{array}{l}\text { Lavas } \\
\text { Lateopla }\end{array}$ & 18 & 31 & 18 & 7 & 3 & 1 & 1 & 1 & 1 & 1 & 82 & 2,0 & 0,1 & 8,2 & 10,5 & NS \\
\hline Adultos & 1774 & 632 & 289 & 294 & 249 & 579 & 397 & 255 & 227 & 1409 & 6105 & 152,6 & 8,6 & 610,5 & $>150,0$ & $\mathbf{S}^{* *}$ \\
\hline 23- Lepldoptera & & & & & & & & & & & & & & & & \\
\hline Lavas & 0 & 32 & 4 & 0 & 2 & 5 & 0 & 5 & 2 & 0 & 50 & 1,2 & 0,1 & 5 & 9,7 & NS \\
\hline Adultos & 3 & 15 & 35. & 31 & 10 & 31 & 3 & 9 & 5 & 0 & 142 & 3,5 & 0,2 & 14,2 & 13,2 & NS \\
\hline 24- Diptera & & & & & & & & & & & & & & & & \\
\hline $\begin{array}{l}\text { Lavas } \\
\text { Nematocera }\end{array}$ & 4 & 5 & 0 & 5 & 1 & 7 & 14 & 3 & 21 & 1 & 61 & 1,5 & 0,1 & 6,1 & 6,6 & NS \\
\hline Cecidomyildae & 2825 & 4874 & 11897 & 3447 & 3830 & 2452 & 675 & 2029 & 1672 & 115 & 33816 & 845,4 & 47,4 & 3381,6 & $>150,0$ & $S^{* * *}$ \\
\hline Sciaridae & 19 & 58 & 603 & 56 & 120 & 313 & 462 & 387 & 542 & 106 & 2668 & 68,5 & 3,7 & 286,6 & $>150,0$ & $\mathbf{S}^{* *}$ \\
\hline Outros Nematocera & 360 & 208 & 1549 & 210 & 287 & 251 & 202 & 1592 & 850 & 690 & 6199 & 155,0 & 8,7 & 619,9 & $>150,0$ & NS \\
\hline $\begin{array}{l}\text { Brachycera } \\
\text { 25- Hymenoptera }\end{array}$ & 271 & 286 & 114 & 84 & 163 & 170 & 461 & 578 & 399 & 90 & 2616 & 65,4 & 3,7 & 261,6 & $>150,0$ & $\mathbf{S}^{*}$ \\
\hline Formicldae & 285 & 470 & 74 & 32 & 15 & 30 & 71 & 37 & 146 & 1207 & 2367 & 59,2 & 3,3 & 236,7 & $>150,0$ & NS \\
\hline Outros Hymenoptera & 747 & 3584 & 1209 & 677 & 402 & 648 & 238 & 613 & 478 & 72 & 8648 & 216,2 & 12,1 & 864,8 & $>150,0$ & $S^{+\infty \rightarrow \infty}$ \\
\hline Total & 6545 & 10877 & 17377 & 5549 & 5937 & 5282 & 2923 & 6048 & 4593 & 6139 & 71270 & 1781,7 & 100,0 & 7127 & & \\
\hline Ind. $/ \mathrm{m}^{2}$ & 1636,3 & 2719,3 & 4344,3 & 1387,3 & 1484,3 & 1320,5 & 730,8 & 1512,0 & 1148,3 & 1534,8 & 17817,5 & & & & & \\
\hline$\%$ & 8,2 & 15,3 & 24,4 & 7,8 & 8.3 & 7,4 & 4,1 & 8,5 & 6,4 & 8,6 & 1000 & & & & & \\
\hline
\end{tabular}


Apêndice 47 - Captura dos grupos de Arthropoda coletados ell foloteclector direcionado para cima (BBt), no periodo de julho/1987 a junho/1988, na floresta inundada por água mista, (número de captura, percentagem $(\%)$, média e desvio padrão $(S)$ ). Meses de inundação = julho/1987 e a partir de junho/1988.

\begin{tabular}{|c|c|c|c|c|c|c|c|c|c|c|c|c|c|c|c|c|c|}
\hline Moses & Jul./87 & Ago. & Set. & Out. & Nov. & Dez. & $\operatorname{Jan} . / 88$ & Fev. & Mar. & Abr. & Mai. & Jun. & Total & $\%$ & Médla & $\mathrm{s}$ & $x^{2}$ \\
\hline Grupos & & & & & & & & & & & & & & & & & \\
\hline $\begin{array}{l}\text { 1- Scorpiones } \\
\text { 2- Uropygi }\end{array}$ & 0 & 0 & 0 & 0 & 0 & 0 & 0 & 0 & 0 & 1 & 0 & 0 & 1 & $<0,1$ & 0,1 & 0,3 & NS \\
\hline Schizomida & 0 & 0 & 0 & 0 & 0 & 0 & 0 & 2 & 0 & 1 & 1 & 0 & 4 & $<0,1$ & 0,3 & 0,7 & NS \\
\hline 3- Araneae & 31 & 47 & 179 & 44 & 29 & 28 & 26 & 43 & 24 & 100 & 206 & 15 & 772 & 4,3 & 64,3 & 63,9 & $S^{*}$ \\
\hline $\begin{array}{l}\text { 4- Pseudoscorpiones } \\
\text { 5- Oplliones }\end{array}$ & 0 & 1 & 0 & 0 & 1 & 0 & 8 & 25 & 13 & 14 & 22 & 13 & 97 & 0,5 & 8,1 & 9,2 & $S^{* * *}$ \\
\hline Laniabores & 0 & 0 & 0 & 0 & 0 & 0 & 0 & 0 & 1 & 0 & 18 & 25 & 44 & 0,2 & 3,7 & 8,5 & NS \\
\hline $\begin{array}{ll}\text { 6- } & \text { Isopoda } \\
\text { 7- } & \text { Chillopoda }\end{array}$ & 0 & 0 & 0 & 0 & 1 & 2 & 0 & 1 & 0 & 4 & 260 & 3 & 271 & 1,5 & 22,8 & 74,8 & $S^{* * * *}$ \\
\hline Geophilomorpha & 0 & 0 & 0 & 0 & 0 & 0 & 1 & 2 & 1 & 0 & 2 & 0 & 6 & $<0,1$ & 0,5 & 0,8 & $S^{*}$ \\
\hline Scolopendromorpha & 0 & 0 & 0 & 1 & 0 & 0 & 0 & 0 & 1 & 2 & $\boldsymbol{\theta}$ & 0 & 13 & 0,1 & 1,1 & 2,6 & $\mathrm{~S}^{* *}$ \\
\hline 8- Diplopoda & 0 & 0 & 3 & 0 & 7 & 6 & 17 & 37 & 15 & 117 & 299 & 2 & 503 & 2,8 & 41,9 & 87,4 & $S^{*+* \pi}$ \\
\hline $\begin{array}{l}\text { \% Symphyla } \\
\text { 10- Archaeognatha }\end{array}$ & 0 & 0 & 0 & 1 & 0 & 0 & 0 & 0 & 53 & 11 & 5 & 0 & 70 & 0,4 & 5,8 & 15,2 & $S^{*+m}$ \\
\hline Meinertellidae & 0 & 5 & 1 & 14 & 14 & $\boldsymbol{\theta}$ & $\boldsymbol{\theta}$ & 19 & 10 & 6 & 1 & 0 & 88 & 0,5 & 7,3 & 6,3 & NS \\
\hline $\begin{array}{l}\text { 11- Odonata } \\
\text { 12- Orthoptera } \\
\text { Tettigonioidea }\end{array}$ & 0 & 0 & 0 & 0 & 0 & 0 & 1 & 0 & 0 & 0 & 0 & 0 & 1 & $<0,1$ & 0,1 & 0,3 & NS \\
\hline Ninfas & 2 & 3 & 1 & 4 & 8 & 21 & $\boldsymbol{9}$ & 15 & 20 & 7 & 4 & 0 & 94 & 0,5 & 7,8 & 7,2 & $S^{* * *}$ \\
\hline $\begin{array}{l}\text { Adultos } \\
\text { Grilloidea }\end{array}$ & 1 & 0 & 0 & 1 & 1 & 0 & 0 & 0 & 1 & 1 & 1 & 0 & 6 & $<0,1$ & 0,5 & 0,5 & NS \\
\hline Ninfas & 4 & 7 & 17 & 45 & 34 & 28 & 52 & 49 & 24 & 30 & 11 & 3 & 304 & 1,7 & 25,3 & 17,4 & $\mathrm{~S}^{*+*}$ \\
\hline $\begin{array}{c}\text { Adultos } \\
\text { 13- Mantodea }\end{array}$ & 0 & 0 & 2 & 0 & 8 & 1 & 0 & 1 & 1 & 0 & 3 & 1 & 17 & 0,1 & 1,4 & 2,3 & NS \\
\hline Ninfas & 0 & 5 & 6 & 2 & 3 & 5 & 5 & 1 & 1 & 3 & 0 & 0 & 31 & 0,2 & 2,6 & 2,2 & NS \\
\hline $\begin{array}{l}\text { Adultos } \\
\text { 14- Phasmatodea }\end{array}$ & 0 & 0 & 0 & 0 & 0 & 0 & 0 & 0 & 0 & 1 & 0 & 0 & 1 & $<0,1$ & 0,1 & 0,3 & NS \\
\hline $\begin{array}{c}\text { Ninfas } \\
\text { 15- Blattodea }\end{array}$ & 0 & 0 & 0 & 9 & 6 & 3 & 1 & 0 & 0 & 0 & 0 & 0 & 19 & 0,1 & 1,6 & 3,0 & $\mathbf{s *}^{*}$ \\
\hline Ninfas & 1 & 15 & 9 & 22 & 32 & 12 & 24 & 13 & 14 & 18 & 18 & 2 & 180 & 1,0 & 15,0 & 8,8 & NS \\
\hline Adultos & 0 & 1 & 0 & 1 & 2 & 3 & 2 & 15 & 0 & 1 & 4 & 2 & 31 & 0,2 & 2,6 & 4,1 & $S^{*=0}$ \\
\hline 16- Isoptera & 1 & 0 & 0 & 0 & 1 & 2 & 2 & 0 & 0 & 0 & 0 & 0 & 6 & $<0,1$ & 0,5 & 0,8 & NS \\
\hline 17- Demaptera & 0 & 0 & 0 & 0 & 0 & 1 & 1 & 0 & 0 & 0 & 5 & 0 & 7 & $<0,1$ & 0,6 & 1,4 & $\mathrm{~s}^{*}$ \\
\hline 16- Embloptera & 12 & 0 & 0 & 0 & 0 & 0 & 0 & 0 & 0 & 0 & 0 & 0 & 12 & 0,1 & 1,0 & 3,5 & $S^{* n=m}$ \\
\hline 19- Psocoptera & 0 & 28 & 44 & 38 & 80 & 65 & 145 & 115 & 42 & 42 & 3 & 2 & 604 & 3,4 & 50,3 & 44,9 & $S^{n+m}$ \\
\hline $\begin{array}{l}\text { 20. Thysanoptera } \\
\text { 21. Heteroptera } \\
\text { Dipsoconidas }\end{array}$ & 1 & 1 & 2 & 2 & 2 & 1 & 9 & 4 & 3 & 2 & 1 & 0 & 28 & 0,2 & 2,3 & 2,3 & NS \\
\hline Ninfes & 0 & 2 & 0 & 0 & 0 & 0 & 0 & 1 & 0 & 0 & 0 & 0 & 3 & $<0,1$ & 0,3 & 0,6 & NS \\
\hline $\begin{array}{l}\text { Adultos } \\
\text { Schlzopteridae }\end{array}$ & 0 & 2 & 0 & 1 & 0 & 0 & 0 & 0 & 0 & 0 & 3 & 0 & 6 & $<0,1$ & 0,5 & 1,0 & NS \\
\hline Ninfas & 0 & 0 & 0 & 0 & 0 & 0 & 0 & 3 & 0 & 0 & 0 & 0 & 3 & $<0,1$ & 0,3 & 0,9 & NS \\
\hline $\begin{array}{l}\text { Adultos } \\
\text { Outros Heteroptera }\end{array}$ & 0 & 0 & 0 & 1 & 3 & 0 & 0 & 1 & 0 & 0 & 0 & 0 & 5 & $<0,1$ & 0,4 & 0,9 & NS \\
\hline Ninfas & 1 & 27 & 28 & 23 & 10 & 10 & 13 & 9 & 4 & 9 & 3 & 0 & 137 & 0,8 & 11,4 & 9,7 & $S^{m * * *}$ \\
\hline $\begin{array}{l}\text { Adultos } \\
\text { 22- Homoptera }\end{array}$ & 0 & 0 & 0 & 0 & 10 & 0 & 2 & 1 & 0 & 0 & 1 & 0 & 14 & 0,1 & 1,2 & 2,9 & NS \\
\hline $\begin{array}{l}\text { Aphididae } \\
\text { Coccoldea }\end{array}$ & 0 & 0 & 0 & 0 & 2 & 1 & 0 & 0 & 0 & 0 & 0 & 0 & 3 & $<0,1$ & 0,3 & 0,6 & NS \\
\hline Ninfes & 0 & 0 & 0 & 0 & 1 & 0 & 0 & 0 & 0 & 0 & 0 & 0 & 1 & $<0,1$ & 0,1 & 0,3 & NS \\
\hline $\begin{array}{l}\text { Adultos } \\
\text { Outros Homaptera }\end{array}$ & 0 & 0 & 0 & 0 & 2 & 0 & 0 & 3 & 0 & 0 & 0 & 0 & 5 & $<0,1$ & 0,4 & 1,0 & NS \\
\hline Ninfas & 2 & 6 & 28 & 13 & 10 & 24 & 29 & 22 & 34 & 38 & 16 & 3 & 225 & 1,3 & 18,8 & 12,2 & $S^{*+m}$ \\
\hline $\begin{array}{l}\text { Adultos } \\
\text { 23- Neuroptera }\end{array}$ & 0 & 0 & 1 & 15 & 9 & 7 & 15 & 14 & 12 & 4 & 4 & 1 & 82 & 0,5 & 6,8 & 6,0 & $S^{* * * *}$ \\
\hline $\begin{array}{l}\text { Laves } \\
\text { 24- Coleoptera }\end{array}$ & 0 & 0 & 3 & 2 & 0 & 0 & 0 & 0 & 0 & 0 & 0 & 0 & 5 & $<0,1$ & 0,4 & 1,0 & NS \\
\hline Laves & 0 & 5 & $\boldsymbol{\theta}$ & 8 & 2 & 1 & 6 & 0 & 0 & 0 & 4 & 0 & 34 & 0,2 & 2,8 & 3,2 & NS \\
\hline Adultos & 6 & 12 & 18 & 13 & 17 & 18 & 19 & 24 & 110 & 24 & 37 & 7 & 303 & 1,7 & 25,3 & 28,0 & $\mathbf{S}^{*+\infty}$ \\
\hline $\begin{array}{l}\text { 25- Strepsiptera } \\
\text { 26- Lepidoptera }\end{array}$ & 0 & 0 & 1 & 0 & 0 & 0 & 0 & 0 & 0 & 0 & 0 & 0 & 1 & $<0,1$ & 0,1 & 0,3 & NS \\
\hline Lavas & 1 & 0 & 4 & 1 & 1 & 1 & 3 & 3 & 2 & 3 & 3 & 0 & 22 & 0,1 & 1,8 & 1,3 & NS \\
\hline $\begin{array}{l}\text { Adultos } \\
\text { 27- Diptera }\end{array}$ & 0 & 0 & 0 & 1 & 0 & 1 & 1 & 0 & 1 & 0 & $\theta$ & 0 & 12 & 0,1 & 1,0 & 2,3 & $\mathbf{S}^{*}$ \\
\hline $\begin{array}{l}\text { Lavas } \\
\text { Nematocera }\end{array}$ & 0 & 6 & 0 & 33 & 1 & 0 & 5 & 2 & 1 & 2 & 2 & 1 & 53 & 0,3 & 4,4 & 9,2 & $\mathbf{S}^{* * *}$ \\
\hline Cecidomyildae & 44 & 16 & 24 & 16 & 85 & 33 & 72 & 82 & 38 & 39 & 4 & 17 & 470 & 2,6 & 39,2 & 27,1 & $S^{* *}$ \\
\hline Sclaridae & 0 & 0 & 0 & 1 & 0 & 3 & 22 & 41 & 8 & 19 & 7 & 5 & 106 & 0,6 & 8,8 & 12,6 & $\mathrm{~S}^{* \pm *}$ \\
\hline Outros Nemabcera & 0 & 1 & 12 & 75 & 11 & 22 & 18 & 25 & 14 & 41 & 13 & 110 & 342 & 1,9 & 28,5 & 32,6 & $\mathrm{~S}^{* * * *}$ \\
\hline Brachycera & 8031 & 0 & 0 & 1 & 3 & 28 & 5 & 11 & 6 & 0 & 1 & 0 & 8086 & 45,2 & 673,8 & $>150,0$ & $\mathbf{S}^{* * * *}$ \\
\hline 28- Hymenoptera & & & & & & & & & & & & & & & & & \\
\hline $\begin{array}{l}\text { Fomicidae } \\
\text { Outros Hymenoptera }\end{array}$ & $\begin{array}{c}188 \\
0\end{array}$ & $\begin{array}{c}277 \\
5\end{array}$ & $\begin{array}{c}329 \\
16\end{array}$ & $\begin{array}{c}582 \\
9\end{array}$ & $\begin{array}{c}448 \\
6\end{array}$ & $\begin{array}{c}852 \\
7\end{array}$ & $\begin{array}{c}577 \\
46\end{array}$ & $\begin{array}{l}425 \\
33\end{array}$ & $\begin{array}{c}288 \\
19\end{array}$ & $\begin{array}{l}248 \\
25\end{array}$ & $\begin{array}{c}340 \\
6\end{array}$ & $\begin{array}{c}39 \\
9\end{array}$ & $\begin{array}{c}4597 \\
181\end{array}$ & $\begin{array}{c}25,7 \\
1,0\end{array}$ & $\begin{array}{c}383,1 \\
15,1\end{array}$ & $\begin{array}{c}>150.0 \\
13,6\end{array}$ & $\begin{array}{l}S^{n+\infty} \\
S^{n+\infty}\end{array}$ \\
\hline $\begin{array}{l}\text { Total } \\
\%\end{array}$ & $\frac{8324}{46,5}$ & $\frac{472}{2,6}$ & $\frac{7 \overline{344}}{4.1}$ & $\frac{979}{5,5}$ & $\frac{850}{4,8}$ & $\frac{1195}{6,7}$ & $\frac{1145}{6,4}$ & $\frac{1042}{5,8}$ & $\frac{761}{4,2}$ & $\frac{813}{4,5}$ & $\frac{1391}{7,4}$ & $\frac{260}{1,5}$ & $\begin{array}{l}17906 \\
100,0\end{array}$ & 100,0 & 1492,2 & & \\
\hline
\end{tabular}


Apêndice 48 - Captura dos grupos de Arthropoda coletados en fotoeclector direcionado para baixo (BBI), no periodo de julho/1987 a junho/1988, na floresta inundada por água mista (número de captura, percentagen ( $(\xi)$, nédia e desvio padrão (S)). Meses de inundação = julho/1987 e a partir de junho/1988.

\begin{tabular}{|c|c|c|c|c|c|c|c|c|c|c|c|c|c|c|c|c|c|c|}
\hline & Moses & Jul./87 & Ago. & Set. & Out & Nov. & Dez. & Jan./88 & Fev. & Mar. & Abr. & Mal. & Jun. & Total & $\%$ & Média & $\mathrm{s}$ & $x^{2}$ \\
\hline \multicolumn{2}{|r|}{ Grupos } & & & & & & & & & & & & & & & & & \\
\hline & $\begin{array}{l}\text { Scorpiones } \\
\text { Uropygi }\end{array}$ & 0 & 1 & 0 & 0 & 0 & 0 & 0 & 0 & 0 & 0 & 0 & 0 & 1 & $<0,1$ & 0,0833 & 0,3 & NS \\
\hline & Schizomida & 0 & 0 & 0 & 0 & 0 & 2 & 3 & 1 & 5 & 0 & 2 & 0 & 13 & 0,2 & 1,0833 & 1,6 & NS \\
\hline \multirow[t]{2}{*}{$3-$} & CSman & 191 & 75 & 53 & 28 & 9 & 7 & 14 & 23 & 12 & 17 & 49 & 48 & 524 & 8,0 & 49,667 & 51,1 & $\mathbf{S}^{* * *}$ \\
\hline & $>5 \mathrm{~mm}$ & 10 & 0 & 0 & 1 & 0 & 0 & 0 & 0 & 0 & 0 & 0 & 2 & -3 & $<0,1$ & 0,25 & 0,6 & NS \\
\hline \multicolumn{2}{|r|}{ 4- Pseudoscorplones } & 12 & $\boldsymbol{\theta}$ & 1 & 0 & 0 & 3 & 11 & 26 & 36 & 17 & 13 & 16 & 144 & 2,2 & 12 & 10,9 & $S^{*+\infty}$ \\
\hline \multicolumn{19}{|c|}{ 5- Opiliones } \\
\hline & Laniatores & 0 & 0 & 0 & 0 & 0 & 0 & 0 & 0 & 0 & 0 & 5 & 15 & 20 & 0,3 & 1,8667 & 4,4 & NS \\
\hline & Isopoda & 6 & 0 & 0 & 0 & 1 & 3 & 7 & 2 & 24 & 18 & 328 & 694 & 1083 & 16,5 & 80,25 & $>150,0$ & $S^{* * *}$ \\
\hline \multicolumn{19}{|c|}{ 7. Chilopoda } \\
\hline & Geophilomorpha & 11 & 36 & 0 & 0 & 0 & 0 & 0 & 0 & 0 & 0 & 0 & 1 & 48 & 0,7 & 4 & 10,6 & $S^{\infty+\infty}$ \\
\hline & Scolopendromorpha & 19 & 4 & 2 & 4 & 0 & 2 & 0 & 0 & 2 & 1 & 2 & 1 & 37 & 0,6 & 3,0833 & 5,2 & S+ete \\
\hline & Lthobiomorpha & 0 & 0 & 0 & 1 & 0 & 0 & 0 & 0 & 0 & 0 & 0 & 0 & 1 & $<0,1$ & 0,0833 & 0,3 & NS \\
\hline & Diplopoda & 52 & 21 & 2 & 1 & 1 & 1 & 4 & 20 & 24 & 16 & 305 & 294 & 741 & 11,3 & 61,75 & 112,0 & NS \\
\hline & Symphyla & 53 & 6 & 0 & 0 & 0 & 0 & 0 & 0 & 5 & $\theta$ & $\theta$ & 1 & 83 & 1,3 & 6,9167 & 15,0 & $S^{\infty+00}$ \\
\hline \multicolumn{19}{|c|}{ 10. Archaeognatha } \\
\hline & Meinertellidae & 0 & 0 & 0 & 2 & 0 & 0 & 0 & 0 & 0 & 1 & 0 & 0 & 3 & $<0,1$ & 0,25 & 0,6 & NS \\
\hline \multicolumn{19}{|c|}{ 11. Orthoptera } \\
\hline & $\begin{array}{l}\text { Grilloidea } \\
\text { Ninfas }\end{array}$ & & & & & & & & & & & & & & & & & \\
\hline & Ninfas & 2 & 0 & 0 & 0 & 0 & 2 & 0 & 0 & 1 & 1 & 0 & 0 & 6 & 0,1 & 0,5 & 0,8 & NS \\
\hline & Adultos & 0 & 0 & 0 & 0 & 0 & 1 & 0 & 0 & 0 & 1 & 0 & 0 & 2 & $<0,1$ & 0,1667 & 0,4 & NS \\
\hline & - Mantodea & & & & & & & & & & & & & & & & & \\
\hline & Ninfas & 0 & 0 & 0 & 0 & 0 & 0 & 1 & 0 & 0 & 0 & 0 & 0 & 1 & $<0,1$ & 0,0833 & 0,3 & NS \\
\hline & - Phesmatodea & & & & & & & & & & & & & & & & & \\
\hline & $\begin{array}{c}\text { Ninfes } \\
\text { Blattodea }\end{array}$ & 0 & 1 & 0 & 0 & 0 & 0 & 0 & 0 & 0 & 0 & 0 & 0 & 1 & $<0,1$ & 0,0833 & 0,3 & NS \\
\hline & Nintes & 1 & 5 & 3 & 1 & 1 & 7 & 6 & 1 & 4 & 7 & 22 & 18 & 78 & 1,2 & 6,3333 & 6,8 & NS \\
\hline & Adultos & 10 & 0 & 1 & $t$ & 0 & 5 & 2 & 0 & 0 & 1 & 4 & 6 & 30 & 0,5 & 2,5 & 3,1 & NS \\
\hline & Isoptera & 4 & 9 & 0 & 0 & 1 & 20 & 0 & 0 & 0 & 0 & 0 & 0 & 34 & 0,5 & 2,8333 & 6,0 & NS \\
\hline & Dermaptera & 10 & 0 & 0 & 0 & 0 & 0 & 0 & 0 & 0 & 0 & 0 & 0 & 10 & 0,2 & 0,8333 & 2,9 & $\mathbf{S}^{* * *}$ \\
\hline & - Psocoptera & 31 & 18 & 7 & 2 & 4 & 3 & 4 & 0 & 0 & 0 & 1 & 5 & 75 & 1,1 & 6,25 & 9,2 & S+ot \\
\hline & - Thysanoptera & 2 & 2 & 0 & 0 & 1 & 6 & 0 & 0 & 0 & 0 & 1 & 4 & 16 & 0,2 & 1,3333 & 1,8 & NS \\
\hline & Heteroptera & & & & & & & & & & & & & & & & & \\
\hline & Dipsocoridae & & & & & & & & & & & & & & & & & \\
\hline & Adultos & 0 & 0 & 0 & 0 & 0 & 2 & 0 & 0 & 0 & 0 & 1 & 0 & 3 & $<0,1$ & 0,25 & 0,6 & NS \\
\hline & Schizopteridae & & & & & & & & & & & & & & & & & \\
\hline & Adultos & 0 & 0 & 0 & 1 & 1 & 1 & 0 & 0 & 0 & 0 & 1 & 1 & 5 & 0,1 & 0,4167 & 0,5 & NS \\
\hline & Gelastocorldae & & & & & & & & & & & & & & & & & \\
\hline & Ninfas & 0 & 0 & 0 & 0 & 0 & 0 & 0 & 0 & 0 & 0 & 0 & 1 & 1 & $<0,1$ & 0,0833 & 0,3 & NS \\
\hline & Outros Heteroptera & & & & & & & & & & & & & & & & & \\
\hline & Ninfas & 0 & 1 & 2 & 0 & 0 & 1 & 0 & 1 & 0 & 0 & 0 & 0 & 5 & 0,1 & 0,4167 & 0,7 & NS \\
\hline & Adultos & 4 & 2 & 5 & 7 & 1 & 1 & 2 & 1 & 0 & 0 & 3 & 2 & 28 & 0,4 & 2,3333 & 2,1 & $S^{*}$ \\
\hline & - Homoptera & & & & & & & & & & & & & & & & & \\
\hline & Ninfas & 0 & 1 & 1 & 1 & 1 & 1 & 1 & 0 & 2 & 0 & 12 & 10 & 30 & 0,5 & 2,5 & 4,0 & NS \\
\hline & Adultos & 1 & 0 & 0 & 1 & 0 & 1 & 1 & 0 & 1 & 2 & 0 & 7 & 14 & 0,2 & 1,1667 & 1,9 & NS \\
\hline & 1- Coleoptera & & & & & & & & & & & & & & & & & \\
\hline & Laves & 19 & 135 & 17 & 6 & 4 & 3 & 6 & 2 & 7 & 4 & 2 & 1 & 208 & 3,1 & 17,167 & 37,5 & $S^{* * * *}$ \\
\hline & Adultos & 211 & 78 & 34 & 39 & 33 & 62 & 20 & 28 & 29 & 36 & 27 & 48 & 641 & 8,8 & 53,417 & 52,1 & $S^{* \ldots * t}$ \\
\hline & 2- Lepidoptera & & & & & & & & & & & & & & & & & \\
\hline & Lavas & 3 & 10 & 18 & 4 & 0 & 2 & 0 & 0 & 1 & 0 & 1 & 1 & 40 & 0,8 & 3,3333 & 5,4 & Sw \\
\hline & Adultos & 0 & 1 & 0 & 2 & 0 & 0 & 1 & 0 & 2 & 1 & 0 & 0 & 7 & 0,1 & 0,5833 & 0,8 & NS \\
\hline & 3- Diptera & & & & & & & & & & & & & & & & & \\
\hline & lenvas & 20 & 66 & 20 & 12 & 20 & 59 & 62 & 6 & 16 & 45 & 207 & 286 & 819 & 12,5 & 68,25 & 87,4 & NS \\
\hline & Nematocera & & & & & & & & & & & & & & & & & \\
\hline & Cecldomylidae & 6 & 8 & 7 & 20 & 17 & 30 & 33 & 11 & 42 & 13 & 2 & 1 & 180 & 2,9 & 15,833 & 13,1 & $S^{*+\infty}$ \\
\hline & Sciaridae & 0 & 0 & 0 & 1 & 1 & 2 & 14 & 6 & 13 & 14 & 9 & 10 & 70 & 1,1 & 5,8333 & 5,8 & Sontent \\
\hline & Outros Nematocera & 159 & 32 & 19 & 24 & 18 & 41 & 64 & 22 & 34 & 22 & 29 & 48 & 512 & 7,8 & 42,667 & 39,0 & Saret \\
\hline & Brachycera & 1 & 0 & 0 & 0 & 1 & 10 & 6 & 1 & 5 & 0 & 17 & 1 & 42 & 0,6 & 3,5 & 5,3 & $S^{* n * *}$ \\
\hline & 4- Hymenoptera & & & & & & & & & & & & & & & & & \\
\hline & Formicldae & 63 & 38 & 23 & 19 & 44 & 61 & 15 & 78 & 51 & 38 & 256 & 260 & 244 & 14,4 & 78,687 & 85,7 & NS \\
\hline & Outros Hymenoptera & 2 & 3 & 2 & 10 & 4 & 8 & 8 & 0 & 2 & 3 & 1 & 4 & 47 & 0,7 & 3,9167 & 3,1 & NS \\
\hline & Total & 893 & 560 & 217 & 186 & 163 & 347 & 285 & 227 & 318 & 267 & 1309 & 1784 & 8556 & 100,0 & 546,33 & & \\
\hline & $\%$ & 13,6 & 8,5 & 3,3 & 2,8 & 2,5 & 5,3 & 4,3 & 3,5 & 4,9 & 4,1 & 20,0 & 27,2 & 100,0 & & & & \\
\hline
\end{tabular}

